University of Louisville

ThinkIR: The University of Louisville's Institutional Repository

\title{
$5-2015$
}

\section{The association of medical student debt on choice of primary care specialty and rural practice location.}

Craig Ziegler

University of Louisville

Follow this and additional works at: https://ir.library.louisville.edu/etd

Part of the Public Health Commons

\section{Recommended Citation}

Ziegler, Craig, "The association of medical student debt on choice of primary care specialty and rural practice location." (2015). Electronic Theses and Dissertations. Paper 2024.

https://doi.org/10.18297/etd/2024

This Doctoral Dissertation is brought to you for free and open access by ThinkIR: The University of Louisville's Institutional Repository. It has been accepted for inclusion in Electronic Theses and Dissertations by an authorized administrator of ThinkIR: The University of Louisville's Institutional Repository. This title appears here courtesy of the author, who has retained all other copyrights. For more information, please contact thinkir@louisville.edu. 
THE ASSOCIATION OF MEDICAL STUDENT DEBT ON CHOICE OF PRIMARY CARE SPECIALTY AND RURAL PRACTICE LOCATION

\title{
By
}

\section{Craig Ziegler}

B.S., University of Louisville, 1988

M.A., University of Louisville, 1994

\begin{abstract}
A Dissertation
Submitted to the Faculty of the

School of Public Health and Information Sciences of the University of Louisville in Partial Fulfillment of the Requirements

for the Degree of
\end{abstract}

\author{
Doctor of Philosophy \\ in \\ Public Health Sciences \\ Department of Health Management and Systems Science \\ University of Louisville \\ Louisville, Kentucky
}

May 2015 
Copyright 2015 by Craig Ziegler

All rights reserved 

THE ASSOCIATION OF MEDICAL STUDENT DEBT ON CHOICE OF PRIMARY CARE SPECIALTY AND RURAL PRACTICE LOCATION

\author{
By \\ Craig Ziegler \\ University of Louisville \\ B.S., University of Louisville, 1988 \\ M.A., University of Louisville, 1994 \\ A Dissertation Approved on
}

April 10, 2015

by the following Dissertation Committee:
Robert Steiner, M.D., Ph.D.
Dissertation Chair

\begin{tabular}{c}
\hline $\begin{array}{c}\text { Robert Esterhay, M.D. } \\
\text { Committee Member }\end{array}$ \\
\hline Barry Wainscott, M.D. \\
Committee Member \\
\hline Doug Lorenz, Ph.D. \\
Committee Member
\end{tabular}




\section{ACKNOWLEDGEMENTS}

This journey of finishing my dissertation and earning my Ph.D. was only made possible through the help of others. I have been extremely fortunate to have Dr. Robert Steiner as my chair and mentor. He is not only a talented and knowledgeable professional in the area of primary care, but also a man of great generosity, personal integrity, and kindness. I was so lucky to have Dr. Steiner to guide me through the dissertation process. Without his advice, I was not even sure how to begin such a grand project, let alone finish. Throughout the process, it became clear to me that he was dedicated to making sure that I became a competent professional in the field of my dissertation topic. The effort that he devoted to being my dissertation chair went well beyond the call of duty, and I am truly grateful. Dr. Robert Esterhay has also been an invaluable source of wisdom and encouragement during this journey. I appreciate his willingness to help me at any time during the process of earning my degree and completing my dissertation. He is also probably one of the nicest persons I have ever met as demonstrated by his willingness to come in one Saturday in order for me to complete my qualifying exams. I am truly grateful to have Dr. Esterhay to be a part of this journey. Dr. Barry Wainscott's effort in helping me complete my dissertation is also greatly appreciated. His advice and guidance concerning my dissertation was also instrumental in completing this project. Finally, I want to express my gratitude for Dr. Doug Lorenz for his statistical expertise which he offered generously, constructively, and in a professional manner. I learned quite a bit from him and was truly lucky to have him on my dissertation committee as well. 


\section{ABSTRACT \\ THE ASSOCIATION OF MEDICAL STUDENT DEBT ON CHOICE OF PRIMARY CARE SPECIALTY AND RURAL PRACTICE LOCATION}

\section{Craig Ziegler}

April 10, 2015

A shortage of primary care physicians (PCP) is present nationally and within Kentucky. The shortage is expected to worsen, unless a dramatic increase occurs in the generation of additional primary care clinicians. Geographical maldistributions of PCP also exist. Whereas $20 \%$ of the US population resides in rural areas, only $10 \%$ of physicians practice in these areas.

This study explores factors that influence medical students' decisions to select primary care residency training programs, and to practice in rural areas. Specifically, the levels of debt among 1391 graduates from University of Louisville School of Medicine (ULSOM) during 2001-2010 were examined in association with their selection of categories of residency training programs. Similarly, levels of debt among 1180 ULSOM graduates during 2001-2008 were examined in association with rural practice locations. Statistical methods included evaluations of receiver-operating curves (ROC) and multiple logistic regression analyses. The ROC analyses showed no association was present for any level of debt with either selection of primary care residency programs or rural practice sites. Multiple logistic regression analyses showed a statistically significant, positive association was present between the two extreme quintiles of medical 
students' debt, whereby medical students in the lower quintile of debt were more likely select a primary care residency, compared to those students within the highest quintile. No statistically significant association was found for students’ debt with rural practice location.

Multiple policy options to increase the primary care workforce were examined, including raising physicians' reimbursements, shortening time for medical training, and altering how medical schools finance medical education. Policy makers may also consider the affinity model, whereby increasing medical school admissions among applicants from rural areas may result in greater numbers of PCP that are more likely to return to practice in rural areas. Similarly, programs to better support rural pipeline programs may be considered.

Other policy solutions may include allowing nurse practitioners and other clinical personnel to work at the full scope of their training as well as a fuller utilization of health information technology. Addressing population health through the Triple Aim may provide novel solutions. 
TABLE OF CONTENTS

ACKNOWLEDGEMENTS .................................................................................... ii

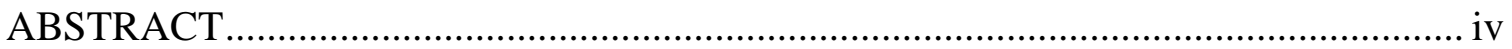

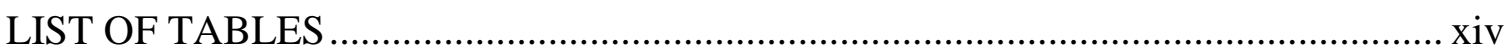

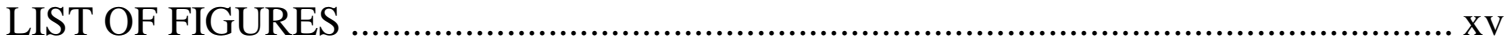

CHAPTER I. STUDY RATIONALE AND RESEARCH QUESTIONS ........................... 1

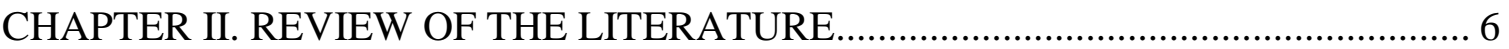

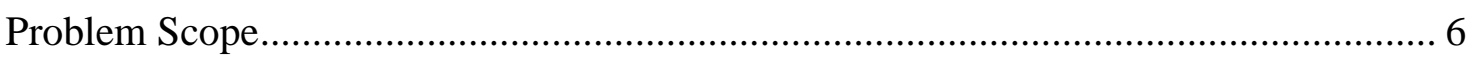

Supply and Demand Issue of Physicians (in General) ................................................... 8

Physician Supply Issues ..................................................................................... 9

Supply of Primary Care Physicians ............................................................................. 10

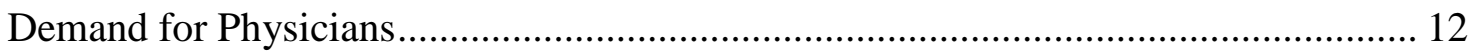

Health Reform and the 2010 Affordable Care Act ........................................................ 13

Issues of Primary Care Physician and Rural Maldistributions in Kentucky .................. 16

The Importance of Understanding the Medical Students Specialty Selection Process. 17

The Importance of Understanding the Medical Student Location Process .................... 23

Specific Literature Review of Covariates Analyzed for this Study ………………....... 26 
Gender and Primary Care Choice.

Gender and Practicing in Rural Areas ..................................................................... 28

Race, Diversity, and the Physician Workforce ......................................................... 29

Race and Primary Care Choice ......................................................................... 32

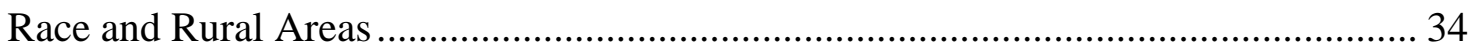

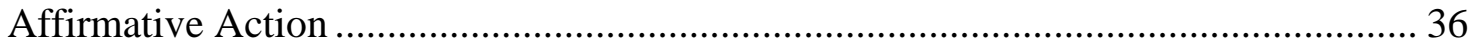

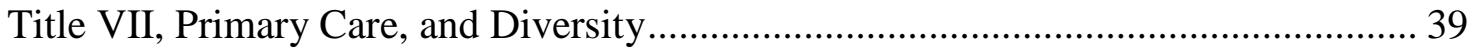

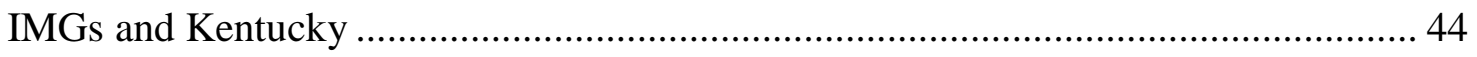

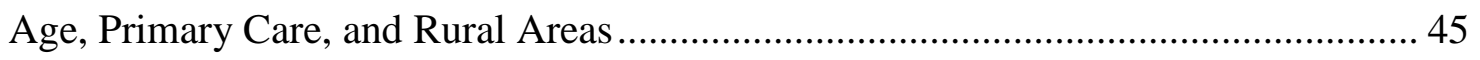

The Affinity Model and Rural Background ......................................................... 46

Medical Students’ Family of Origin Social Economic Status and Specialty Choice.... 49

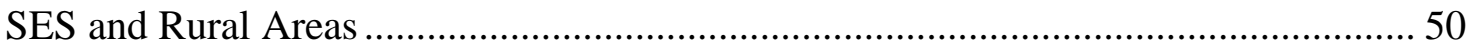

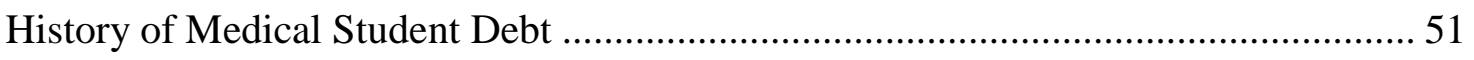

Issues Related to Medical Student Debt.................................................................. 54

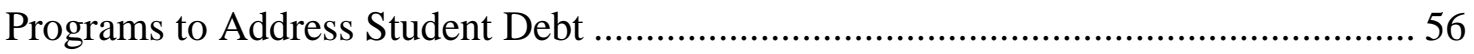

Studies Addressing Student Debt’s Association with Primary Care Specialty Choice 62 Studies Addressing Student Debt’s Association with Rural Practice Location ............ 71

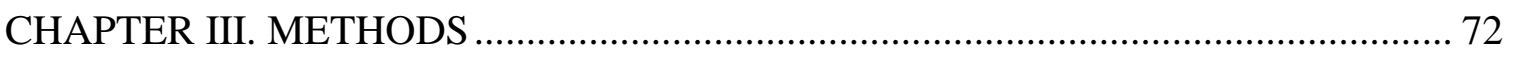

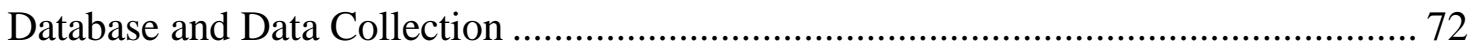

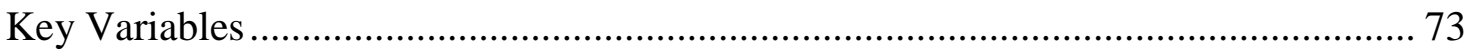


Statistical Methods

Limitations 89

CHAPTER IV. RESULTS 91

Descriptive Statistics of Student Characteristics 91

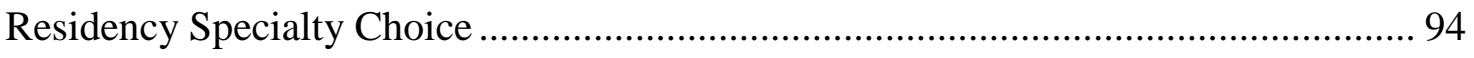

Receiver Operator Characteristic Curve ........................................................... 97

Training and Testing Sample Analysis of Unadjusted Odds Ratio............................ 97

Multiple Logistic Regression and Assessment of Training and Testing Samples ...... 102

Practice Location Choice ................................................................................. 107

Receiver Operator Characteristic Curve ............................................................ 110

Training and Testing Sample Analysis of Unadjusted Odds Ratio.......................... 110

Multiple Logistic Regression and Assessment of Training and Testing Samples ...... 115

Discussion of Analysis: Specialty Choice........................................................ 120

Specific Solutions Related to Medical Student Debt: Increased Pay ........................ 122

Increasing PCP Pay, the ACA, Patient Centered Medical Homes and Accountable Care

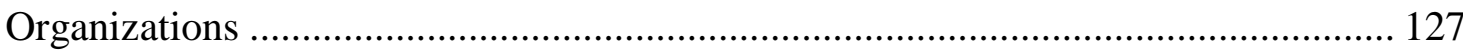

Specific Solutions Related to Medical Student Debt: Make Medical School Cost

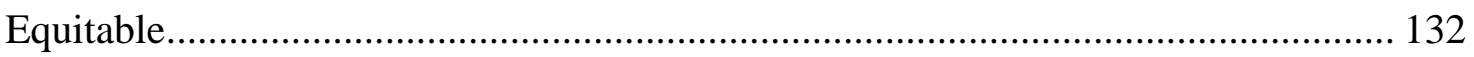

Discussion of Analysis: Practice Location .......................................................... 134

Overall Solutions to the Primary Care Physician and HPSA Workforce Shortage .... 136 
Find Someone Else: Nurse Practitioners

Obstacles Facing Nurse Practitioners as a Solution to Primary Care Shortage .......... 138

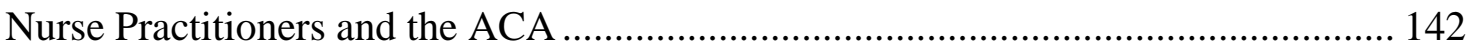

Nurse Practitioners, SOPs, and Retail Clinics..................................................... 143

Find Someone Else: Physician Assistants ........................................................... 145

Obstacles Facing Physician Assistants as a Solution to Primary Care Shortage ........ 148

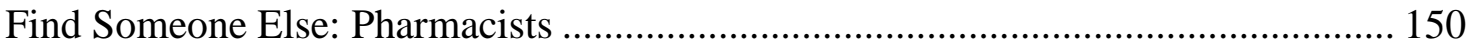

Is There Is a Sufficient Supply of Pharmacists? ................................................. 151

Pharmacists and Retail Clinics ......................................................................... 151

Obstacles Facing Pharmacists in Retail Clinics .................................................. 152

Pharmacists and Team-Based Care ......................................................................... 153

Obstacles Facing Pharmacists in Team-Based Care .............................................. 154

Finding Someone Else and Team-Based Care ..................................................... 155

Train More: “Pipeline” Medical Educational Programs ........................................ 159

Undergraduate Medical Education Regional Rural Health Track “Pathway” Programs 161

Train More: Shorten the Duration of Medical Training......................................... 161

Shorten Training: Combined Premedical School Curriculum/Medical School Programs 162 
Shorten Training: “Pathway” Programs, Combined Undergraduate Medical

Education/Graduate Medical Education Based on a Competency-Based Curriculum 162

Shorten Training: Undergraduate Medical Education ................................................. 164

Shortening Undergraduate Medical Education: The Positive ....................................... 165

Shortening Undergraduate Medical Education: The Negative..................................... 166

Shorten Training: Graduate Medical Education....................................................... 167

Shortening Graduate Medical Education (Family Medicine): The Positive ................ 168

Shortening Graduate Medical Education: The Negative.............................................. 170

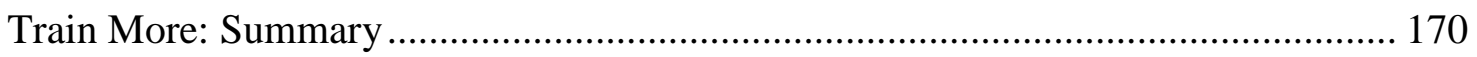

Waste Less: Non-Technology ………………………........................................ 172

Waste Less: Technology ………………............................................................. 173

Technology: Digital Clinical Workflow Systems ....................................................... 174

Digital Clinical Workflow Systems’ Impact on Efficiency (Assessment of the

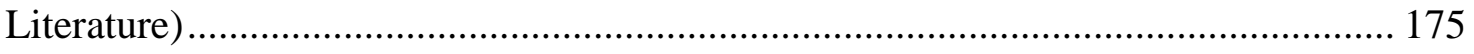

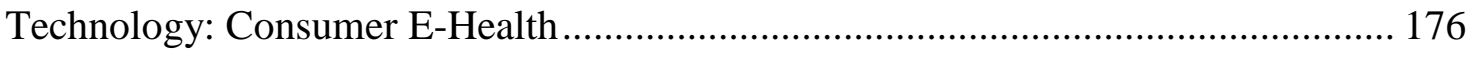

Consumer E-Health’s Impact on Efficiency (Assessment of the Literature)............... 177

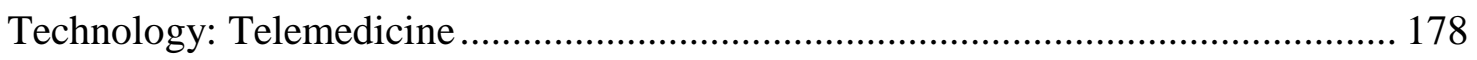

Telemedicine’s Impact on Efficiency (Assessment of the Literature) ......................... 178

Telemedicine’s Impact on Rural Recruitment and Retention ...................................... 179

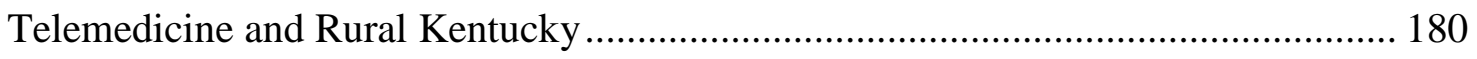


Technology: Government Incentives to Overcome HIT Barriers 181

HITECH and HIT Economic Barriers 181

HITECH and HIT Logistical and Technical Barriers 182

HITECH and HIT Health Information Exchange Complications 184

HITECH and HIT Privacy and Security Barriers. 184

Waste Less: Summary. 185

Conclusion 186

REFERENCES 192

APPENDICES 211

Appendix 1: Sensitivity Analysis to Assess if SES Nonresponses Bias Primary Care Residency Choice Estimates 211

Appendix 2: Sensitivity Analysis to Assess if SES Nonresponses Bias Rural Practice Location Estimates 213

Appendix 3: USMLE Step 1 Score by Medical Student Debt Interaction for Primary Care Specialty Choice. 215

Appendix 4: Gender by Medical Student Debt Interaction for Primary Care Specialty

Choice. 216

Appendix 5: Age by Medical Student Debt Interaction for Primary Care Specialty

Choice. 217

Appendix 6: Rural Upbringing by Medical Student Debt Interaction for Primary Care Specialty Choice 218 
Appendix 7: Rural Medical Training by Medical Student Debt Interaction for Primary

Care Specialty Choice

Appendix 8: Race (White) by Medical Student Debt Interaction for Primary Care

Specialty Choice

Appendix 9: Race (Other) by Medical Student Debt Interaction for Primary Care Specialty Choice

Appendix 10: Primary Care Base Model Modeling SES by Medical Student Debt Interaction for Primary Care Specialty Choice 222

Appendix 11: USMLE Step 1 Score by Medical Student Debt Interaction for Rural

Practice Location 223

Appendix 12: Gender by Medical Student Debt Interaction for Rural Practice Location 224

Appendix 13: Age by Medical Student Debt Interaction for Rural Practice Location 225 Appendix 14: Rural Upbringing by Medical Student Debt Interaction for Rural Practice Location 226

Appendix 15: Rural Medical Training by Medical Student Debt Interaction for Rural Practice Location 227

Appendix 16: Race (White) by Medical Student Debt Interaction for Rural Practice Location. 228

Appendix 17: Race (Other) by Medical Student Debt Interaction for Rural Practice Location. 229 
Appendix 18: SES by Medical Student Debt Interaction for Rural Practice Location 230

Appendix 19: List of Abbreviations ....................................................................... 232

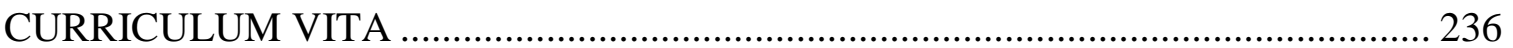




\section{LIST OF TABLES}

\section{TABLE}

1. Influences Affecting Different Groups of Medical Students Regarding Primary Care or Non-Primary-Care Career Choice....

2. A Literature Review of Medical Students Debt Predictive Relationship on Primary Care Choice

3. Summary of the factors and Categories that Make Up the Hollingshead

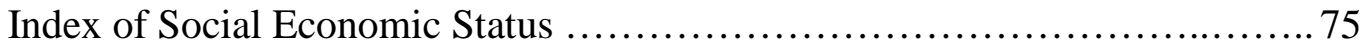

4. USDA, ERS Rural-Urban Continuum Codes ................................. 78

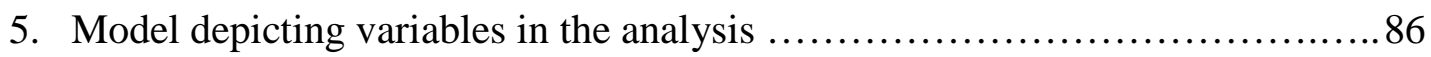

6. Demographic and other Characteristics for 1391 University of Louisville School of Medicine Students, 2001-2010 .................................. 92

7. Demographic and other Characteristics by Residency Specialty Choice..........95

8. Descriptive Statistics and Unadjusted Odds Ratios of Demographic and Other Characteristics by Residency Specialty Choice (Training and Testing Samples).

9. Adjusted Odds Ratios of Medical Student Debt on Primary Care Choice after Adjusting for Demographics and Other Characteristics Using Multiple Logistic Regression (Training and Testing Data Sets)................................ 105

10. Demographic and other Characteristics by Practice Location. 108

11. Descriptive Statistics and Unadjusted Odds Ratios of Demographic and Other Characteristics by Practice Choice Location (Training and Testing Samples).

12. Adjusted Odds Ratios of Medical Student Debt on Practice Location Choice After Adjusting for Demographics and Other Characteristics Using Multiple Logistic Regression (Training and Testing Data Sets).... 


\section{LIST OF FIGURES}

\section{FIGURE}

1. Temporal and Barer et al. Typologies for Physicians Rural Location Influencers ................................................... 25

2. Greysen, et al., Enrollment of Women and Underrepresented Minorities in Medical School, 1963-2003 ...........................................53

3. Example of ROC Curve Demonstrating High Sensitivity and Specificity ..........80

4. ROC Curve of Debt Level Predicting Primary Care Specialty Choice........... 97

5. ROC Curve of Debt Level Predicting Rural Practice Location...................110

6. Nurse Practitioner Scope-of-Practice Authority, 2012...................... 140 


\section{CHAPTER I}

\section{STUDY RATIONALE AND RESEARCH QUESTIONS}

US physician workforce requirements are increasing and cannot meet current or future healthcare demands. ${ }^{1,2}$ Recent projections have postulated that by 2015 an additional 63,000 full-time equivalent (FTE) physicians are necessary to meet US healthcare needs, and by 2025 there will be an overall shortage of 131,000 physicians in all specialties. ${ }^{3}$ Further, projections for the US primary care workforce indicate that an expansion is necessary to meet future healthcare challenges. One recent study estimated that by 2025 the number of primary care physicians (PCPs) will need to increase by 52,000 (25\%), from approximately 209,000 to 261,000, to meet the impending healthcare shortcomings. ${ }^{4}$

Underlying these estimates were specialty and geographic maldistributions of physician services. A maldistribution refers to a population with an excess or shortage of physicians to optimally meet its healthcare needs within a defined geographic area. ${ }^{5} \mathrm{~A}$ dearth of physicians existed in all specialties of medical practice, but this dearth was most notable among primary care physicians (PCPs) living in health professional shortage areas (HPSAs). The Health Resources and Service Administration (HRSA), a federal agency, defines a HPSA as an area where the population-to-provider ratio is 3500:1 or greater; thus HPSAs are usually found in rural and inner-city regions. Regarding rural

areas, $20 \%$ of the US population resided here; however, only $10 \%$ of physicians served 
these communities. ${ }^{6,7}$ This phenomenon will worsen based on 2007 data that stated only $3 \%$ of medical students plan to work in rural areas. ${ }^{6,8}$ Primary care physicians accounted for almost half of physicians in rural areas. ${ }^{7}$ Those who specialized in family medicine distributed almost equally to the population in rural HPSAs; that is, $24 \%$ of the US population lived in HPSAs, while $23 \%$ of family medicine physicians practiced in these areas. ${ }^{9}$ Moreover, the number of internal medicine and pediatrics physicians distributed rurally at about $10 \% .{ }^{9}$ These specialty and geographic maldistributions increased healthcare costs, decreased healthcare quality, and limited access to medical care.

Health services in Kentucky also are heavily constrained by a shortage of physicians and other healthcare workers with a shortage that is above the national average in rural areas. ${ }^{10}$ By 2012 estimates, there were 10,475 physicians in the Commonwealth with a mean of 3,790 full-time equivalent (FTE) physicians. According to a 2013 report by Deloitte, an additional 183 FTE physicians, a 5\% increase, is necessary to currently meet population needs, with Kentucky’s rural counties needing 112 of the those 183 FTE physicians. ${ }^{10}$ With the advent of the Accountability Care Act (ACA) and the Kentucky Health Benefits Exchange (KHBE), an additional 640,000 uninsured individuals now may have access to the Commonwealth's healthcare resources. These facts, compounded with Kentucky's overall poor health status (ranked 44th nationally), pose a dire threat for the physician workforce in meeting the state's medical needs. ${ }^{10}$ By 2017, an estimated additional 205 to 256 physicians will be necessary depending on the number of people who utilize Medicaid through the KHBE. ${ }^{10}$

A 2011 study sponsored by the Louisville Primary Care Association ${ }^{11}$ for Jefferson County (Louisville, Kentucky) showed that this county had 697 practicing 
primary care physicians (PCPs), but needed a total of 711 PCPs to meet the HRSA ratio of 96 primary care physicians to 100,000 population. Further, by 2020 more than 336 new PCPs and 50 additional obstetricians-gynecologists will be necessary in Jefferson County to meet HRSA-recommended guidelines. Of note is the discrepancy between the Deloitte report's estimates of needed primary care physicians for Kentucky and the Louisville Primary Care Association's estimates for Jefferson County. The Deloitte report estimates fewer physicians for Kentucky than the Louisville Primary Care Association’s study does for Jefferson County.

Medical schools have a societal obligation to foster a supply of medical students to enter into primary care and to work in rural areas to alleviate workforce shortages. ${ }^{12}$ Medical school admission committees and administrators can play a vital role in alleviating this problem by admitting medical school applicants who possess characteristics, intentions, and training experiences favorable to becoming PCPs or practicing in rural HPSAs. ${ }^{13}$ Some factors affecting medical students becoming PCPs or practicing in rural areas include gender, race, age, marital status, parental socioeconomic status (SES), rural educational experiences, and the affinity model. The affinity model shows applicants from rural hometowns are more likely to practice in rural areas after completing medical training. ${ }^{13,14}$

One factor that influences medical students' and residents' choices of specialty and practice location, and that is beyond the control of admission committees, is medical student debt. ${ }^{13,15-17}$ In 2002, the mean debt burden of US graduating medical students exceeded $\$ 100,000$. By 2011, 86\% of graduating medical students had an average debt of $\$ 160,000 .{ }^{18}$ Based on adjustments for inflation, debt for current medical students is 3.5 
times greater than in $1978 .{ }^{18}$ Further, an exacerbation to medical students' financial stress is the 2013 bill passed by the House of Representatives that doubled interest rates on Stafford student loans from $3.4 \%$ to $6.8 \% .{ }^{19}$ Nationally, a causal relationship between debt and specialty choice has been modest at best and overshadowed by other factors. ${ }^{13,15,17}$ Although magnification of debt may play a small role in medical students’ decisions in selecting a specialty or practice location, in the face of a shortage of PCPs and rural physicians, the impact of policies addressing student debt may be significant. Currently it is a challenge to fill primary care residencies with graduates of US medical schools. ${ }^{15}$ Just a small number of students choosing to practice in rural areas provided their debt was eliminated could have an impact in health outcomes and change some rural HPSAs to better-served classifications. ${ }^{20}$ Small changes may be meaningful. For example, if 18 students chose to locate in a rural area, it could change 6 to 10 health professional shortage areas to better-served categories ${ }^{20}$ No study has specifically examined the association between debt, specialty choice, and practice location in Kentucky among medical students graduating from U of L. The Commonwealth's medical leaders' and school administrators' understandings of how debt influences students' specialty choices and practice locations may help them better plan to alleviate Kentucky's shortage of primary care and rural physicians.

A 2007 systematic review of the literature was conducted to stimulate primary care quality research as an aid to policy formation. The authors of that review noted that “to date, debt's influence on specialty choice has been nominal, however, as debt levels persistently increase, does a threshold exists that prevents students from a primary care career. ${ }^{21}$ Another study addressing the effect of debt on medical school graduates noted 
specifically “an advantage of multivariate analysis in assessing debt’s influence on specialty choice or practice location is the ability to appraise debt's relative strength after controlling for other factors." ${ }^{22}$ The study in this dissertation used quantitative methods to address the inquiries put forth in the aforementioned two studies.

Thus, the overall goal of this dissertation was to find whether a relationship existed between medical students' levels of debt after graduation and selection of primary care specialty choice and rural practice location:

Specific Aim 1: To determine if a relationship exists between student debt and selection of primary care residencies and the magnitude and form of this relationship.

Hypothesis 1: An optimal debt level exists with high sensitivity and specificity that detects residency specialty choice.

Hypothesis 2: A modest association exists between medical students' levels of debt with their selection of residency training programs.

Specific Aim 2: To determine if a relationship exists between student debt and physicians initially practicing in a rural location.

Hypothesis 1: An optimal debt level exists with high sensitivity and specificity that detects where students choose to practice medicine.

Hypothesis 2: A modest association exists between medical students' levels of debt with their initial choice of practicing in rural locations. 


\section{CHAPTER II}

\section{REVIEW OF THE LITERATURE}

\section{Problem Scope}

Twenty-four thousand residents enter the workforce each year with approximately $66 \%$ coming from allopathic medical schools and 13\% from osteopathic schools; $20 \%$ are international medical school graduates (IMGs). ${ }^{23}$ Approximately $75 \%$ of all medical school graduates will become specialists, while the remaining $25 \%$ become generalists or primary care physicians. Currently only $3 \%$ of medical students express an interest to practice rurally. ${ }^{24}$ These statistics are pertinent because work-related functions of primary care differ from specialty care. The literature noted primary care physicians holistically focus on the patient and are the patient's first contact to the healthcare system; specialty care then may follow. As the gateway to the healthcare system, primary care physicians (PCPSs) are vital to controlling costs and the usage and distribution of healthcare, and often arrange and oversee patient care with specialists, particularly when patients have chronic diseases and/or comorbidities. ${ }^{5}$ Numerous studies have shown an increased supply of PCPs at different levels of geographic areas (e.g., state, county, urban, rural, country) led to better healthcare quality, health outcomes, and decreased costs, and, in comparison to specialty care, a larger magnitude of PCP-to-specialist ratio enhanced population health. ${ }^{24-27}$ Rationales for these findings may include primary care physicians' 
focus on preventive medicine, including early disease detection techniques, early management of health problems, and the mitigation of unwarranted specialty care. ${ }^{27}$ Inherent within these rationales are the concepts of moral hazards and "defensive medicine.” Accordingly, evidence-based medicine’s goal is to achieve a high quality of medical care inexpensively; however, physicians and patients can face uncertainties concerning the medical diagnosis. Hence, insured patients, thought to be apathetic to cost, and willing specialists, thought to be concerned over malpractice liabilities, possibly lead to higher healthcare costs and lower quality. ${ }^{28}$ One study showed that states with higher Medicare spending had lower quality of care on six medical conditions and had a negative correlation with patients receiving the appropriate intervention. ${ }^{25}$ In addition, states with more primary care physicians showed greater use of high-quality care mechanisms at a lower cost, while states with more specialists had lower quality and higher cost. ${ }^{25}$ Another study found an association between increases in malpractice liability cost and changes in medical practice expenditures. ${ }^{28}$ Accordingly, a $10 \%$ increase in physicians' average malpractice payments was associated with a $1 \%$ increase in Medicare payments for physician services. ${ }^{28}$ The combination of the moral hazards associated with insurance and the justification for "defensive medicine” detrimentally influences medical decision-making. ${ }^{5}$ Patients preferred specialists over generalists (particularly if generalists were unavailable) and conceded any treatment to the specialists, while the specialists requested a gamut of tests to avoid a lawsuit. ${ }^{5}$ Hence, it is important when considering supply issues to focus not only on the numbers of physicians, but the array of tasks and procedures conducted by the physician. ${ }^{29}$ 


\section{Supply and Demand Issue of Physicians (in General)}

The US faces supply and demand issues regarding physicians meeting societal healthcare needs. ${ }^{1,2}$ HRSA defines "supply" of the healthcare workforce as the amount of persons working or capable of working in healthcare venues and their agreed upon financial level of compensation. HRSA characterizes "demand" as an economic concept based on employers' motivations to purchase a particular amount of healthcare services. ${ }^{30}$ Medical demand is associated with, but distinct from, medical need. Need, by one definition, reflects treatable illnesses in a population, some of which may be neglected due to inability to pay. Need has also been described as the necessary degree of medical care that health authorities maintain a person should have to stay or become healthy, and also reflects a person's self-appraisal of his or her state of health. ${ }^{5}$ Ideally, population healthcare needs, as decided by experts, should determine physician prevalence, but individuals' ability to pay, primarily through insurance and individuals' health selfassessments, helps determine the distribution and quantity of healthcare providers. Further, because physician supply is determined primarily by population healthcare demands and medical services are delivered in markets that link delivery of services to people's capacity to pay, rural and inner-city areas fall victim to geographic maldistribution due to their populations having low rates of health insurance coverage. ${ }^{5}$

Other factors further delineate the supply and demand of physicians.

Theoretically, the Physician Supply and Demand Model (PSDM) (and its predecessors the Physician Supply Model [PSM] and the Physician Requirements Model [PRM]), developed by HRSA, provides a prototype for projecting physician manpower and usage. ${ }^{6,23}$ The supply component of the PSDM forecasts two measures of physician 
supply: the quantity of working doctors and the quantity of full-time equivalent (FTE) doctors. The FTE supply measure considers the potential changes in average hours that physicians are participating in patient care activities. Estimates are based on (a) the prevalence of current physicians; (b) the physician workforce departures due to retirement, mortality, disability, and career change; (c) the number of new medical school graduates. The demand components of the PSDM focus on the present and likely future patterns use of physician services. Demand elements of the PSDM entail (a) epidemiological considerations; (b) population and insurance projections by age, gender, and metropolitan/non-metropolitan areas; (c) decision of individual patients regarding whether, when, and where to seek care; (d) physician preference on what services to impart, all of which are integrated with complex and comprehensive physician-topopulation ratios.

\section{Physician Supply Issues}

PSDM supply-related features that influence (currently or prospectively) the physician labor force are numerous. ${ }^{31}$ Demographically, since the mid-1970s, female medical school graduates increased fivefold, from $10 \%$ to almost $50 \%$. Gender differences exist in working patterns as female physicians are more likely to choose a generalist practice and work fewer hours per week, and they are less prone to practice in rural areas than male physicians. Historically, US medical school enrollment doubled in the 1960s and 1970s and then leveled between 1980 and 2005. From 2000 to 2020, active physicians reaching retirement age is expected to increase substantially, going from 9,000 to $22,000,{ }^{2,31}$ with economists predicting one-third leaving the workforce. ${ }^{32}$ One in eight active female physicians are 55 or older (based on 2006 estimates), compared to just one 
in three active male physicians. Further, the proportional decline in entering the workforce of younger male physicians, who are apt to working longer hours (males, 57 hours; females, 49 hours), ${ }^{31}$ indicates that physicians’ total labor hours are declining compared to the quantity of forecasted licensed physicians (13\% versus $16 \%$ between 2005 in 2020). ${ }^{31}$ Female physicians also are more likely to work in general and family practice, OB/GYN, and pediatrics. From 1985 to 2001, average work hours have declined in these fields while remaining steady in most other specialties such as internal medicine and surgery. ${ }^{31}$ This gender-by-age interaction of proportionally more women entering the physician workforce and working less hours along with the significantly higher rates of men retiring will increase the prevalence of female physicians, thus altering the physician workforce's operational and functional makeup. These findings, coupled with the aging of physicians and their impending retirements, may dramatically affect supply in future years.

\section{Supply of Primary Care Physicians}

According to one study, by 2025 an additional 52,000 (25\%) primary care physicians (PCPs), from around 209,000 to 261,000, will be necessary to effectively address the imminent healthcare crisis. ${ }^{4}$ Possibly causing the shortage are the future physicians' financial outlooks and attitudes along with other economic factors systemic to healthcare. Supply and demand theory may not appropriately explain primary care physician supply issues, ${ }^{33}$ as “imperfect economics” influences physicians' career options and the healthcare system. Theory dictates that salary increases occur as supplies diminish, but these salary increases curtail demand. This eventually causes equilibrium of the labor market and a halt to the deficiency. Regarding traditional healthcare dynamics, 
reasons exist for why rebalancing of the primary care market has not occurred.

Differences in salaries between generalists and specialists are daunting. ${ }^{33-35}$ In 2008 , annual salaries for PCPs ranged from $\$ 180,000$ to $\$ 192,000$; these salaries were dwarfed by the annual salaries of such specialties as emergency medicine $(\$ 258,000)$, general surgery $(\$ 320,000)$, and other fields. ${ }^{33}$ Specialist career earnings, on average, were $\$ 3.5$ million greater than PCPs. These factors decrease the likelihood of a physician becoming a PCP by 50\%. ${ }^{24,36}$ Further, between 1998 and 2008, teaching hospitals expanded graduate medical education (GME) to train residents in more lucrative specialties, and they reduced primary care residency positions as specialty care is more financially advantageous. ${ }^{24}$ Additionally, physician salary has been shown to positively correlate with both structural and personal economic factors and with job satisfaction. ${ }^{37}$ In effect, fee-for-service and managed care provide no financial incentives for patients to use primary care services such as rewarding health promotion and disease prevention behaviors. This constrains PCPs’ incomes, thereby diminishing autonomy and job satisfaction. Hence, medical students' awareness of this phenomenon leads them to choose specializations that contribute to the primary care physician shortage, ultimately harming the US healthcare system. ${ }^{5,33} 37$ Hence, the medical profession's existing economic milieu rewards students who choose medical specializations and penalizes those selecting careers in primary care. Interacting with the PCP/specialist salary discrepancy is the fact that physician salaries have increased annually at a much lower rate than student debt amounts, possibly further influencing students to choose specialties. $^{38}$ 


\section{Demand for Physicians}

PSDM demand components affecting the physician labor force also are numerous. Demographically, the two major trends most significantly affecting physician service demands are population growth and aging. ${ }^{2,6,31,39}$ The US Census Bureau notes that every decade our country’s population swells by 25 million people ( $0.8 \%$ annually) and will reach 349 million by 2025, thus further increasing the patient/physician ratios. ${ }^{2,40}$ Accordingly, population growth between 2005 and 2020 for those less than 65 years of age will grow by 9\%. For baby boomers reaching retirement that are between 65 to 74 years of age, population growth will be at 71\%, and population growth for those older than 74 years of age is projected at $26 \%$. The elderly need a higher rate of healthcare services as they acquire the most illnesses, use ambulatory care visits more frequently, have higher hospitalization rates, and live longer with chronic diseases than prior generations.

Economic growth also influences the physician labor force. ${ }^{6,41}$ Cooper's Trend model argued the positive correlation of developed countries' gross domestic products (GDPs) or national income with healthcare spending and the growth of the healthcare labor force. ${ }^{41}$ Theoretically, increased wages permitted further opportunities to acquire medical insurance and to pay for co-pays and deductibles. ${ }^{42}$ Economic growth also allowed governments and employers to expand and provide insurance policies with greater coverage and more benefits. Accordingly, the physician-to-population ratio increased by $0.75 \%$ for each $1 \%$ increase in GDP. For over 70 years in the US, this trend has ensued regarding physician supply as physician supply drifted with state per capita income. The strength and direction of this correlation differed with physician type. 
Medical specialties such as internal medicine and pediatrics had the strongest positive correlation with income, while surgery specialties had a weaker positive correlation. Family and general practice had a modest negative relationship. The trend model, as mentioned above, suggested that geographical income discrepancies also affected the supply of physicians. In a cross-sectional analysis of the 50 states, physician supply was positively associated with state per capita income. Taking this one step further, the trend

model speculated that regional differences within states influenced physician supply., ${ }^{6,31,41}$

Although the relationship between economic growth and healthcare service demand is positively correlated, it is not necessarily linear. Lower socio-economic status persons who experience income growth are more likely to increase demand for physician services. Among higher class persons, a leveling point is present as individuals will not purchase more general physician services with increased income as their healthcare needs are already saturated, although they may increase the purchase of specialty services. ${ }^{23}$

The public have higher living standards and expectations for medicine now than in previous generations. ${ }^{23}$ Further, many aging baby boomers also have inflated hope in the healthcare system and the wealth and desire to acquire services to keep them active. ${ }^{2}$ All of these factors increase medical demands.

\section{Health Reform and the 2010 Affordable Care Act}

Health reform will significantly affect the supply and demand of physicians, along with other healthcare professions. ${ }^{33,43}$ The 2010 Patient Protection and Affordable Care Act (P.L. 111-1148) (ACA) provided an intertwining of programs and policies that sought to stem healthcare costs, enhance quality, and broaden health insurance coverage. Regarding expanding health insurance coverage, the insured use more medical services 
than the uninsured as the "moral hazard" effect increases. ${ }^{42}$ The expansion of government health insurance programs, both federal and state, along with the mandate for businesses to provide health insurances for full-time workers and the mandate for citizens to procure health insurance, will trigger an approximate additional 32 to 35 million Americans to seek healthcare services (near universal coverage with only $3 \%$ uninsured). ${ }^{33,39,44}$

The ACA legislation realized more healthcare providers were necessary and legislated policies to account for this need, particularly regarding primary care. ${ }^{33}$ First, in terms of education and worker training, the ACA authorized programs, anticipated to relieve existing and projected shortages of PCPs, included a \$1.5 billion, five-year funding expansion of the National Health Service Corps (NHSC) ${ }^{45}$ and the Title VII primary care education grant funding program entitled “Teaching Health Center” that focuses on graduate medical education. ${ }^{46}$ The NHSC program incentivized professionals who chose primary care, dental, and mental health practices by granting scholarships and loan repayment to those who practice in HPSAs. Funding increases through the 2009 and 2010 American Recovery and Reinvestment Act (ARRA) caused a participant expansion in the program of over $227 \%$ and is expected to add more than 12,000 primary care professionals by $2016 .{ }^{33,45}$ Related to rewarding students for working in HPSAs, the ACA provided tax breaks for individuals working in certain health professions, including primary care. $^{45}$

The Teaching Health Center program supplied grant funding to cover the cost of conducting healthcare education programs for preparation of family physicians, general internists, general pediatricians, geriatricians, psychiatrists, obstetrics and gynecology physicians, general dentists, pediatric dentists, dental hygienists, and public health 
dentists. $^{33,46}$ The ACA addition to this Title VII program also sanctioned monies to train primary care physicians to work in patient-centered medical homes (PCMH), supporting interdisciplinary recruitment, training, and faculty development in primary care fields. ${ }^{33}$

The ACA also provided an additional $\$ 40$ billion in Pell grants for students. ${ }^{33,45}$ In addition, the ACA altered Medicare graduate medical education funding. New funds were allocated to expand medical residents' education in non-hospital arenas such as federally qualified health centers, community mental health centers, rural health clinics, and health centers managed by the Indian Health Services. ${ }^{33,45}$

The ACA’s Prevention and Public Health Fund (PPHF) allocated \$500 million to create a healthcare foundation to avert, detect, and manage diseases before they manifest or become severe. ${ }^{45}$ About $\$ 230$ million was initially designated for increasing the supply of primary care providers, including \$168 million for preparing more than 500 new PCPs by $2015 .^{45}$ The PPHF’s monies to increase primary care providers were eliminated after the first year. However, a new initiative that started in 2014 boosted the Teaching Health Center program by adding $\$ 230$ million to the program. ${ }^{46}$ The Teaching Health Center program’s intent was to place 1500 new primary care providers in underserved areas and to increase educational institutions’ capacities to train 2800 additional primary care providers (i.e., primary care physician assistants and nurse practitioners) over five years. $^{46,47}$

The ACA offered Medicare and Medicaid financial incentives to promote primary care and rural area practices. Primary care providers received Medicaid incentive payments to $100 \%$ of Medicare payments; for primary care and general surgeons working in HPSAs, they received an additional 10\% bonus payment. The increased income should 
increase supply of these providers. ${ }^{33}$ Hence, provisions stipulated by ACA policies included: (a) enhancements of the federal student debt relief program (NHSC); (b) enrichments of primary care educational funding (Title VII) to, among other things, train residents and PCPs to work in ambulatory settings and practice preventive medicine; (c) financial inducements to practice primary care and work in HPSAs. ${ }^{24,33}$ It is noted, however, that the ACA's policies that intended to increase the number of PCPs in the short-term will not meet the US population's long-term needs. ${ }^{4}$

\section{Issues of Primary Care Physician and Rural Maldistributions in Kentucky}

Recent studies (published in 2007 and 2013) have shown Kentucky has a physician shortage ${ }^{10,48}$ and this shortage will worsen with the ACA and Kentucky Health Benefit Exchange (KHBE) implementations. ${ }^{10}$ Kentucky’s physician shortage is more severe than the national shortage. Kentucky's physician-to-population ratio, ranking $32^{\text {nd }}$, is only 213.5 doctors per 100,000 residents in comparison to the national figure of 268 per 100,000. ${ }^{48,49}$ Considerable disparities exist in the need for physicians and PCPs, particularly in Kentucky's rural and underserved areas. Approximately 45\% (55 out of 120) of Kentucky's counties are officially designated HPSAs for primary care, with most counties being rural. ${ }^{50}$ Maldistribution is prevalent as $43 \%$ of the state's population resides in rural counties, but only $23 \%$ of allopathic physicians practice in these areas. ${ }^{49}$ The KHBE's implementation could allow 640,000 additional persons access to affordable healthcare services. Kentucky’s current physician shortage will intensify as pent-up demand occurs and stresses the healthcare labor force. The 2007 study, which used the Physician Requirements Model (PRM), estimated that by 2020 the Commonwealth will need 622 active physicians (PCPs and specialists) to meet healthcare needs (1,198 
physicians) and demands (2,765 physicians) ${ }^{48}$ Based on the 2013 study, Kentucky currently needs 183 PCP FTEs (representing an increase of 5\% of statewide supply), and by 2017205 FTEs. PCP need is greatest in the rural areas of Bullitt and Spencer counties which require eight FTEs each (and will increase to 11 FTEs by 2017). Further, eight southwest rural border counties need a total of 36 FTEs (and will increase to 51 PCPs with the KHBE expansion). Eastern Kentucky has the least amount of need for additional PCP FTEs, and the KHBE expansion does not significantly impact this area. ${ }^{10}$

Further complicating the Commonwealth's physician and PCP shortage is Kentucky's dismal health status that adds additional strain to the healthcare system. Kentucky’s overall health ranks 44th nationally. ${ }^{10}$ Epidemiologically, Kentucky ranks last in smoking and cancer deaths and ranks 40th or higher in obesity, diabetes, premature deaths, cardiovascular deaths, and "all outcomes.” There are almost one-million adult smokers (29\% of the adult population) and over one-million obese (30\%) adults. The rate of diabetes is $11 \%$ (332,000 adults), while $38 \%$ of senior citizens are edentulous. ${ }^{10,51}$ Based on the rankings, extensive use of PCPs is necessary to provide Kentucky citizens healthcare that emphasizes chronic and long-term behavioral health and disease management strategies..$^{10,49,50}$

\section{The Importance of Understanding the Medical Students Specialty Selection Process}

The Association of American Medical Colleges (AAMC) has urged medical schools to increase enrollment by $30 \%$ to address the current and predicted physician shortages. ${ }^{49}$ The Kentucky Institute of Medicine’s (KIOM) Comprehensive Statewide Physician Workforce Study and the Deloitte report also stressed increasing medical school enrollment to grow the supply of and to diversify the Kentucky physician labor 
force. ${ }^{10,49}$ Increasing the number of medical students will produce more physicians, but this will not necessarily increase the quantity and percentage of PCPs and rural-based physicians; currently only 3\% of medical students indicate an interest in working in rural areas. $^{8}$

The choice of career specialty and practice location can be a complex and an inadequately comprehended process where individual career decisions are the combination of many interdependent subtle and complex factors. ${ }^{14,52}$ Bennett and Phillips' literature review from 1995 to 2010 offered a primary care physician specialty choice conceptual model. ${ }^{52}$ Specifically they acknowledged four "types" of students at medical school admission and their course through medical school (i.e., admissions, matriculation, and graduation). Those types are (a) those at onset who are primary carecommitted, and matriculate and graduate committed; (b) those who have an interest in primary care and may go to either primary care or another specialty choice throughout the matriculation process; (c) the genuinely undecided students; (d) those who matriculate and graduate dedicated to non-primary care. The significant factors influencing students' specialty choice and "type” over time include (a) demographic and predisposition; (b) financial and lifestyle consideration; (c) choice process and identity development; (d) student interest relative to perceived specialty characteristics; (e) curriculum and school experience; (f) healthcare environment. Table 1 depicts the significant factors by the four types of students: 


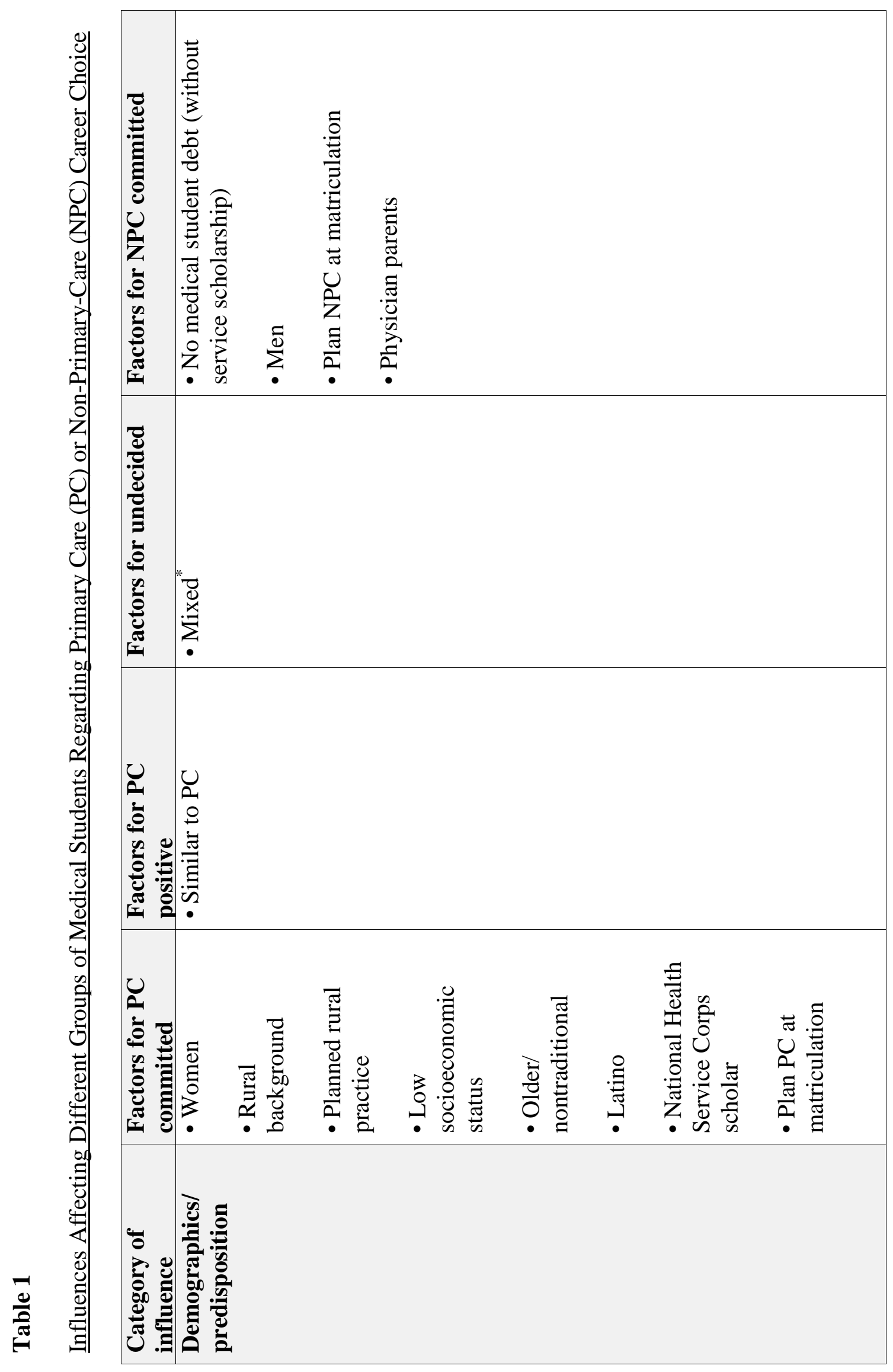




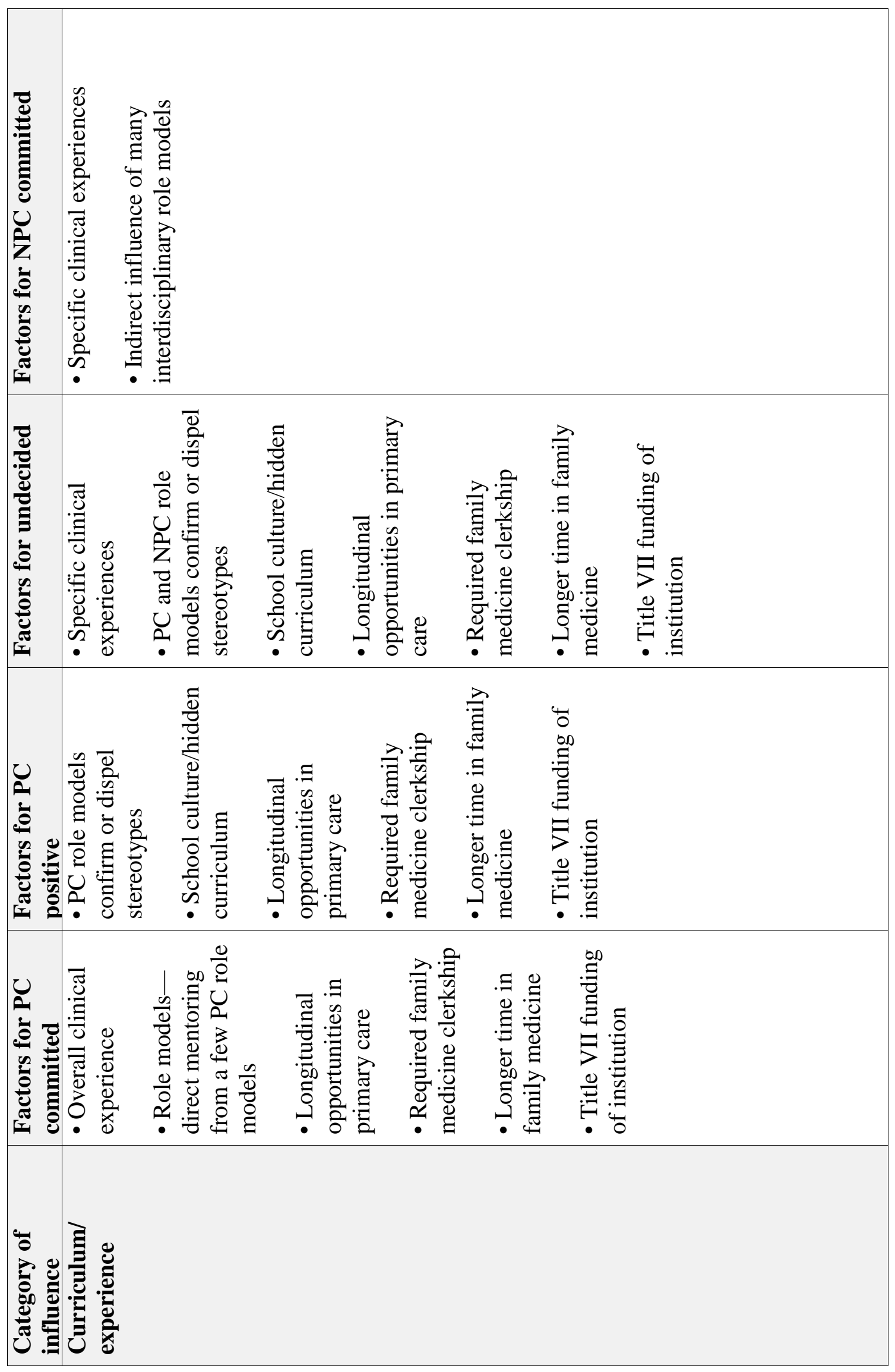




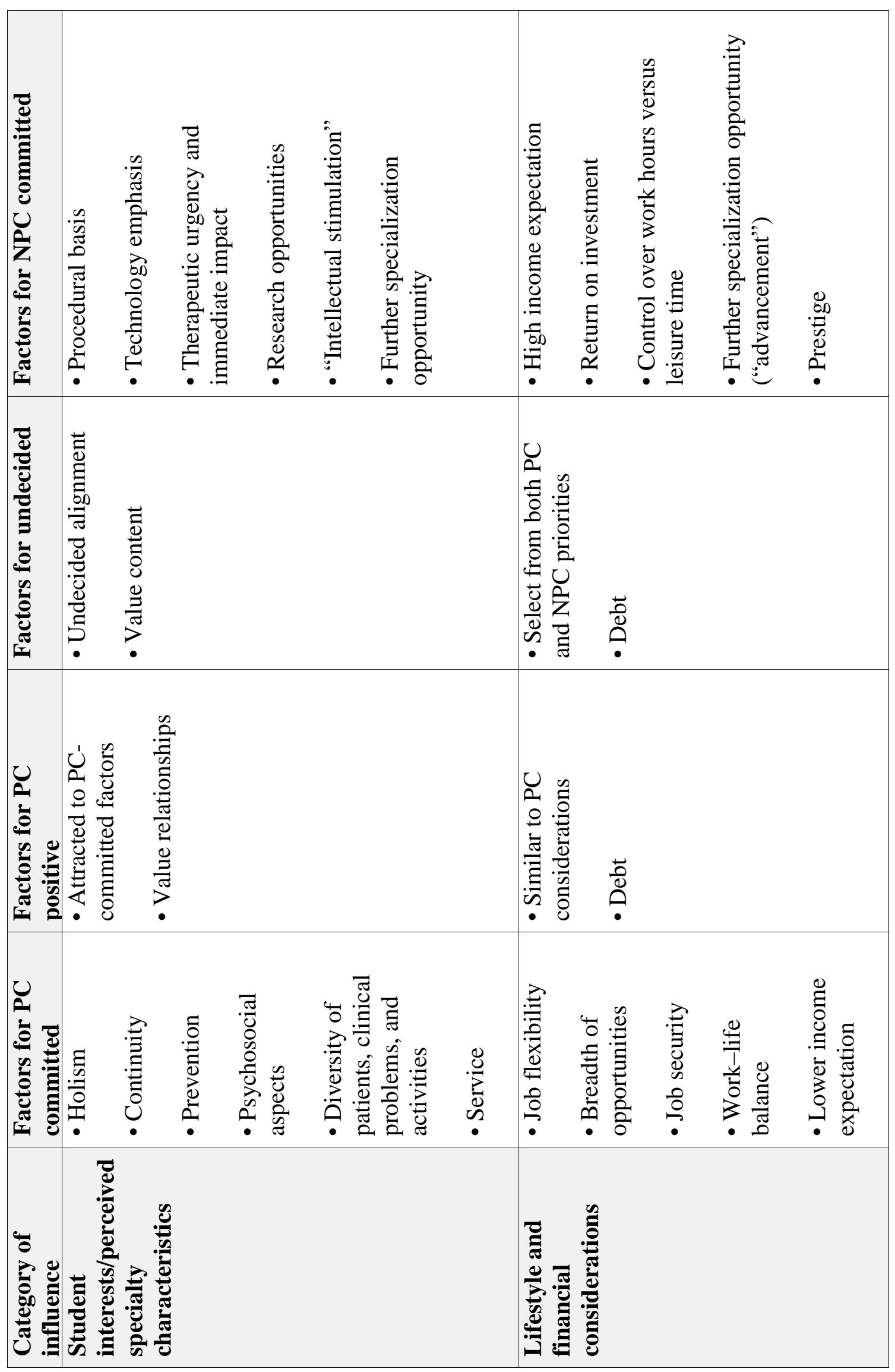




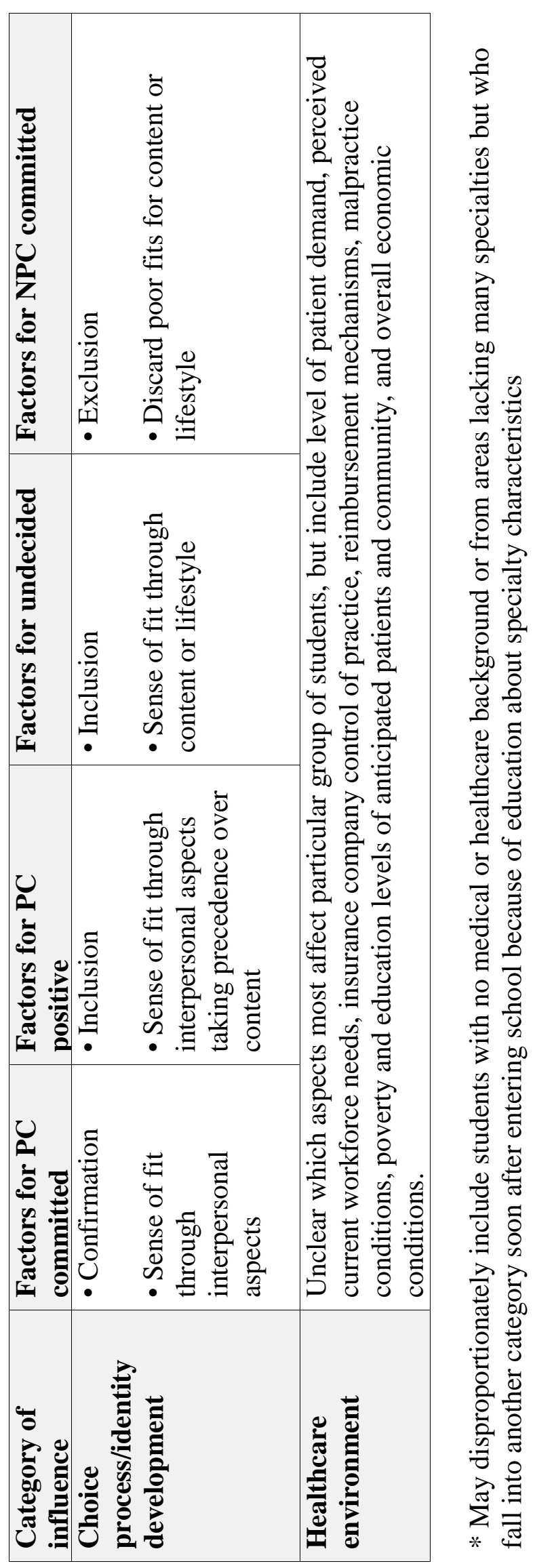


Based on this model, knowledge of the student "type" can lead to different interventions. ${ }^{52}$ For example, strategies for primary care-committed students targeting recruitment and retention in developing a premedical pipeline with academic support would be important; however, for students committed to non-primary care, emphasizing strategies promoting interdisciplinary collaboration and primary care's worth is important. $^{52}$

\section{The Importance of Understanding the Medical Student Location Process}

Regarding rural practice location, factors significant to physicians on where to initially locate may only moderately overlap with factors that impel physicians to remain in an area, and the overlapping factors may have "weights" of relative significance that should be considered. Hence, strategies and policies for physician recruitment and retention will differ. ${ }^{53}$

Barer articulated a typology that proposes six factors affecting rural location: (a) personal background; (b) professional education; (c) professional practice; (d)

personal/family; (e) community; (f) economic factors. ${ }^{53,54}$ Personal background factors considered gender, race, age, rural upbringing, among other things. Professional education factors focused on training physicians; these may include the type, size, funding, work location in medical school, and curriculum in and exposure to rural medicine in undergraduate medical education (UME) and residency training. ${ }^{54,55}$ Professional practice factors focused on career opportunities such as the physician's capacity to establish and own a group practice, to procure assorted medical experiences, and to have access to specialists for referrals; professional practice factors also included practice advantages like realistic work schedules and available locum programs. 
Personal/family factors included geographical closeness to family and friends, professional and social networks, consideration of spouse's inclination, and children's educational and extra-curriculum prospects. Community factors included typical weather and temperature, cultural and recreational opportunities, and the area's social economic status. Economic factors included work earnings, practice administrative expenses, monetary enticements, and spouses’ occupational prospects. Medical student debt level is another economic consideration that physicians must contemplate in relation to the mentioned economic factors, but, interestingly, debt is noted only in the professional educational factors.

Another rural practice location typology commonly found in the literature has a temporal framework. Accordingly, this typology's components consisted of (a) the role of nature which encompassed premedical school factors such as where students grew up, race, gender, future career plans, and personal altruistic motivation, among other things.; (b) the role of nurture which dealt with the medical training pipeline such as initiatives to recruit rural middle and high school students, along with medical school and residency rural curriculum programs; (c) the post-training factors such as economic considerations, practice characteristics, and role of mate, among other things. ${ }^{55-57}$ Personal background factors of the first typology are analogous to the role of nature, while professional education factors are similar to the role of nurture. Post training factors are congruent with professional practice, personal/family, community, and economic factors. Medical students' levels of debt and their interaction with the NHSC and other loan repayment programs overlap the role of nurture and post-training factors. Figure 1 depicts these typologies. 


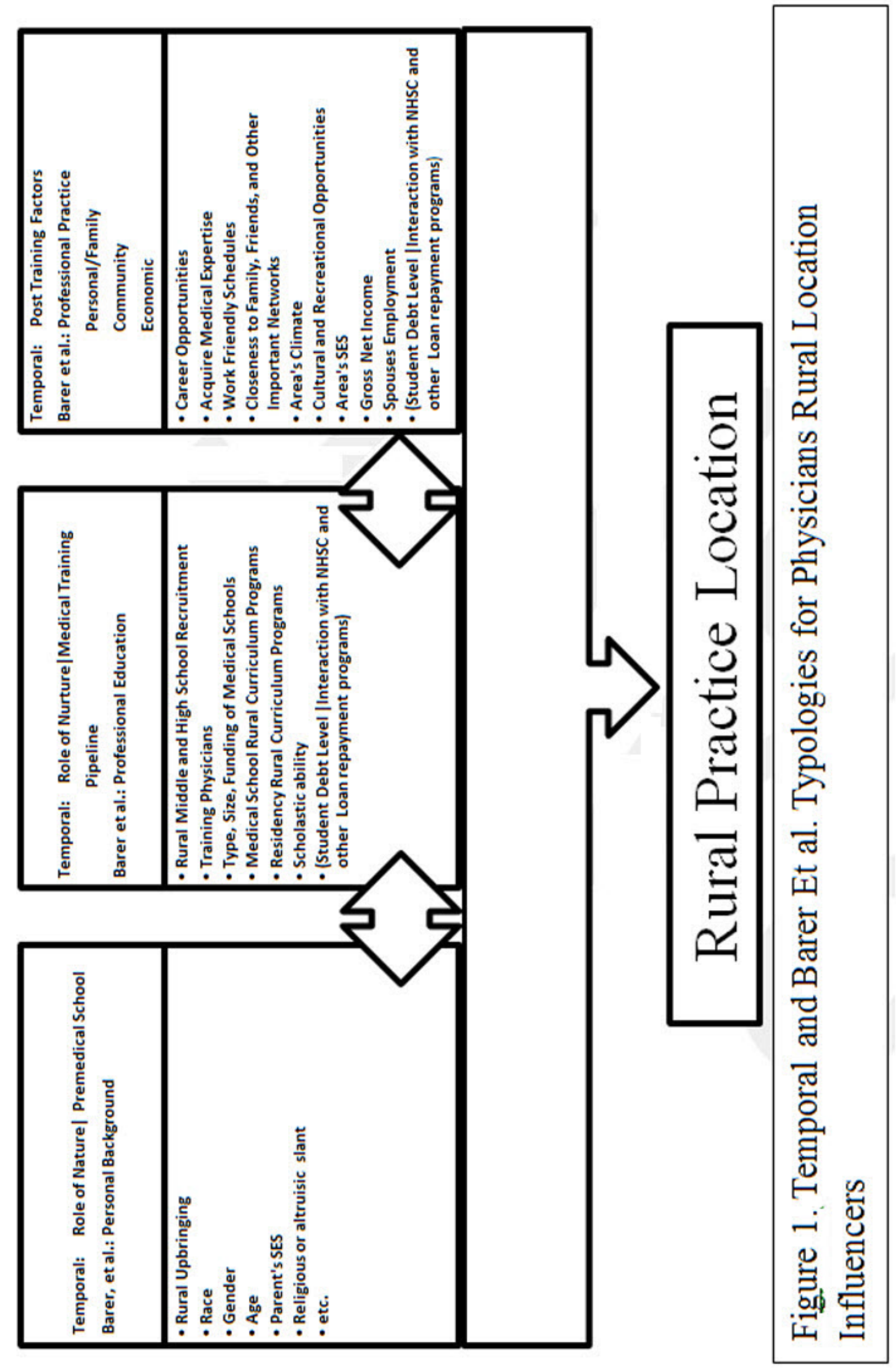


Awareness of factors that predict medical students choosing careers as PCPs and locating to rural areas can allow medical school admission committees to select applicants with a high likelihood of becoming PCPs or working in rural areas. ${ }^{14}$ Medical school administrators also may take some of these factors and tailor the medical school curriculum to encourage more PCPs or rural-based physicians by exposing medical students to rural training and to rural communities. Further, knowing medical student debt's influence on becoming PCPs or working in rural HPSAs shortage areas may cause the expansion and/or modification of national or state level governmental policies such as loan repayment and scholarship programs.

\section{Specific Literature Review of Covariates Analyzed for this Study}

The below information discusses the covariates that were analyzed for this dissertation, along with medical student debt and how the variables are noted to impact specialty choice and rural practice location. The covariates discussed include gender, race, age, rural background, rural medical training, parents’ socioeconomic status, and debt. Covariates that were not discussed include USMLE Step 1 scores and students receiving a medical school scholarship. These covariates were not discussed because there was no information found in the literature that linked them with being associated with specialty choice and rural practice location.

\section{Gender and Primary Care Choice}

In the US, since the 1990s, female physicians in the workforce have risen from $8 \%$ to $46 \%,{ }^{31,58,59}$ and for all westernized countries, greater than half of medical school graduates are female. ${ }^{60}$ Regarding specialty choice, women select primary care over other

specialties at much higher rates than men. ${ }^{61,62}$ In 2004, the top two specialties that women 
practiced were general pediatrics, $52 \%$ as compared to $48 \%$ for men, and obstetrics and gynecology (41\%); the percentage of other primary care and specialties included general and family practice (31\%) and general internal medicine (31\%). ${ }^{31}$ Although these figures appear encouraging - as the female physician workforce grows, so should the primary care workforce - the following information reveals otherwise. ${ }^{59,63}$

A key concept in specialty choice that has been studied in conjunction with gender is "controllable lifestyle specialties" (CLS). CLS are those specialties that permit personal time free of work obligations for leisure, family, and avocational activities, and permit total control of hourly demands spent on professional responsibilities. CLS specialties include, among others, anesthesiology, dermatology, emergency medicine, neurology, and ophthalmology. ${ }^{35,63}$

Uncontrollable lifestyle specialties (ULS) include the primary care specialties of family practice, internal medicine, and pediatrics. Two studies focusing on CLS/ULS issues noted that CLS is an important factor in the specialty choice of both genders. 35,59 One study demonstrated that CLS explained $55 \%$ of the variability in specialty choice. ${ }^{35}$ Both studies showed movement away from ULS and toward CLS as 20\% of medical school graduates, male and female, between 1996 and 2003, migrated away from ULS. Regarding women, in 1996 75\% of female medical school graduates chose a career in primary care; by 2003 only 53\% chose primary care. 'Men’s interest in family medicine declined from $15.4 \%$ to $6.1 \%$ and in internal medicine from $22.6 \%$ to $18.5 \%$ during the same time. ${ }^{35}$ Although both genders migrated away from ULS, certain ULS attracted female medical school graduates to them at a higher rate than male graduates. In 2003, out of all specialty choices, $11 \%$ and $17 \%$ of graduating women entered their residencies 
in pediatrics and OB/GYN, respectively, representing $70 \%$ and $80 \%$ of the residents in these fields (males constituted $30 \%$ and $20 \%$ respectively). ${ }^{35,59}$ Based on CLS, the Y2K generation of physicians' lifestyle values are cramping the necessary supply of PCPs.

A recent systematic review addressing females' rise in the physician workforce noted that, regarding primary care, female PCPs in comparison to male PCPs (a) selfreport fewer hours of work; (b) meet with fewer patients and provide less services while spending more time with patients; (c) write fewer prescriptions, charge more laboratory tests, and refer more patients to specialists. ${ }^{64}$ However, the authors concluded that the available research on the feminization of the physician workforce could not adequately address the impact on physician supply and that other studies are warranted. ${ }^{64}$

\section{Gender and Practicing in Rural Areas}

Women, in comparison to men, are less likely to practice in rural areas. ${ }^{56,65-68}$ One study using the American Medical Association master data file showed that, of rural family medicine physicians under the age of $45,24 \%$ are men and $16 \%$ are women. ${ }^{66}$ Another study using the same database revealed that in the field of pediatrics where women constituted two-thirds of residents, males were 50\% more likely to practice in rural areas. ${ }^{31,67}$ Hence, the rural physician maldistribution was compounded by the interaction of medical school graduates being almost 50\% women and women physicians being under-represented in rural areas. ${ }^{65,69}$

Rural female physicians can influence healthcare in ways male physicians cannot. ${ }^{65}$ Female patients are more comfortable addressing feminine health concerns with female doctors; female physicians’ positions in the community allow them to function as leaders for women's health issues; and rural female physicians may inspire as female role 
models. ${ }^{65,68}$ Thus, addressing the reasons why women are tentative to engage in rural practice will help reduce the rural physician shortage.

Rural female physicians list numerous professional and personal problems they encounter. Professional problems noted are (a) a possible excessive demand for their services; (b) a lack of female colleagues and mentors to discuss family and career; (c) an undervaluing of female physicians' status by patients and other male doctors along with possible difficulties in performing duties due to male physicians' hostilities. ${ }^{68,70}$ Several personal issues also influence rural female physicians. First, these physicians must deal with the role strain of balancing work and family as many rural female physicians are married to other professionals (i.e., due to their status as women, they feel obligated to care for children, cook, clean, and so forth). Next, married 'female physicians' spouses often have trouble finding jobs in rural areas. Third, single female physicians have difficulty meeting single men with similar education and life experiences and also have problems forming friendships. Finally, maternity leave, working part-time, and not being on call to 'take care of children are discouraged as a large pool of physicians to job share with is non-existent and child care is often unavailable. ${ }^{31,68,70}$ These lists of problems further complicate the issue of physician shortages in rural areas.

\section{Race, Diversity, and the Physician Workforce}

A major US healthcare obstacle is the need for additional minority physicians to treat the increasing population of underrepresented minorities (URMs). ${ }^{71}$ Approximately $26 \%$ of the US population is African-American (12\%), Hispanic (13\%), or Native American (1\%), while just 6\% of URMs are practicing physicians (African-American and Hispanic,3\% each; Native American, less than 1\%). ${ }^{71,72}$ This population-to-physician 
ratio discrepancy, known as the "diversity gap,"73 turns potentially bleaker as the URM population forecast increases to $32 \%$ by 2025 and doubles to $50 \%$ by $2050 .^{71}$

Cohen, the former president of the AAMC, stressed four pillar values of diversity and the need to include URM groups in the physician workforce. ${ }^{73,74}$ First, URMs, as both medical students and physicians, increased the profession's level of cultural competence. Cultural competence implies the physician’s knowledge, skills, attitudes, and behavioral requisites to provide optimal healthcare to patients from diverse races and cultures. Medical school diversity among students (and faculty) allows for an exchange of different belief systems. This exchange brings awareness to the physician trainees' cultural biases, ethnic origins, family structures, and other cultural influences that affect health outcomes, i.e., how patients may experience illness, comply with medical counsel, and react to prescribed therapy. Without student interaction among diverse groups, the future practitioners’ patient care will likely be subpar. ${ }^{71,73,74}$

Another diversity pillar value was the fact that minority physicians are more apt to practice in HPSAs and to treat Medicaid recipients and indigent populations than their non-URM colleagues. ${ }^{31,71,73,74}$ A 2004 AAMC medical student survey showed that 20\% of all graduates intended to practice in HPSAs; Hispanics (31\%), Native Americans (41\%), and African-Americans (51\%) were approximately 1.7 to 3.0 times more likely than white physicians (18\%) to plan to work in HPSAs. ${ }^{71}$ Further, when minority patients have access to and use minority physicians as their PCPs, this minority-with-minority concordance leads to increased patient satisfaction ${ }^{31,71,75}$ and decreased levels of mistrust, ${ }^{75,76}$ in comparison to minorities seeing white physicians. Patients’ physician dissatisfaction and mistrust have been associated with patient treatment non-compliance 
and failure to return for doctors' appointments. ${ }^{75}$ One of the Healthy People 2010 goals, a publication of HRSA, was to remove the racial and ethnic disparities in health and healthcare services. ${ }^{73}$ URMs have higher rates of poor health status indicators than whites have. $^{77}$ These include life-threatening and chronic diseases such as cancer, stroke, diabetes, HIV infection, hypertension, among other diseases, along with a shorter lifespan and higher mortality rates. ${ }^{73}$ The changing US racial population-to-physician distribution, if not corrected, will likely increase health disparities between URM and non-URMs groups ${ }^{77}$ Hence, an influx of more URM medical students, residents, and physicians could provide healthcare access to the URM underserved populations and improve healthcare quality as directed by Healthy People $2010 .^{73}$

The third pillar value advocating physician diversity concentrated on expanding medical and public health research. ${ }^{73}$ Implicit of this goal implies increasing academic medicine’s URM workforce. Minorities, working in medical schools which have traditionally only employed Caucasians, constitute just $7.3 \%$ of the faculty ${ }^{78}$ and hold few chief positions. ${ }^{31}$ Emphasis on increasing medical school diversity among faculty and persons in leadership roles will positively alter the US healthcare system. Increase in URM faculty would permit different perspectives on research that would tackle unsolved health problems facing the US. Essentially, researchers and physicians view problems through their cultural prisms and work on issues of interest to them. Existing problems, unknown to white academic physicians, would be addressed, while longstanding problems would get a new perspective. ${ }^{73,74,78}$ Further, URM research subjects, like patients, may be distrustful of studies that do not include researchers of their own race. ${ }^{73}$ Broadening the research agenda in academic medicine begins with selecting racially, 
ethnically, and gender diverse students and faculty to MD and $\mathrm{PhD}$ educational programs. $^{74}$

Cohen’s fourth pillar value argued that diversity in the leadership and administration roles of healthcare professions is a good business strategy. ${ }^{73,74}$ When organizational leaders, such as those in the AMA, are well-informed about their constituents, strategic decisions are effectively made for all parties concerned. The AMA, AAMC, and other health professional organizations must consider the increasing diversity of the US and are obligated to allow more qualified URMs to matriculate through medical school and take leadership and policy-making positions in academic medicine. $^{73,74}$

\section{Race and Primary Care Choice}

Specialty choice among URMs focus on primary care fields more so than specialization. ${ }^{31}$ Although blacks reflect $3-4 \%$ of the physician workforce, they have their greatest representation in general preventive medicine (8\%), OB/GYN (7\%), and public health (5\%); underrepresentation occurs in specialties like medical genetics, radiation oncology, and allergy and immunology (2\% each). Hispanics select family medicine (11\%) and pediatrics (7\%) at greater rates than their representation in the workforce and select specialized medicine fields at lower rates, i.e., orthopedic surgery (2\%), radiology, and dermatology (3\% each). ${ }^{31}$

The rationale for minorities choosing primary care has been explained by the “service patterns hypothesis” which reasons that URM physicians select primary care because of the excessive demand for primary care in chiefly minority, rural, and innercity HPSAs. $^{31,79}$ This hypothesis stipulates that URM health professionals, having come 
from underprivileged backgrounds, are more likely than others to serve other URM disadvantaged groups. A comprehensive HRSA minorities physician workforce literature review of 17 studies showed overwhelmingly convincing evidence that URM physicians are more likely than non-URM physicians to disproportionately care for both URM and underserved populations, including the poor, the uninsured, Medicaid recipients, and those living in HPSAs. ${ }^{79}$ Findings from this literature review showed that in a national sample of 2001 Medicare patients, 22\% of black patients' physician visits were to black physicians who make up $4 \%$ of the physician workforce; black physicians constituted $13 \%$ of physicians in areas where African-American patients sought care; and black patients sought out black physicians even if the office location was inconvenient. Further, similar findings held for other minority groups; that is, Hispanics served and sought out other Hispanics, likewise, Asians with Asians. Finally, it should be noted that minority physicians not only disproportionately serve patients from their own racial and ethnic groups, but they also disproportionately serve other minority patients as well.

Integrating the "service patterns" hypothesis with primary care choice, arguments are made that minority physicians serve minority and underserved communities because they are not as academically competent as white physicians. Accordingly, minorities match only to the less competitive primary care specialties, and after completing residency are noncompetitive for positions in more affluent areas. ${ }^{79}$ However, studies have shown minority graduates from elite medical schools were considerably more prone than their nonminority counterparts to practice in minority and underserved communities. $^{79}$ 
Race, separate from social economic background, has been shown to influence URMs serving the underserved. ${ }^{79}$ One study showed that URM pediatricians care for more Medicaid and uninsured patients than non-URM physicians, even when the URM doctors came from affluent backgrounds, and the non-URM doctors did not. This indicates that affirmative action programs focusing on medical students' race, and not their socioeconomic backgrounds, will do more to increase the number of physicians tending underserved populations. ${ }^{79}$

\section{Race and Rural Areas}

In a search of the literature, few studies found have demonstrated an association between physicians practicing in rural or HPSAs rural areas and race (as defined by URM's or non-URM status). ${ }^{14,80,81}$ A North Carolina physician practice database study from the period 1981 to 1989 showed that upon entering practice, a greater percentage of whites practice in rural areas versus urban areas (81\% versus 68\%, respectively; $\mathrm{p}<0.001) .{ }^{80}$ A study surveying northwest osteopathic medical students' intentions towards practice location found no significant race differences between those leaning toward choosing a rural setting and those an urban setting, although a larger sample size might have detected a difference (whites/rural, 79\%; urban/rural, (90\%), $\mathrm{p}=0.063) .{ }^{81}$

One 1996 study showed NHSC minority physicians placed in rural areas were more likely to have urban backgrounds and to be dissatisfied with their rural placement; similarly, their families also were dissatisfied. ${ }^{82}$ Specifically, minorities place more value on urban amenities than non-minorities. Minorities also stressed aspects of urban practice settings, such as having colleagues accessible for referrals and for counseling on difficult cases, higher than non-minorities. Rural retention rates between minority and non- 
minority physicians one year after their NHSC tenure were not significantly different. ${ }^{82}$ These findings fit with the Affinity model discussed below.

IMGs play a role in the physician work force. As mentioned above, $20 \%$ to $25 \%$, approximately 6000, IMGs enter residency programs annually. ${ }^{2,5,23}$ Theories argue the pros and cons of IMGs. The "safety net" theory posits that IMGs do what US medical school graduates (USMGs) do not do, including practicing as rural HPSA PCPs; the IMG “surplus exacerbation” theory argues IMGs just add to the aggregate number of physicians. ${ }^{83}$ The "correct" theory would determine policies of increasing or limiting FBIMGs entering residency programs. ${ }^{84}$

Knowledge is mixed regarding the theories and IMGs’ likelihood to practice in rural HPSAs in comparison to US medical school graduates (USMGs). ${ }^{5,84-86}$ One study using the 1996 AMA Masterfile found that IMGs compose an increased percentage of the US PCPs workforce in rural underserved areas than rural non-underserved areas. Nationally, IMGs made up 19\% of PCPs in whole HPSAs, 15\% in partial HPSAs, and $14 \%$ in non-HPSAs. However, interstate variation exists; for instance, Kentucky IMGs represented 24\% of PCPs in whole HPSAs, while in Pennsylvania and Minnesota the percentage was $0 \%$ and $6 \%$, respectively. ${ }^{86}$ Another study that used the 1997 AMA Masterfile and 1996 Area Resource File (ARF) concluded that states had a disproportional amount of IMGs in comparison to USMGs working in rural areas. ${ }^{83,87}$

Studies supporting the “surplus exacerbation” theory include a 1995 analysis that look at published data from the AMA, AAMC, and the ARF. The study noted that IMGs subspecialized at a disproportionately high rate, lessening their impact on primary care, and their practice location patterns matched USMGs. ${ }^{88}$ A 2003 study showed that 2.1\% 
of IMGs and USMGs practiced in rural HPSAs, with interventions to coax IMGs to practice in rural areas being no more beneficial than USMGs' self-selection to practice in these areas. ${ }^{84}$ However, the PCP supply of IMGs in rural HPSAs contrasted with those of USMGs: USMGs practiced as family physicians at a higher rate, and IMGs were more likely to be internists and pediatricians. ${ }^{84}$

Controversies exist over IMGs' roles in the US. ${ }^{89}$ Ethically, both developed and non-developed countries are increasingly relying on potential US-trained IMGs to enhance or expand their healthcare capabilities, while many IMGs do practice in the US after completing their residencies. ${ }^{2,31}$ Moral questions abound as the US and other developed countries expedite "brain drain” and poach physicians trained in other, less developed countries, attenuating those countries’ capacity to deal with HIV infection, AIDS, and other grave needs. ${ }^{2,89,90}$ Further, countries that provide undergraduate medical education for IMGs have contributed to their training and have lost financially; this foreign education and cultural barriers of speech, dialects, and so forth, may lead to subpar care. ${ }^{89}$ A positive contribution, not discussed above, relates to causing more cultural diversity to an increasingly growing diverse nation. ${ }^{89}$

\section{Affirmative Action}

Affirmative action has been successful in increasing the percentage of URM medical students and physicians as evidenced by US Supreme Court and state courts affirmative action decisions. ${ }^{72-74,91}$ Until the 1960s civil rights movement, blatant discrimination against URMs excluded them from the medical field. The US Civil Rights Act of 1964 banned discrimination on bases of race, color, religion or national origin in 
voting, public accommodations, facilities, and education. ${ }^{91}$ This legislation set the tone for affirmative-action policies in medical school.

Affirmative action refers to administrative polices designed to increase women’s and minorities' presence in employment, education, and business from which they have been historically excluded and may not necessarily involve quotas. ${ }^{92}$ The 1978 Supreme Court case, Regents of the University of California v. Bakke, ruled that colleges can consider race favorably in admissions to achieve student diversity for the purpose of educationally benefitting all students; quotas, however, cannot be imposed. The rationale for Bakke is that all students benefit educationally from diversity. Affirmative action allowed URM medical school matriculants to increase fourfold by 1971 (2\% to 8\%), and this $8 \%$ matriculation rate endured throughout the 1970 s and 1980 s. $^{72-74}$ The diversity gap, however, widened during this period as the US population of URMs rose; medical schools reenergized affirmative action guidelines with Project 3000 by 2000. The AAMC, in the early 1990s, initiated this program to identify and admit additional qualified minorities from the prevailing applicant pool by working with K-12 school systems and pipeline colleges to expand the number of suitable URMs. By 1994, URMs represented $12.4 \%$ of medical students. ${ }^{72-74}$

By the mid to late 1990s, states’ anti-affirmative action initiatives curtailed URMs' medical school entry. California Proposition 209, Washington State Initiative 200, Hopwood v. Texas (which halted affirmative action for public universities in Louisiana, Mississippi, and Texas), and other state legislation prohibited racial consideration in admission decisions. ${ }^{72-74,91}$ Since the passage of these anti-Affirmative Action laws, the number of US medical school URM matriculants decreased 8\% from 
1995 to 2001 (a decrease of 239 matriculants). In the five states where anti-affirmative action legislation passed, the medical school matriculants decreased anywhere from $17 \%$ to $64 \%{ }^{72-74,91}$

The most recent Supreme Court decisions influencing Affirmative Action in medical schools focus on 2003 rulings concerning the University of Michigan. ${ }^{91}$ Grutter v. Bollinger and Gratz, et al. v. Bollinger, et al. were anti-affirmative action challenges to Michigan’s law school and their undergraduate programs. In Grutter v. Bollinger, an unsuccessful white law school applicant argued reversed discrimination against her because the University took race and ethnicity into consideration in its admission procedures. The University maintained it was constitutional to consider race and ethnicity in admissions to achieve the "compelling government interest" of a diverse student body. The court ruling favored the University and their right to "narrowly tailor" the student body for diversity as long as individual consideration for each applicant exists. The Court also noted Cohen's argument for society to have diversity in leadership roles. In Gratz, et al. v. Bollinger, et al., two unsuccessful applicants to Michigan's College of Literature, Science and the Arts disputed race as a "plus" factor in admissions. The University used the rationale of Grutter v. Bollinger; however, URM undergraduate applicants automatically received 20 out of 100 points, guaranteeing admission. The court ruled adversely toward the University noting the way the University attained diversity was impermissible. Hence, the Court upheld diversity to be a "compelling interest" of the state; that admissions policies can narrowly tailor their student body for diversity purposes, but mechanical and automatic assignment of significant benefits based on race is unlawful. ${ }^{91}$ 
Since these two court decisions, 2011 statistics show the percentage of medical school URM matriculants has increased to 15\%, (African-American [6\%], Hispanic[9\%], and Native American [0.2\%].${ }^{93}$ Thus, an association exists between affirmative action and URMs becoming physicians. As favorable and unfavorable affirmative action court rulings and legislation take place, these rulings possibly influence the degree that URMs matriculate through medical school and ultimately are employed in the physician workforce. $^{73,74}$

URM applicants are not competitive with whites and Asians on MCAT scores and GPAs. Medical school admission committees, however, have selected URM applicants on leadership, overcoming hardships, diligence, having a service-orientation makeup, compassion, sensitivity, and other important traits. ${ }^{74}$ Because of admission committees' judicious choice of accepting URM applicants, 90\% of URM matriculants, in comparison to $96 \%$ of whites, overcome all academic obstacles and earn the MD degree. ${ }^{74}$ Further, 2001 statistics show that if affirmative action is non-existent, the number of URMs admitted for medical school is decreased $70 \%$ (from 1697 to 513). ${ }^{73,74}$ Although this discrepancy of $6 \%$ between URM and white matriculants may deny a few non-minorities medical school admission, most medical educationalists judge that the advantages of a diversified class outweigh the cost. ${ }^{73,74}$

\section{Title VII, Primary Care, and Diversity}

The Title VII Training in Primary Care Medicine and Dentistry grant program has been operating since 1976 to improve the nation's access to PCPs and dentists through student, resident, and faculty education curriculums that are community and primary care-based. ${ }^{94}$ Historically, Title VII had three theme-focused eras to which Congress 
allocated grant funding. In the first era, between 1963 and 1975, the Health Professions Educational Assistance Act of 1963 amended Title VII of the United States Public Health Service Act to approve funding for the training of physicians, dentists, and other healthcare professionals. Title VII legislative rationale addressed reports of a national physician shortage. ${ }^{95}$ The two major directives were (a) construction of new health professions training schools since many states had no medical schools or means to recruit from other states; (b) student loan grants to attract students from low-income families. The numerical goal was to graduate more physicians and dentists, increasing physicians by $50 \%$ and doubling dentists by $1975 .{ }^{96}$ The legislation did increase the primary care workforce, however, specialty and geographical maldistributions occurred, causing healthcare access inadequacies among the underserved and rural populations. ${ }^{95}$

Title VII’s second era, which occurred between 1976 and 1981, was initiated with the Health Professions Assistance Act of 1976 (PL 94-484). The legislation addressed, among other things, the problems of (a) an increasingly disproportionate number of specialists trained for hospitals and not for community or ambulatory care settings; (b) PCP and dentist shortages; (c) physician underrepresentation in rural areas; and (d) too few minority and disadvantaged students training in all healthcare disciplines. ${ }^{96}$ The shifting priorities reallocated grant appropriations, now capitative in nature as opposed to the first era's seemingly limitless funding, to increase the number of ambulatory, primary care educational facilities and primary care residents. Forty-million dollars was budgeted for building grants, however, 50\% was authorized for primary care building capacities. Medical school grant recipients had to reduce specialty residency positions and increase primary care trainees (at this point legislatively defined as family medicine, general 
internal medicine, and general pediatrics) ${ }^{97}$, from $35 \%$ in 1978 to $50 \%$ by 1980 . In addition, a medical school's student body had to increase by the greater of $10 \%$, or 10 students. ${ }^{96}$ Thus, Title VII modestly increased the number of PCPs, but had miniscule production of minority and disadvantage physicians.

The Title VII legislation favored the emerging field of family medicine to facilitate its development. Family medicine’s preferential funding included the “Grants for Establishment of Departments of Family Medicine” which permitted the formation of new allopathic and osteopathic family medicine departments. The establishment grants' purposes were to develop educational capacity and bring family medicine’s status equal to other specialties. Establishment grants permitted broad use of their monies. Family medicine pursuits included all-inclusive planning, development, administration, coordination, and appraisal of undertakings along the learning continuum, i.e., predoctoral, residency, faculty development, and scholarly activities such as pilot testing model curricula along this continuum. Innovations in preventive medicine, ethics, distance learning, behavioral health, and evidence-based medicine arose as well as in ambulatory care training with a concentration on community-oriented primary care (COPC). ${ }^{97,98}$ The establishment grants created the educational framework of family medicine (and the other primary care fields) ${ }^{97}$

Student loan legislation shifted as well. ${ }^{96}$ Loans were limited to $\$ 50,000$, with a three-year deferment for remuneration. An expansion of the NHSC occurred to address medical rural and urban geographic maldistribution, particularly physician maldistribution. Scholarship support, once easily available, was limited for students with 
notable financial privation. In essence, Title VII’s first era of unrestricted access to physician's financial aid became to some extent more restrictive. ${ }^{96}$

Title VII’s third era, from 1992 to present, began with the 1992 Title VII reauthorization under the Health Professions Education Extension Amendments (PL 102408). This era's focus, in comparison to the second era's promotion of primary care, is more so on vulnerable populations, medically underserved communities (MUC), and health professions diversity. ${ }^{96-98}$ Regarding vulnerable populations, a recipient of a Title VII grant main population outcome benefactor must include an ethnically and racially assorted populace and patients with medical access issues in order to eradicate health outcome discrepancies. ${ }^{98}$ These populations also include the homeless, aged, HIV/AIDSinflicted persons, substance abusers, and domestic violence victims. ${ }^{96-99}$ This new focus has compelled medical schools and residency programs to collaborate with community health centers and Area Health Education Centers' (AHECs) network of clinical sites to reach vulnerable populations. ${ }^{98}$

HRSA's policy of enticing graduates to HPSAs is to use the federal purse to prod medical schools into accepting federal policy goals they might otherwise reject. To obtain Title VII funding, the grant process's mechanisms for scoring are the "Primary Care Priority" and the "MUC Preference." HSRAs Title VII reviewers place high priority for grant proposals to those departments and divisions that trained students and residents in primary care careers and/or who, as clinicians, provided care to patients in MUCs. Innovative and quality proposals that fail to address these two mechanisms receive lower scores than weaker proposals that speak to these mechanisms. Hence, primary care 
training departments must implement MUC development strategies to acquire the federal government’s financial awards. ${ }^{96-98}$

A third focal point of current Title VII policy is to interest students, residents, and physicians in serving HPSAs and diverse populations. Educationally, the curriculum now focuses more on training students and residents with the capacity to care for the nation's underserved in rural and urban HPSAs. ${ }^{98}$ Further, the "Primary Care Priority" and "MUC Preference” mechanisms gave additional points to grant applicants who had successfully produced primary care graduates and/or recruited minority and disadvantaged students. ${ }^{97}$ Financial support for AHECs increased to \$25 million annually, permitting the growth of community-based clerkships for medical students as well as primary care residents; this strengthened medical schools’ interaction with rural communities and their practitioners. ${ }^{96}$ Moreover, Title VII funding boosted minority recruitment with two major pipeline programs, Health Careers Opportunity Program (HCOP) and Centers of Excellence. ${ }^{96}$ HCOP’s purpose is to foster minority youths by recruiting, mentoring, financial counseling, and facilitating these youths into college and health professions training programs that focus chiefly on primary care. Those receiving a HCOP grant must work with school districts, undergraduate institutions, and other community-based organizations to nurture these potential healthcare providers. The Centers of Excellence program has four legislative conditions. These include (a) developing capable medical school applicants and students and then fostering their academic success; (b) supporting the training, recruitment, and retaining of URM faculty; (c) addressing minority health concerns in clinical training, curriculum and information resources that must involve community-based training in clinics that help considerable quantities of minority patients; 
(d) supporting minority health research. Finally, the creation of a new primary care loan program took place where students who commit themselves to family medicine, general internal medicine, general pediatrics, preventive medicine, and osteopathic medicine careers are the benefactors. Further, scholarships for underprivileged students with financial hardships are limited to only those who agree to pursue residency training in primary care fields or in general dentistry ${ }^{96}$ Hence, Title VII's third era fostered a diverse health professions workforce through specifically focused policies that ultimately altered the primary care fields; these alterations included curriculum adjustments, community outreach, the recruitment and fostering of minorities, and student loan modifications.

Title VII's three era historical trend has shifted from (a) increasing the overall production of the healthcare workforce, to (b) increasing the primary care workforce, to (c) policies that stress vulnerable population care, increasing workforce diversity, and curricular innovations to successfully care for the changing populace and healthcare needs of the nation. As Title VII went through the three eras, grant stipulations became more restrictive, representing the national healthcare needs of the particular era. Implicit in this happening is that the federal government attempts to sculpt the physician workforce. Since 1992, policy has focused on the national priority of meeting URM healthcare needs and increasing the quantity of URM physicians. ${ }^{96-98}$

\section{IMGs and Kentucky}

The Deloitte report notes that IMGs constitute 21\% of Kentucky’s physician supply (somewhat below the national average of 25\%). ${ }^{10}$ Although the percentage of Kentucky's primary care specialties for IMGs (37\%) and USMGs (35\%) are comparable, overall IMGs practice in rural areas at greater rates than USMGs (39\% versus 26\%), and 
the more rural the county, the greater the IMG/USMGs discrepancy. ${ }^{10,100}$ India, the Philippines, Syria, Pakistan, and the West Indies are the top four countries where Kentucky IMG physicians originate. ${ }^{10}$ Kentucky’s IMG physicians supply is lower than the national average of 25\%, and studies advocate implementing policies to increase IMGs and Kentucky’s workforce. ${ }^{10,100}$

\section{Age, Primary Care, and Rural Areas}

“Age”-reported influences on specialty choice and geographic location is minimal and somewhat antiquated. ${ }^{14,61,62,101}$ Two studies focusing on alumni from California universities note an association between age and primary care specialty choice. The first study assessed survey data from the University of California-San Diego School of Medicine (classes of 1974, 1978, 1982, 1986, and 1990) and revealed a significant increasing linear trend as a greater percentage of older alumni practice in primary care. ${ }^{62}$ The second study surveyed alumni from the Drew and UCLA classes of 1985 and $1987 .{ }^{61}$ The results reported were incongruent with the conclusions drawn. Accordingly, the authors note older physicians were more likely to choose primary care, yet the odds ratio reported indicated an inverse association, i.e., that they were less likely; OR $=0.92,95 \%$ CI (0.86, 0.99). Other inconsistent reporting of findings occurred in this article as well. A Canadian study conducted at the University of Alberta showed that older medical students desired a family medicine career over other specialty choices ( $\geq 25$ years; 69.9\% versus 41\%, $\mathrm{p}=0.001) .{ }^{101}$ Regarding Kentucky, University of Louisville admissions data from 1986 and 1987 medical students $(n=214)$ showed no relationship between age and primary care specialty choice. ${ }^{14}$ Hence, contrary evidence exists regarding older 
graduating medical students choosing primary care careers with increased probability over younger graduates.

Studies have shown older medical school graduates are more apt to practice in rural areas after medical training, albeit a modest effect. ${ }^{14,80,81}$ The North Carolina study mentioned above showed that, upon entering practice, slightly older physicians practice in rural areas versus urban areas (rural, mean age $=31.7$; urban, mean age $=30.1$, $\mathrm{p}<0.001) .{ }^{80}$ The Northwest osteopathic medical students study mentioned earlier found no significant age differences between those leaning toward choosing a rural setting and those choosing an urban setting (rural, mean age $=28.6$; urban, mean age $=27.2$, $\mathrm{p}=0.138) .{ }^{81}$ For both studies, mean age difference between rural and urban settings was a little over one year, indicating a lack of practical significance, and statistical significance for the first study is possibly only reflective of a large sample size ( $n=1947)$. The Kentucky study mentioned above revealed no association between age and rural/urban practice location. $^{14}$

\section{The Affinity Model and Rural Background}

The affinity model addresses generating physicians for rural practice by targeting potential physicians from rural areas and/or incorporating rural practice setting medical training. ${ }^{20,55,102}$ The affinity model's goal is to foster an individual's desire for rural practice or rural living so that physicians choose rural practice settings based on the evidence that rural origin is strongly associated with practicing in a rural community. ${ }^{55,57,103}$ One 2002 literature review documented four methodically sound studies from 1990-2000 confirming this association. ${ }^{55}$ 14,104,105 Rabinowitz's work with the Pennsylvania-based Physician Shortage Area Program at the Jefferson Medical 
College has consistently shown over time that physicians with a rural upbringing practice in rural areas $25 \%-29 \%$ of the time. ${ }^{55,57,103}$ The Kentucky study mentioned above (under 2.1.16 Age, Primary Care, and Rural Areas) revealed that physicians with rural backgrounds were 2.5 times more likely to practice in rural areas. ${ }^{14}$ A 1997 survey that assessed Colorado family medicine physicians ( $\mathrm{n}=986)$ concluded that a physician coming from a rural background was the most powerful predictor of rural practice location. ${ }^{105}$ A North Dakota study surveying 924 physicians also established that rural upbringing fuels rural recruitment. ${ }^{104}$ Later studies also have established the relationship of rural upbringing to physicians practicing in rural areas. ${ }^{81,106}$ A 2011 Canadian study showed that physicians who had attended a rural high school were 4 times more likely to practice in rural areas. ${ }^{106} \mathrm{~A}$ study on northwest region osteopathic medical students $(n=225)$ showed that students raised in rural communities intention to practice in a rural community was 2.6 times greater than their urban-raised counterparts. ${ }^{81}$

Affinity model factors can consist of aiding rural students in admittance to medical school. This aid can start in middle and high schools by nurturing students’ medical career interests and cultivating their career goals. A more common mechanism is using selective admission policies to allow students with rural upbringing, or who indicate a preference to work in rural areas and/or primary care, to acquire favored admission status. These admission policies are often accompanied with rural medical school curricular instruction that foster students' retention of rural interest through medical training that present learners with opportunities to cultivate necessary rural practice skills and attitudes. ${ }^{102}$ Rural curriculums potentially counteract “urban disruption" and the allure of conventional medical training characterized by being in 
technology-intensive and tertiary care hospitals where specialized expertise is highly regarded and faculty may dissuade primary care or rural practice careers. ${ }^{102}$ Rural curriculums can keep the rural pipeline from becoming less "leaky” by undermining "urban disruption” and discouraging students from becoming enthralled by metropolitan amenities, and possibly clarifying misunderstandings from non-rural students about working (and living) in rural settings. ${ }^{20,107,108}$

A literature review of rural comprehensive medical school programs showed a current and future significant impact on rural physician supply. ${ }^{8}$ This 2006 study noted six top US rural medical school curriculums having three conditions defining “comprehensive”: (a) the programs' central goals are to boost rural physicians supply; (b) distinct groups of students are drafted; (c.) the programs involve a deliberate rural admissions process and mandatory rural curriculum, and/or an extended, year three and four rural clinical curriculum. A weighted average of $57 \%$ of the six program graduates practice in rural areas. Program estimates showed that if all 125 US allopathic medical schools developed similar, albeit smaller agendas, i.e., 10 students per year, the annual quantity of rural physicians will double in comparison to if no rural programs existed (where only 3\% of students nationwide have intent for rural practice), 1,139 versus $513 .^{8}$ Other successful US rural medical school curriculum (not included in the above literature review) include the University of Louisville rural curriculum program where participants were six times more likely to choose a rural area as a practice site than non-participants; they were also $40 \%$ more likely to choose primary care and 4.5 times more likely to choose family medicine than non-participants. ${ }^{20}$ In addition, the University of Missouri (UM) where 57\% of scholars participating in UM's rural longitudinal pipeline program 
chose an initial rural practice (and were 2.6 times more likely to choose a family medicine specialty than non-participants). ${ }^{109} \mathrm{UM}$ 's rural summer program is also promising with $46 \%$ of participants choosing rural locations for their first practices, and participants were 31\% more likely to enter primary care residencies and 2.2 times more

likely to choose family medicine compared with nonparticipants. ${ }^{110}$ Hence, the literature justifies the curricular component of the affinity model.

\section{Medical Students' Family of Origin Social Economic Status and Specialty Choice}

Parents’ socioeconomic status (SES) may influence medical students’ specialty choice. Current thought notes that medical students from upper SES backgrounds are more likely to choose specialties over primary care to preserve their prior living standards, while lower SES students are more apt to choose primary care. ${ }^{13}$ AAMC Matriculating Student Questionnaire data from 1987 to 2005 shows that roughly 75\% of medical students' parental income resided in the fourth quintile or above out of all US citizens and less than $6 \%$ of medical students constitute the lowest quintile. ${ }^{111}$ In addition, most medical students' parents have high educational levels in comparison to the US population; approximately $50 \%$ of medical student fathers possess graduate degrees versus $12 \%$ of males in the US, and one-third of medical student mothers hold graduate degrees versus $10 \%$ of US women. ${ }^{112}$ If medical students from high SES standings choose specialization more often than not and medical students from low SES standings choose primary care fields, a disturbing crisis arises regarding the primary care physician shortage.

Interestingly, no recent studies on SES and specialty choice were found. However, earlier studies addressing SES, specialty choice, and debt do exist. One study 
using comprehensive multivariate analysis looking at 1991 and 1992 graduates of US medical schools found a significant, albeit modest, negative association of SES with specialty choice; students from lower SES families tended to choose primary care over non-primary-care specialties. ${ }^{22}$ This same study also found that students with physician parents were $52 \%$ and $28 \%$ less likely to choose pediatrics and internal medicine,

respectively. ${ }^{22}$ Rabinowitz showed physicians whose fathers had no college background were two times more likely to practice in a rural area. ${ }^{103}$ Another study, using multivariate statistics, of the 1995 AAMC medical student questionnaire found a positive association with father's SES and a surgical specialty choice, and a negative association with primary care choice. $^{113}$

The section, "Race and Primary Care Choice” on page 32 of this chapter, purports that URM medical students, who generally come from disadvantaged backgrounds, choose primary care specialties at much higher rates than non-URMs and are more willing to serve underprivileged areas. One study, mentioned above, argued URM status and SES to be separate in choosing a primary care specialty. ${ }^{79}$

\section{SES and Rural Areas}

Findings on SES and physicians practicing in rural areas have been scarce and mixed. A multivariate study of 1972 to 1991 graduates of Jefferson Medical College in Pennsylvania ( $n=1609)$ found that, among physicians whose father had some college, their odds were two times greater to practice in a rural area that physicians whose fathers had no college. No association was found between father's and mother's occupation and mother's education level on rural practice. ${ }^{103}$ A 2012 study of osteopathic medical students ( $\mathrm{n}=141)$ using bivariate analysis found that students whose parents (either 
mother or father) had bachelor degrees or less were 50\% more likely to intend to practice in rural areas. ${ }^{81}$

\section{History of Medical Student Debt}

Following the 1910 Flexner Report publication until the 1960s, medical student debt in the United States was not problematic. The cost of medical school was constant and minimal enough that family loans and gifts adequately compensated tuition and fees without private or public loans. ${ }^{114,115}$ According to one early 1960 s study, only $31 \%$ of students acquired educational debt, and the family provided $83 \%$ of student expenses. ${ }^{116}$ From the latter half of the 20th century to present (1960 - 2010), medical student debt has become a personal and national problem, with approximately $86 \%$ of students borrowing money to finance their educations ${ }^{117}$ and owing more than $\$ 150,000$ on average. $^{118,119}$

Greysen, Chen, and Mullan note causes for the acceleration of medical student debt that include: (a) social and economic trends; (b) federal initiatives for university finances that broadened higher institutions roles and functions causing corresponding uncertainty of educational costs; (c) progressive movements that promoted women and minorities physician workforce diversity, along with the concept of "primary care” vis-àvis a workforce expansion. ${ }^{114}$ Social trends, like the federal 1944 G.I. Bill and the ensuing cohort of baby boomers, commanded more autonomous and independent lifestyles. The G.I. Bill participants were older and more likely to be married than their preceding student counterparts. The traditional student transformed over time to a “professional student,” as the number of working medical students declined and medical specialization took longer to achieve. Economic trends included the rising cost of 
attending medical school and the mentality of a consumer-driven economy where personal loans for higher education became acceptable. Further, in the early 1980s, medical students gave up "delayed gratification” unlike previous generations and lived the lifestyle of their non-medical, professional working cohort. These economic trends intertwined with the social trends to hasten medical student debt. ${ }^{114}$

The post-World War II era entailed the development of three progressively complex federal financing mechanisms for medical schools. Higher education, and specifically medical education, changed as federal dollars ignited the trend toward expansion of the university's role. The expansion of the National Institute of Health (NIH) and subsequent monies led to the "research university" and became the new model and primary area of fiscal growth for medical schools. Greysen, et al., citing Ludemerer, argues the 1965 Medicare enactment led to the development of clinical practice plans, the second key segment of medical schools’ financial expansions. ${ }^{114,120}$ Third, the 1963 Health Professions Educational Assistance Act also provided a major propellant to enhance and better medical education. These government initiatives helped academic medicine to expand its role and capacity, but did not foster durable financial remedies as medical education became more complex, technological, and costly to sustain. ${ }^{114}$ Greysen et al., citing the Institute of Medicine, Millis, and the Carnegie Council, further notes complications arise due to lack of transparency on the cost of educating a medical student, who should bear the cost, and how much of the burden of supporting the other missions of the medical school should fall to the student. ${ }^{114,121-123}$ Hence, there is no accountability from medical schools to students, potentially leading to increased student debt. $^{114}$ 
A US physician workforce expansion from 1965 to 1985 and the 1960’s civil and women's rights movements catapulted minorities and women into medical education as their numbers doubled between 1969 and 1973 in comparison to before 1950 where African-Americans comprised only 3\% and women 6\% of medical students. For women, this upward trend continued until they achieved gender parity; for minorities, the trend stagnated (see Figure 2). Correspondingly, the workforce expansion augmented the number of "primary care” physicians, although the "generalist” physician, percentagewise, was on the decline compared to "specialist.” Student debt among minorities and those choosing primary care becomes more burdensome because minorities usually are of lower social economic status and primary care compensates less than higher paying specialties. $^{114}$

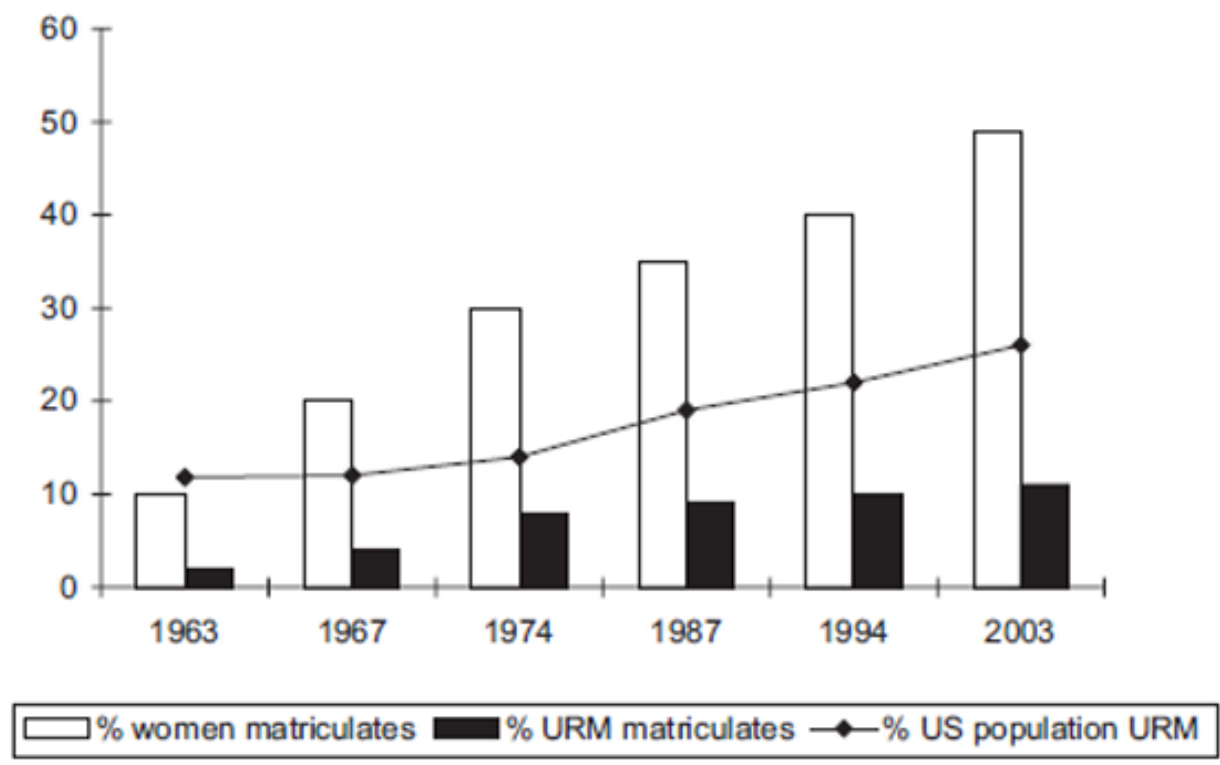

Figure 2. Greysen, et al. Enrollment of Women and Underrepresented Minorities in Medical School, 1963-2003. 


\section{Issues Related to Medical Student Debt}

Student debt correlates with rising tuition costs. The rate of medical school tuition increases outpaced the inflation rate, and this trend is likely to continue. According to the AAMC, 2003 median tuitions and fees were \$16,322 and \$34,550 for public and private medical schools, respectively. ${ }^{38,111}$ For a five-year period starting in 2001, total medical school charges increased $11.1 \%$ for public medical schools and $4.7 \%$ for private schools. In 2008, public schools’ charges increased 42\% $(\$ 23,260)$ over a five-year period and in private schools $21 \%$ (\$43,897). Considering everyday cost and health insurance, the average amount of attending a public medical school in 2008-2009 is \$44,390 and a private school is $\$ 62,243 .^{38,124}$ Overall student debt has increased 6.9\% per year for public education and 5.9\% for private education from 2001-2006. The 2008 median graduating public medical student debt burden was $\$ 145,000$ and for private students, $\$ 180,000$, with one-quarter of students having debt greater than $\$ 200,000 .^{38,124}$ A medical school graduate’s average educational debt after adjusting for inflation is almost 3.5 times greater than it was in $1978 .^{18}$

Furthering the stress of the rising debt situation is the fact that medical school

class sizes are increasing, causing more students to compete for limited financial aid. ${ }^{38,124}$ Based on 2006-2007 data, \$2.5 billion aided medical students in the US. Almost $80 \%$ was given in the form of unsubsidized loans that were not backed by the federal government or other lenders. Just $20 \%$ of this amount was for scholarships and grants, including aid in the form of a service pledge, such as that from the National Health Service Corps and the armed forces, and aid based on need or non-need based assistance. Additionally, from 2004-2007, the federal Stafford loan interest rate rose 140\%, from 
$2.82 \%$ to $6.8 \%{ }^{38,124}$ The current federal monetary stimulus implemented due to the "great recession" likely will boost interest rates, thus exacerbating medical student debt. ${ }^{38}$ With state government budgets tightening, medical schools will continue to rely on tuitions and fees as a key source of revenue, and the costs of attending medical school and associated student debt will continue to rise..$^{38,111,124}$

Although the student debt rate has increased at rates between 6\%-7\% annually, physicians' salaries have not kept pace over the same period. Primary care physicians' compensation increased only $2.6 \%$, while specialists' increased $4.3 \%$. It is expected that rates of medical student debt will outpace the rate of physician income increases and inflation, further straining medical students living standards and ability to pay their debt. $^{38}$

The rising cost of tuition and student debt has consequences for society. As mentioned above, a specific objective of AAMC and medical schools nationwide is to increase diversity among students and faculty. Diversity is thought to enrich medical students' educational experiences by exposing students to different backgrounds, experiences, and identities. Diversity includes racial and ethnic criteria, but also students coming from low income backgrounds. ${ }^{125}$ From 1987-2005, approximately $60 \%$ of medical students come from the top quintile tier of family income, $20 \%$ from the next tier, and 20\% from the collective bottom three tiers. Only 3\% are from the lowest quintile of family income..$^{38,125}$ This trend is likely to exacerbate as student debt increases, ${ }^{38}$ and a more dramatic systematic skewing to favor children of upper income families becoming physicians will likely take place, ${ }^{125}$ thus limiting medical students' exposure to studying with lower-class medical classmates. 
Medical student debt is assumed to impact specialty choice for several reasons. ${ }^{17}$ Physician trainees holding excessive debt are more likely to acknowledge that debt affects their specialty choice. ${ }^{17,126}$ Debt is considered by medical educators and others to be a deciding factor for choice of specialty. ${ }^{17}$ Further, the monetary return on investment of specialist education is almost $75 \%$ greater than a primary care education. ${ }^{17,127}$ In addition, 2007 AAMC data shows high earning specialty residencies fill at higher rates than lower earning primary care residencies, $(r=0.82, p=0.001) .{ }^{17,128}$ Hence, medical students value earnings when choosing their careers, and specialization offers elevated living standards and easier debt relief than primary care careers. ${ }^{17,129}$ On the other hand, some argue that primary care residencies’ shorter temporal training spans incentivize students to choose primary care to pay off debt sooner. ${ }^{22,130}$

\section{Programs to Address Student Debt}

Financial incentive programs (FIPs) exist to recruit and possibly retain healthcare practitioners to work in underserved areas. Potentially, FIPs enable qualified, but economically deprived, individuals to become physicians, influence medical trainees to choose rural primary care over urban tertiary care, and, depending on the type of FIP, lengthen retention times through offering incentives to remain in rural areas. ${ }^{131}$ Successes of FIPs are based on two assumptions: (a) that a sizable, unused cohort of clinicians/medical students exist whose career can be influenced with the pledge that their educational debt will be repaid; (b) that there are sufficient eligible practice organizations in HPSAs willing to make obligatory changes to become loan repayment sites. ${ }^{132}$ Five FIP types have been identified. They differ based on time and type of commitment, when remuneration is received, and spending constraints. Spending constraints include: service 
requiring scholarships, service-option educational loans, loan repayment programs, direct financial incentives, and resident support. ${ }^{131,133}$ Service requiring scholarships requires a commitment from medical students before or early in their medical education. The program's expectation of participants to fulfill their service commitment is firm, and stringent fines are used to discourage participants from buying out of the contract. Service option loan programs target medical students early and provide the choice of completing service or paying back funds at standard interest rates. For both scholarships and loan programs, money is received during training and can only be used for educational expenses.

Loan repayment and direct financial incentive programs obligate participants near the end of residency training at their career onset. Loan repayment programs provide debt relief to pay off educational loans, while financial incentive programs allow received money to be used for any need. Penalties for physicians opting out of their service contract are minimal or nonexistent.

Resident support programs provide support to residents that include scholarships, loan repayment, and direct financial incentives. The commitment is made early in residency training, and service begins at the end of residency.

HRSA's NHSC program, established in 1970, is most notable as a FIP. The program offers scholarships and loan repayment opportunities. Students choosing the scholarship option join early in their medical training and accept a full tuition-based scholarship. For every year tuition is covered, the student serves one year in a HPSA, with several areas of choice approved by the NHSC. Physicians choose a preference for a specific area from a list of options (that might be limited), and medical organizations 
located in the areas choose from those conveying an interest. After satisfying the contract, physicians may enter the private workforce and work anywhere. The NHSC loan repayment option allows physicians to join the Corps after graduation and recompenses a share of medical student debt for every year of service. ${ }^{134}$

Since its 1970 launching, 40,000 NHSC PCPs have joined the program. ${ }^{135}$ The NHSC also has established current retention rates of $82 \%$ for participants serving more than one year after service ends and 55\% of clinicians practice in underserved areas 10 years after completion based on 2012 survey data. ${ }^{135}$ In 2009, the American Recovery and Reinvestment Act (ARRA) reinforced NHSC funding with an additional \$200 million allocation, which doubled its workforce size to over $8,000 .{ }^{33}$ In addition, and as mentioned in the section, "Health Reform and the 2010 Affordable Care Act" found on page 32 of this chapter, an additional $\$ 1.5$ billion has been appropriated through the ACA $^{45}$

States correspondingly have financial incentive programs to address healthcare workforce deficiencies that work separately from or in conjunction with the NHSC. ${ }^{132}$ The current number and workforce size for exclusively administered state programs is unknown, while 32 states (as of 2011) have joined sponsorships with the NHSC and a combined workforce size of approximately 600 physicians. ${ }^{132}$ States with joint sponsorship usually match NHSC funding with state government funding or with practice organizations match funding that benefit from the participating physician.

Benefits of state programs (solely run or co-sponsored with the NHSC) are numerous. ${ }^{132}$ They include the ability to tailor and operate the program to meet their state's distinct needs and to fill gaps in the NHSC program, i.e., by supporting 
underserved areas not assigned as HPSAs or clinical disciplines not qualifying for NHSC support. States are noted to use funding as "fallback" for physicians whose debt is not expended after NHSC involvement, for candidates unsure of receiving an NHSC award, or when the NHSC had limited funding. In general, states have used their programs to complement the NHSC program. ${ }^{132}$

The ACA and ARRA fundings have cushioned budget shortfalls for many state FIPs. ${ }^{132}$ Accordingly, with the recent financial stress on state budgets due to the "great recession," these programs have been threatened, reduced, or eliminated. In effect, the ACA and ARRA's additional fundings are timely and compensate for state program funding reductions. ${ }^{132}$

The new influx of federal dollars for these FIPs have caused competition among state programs and NHSC. ${ }^{132}$ Some state program administrators have noted that the federal funding surge has caused less need for their programs, although no administrator stated they wanted to give up the program. Some program positions are left vacant, causing many programs to improvise and to implement new "niche" areas, like offering funding for surgeons and hospitalists. ${ }^{132}$

One of Kentucky’s FIP programs, as traditionally specified above, was discontinued in 2003. In 2003, the Kentucky Medical Association administered the Established Practice Grant Program which awarded grants for practice startup assistance to those consenting to a full-time primary care practice in underserved counties. ${ }^{136}$ Grant recipients received four disbursements over seven years. After the first year of practice, physicians received $\$ 20,000$, and then $\$ 30,000$ for the third year and for each additional year. This was suspended in 2010 due to low participation rates. ${ }^{136}$ 
Currently, the Kentucky Office of Rural Health administers the Kentucky’s State Loan Repayment Program. ${ }^{137}$ This is a 50/50 matching loan program where the NHSC and a sponsoring organization agree to pay down debt incurred by primary care health professionals in exchange for a two year commitment to work in HPSAs. In Kentucky, the recipient of this award must seek his or her own sponsor for loan repayment. The maximum award amount is $\$ 35,000$ annually ( $\$ 17,500$ federal funds, $\$ 17,500$ sponsor matching) for a total of $\$ 70,000$ over two years. ${ }^{137}$

Funding for the ACA's NHSC (and the Teaching Health Centers grant program) is done on a competitive grant basis and not given to specific states. From March 2010 to February 2015, 30 Kentucky agencies have received \$174,115,909 dollars in grant funding through the ACA, although it is unclear how much grant funding came from these two programs. ${ }^{138}$

A 2009 systematic literature review documented the success of FIPs and four key findings. ${ }^{131}$ A key finding concerning recruitment was that 30\% of FIPs' commitments did not fulfil their obligation to work in HPSAs. This possibly is due to students' initial interest in primary care shifting to specialization as they matriculate through medical school. Further, no proportional difference in recruitment was found between FIPs with and without a buyout option, suggesting participants who reversed their service decision would have done so regardless of program conditions.

A second finding of the literature review concerning retention was that FIP participants left their sites of practice after contract completion at higher rates, as compared with non-FIP participants in first practices located in similar sites, after a comparable time length. This suggests that FIP participants entered the programs for debt 
relief; once the service obligation was fulfilled, they tended to move to locations more attractive to them. More so, FIP participants who liked working in underserved areas might also leave their assigned (or semi-assigned) location, as a matter of wanting complete autonomy of where they live. Although FIP participants were more likely to leave their initial location than non-FIP physicians who practice in comparable areas, FIP participants were more likely than their non-FIP peers to practice in some underserved areas or work with underserved populations. This suggests some promise to FIPs' retention success. (This finding contradicts an earlier, less comprehensive systematic literature review noting that FIPs’ long-term retention was ineffective. ${ }^{131,139}$ However, the actual causal link between FIPs and retention is suspect, since participants self-select into programs. FIP studies cannot control for all possible participant characteristics and therefore cannot identify if physicians would have practiced in underserved areas for the same stint without the inducements they received.

Third, FIPs' participants' career and personal satisfaction differed depending on the particular FIP. Depending on the FIP program, some participants had favorable experiences while others were unfavorable. This is pertinent for several reasons: (a) participants with higher satisfaction levels have higher retention rates; (b) participants probably share their FIP involvement with others, which possibly influences the healthcare supply; (c) physician career satisfaction is associated with patient satisfaction and quality of care. FIPs with high participant satisfaction are involved with participants in all phases of the process. This includes candidate selection, the matching of underserved areas to participant's preferences, grooming the participants and family 
members for rural living, offering career counseling and mentoring, monitoring glitches, and providing ongoing assistance during their service.

The literature review's final important finding was that FIPs' impact on the supply of healthcare workers in underserved areas was inconclusive. Three studies on FIPs suggested they increased healthcare worker densities, while two found no effect. It is thought that FIP participants deter nonparticipants from working in underserved communities because of competition for patients and personnel. Counterarguments posit that FIP participants draw nonparticipants by lessening a perceived high workload per worker and boosting opportunities for referral and communications among colleagues.

\section{Studies Addressing Student Debt's Association with Primary Care Specialty Choice}

Inconclusive and mixed findings exist on student debt and its relationship with primary care. ${ }^{17,21,129,140,141}$ One study surveying 4501 female physicians who graduated medical school during 1950-1989 showed no significant association between level of indebtedness and specialty choice, even when stratified by decade. ${ }^{129}$ Another longitudinal study with 30,789 US medical students who graduated in 1991 and 1992 found no debt differences among four groups of students: students who selected family medicine at admissions; students originally not choosing family medicine, but entered a family medicine residency; student losing interest after initially choosing family medicine; and students who during their matriculation were never interested in family medicine. ${ }^{141}$ A five-year assessment (2001-2005) of student debt and residency choice among graduates of three US Southeastern medical schools ( $\mathrm{n}=2022)$ found no relationship between student debt and choosing a primary care residency after controlling for medical school, graduation year, and number of years the residencies required 
training. ${ }^{142}$ A 2007 web-based survey of fourth-year medical students from 11 US medical schools representing a diversity of regions, public/private status, research support, and students matching in IM also showed no relationship between student debt and internal medicine specialty choice with both bivariate and multivariate analysis. ${ }^{143}$

The most comprehensive recent study, by the Robert Graham Center, addressing debt analyzed 322,000 US medical students from 1979 to 2004 using various national databases including the AAMC graduation questionnaire and the AMA masterfile. ${ }^{13}$ The authors noted no meaningful association with debt and primary care choice, after controlling for gender, marital status, rural upbringing, age, year of medical school graduation, NHSC programs, students expected income, location and type of medical school, and Title VII funding of medical school. In the limitations of this study, it is noted that measures related to parental social economic status were not available for analysis.

Another recent study surveying 983 medical students from the University of Michigan, Michigan State University, and Brown University between 2006 and 2008 found no relationship between debt and primary care specialty choice after controlling for gender, race, age, and family. ${ }^{17}$ See Table 2 below for a summary of these studies.

Numerous studies cite a relationship between debt and primary care choice. One multivariate analysis using 1991-1992 US medical school graduates $(n=9,166)$ found complex associations between debt and primary care specialty choices. ${ }^{22}$ Accordingly, the study found a debt level beyond which students were more likely to choose family medicine, but above that threshold, students were less likely to enter family medicine. ${ }^{22,144}$ The study's findings also showed that debt's influence on specialty choice 
differed by gender as the debt levels of females' who had unsubsidized loans influenced specialty choice, while no relationship was found for males; another interaction was found between debt and students who anticipated practicing in the US Western region, as these students were least likely to choose a primary care career.

Another multivariate study analyzing 326 Pennsylvanian 1992-1993 medical school graduates found a relationship between debt and primary care choice when the debt was below $\$ 75,000$, after controlling for income expectation, age, gender, and intent to practice family medicine. ${ }^{140,144}$ A third study using multinomial logit regression on 1995 US medical students found that debt was reported to positively influence students' career choice in a surgical specialty and negatively influence students' career choice in primary care. $^{113}$

A fourth multivariate study using 2002 US fourth-year medical school students $(n=14,097)$ found that, as self-reported debt increased, a modest negative relationship with intent to select a primary care residency transpired, after controlling for age, gender, and race. Furthermore, students with reported debt over $\$ 150,000$ were most impacted and least likely to report choosing primary care. ${ }^{15}$

In addition, a longitudinal study between 1993and 2012 of New York Medical College and East Carolina University Year 1 and Year 4 medical students ( $\mathrm{n}=4981$ ) found that students with primary care choice practice intentions had significantly lower anticipated debt than students with non-primary care intentions $(\$ 24,904) .{ }^{145}$ Further, Year 1 students with primary care practice intentions who switched to non-primary care by Year 4 had significantly greater debt (greater than $\$ 10,000$ ) at Year 4 than anticipated in Year 1 in comparison with students who remained committed to primary care. The 
"switchers" and "sustainers" self-rated the value of income in their life: at Year 1, no ratings difference existed; at Year 4, the switchers had significantly higher ratings.

A cross-sectional analysis surveying 22,563 third-year internal medicine residents from 2003 through 2007 found a linear association between resident debt and choosing a generalist/hospital career. ${ }^{146}$ USMG residents with levels of debt greater than $\$ 100,000$ were more likely to choose a generalist/hospitalist career, and, inversely, those with levels of debt between $\$ 50,000$ - $\$ 99,999$ were more apt to subspecialize in higher paying professions. These trends also were found for IMGs; however, the trends were not statistically significant.

A 2007 multivariate analysis using the Canadian national physician survey showed clinical (n=1109) and pre-clinical [years] (n= 829) medical students were 15 times and 8.8 times, respectively, more likely to state they will choose family medicine because of a shorter residency to pay off debt. ${ }^{130}$ However, the same study showed that clinical medical students were 20 times more likely to choose a non-family medicine specialty with high earning potential to pay off debt, and pre-clinical medical students were 14 times more likely to choose non-family medicine. ${ }^{130}$ Table 2 below summarizes the studies 


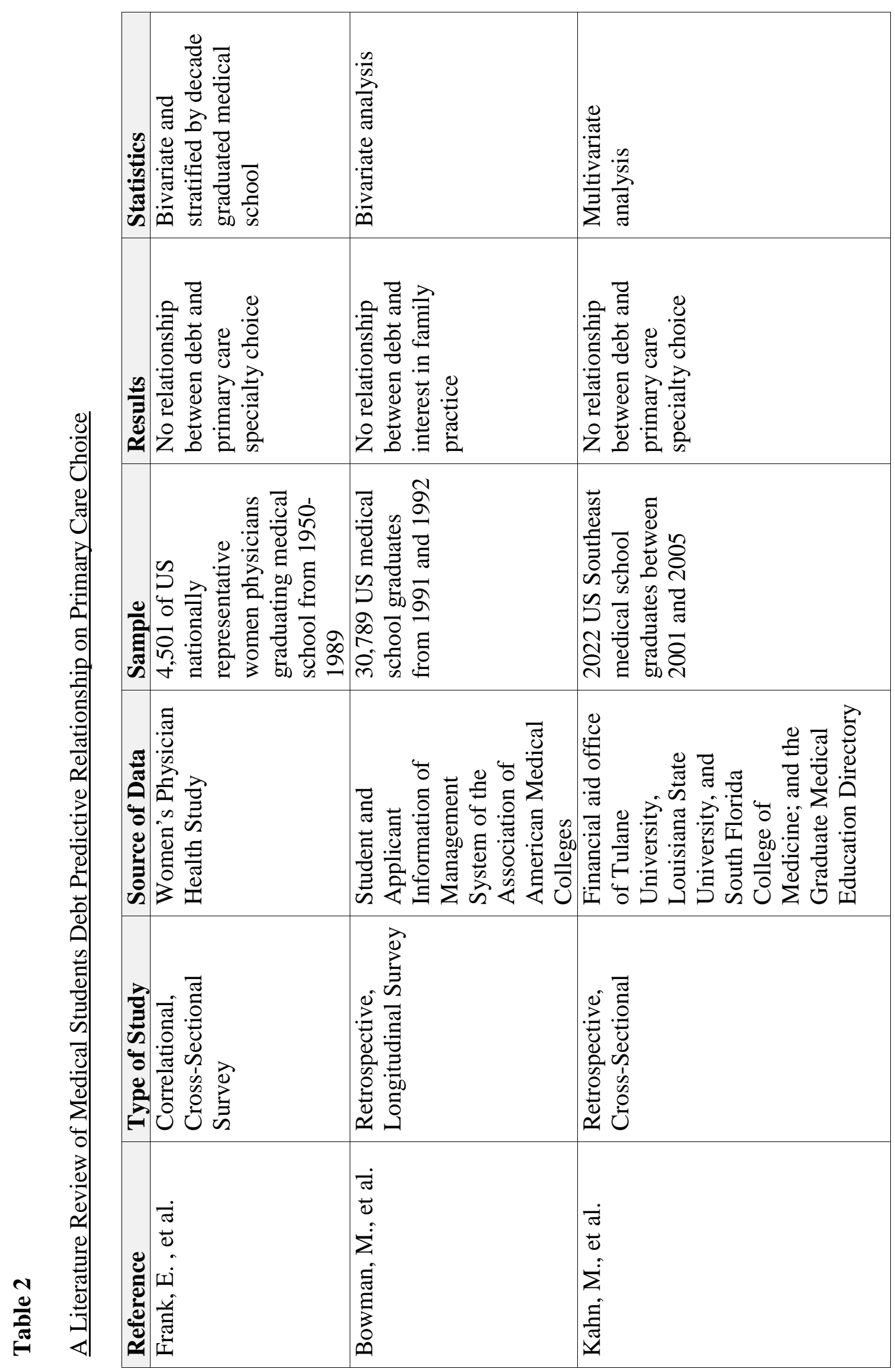




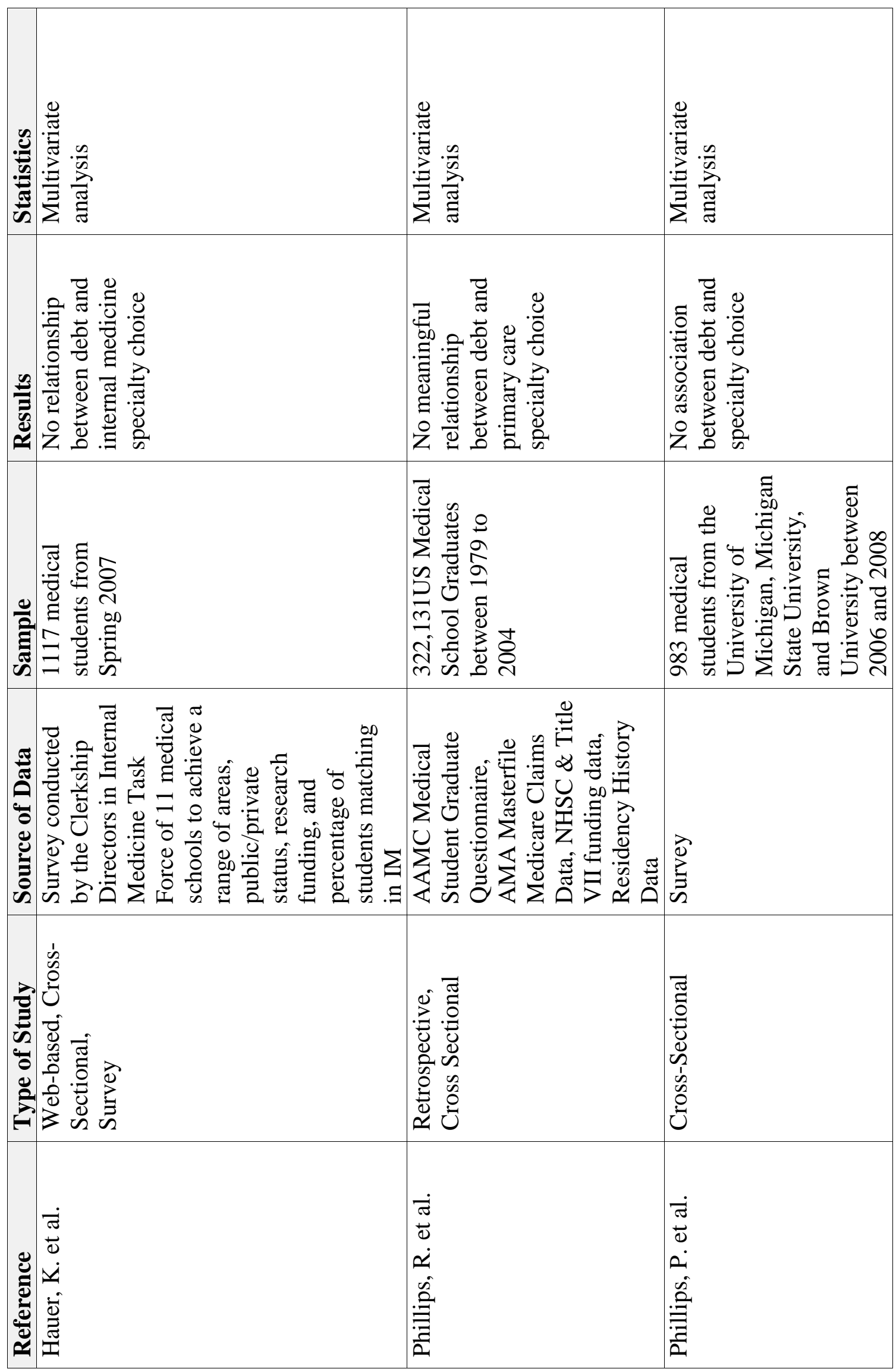




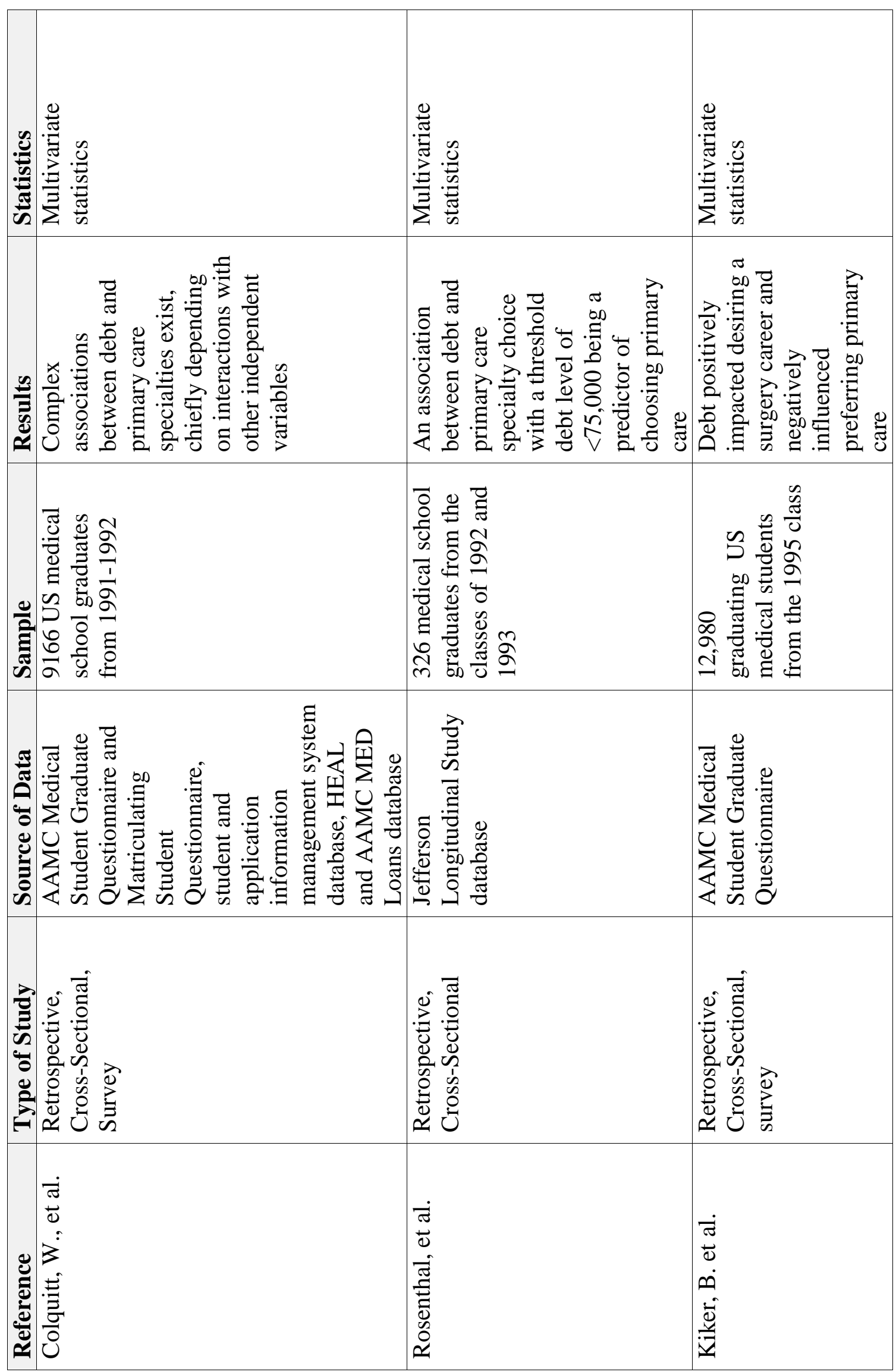




\begin{tabular}{|c|c|c|}
\hline 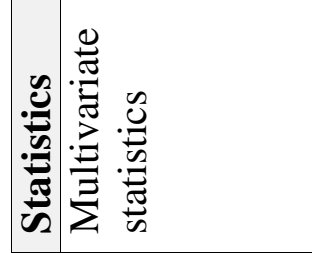 & 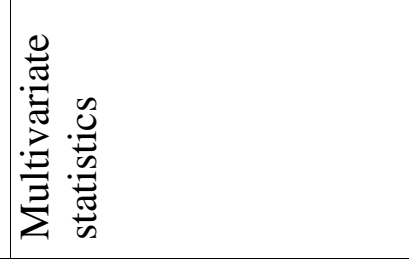 & 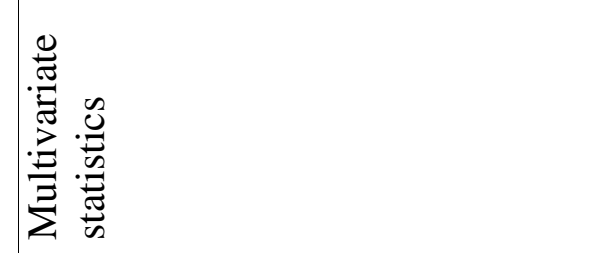 \\
\hline 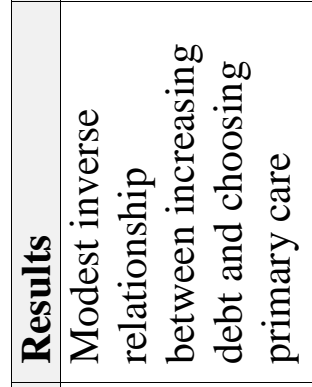 & 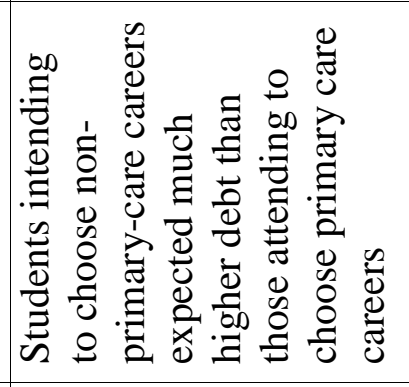 & 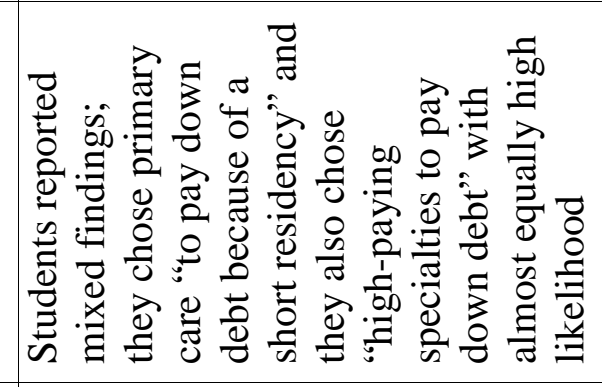 \\
\hline 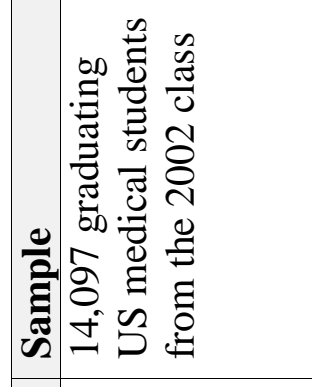 & 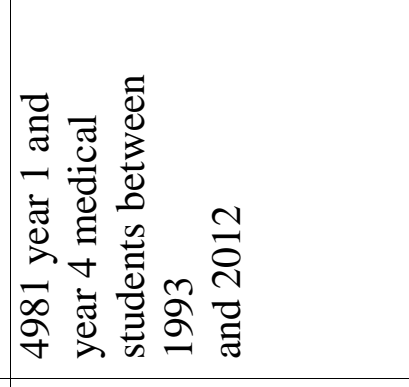 & 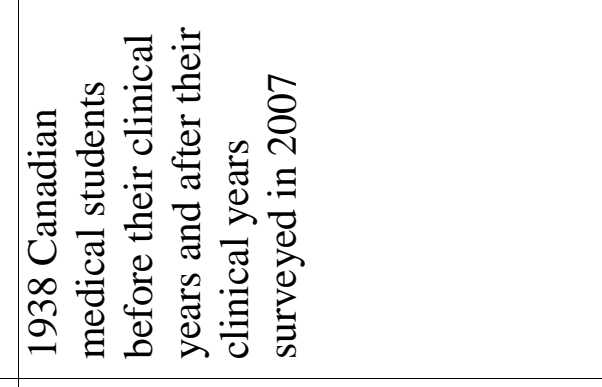 \\
\hline 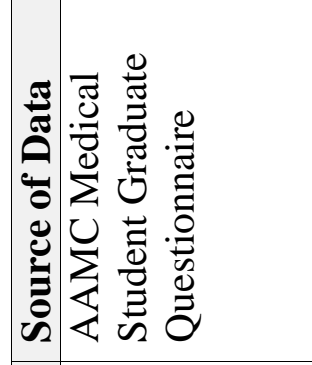 & 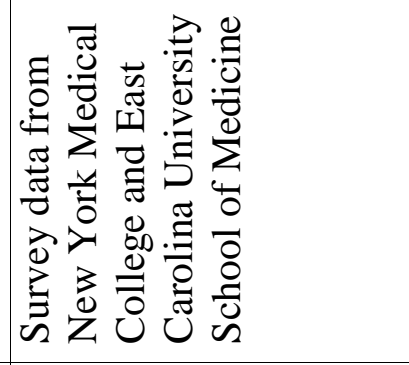 & 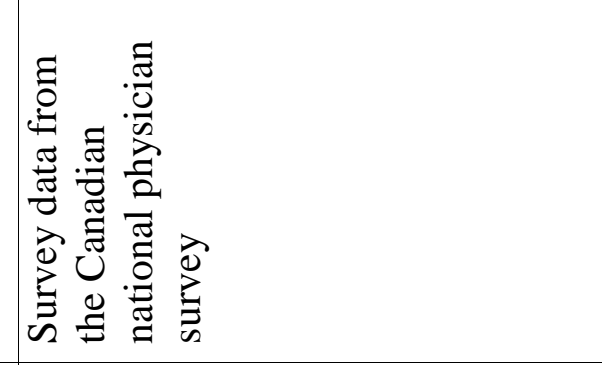 \\
\hline 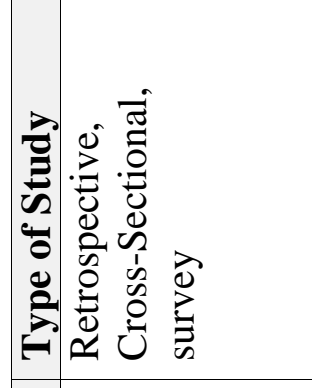 & 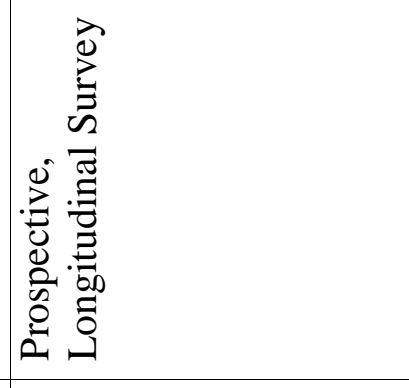 & 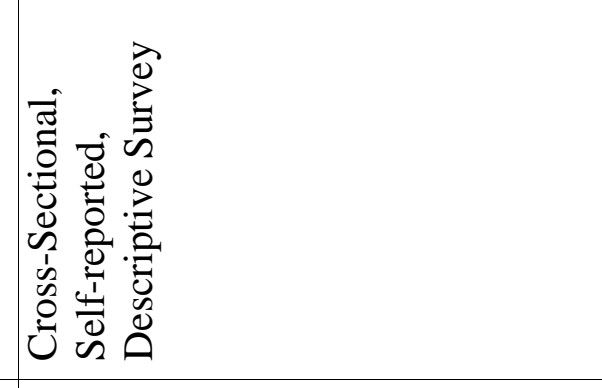 \\
\hline 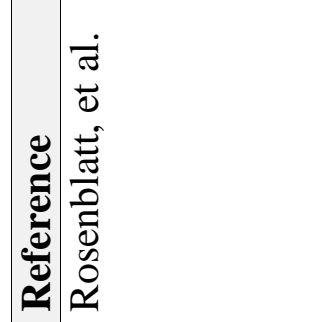 & 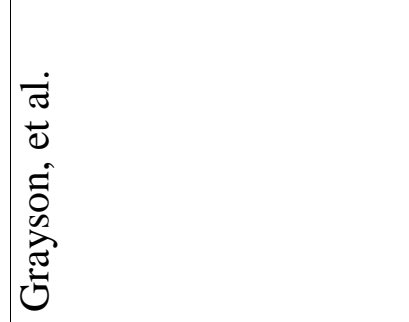 & 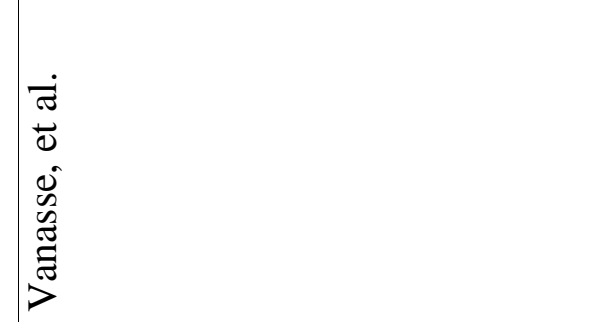 \\
\hline
\end{tabular}




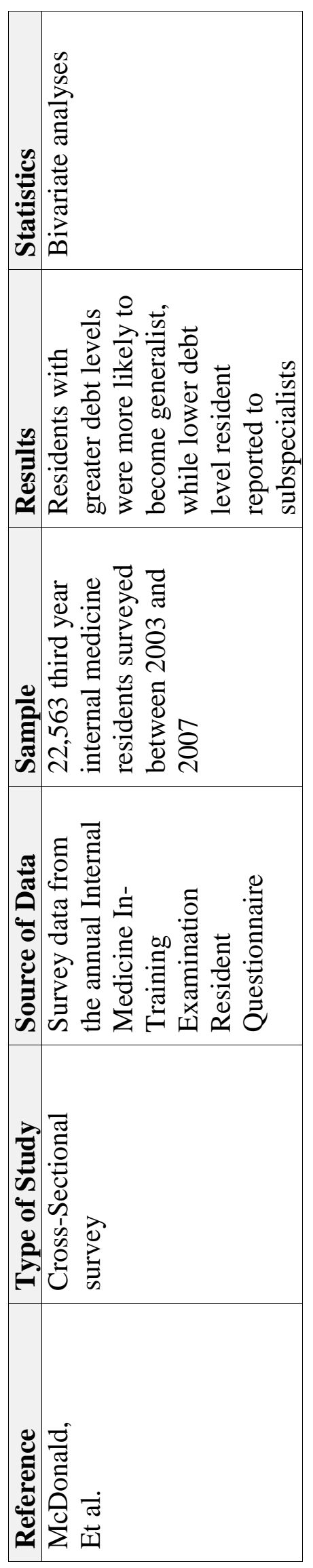




\section{Studies Addressing Student Debt's Association with Rural Practice Location}

There are inconsistent results concerning studies about student debt and students’ selection of rural practice location. The Robert Graham Center study (Phillips 2009) found a positive modest association of debt with rural practice (higher debt led to higher probability of relocating in a rural practice) after controlling for gender, marital status, rural upbringing, age, year of medical school graduation, NHSC programs, students expected income, location and type of medical school, and Title VII funding of medical school. ${ }^{13}$ On the other hand, a multivariate study of 1972 to 1991 graduates of Jefferson Medical College in Pennsylvania $(n=1609)$ found that graduates with a debt level greater than $\$ 75,000$ (a high debt level at that time) were five times less likely to initially practice in a rural area, and even graduates who went through their rural training program (almost all of whom had a rural upbringing and intended to practice family medicine) were less likely to locate rurally due to high debt. ${ }^{103}$ A third multivariate study of primary care physicians who graduated from medical school in 1988 and $1992(\mathrm{n}=468)$ found no association between debt and rural practice location. ${ }^{147}$ 


\section{CHAPTER III}

\section{METHODS}

\section{Database and Data Collection}

The quantitative study in this dissertation explored the relationship of medical student debt on students' selection of residency and practice location. A data set was collected for all University of Louisville School of Medicine (ULSOM) students who graduated from 2001 through 2010 (n=1391). Participants who compiled this dataset included the Associate Dean of the ULSOM Rural Trover Campus and members of the ULSOM Medical Education Research Team which includes the author of this dissertation. Existing data collected was found in the American Medical College Application Service ${ }^{\circledR}$ (AMCAS) medical school application, the Kentucky Medical Association (KMA) physician database, the AMA Physician Masterfile, the University of Louisville Office of Undergraduate Medical Education, and the University of Louisville Office of Medical Financial Aid. Student characteristics, gathered from the AMCAS medical school application, housed in the Office of Medical Student Affairs, included gender, race, age, rural hometown, and 'parents' educational levels and occupations. Academic and educational measures also made up this database and included the United States Medical Licensing Examination (USMLE) Step 1 and Step 2 Clinical Skills (CK) scores, along with whether students had participated in a ULSOM rural training program. Total student debt at graduation was collected from the Office of Medical Financial Aid. 
The outcome of ULSOM residency choice was generated by pairing the yearly residency match list to the ULSOM graduates (based on the AMCAS medical school application) for the 2001 through 2010 classes. Data also was matched from ULSOM graduates to the AMA Physician Masterfile for the classes of 2001 through 2008 to ascertain the established practice location office address. Approval for the study was obtained from the University of Louisville's institutional review board (IRB number: 13.0881, December 11, 2013).

\section{Key Variables}

Covariates used for this study included gender, race, age (which was dichotomized into non-traditional versus traditional student classifications), and USMLE Step 1 scores. (USMLE Step 2 scores were not included in the model due to multicollinearity with USMLE Step 1 scores.) Other covariates included whether students had a rural origin, defined by the reported hometown having a population of less than or equal to 30,000 . This categorization of rural origin was recommended on expert opinion by the Director of the ULSOM Rural Trover Campus, Dr. Bill Crump, who stated that this classification best represents Kentucky's rural areas. Another covariate was the Hollingshead Index of Socioeconomic Status, which is based on parental SES. The Hollingshead Index of Socioeconomic Status is a measure of social status based on

educational attainment and occupational prestige. ${ }^{148,149}$ A parent's education level was rated on a 7-point scale in which 7=graduate/professional training; 6= standard college or university graduation; 5=partial college, with at least one year of specialized training; $4=$ high school graduate; 3=partial high school, 10th or 11th grade; 2= junior high school, including 9th grade; $1=$ less than 7th grade; $0=$ not applicable or unknown. A parent's 
occupational level was rated on a 9-point scale: 9=higher executive, proprietor of large businesses, major professional; 8=administrators, lesser professionals, proprietor of medium-sized business; 7=smaller business owners, farm owners, managers, minor professionals; 6=technicians, semi-professionals, small business owners (business valued at \$50,000-70,000); 5=clerical and sales workers, small farm and business owners (business valued at $\$ 25,000-50,000$ ); $4=$ smaller business owners (less than $\$ 25,000$ ), skilled manual laborers, craftsmen, tenant farmers; 3=machine operators and semi-skilled workers; 2=unskilled workers; 1=farm laborers, menial service workers, students, housewives (dependent on welfare, no regular occupation); 0=not applicable or unknown. A total parental SES score, ranging from 8 to 66, was then calculated by a sophisticated formula that incorporates the education and occupation measures. Often this score is classified into a 5-point social strata index of 1=unskilled laborers, manual service workers (8-19); 2=machine operators, semiskilled workers (20-29); 3= skilled craftsmen, clerical, sales workers (30-39); 4=medium business, minor professional, technical (4054); and 5=major business and professional (55-66). Table 3 summarizes this scale. 


\section{Table 3}

Summary of the Factors and Categories That Make up the Hollingshead Index of Social Economic Status

\begin{tabular}{|c|c|c|c|}
\hline $\begin{array}{l}\text { Parents' educational } \\
\text { attainment }\end{array}$ & $\begin{array}{l}\text { Parents' } \\
\text { occupational } \\
\text { prestige }\end{array}$ & $\begin{array}{l}\text { Parents' social } \\
\text { strata }\end{array}$ & $\begin{array}{l}\text { Range of } \\
\text { computed } \\
\text { scores } \\
\end{array}$ \\
\hline $\begin{array}{l}7=\text { Graduate/ } \\
\text { professional training }\end{array}$ & $\begin{array}{l}9=\text { Higher } \\
\text { executive, } \\
\text { proprietor of large } \\
\text { business, major } \\
\text { professional }\end{array}$ & $\begin{array}{l}\text { Major business } \\
\text { and professional }\end{array}$ & $66-55$ \\
\hline $6=$ College degree & $\begin{array}{l}8=\text { Administrators, } \\
\text { lesser professionals, } \\
\text { proprietor of } \\
\text { medium-sized } \\
\text { business }\end{array}$ & $\begin{array}{l}\text { Medium business, } \\
\text { minor } \\
\text { professional, } \\
\text { technical }\end{array}$ & $54-40$ \\
\hline $\begin{array}{l}5=\text { Partial college, one } \\
\text { year of specialized training }\end{array}$ & $\begin{array}{l}7=\text { Smaller } \\
\text { business owner, } \\
\text { farm owner, } \\
\text { managers, minor } \\
\text { professionals }\end{array}$ & $\begin{array}{l}\text { Skill craftsman, } \\
\text { clerical, sales } \\
\text { workers }\end{array}$ & $39-30$ \\
\hline $4=$ High school graduate & $\begin{array}{l}6=\text { Technicians, } \\
\text { semiprofessionals, } \\
\text { small business } \\
\text { owners }\end{array}$ & $\begin{array}{l}\text { Machine operators, } \\
\text { semiskilled } \\
\text { workers }\end{array}$ & $29-20$ \\
\hline $3=10$ th, 11 th grade & $\begin{array}{l}5=\text { Clerical and } \\
\text { sales workers, small } \\
\text { farm and business } \\
\text { owners, }\end{array}$ & $\begin{array}{l}\text { Unskilled laborers, } \\
\text { menial service } \\
\text { workers }\end{array}$ & $19-8$ \\
\hline $2=7$ th, 8th, 9th grade & $\begin{array}{l}4=\text { Smaller } \\
\text { business owners, } \\
\text { skilled manual } \\
\text { laborers, craftsmen, } \\
\text { tenant farmers }\end{array}$ & & \\
\hline $1=<7$ th grade & $\begin{array}{l}3=\text { Machine } \\
\text { operators and } \\
\text { semiskilled workers }\end{array}$ & & \\
\hline 0 = NA/unknown & $\begin{array}{l}2 \text { = Unskilled } \\
\text { workers } \\
1 \text { = Farm laborers, } \\
\text { menial service } \\
\text { workers, students, } \\
\text { housewives } \\
0=\text { NA/unknown }\end{array}$ & & \\
\hline
\end{tabular}


The Hollingshead Index was modeled in an exploratory fashion to assess its impact on the two outcomes of primary care specialty choice and practice location, and to assess if SES mediated the impact of medical student debt on the two outcomes. The total Hollingshead Index score was modeled as a continuous variable and the Hollingshead index classified as a 5-point social strata index was modeled as an ordinal variable, and a categorical variable where the highest classification was compared to each of the four lower classifications. Non-significant odds ratios on the continuous SES score, the ordinal SES classification, and the contrasts tested on the 5-point social strata index were found for both outcomes. Further, SES, whether treated as a continuous, ordinal, or categorical variable, did not seem to mediate medical student debt, i.e., the change in the medical student debt odds ratio were negligible. Hence, the total parental SES score is presented in the "Results" chapter. The Hollingshead Index has been noted as one of the most commonly used measures of SES and has high inter-rater reliability and intermeasure concordance with other SES scales. ${ }^{150}$

An additional covariate was student participation in a University of Louisville rural track training program, located at Madisonville, Kentucky’s Trover Clinic. This program is a rural training opportunity that allows 6 to 10 medical students annually to complete their third and fourth years of medical school. Participants are established within a rural integrated medical structure with a 400-bed hospital with 80 physicians. There are 10 outlying clinics within a 30 minute drive that are located in towns of 4,000 to 8,000 people that present segments of clinical rotations. ${ }^{20}$ Measures for whether students participated in the program or whether they received training at the main medical school were modeled in the analyses. 
The final covariate was the percentage of scholarship funding a student received during medical school. Scholarship funding was dichotomized, based on different levels for categorizations, including students receiving greater than $25 \%$ funding or not, greater than $50 \%$ funding, greater than $75 \%$ funding, or $100 \%$ funding. Only students who received full funding (versus those who did not) achieved significance based on the Pearson Chi-square, while greater than 75\% funding approached significance. These two classifications were included in the logistic regression model and were assessed by the AIC index and the magnitude of the odds ratio. Ultimately, the pre-classification of $100 \%$ funding was used in the analysis.

The predictor of interest was total medical student debt, adjusted annually (from 2001 to 2010) for inflation using the consumer price index (CPI) with 2010 as the baseline year. Hence, all student total debt was adjusted to the 2010 real dollar value. Different categorization of percentiles (tertiles, quartiles, and quintiles) and debt as a continuous variable was explored to assess which categorization had the greatest effect on residency selection and rural location. Quintiles had the greatest magnitude of odds ratios, and, because they fell close to logical categorizations, they were rounded, i.e., $\$ 0$ $\$ 49,551$ was re-classified as $\$ 0-\$ 49,999, \$ 49,551-\$ 103,299$ was re-classified as $\$ 50,000$ \$99,999, and so forth. All percentile categorizations compared the top percentile categorization with the lower categories. Theoretically, this mode of analysis was in line with Rosenthal, et. al., mentioned above, who showed an association between debt and primary care specialty choice based on a threshold debt level. ${ }^{140}$

Two outcomes were assessed. The first outcome was residency type medical students selected categorized as either primary care or non-primary care. Numerous 
medical professional organizations define primary care to include family medicine, internal medicine, and pediatrics, ${ }^{31,151}$ hence, these residencies constituted primary care in this study. Non-primary care included all specialties that were not primary care. The database contained residency type for all students in the years 2001 to 2010 (n=1391).

The second outcome of interest was the location of the physician practices, categorized as either rural or non-rural, from 2001 to 2008 (n=1121). The Rural-Urban Continuum Codes (RUCC) groups metropolitan counties into four categories by size, and non-metropolitan counties into six categories by urban population size (quantity of individuals populating towns of 2,500 or more) and proximity to a metropolitan area (Table 4). ${ }^{152}$ The RUCC has been dichotomized into metropolitan and non-metropolitan counties by others for similarly related research ${ }^{20}$ and will be dichotomized in this fashion for this study.

\section{Table 4}

\section{USDA, ERS Rural-Urban Continuum Codes}

\begin{tabular}{|c|l|}
\hline Code & Metropolitan Counties: \\
\hline 0 & Central counties of metropolitan areas of 1 million population or more \\
\hline 1 & Fringe counties of metropolitan areas of 1 million population or more \\
\hline 2 & Counties in metropolitan areas of 250,000 to 1 million population \\
\hline 3 & Counties in metropolitan areas of fewer than 250,000 population \\
\hline Code & Non-metropolitan Counties: \\
\hline 4 & Urban population of 20,000 or more, adjacent to a metropolitan area \\
\hline 5 & Urban population of 20,000 or more, not adjacent to a metropolitan area \\
\hline 6 & Urban population of 2,500 to 19,999, adjacent to a metropolitan area \\
\hline 7 & Urban population of 2,500 to 19,999, not adjacent to a metropolitan area \\
\hline 8 & Completely rural or less than 2,500 urban population, adjacent to a metro area \\
\hline 9 & Completely rural or less than 2,500 urban population, not adjacent to a metro area \\
\hline
\end{tabular}
(Source: Butler and Beale, 1994) 


\section{Statistical Methods}

SPSS version $22.0^{153}$ and SAS version $9.3^{154}$ were used to analyze this data. Descriptive statistics of student characteristics were presented as frequencies and percentages, means and standard deviations (SD), or medians (minimum and maximum values) when appropriate. Univariate analysis assessing the association of the covariates and the primary predictor (medical student debt) on the two outcomes of residency choice and practicing in rural locations was performed with the Chi-square statistic, Fisher's exact test, Chi-square test for linear trend, independent samples t-test, or Mann-Whitney U where appropriate.

Receiver operating characteristic (ROC) curves were used to assess if an optimal debt level threshold existed with high sensitivity and specificity that detected primary care residency choice and practicing in rural locations.

This refers to hypothesis 1 :

Hypothesis 1: An optimal debt level exists with high sensitivity and specificity that detects residency specialty choice, and where students choose to practice medicine.

ROC analysis is a statistical method that assesses the diagnostic performance of a test in its ability to distinguish one group from another group of cases. ${ }^{155}$ In this case, the "test” was student debt and the "groups" of cases were residency choice (primary care versus non-primary care) and practice location (rural versus non-rural). When comparing two groups on a test, i.e., one group choosing primary care, the other choosing nonprimary-care, perfect separation between the groups rarely occurred. For example, with every possible cut-off point of debt selected to differentiate between the two groups, there were some students correctly classified as choosing non-primary care $(\mathrm{TP}=$ True 
Positives), but some choosing non-primary-care were classified as choosing primary care (FN = False Negatives). Likewise, some students choosing primary care were correctly classified as choosing primary care $(\mathrm{TN}=$ True Negatives), but some choosing primary care were classified as not choosing primary care ( $\mathrm{FP}=$ False Positives). ROC curves depict the true positive rate (sensitivity) plotted with the false positive rate (100specificity) at different cut-off values. Each value on a ROC curve denotes a sensitivity/specificity pair corresponding to a particular decision threshold. In this study, if debt discriminated perfectly (100\% sensitivity, $100 \%$ specificity), then the ROC curve would pass through the upper left corner. Therefore, the closer the ROC curve is to the upper left corner, the higher student debt accuracy would be in assessing an optimal debt level threshold that detected residency and specialty choice and practicing in non-rural locations. Figure 3 displays what a near ideal ROC curve would look like:

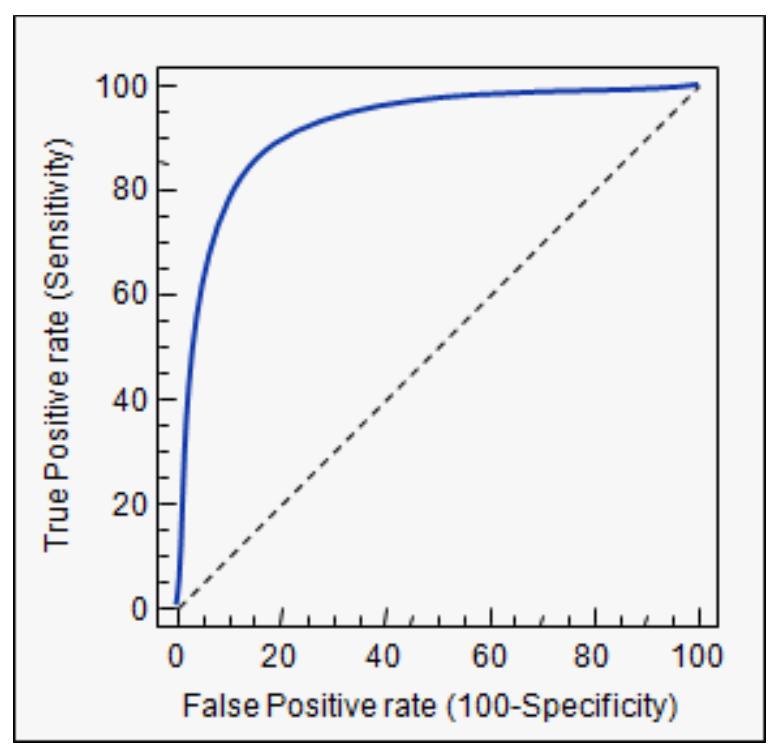

Figure 3. Example of ROC curve demonstrating high sensitivity and specificity. The curve was found online at MedCalc.Org. http://www.medcalc.org/manual/roc-curves.php

The ROC curve's y-axis shows the sensitivity rate, while the $\mathrm{x}$-axis shows the 100-specificity rate. The black dashed line represents the reference line; the further the 
curve lays above the reference line, the more accurate the test. The blue line depicts the cut-off values of the test where the optimal cutoff value is the coordinates of roughly $10 \%$ on the $\mathrm{x}$-axis and roughly $85 \%$ on the $\mathrm{y}$-axis. This signifies that there is an optimal value where the specificity is $90 \%$, i.e., 100 -specificity $=10 \%$, while the sensitivity is 85\%. Hypothetically, if this curve was a reflection of medical student debt predicting primary care specialty choice, and the debt level that corresponded to these two coordinates was $\$ 165,000$, then $\$ 165,000$ would be the value of debt that had the highest sensitivity and specificity in predicting primary care specialty choice.

Multiple logistic regression analysis was used to assess the research question "Does an association between student debt level and their residency choice and area of practice location exist after controlling for the covariates of gender, race, rural hometown, SES, participation in rural training at $\mathrm{U}$ of $\mathrm{L}$, scholarship funding, and USMLE Step One scores?” and the corresponding hypotheses:

Hypothesis 2: A modest association exists between medical students' levels of debt with their selection of residency training programs and practice locations.

Logistic regression was the analytical technique of choice because the outcome variables are dichotomous in nature. The form of the logistic model is:

$$
\text { Logit }(Y)=a+B_{1} X_{1}+B_{2} X_{2}+B_{3} X_{3} \ldots B_{k} X_{k}
$$

where $Y=1$ is the log odds of an event occurring. ${ }^{156}$ Because the log odds is unintuitive, logit coefficients are often exponentiated and converted to odds ratios for easier interpretability: ${ }^{156-158}$

$$
\text { Odds }(\mathrm{Y})=e^{a+B_{1} X_{1}+B_{2} X_{2}+B_{3} X_{3} \ldots+B_{k} X_{k}}
$$

For this data set, the formula for assessing primary care residency selection became: 
Odds [Y=1 (primary care)]

$=$

$e^{a+b_{1}(\text { debt })+b_{2}(\text { gender })+b_{3}(\text { race })+b_{4}(\text { age })+b_{5}(\text { Rural Hometown })+b_{6}(S E S) \ldots+b_{k}(\text { USMLE Step Scores })}$

Along with assessing two-way interaction terms, i.e.,

Odds $[\mathrm{Y}=1$ (primary care) $]=$

$$
\begin{aligned}
& e^{a+b_{1}(\text { debt })+b_{2}(\text { gender })+b_{3}(\text { race }) \ldots+b_{k}(\text { USMLE Step Scores })+b_{k}(\text { debt }, \text { gender })} \\
& e^{a+b_{1}(\text { debt })+b_{2}(\text { gender })+b_{3}(\text { race }) \ldots+b_{k}(\text { USMLE Step Scores })+b_{k}(\text { debt }, \text { race })} \\
& \text { and so forth. }
\end{aligned}
$$

In terms of interpretation, hypothetically, if the data and model produced a logit

coefficient of .25 for debt, then this would be interpreted as the log odds of primary care increasing by .25 for every 1 unit increase in debt, when all other variables were held constant. However, the odds ratio provided a more meaningful interpretation - for every 1 unit increase in debt, the odds of choosing primary care increased $28 \%$ when all other variables were held constant.

Although logistic regression coefficients and odds ratios can be converted to probabilities for predicting the outcomes of individual observations, the analysis for this study was primarily focused on assessing medical student debt in order to guide medical associations as well as state and federal policymakers on strategies that may influence future physicians to enter primary care or work in rural areas. Hence, the magnitude and significance of the odds ratios became important. For this study, it was determined that an odds ratio of 1.5 or greater indicated practical significance and held a magnitude of such that policymakers should consider debt alleviation policies. 
The null hypothesis concerning debt that was used assessed the overall association of debt by testing the null hypothesis that all debt levels mutually had coefficients of 0 , i.e., $\mathrm{H}_{0}: \beta_{1}=\beta_{2}=\beta_{3}=\beta_{4}=0$. The $-2 \log$ likelihood test was used to assess this relationship. Other hypotheses concerning debt were also performed in an exploratory fashion. These included:

$$
\begin{aligned}
& \mathrm{H}_{0}: \beta_{1}=0 \\
& \mathrm{H}_{0}: \beta_{2}=0 \\
& \mathrm{H}_{0}: \beta_{3}=0 \\
& \mathrm{H}_{0}: \beta_{4}=0
\end{aligned}
$$

The Wald statistic was used for these assessments.

Most covariates were documented to influence the outcomes, so they were automatically entered in the model. The exceptions, however, were USMLE Step 1 scores and percentage of scholarship funding which have not been evaluated in the literature (see Table 5, page 86).

Since the categorization of medical student debt was exploratory (i.e., tertiles, quartiles, and quintiles were assessed in order to evaluate which percentile categorization most impacted the outcomes), the data set was divided into two subsamples. The first was a training subsample where $80 \%$ of the cases were randomly selected. This left a testing sample of $20 \%$, which was used to validate the training sample. This analytical strategy's goal was to ensure that the estimated coefficients were not sample specific and the model's results were not over fitted to this specific data set, but were generalizable to the population. ${ }^{159}$ Exploratory analysis regarding the categorization of other covariates, i.e., social economic status, scholarship funding, and USMLE Step 1, was also performed, 
along with assessing two-way interaction effects with debt and the other covariates in the model. The process of assessing two-way interaction effects incorporated the process of including a single interaction term at a time. For example, levels of debt by gender were assessed after controlling for all covariates in the model; then levels of debt by race were assessed in a similar fashion until all two-way interactions of debt with the covariates were examined. When necessary, the Firth method of estimation was used in the analysis of interaction effects. The Firth method yields finite, bias corrected, and consistent estimates of regression parameters when maximum likelihood estimates are incalculable due to the small number of events that occur in the outcome which causes complete or quasi-complete separation. ${ }^{160}$

Because 20\% (1117/1391) of the SES scale encompassed missing data, it was questioned whether complete case analysis on the missing data would lead to biased estimates, which occurs sometimes when the "missingness" is missing at random (MAR), as opposed to missing completely at random (MCAR). The data was analyzed to assess if the missing data mechanism was not MCAR, and therefore, possibly MAR. Little's MCAR test $\left(X^{2}=34.5, \mathrm{df}=14, \mathrm{p}=0.002\right)$ showed the data was not MCAR. ${ }^{161}$ Further, a separate variance t-test between missing and non-missing data on the SES scale showed significant differences in total debt (missing, mean $=\$ 120,473$; non-missing, mean $=\$ 108,660, t=2.6, d f=399, p=0.009)$.

It was noted, however, that when data is missing at random, complete case analysis on regression models can still produce unbiased estimates. ${ }^{162}$ Specifically, in a regression model when missing values appear in either the outcome or the covariates, fitting the regression model to the complete cases is unbiased provided the probability of 
being a complete case is independent of the outcome, conditional on the covariate(s). ${ }^{162}$ A sensitivity analysis was performed to assess if the degree of SES's missing values would bias the coefficients. First, the outcomes were analyzed with all covariates in the model using listwise deletion of missing values. Next, SES was removed from the model and only non-missing cases for SES were used. For the outcomes, the comparisons between the two analyses of the covariate coefficients were relatively similar, indicating that the pattern of nonresponses in SES was probably not biasing the results. (See Appendices 1 and 2.)

Splitting the data set reduced the statistical power. A power analysis revealed that a total of 1305 observations would be necessary to achieve $80 \%$ power, given a practically meaningful odds ratio of 1.5 for debt and given the multiple $\mathrm{R}^{2}$ of 0.08 of debt regressed on all covariates. Consequently, in view of the sample size for the training dataset being only 1113, in assessing the odds ratios for debt, attention to the magnitude was also considered along with statistical significance. Once the training sample was evaluated, the testing sample was used to validate the results. Only statistically significant covariates from the training sample $(\mathrm{p}<0.05)$ were included in the testing sample model in order to decrease the degrees of freedom and increase statistical power.

Table 5 describes all the variables in the model and how they were categorized for analysis. 
Table 5

Model depicting variables in the analysis

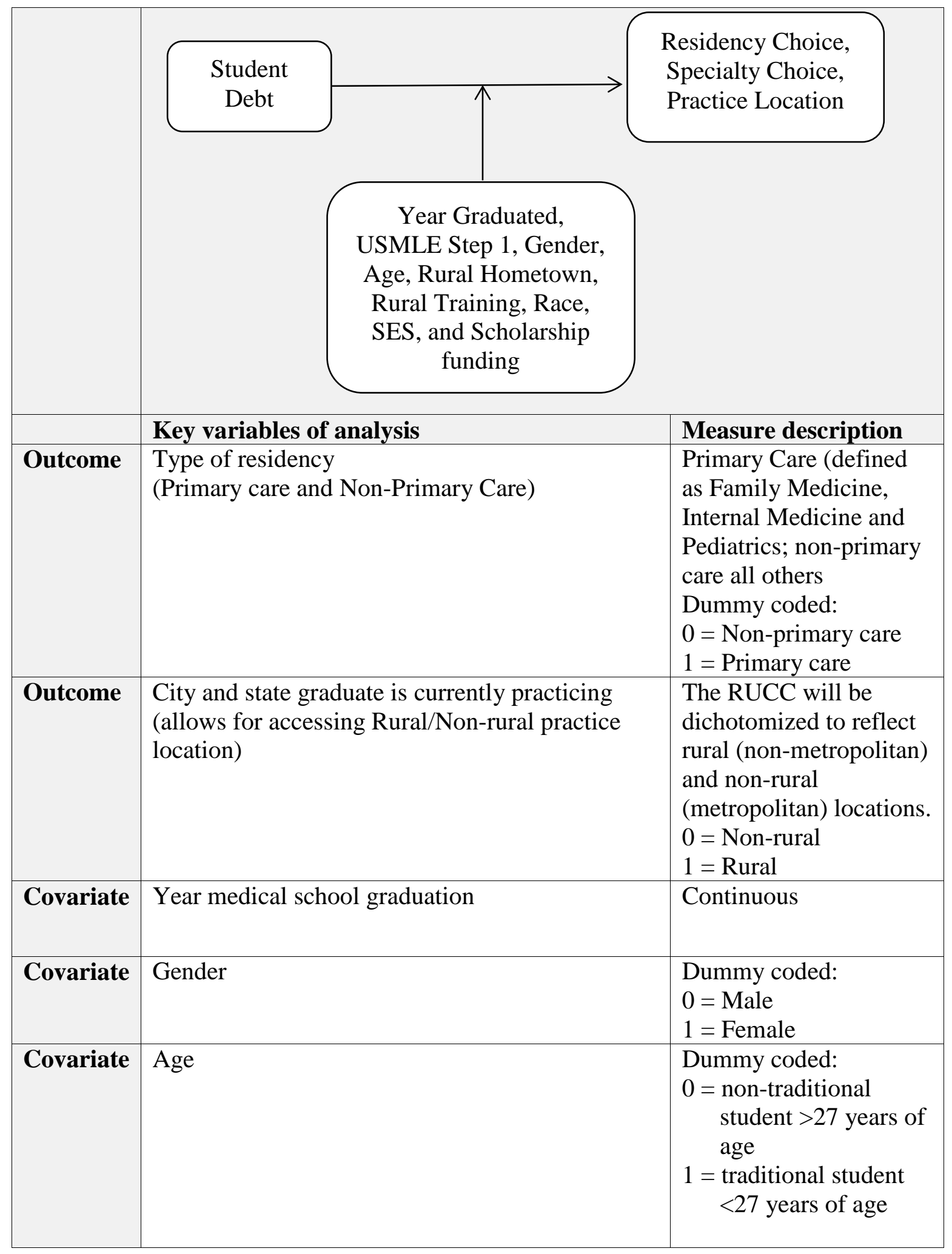




\begin{tabular}{|c|c|c|c|}
\hline & \multicolumn{2}{|l|}{ Key variables of analysis } & Measure description \\
\hline Covariate & \multicolumn{2}{|c|}{ Students upbringing from rural hometown } & $\begin{array}{l}\text { Defined by high school } \\
\text { being located in a city } \\
\text { with a population less } \\
\text { than } 30,000 \text {. Dummy } \\
\text { coded: } \\
0=\text { Population } \geq 30,000 \\
1=\text { Population }<30,000\end{array}$ \\
\hline Covariate & \multicolumn{2}{|c|}{ Participated in rural training (at UofL) } & $\begin{array}{l}\text { Dummy coded: } \\
0=\text { ULSOM medical } \\
\text { campus } \\
1 \text { = ULSOM Rural } \\
\text { Trover Campus }\end{array}$ \\
\hline Covariate & \multicolumn{2}{|l|}{ Race } & $\begin{array}{l}\text { Dummy coded: } \\
0=\text { African-American } \\
1=\text { Caucasian } \\
0=\text { African-American } \\
1=\text { Other }\end{array}$ \\
\hline Covariate & $\begin{array}{l}\text { Mother and fathers' educational } \\
\text { Levels }\end{array}$ & \multirow{2}{*}{$\begin{array}{l}\text { Hollingshead } \\
\text { Index of } \\
\text { Socioeconomic } \\
\text { Status. } \\
\text { After } \\
\text { exploratory } \\
\text { analysis } \\
\text { showed the } \\
\text { difference } \\
\text { between SES } \\
\text { measured on a } \\
\text { continuous, } \\
\text { ordinal, and } \\
\text { categorical } \\
\text { scale was } \\
\text { negligible, the } \\
\text { continuous } \\
\text { measurement } \\
\text { was used for } \\
\text { the analysis. }\end{array}$} & $\begin{array}{l}\text { Continuous scale } \\
\text { ranging from } 8 \text { (low } \\
\text { SES) to } 66 \text { (high SES). } \\
\text { Ordinal scale: } \\
\text { 1= unskilled laborers, } \\
\text { menial service workers } \\
\text { (8-19) } \\
2=\text { machine operators, } \\
\text { semiskilled workers } \\
\text { (20-29) } \\
3=\text { skilled craftsmen, } \\
\text { clerical, sales workers }\end{array}$ \\
\hline Covariate & $\begin{array}{l}\text { Mother and fathers' } \\
\text { occupational level }\end{array}$ & & $\begin{array}{l}\text { (30-39) } \\
4=\text { medium business, } \\
\text { minor professional, } \\
\text { technical (40-54) } \\
5=\text { major business and } \\
\text { professional (55-66). }\end{array}$ \\
\hline Covariate & \multicolumn{2}{|l|}{ USMLE Step 1} & Continuous \\
\hline Covariate & \multicolumn{2}{|l|}{ 100\% medical school scholarship } & $\begin{array}{l}\text { Dummy coded: } \\
1=\text { Yes } \\
0=\text { No }\end{array}$ \\
\hline
\end{tabular}




\begin{tabular}{|c|c|c|}
\hline & Key variables of analysis & Measure description \\
\hline $\begin{array}{l}\text { Key } \\
\text { predictor }\end{array}$ & $\begin{array}{l}\text { Medical school debt inflation adjusted using the } \\
\text { CPI with } 2010 \text { as the baseline year }\end{array}$ & $\begin{array}{l}\text { Dummy coded: } \\
1=<\$ 50,000 \\
0=\geq \$ 165,000 \\
1=\$ 50,000-\$ 99,999 \\
0=\geq \$ 165,000 \\
1=\$ 100,000-\$ 134,999 \\
0=\geq \$ 165,000 \\
1=\$ 135,000- \\
\$ 164,999 \\
0=\geq \$ 165,000\end{array}$ \\
\hline
\end{tabular}




\section{Limitations}

This study was subject to the inadequacies of secondary data and correlational analysis. Data were collected on all available important study-related variables. However, like most studies on this topic, many influencing variables determining specialty choice and practice location were unobtainable. One such variable was participation in a loan repayment or scholarship program for rural area service. Attempts were made to acquire this data from the Kentucky Office of Rural Health and the KMA-Kentucky NHSC Program Primary Care Office, but confidentiality issues were cited as reasons not to release this information. Of note was that only six students participated in the federal NHSC scholarship or loan repayment program from 2001 to 2010 (according to its federal office) and the KMA program was discontinued in 2003. Another variable noted in the literature that possibly influenced specialty choice was the personal characteristics of altruism; having a scale that measured altruism would have provided an important covariate to be placed in the model.

Further, students not providing responses to variables that make up the Hollingshead SES Scale caused the data set to be reduced by $20 \%$. Although analyses were performed that suggested the missing data on the Hollingshead SES scale did not bias model results, it cannot be confirmed with absolute certainty that the missing data did not cause some degree of bias.

Another limitation was that residency specialty choice was modeled as an outcome, and not the specialty choice that students ultimately chose for practice. Approximately $20 \%$ to $25 \%$ of pediatric and internal medicine residents chose to sub- 
specialized in areas that eliminated them from being categorized as primary care physicians. ${ }^{163}$ Hence, these findings could be biased by looking at residency choice.

This also was a single institutional study; hence, its generalizability could be questioned. However, the relatively large sample size across 10 years allowed the findings to be generalized to a larger population, even more so to the Kentucky population.

Like with all correlational studies, "correlation does not imply causation.” The significant coefficient between debt and specialty choice found in in this study's findings could be the result of other variables not modeled mediating this association. 


\section{CHAPTER IV}

\section{RESULTS}

\section{Descriptive Statistics of Student Characteristics}

A total of 1391 medical students graduating from the academic years 2001-2010 constituted this database. Forty-six percent (636/1391) of students were female, 81\% (1150/1381) were white with the mean age being 23.8 years (SD 3.3). Forty-one percent (557/1355) chose primary care residencies, while just 9\% (101/1070) from 2001-2008 located in rural areas. The adjusted debt level was positively skewed (median $=\$ 119,955$, range \$0-\$322,589). A majority of students, 57\% (786/1391), came from non-rural backgrounds, and 82\% (921/1117) were in the top two categories of the Hollingshead SES scale. Four percent (60/1391) participated in rural medical training the last two years of medical school, 7\% (93/1391) had full scholarships, and the mean USMLE Step 1 score was 215 (SD 22.6). Only six medical students participated in the NHSC (2 scholarship recipients and 4 loan repayment recipients). Table 6 summarizes the student characteristics. 


\section{Table 6}

Demographic and other Characteristics for 1391 University of Louisville School of Medicine Students, 2001-2010 (based on valid responses)

\section{Characteristics}

Residency Choice [n (\%)]

Location Choice $^{¥}[\mathrm{n}(\%)]$

...Primary Care $\quad 557$

...Non Primary Care $\quad 798$

...Rural

101

...Non-rural

969

Class Year Student Graduated [n (\%)]

$$
\begin{aligned}
& \ldots 2001 \\
& \ldots 2002 \\
& \ldots 2003 \\
& \ldots 2004 \\
& \ldots 2005 \\
& \ldots 2006 \\
& \ldots 2007 \\
& \ldots 2008 \\
& \ldots 2009 \\
& \ldots 2010
\end{aligned}
$$

151

USMLE Step 1 Score [Mean (SD)]

215.1

\section{Gender [n (\%)]}

Age [n (\%)]

$$
\begin{array}{ll}
\text {...Female } & 636 \\
\text {...Male } & 755
\end{array}
$$

...Traditional (<27years of age) 1194

....Non-traditional $(>26$ years of

192 age)

Did student grow up in Rural area? [n (\%)]

...Rura

....Non-Rural

Rural Training in Medical School M3/M4 Years [n (\%)]

$$
\begin{aligned}
& \text {...Yes } \\
& \text {...No }
\end{aligned}
$$




\section{Table 6}

Demographic and other Characteristics for 1391 University of Louisville School of Medicine Students, 2001-2010 (based on valid responses)

\section{Characteristics}

Race [n (\%)]

...African American

...Caucasian

...Other
102

1150

129

56

(19-66)

Hollingshead SES Scale [Median (Minimum-Maximum)]

Hollingshead SES Scale [n (\%)]

...8-19 Unskilled laborer, menial service worker

...20-29 Machine operator, semiskilled worker

...30-39 Skill craftsman, clerical sales worker

...40-54 Medium Business and Minor Professional

...55-66 Major Business and Professional

USMLE Step 1 Score [Mean (SD)]

215.1

Full scholarship [n (\%)]

NHSC Recipients [n (\%)]

$$
\text { ...Yes }
$$

1298

...No

...Scholarship

...Loan repayment

....Non-NHSC recipient

2

4

1385

Medical Student Debt Adjusted by 2010 CPI

[Median (Minimum - Maximum)]

$\$ 119,955$ \$322,589)

Medical Student Debt Quintile [n (\%)]

$$
\begin{aligned}
& \ldots<\$ 50,000 \\
& \ldots \$ 50,000-\$ 99,999 \\
& \ldots \$ 100,000-\$ 134,999 \\
& \ldots \$ 135,000-\$ 164,999 \\
& \ldots>\$ 165,000
\end{aligned}
$$

${ }^{¥}$ Collected for 2001-2008 years only 


\section{Residency Specialty Choice}

Univariate and bivariate analysis assessing the associations of study characteristics on residency specialty choice showed significant associations for gender, rural training, USMLE Step 1 scores, class year student graduated, and whether students received a full scholarship. More females chose primary care residencies (51\%, 318/622) than males $(33 \%, 239 / 733), X 2(1, \mathrm{n}=1355)=47.7, \mathrm{p}<0.001$. A greater percentage of rural training participants selected primary care residency $(56 \%, 32 / 57)$ than nonparticipants $(40 \%, 525 / 1298), X 2(1, \mathrm{n}=1355)=5.6, \mathrm{p}=0.018$. Differences also were found between USMLE Step 1 scores (primary care, mean = 209; non-primary care, mean $=219, \mathrm{t}(\mathrm{df} 1353)=8.0, \mathrm{p}<0.001)$. From 2001-2010, the percentage of students choosing to go into primary care residencies decreased linearly, $X 2(1, \mathrm{n}=1355)=8.1$, $\mathrm{p}$ $=0.004$. Students who received full scholarships were less likely to choose primary care (25\%, 23/93) than students not receiving full scholarships (42\%, 534/1262), X2 (1, n = $1355)=11.1, \mathrm{p}=0.001$

No associations were found between student debt level and residency choice. The Hollingshead SES scale classification approached significance with the test of linear trend, $X 2(1, \mathrm{n}=10)=3.8, \mathrm{p}=0.052$; students with higher SES classification entered non-primary care residencies at higher rates than lower SES classifications. Table 7 summarizes these findings. 
Table 7

Demographic and other Characteristics by Residency Specialty Choice

\begin{tabular}{|c|c|c|c|c|c|}
\hline & \multicolumn{2}{|c|}{ Primary Care } & \multicolumn{2}{|c|}{$\begin{array}{c}\text { Non-Primary } \\
\text { Care } \\
\end{array}$} & \multirow[t]{2}{*}{$P$ value } \\
\hline \multicolumn{5}{|l|}{$\begin{array}{l}\text { Class Year Student Graduated } \\
\text { [n }(\%)]\end{array}$} & \\
\hline ...2001 & 65 & $(46)$ & 76 & (54) & 0.004 \\
\hline ...2002 & 69 & (51) & 67 & (49) & \\
\hline$\ldots 2003$ & 45 & $(36)$ & 80 & (64) & \\
\hline$\ldots 2004$ & 65 & $(45)$ & 78 & (55) & \\
\hline$\ldots 2005$ & 50 & (38) & 82 & (62) & \\
\hline ...2006 & 60 & $(44)$ & 75 & (56) & \\
\hline$\ldots 2007$ & 58 & $(42)$ & 80 & (58) & \\
\hline$\ldots 2008$ & 59 & $(40)$ & 90 & (60) & \\
\hline$\ldots 2009$ & 43 & (34) & 84 & (66) & \\
\hline$\ldots 2010$ & 43 & (33) & 86 & (67) & \\
\hline USMLE Step 1 Score [Mean (SD)] & 209 & $(22)$ & 219 & $(22)$ & $<0.001$ \\
\hline \multicolumn{6}{|l|}{ Gender [n (\%)] } \\
\hline ...Female & 318 & (51) & 304 & (49) & $<0.001$ \\
\hline ...Male & 239 & (33) & 494 & (67) & \\
\hline \multicolumn{6}{|l|}{ Age [n (\%)] } \\
\hline ...Non-Traditional (>26 years of & 66 & $(37)$ & 113 & (63) & 0.200 \\
\hline ... Traditional (<27 years of age) & 491 & $(42)$ & 680 & $(58)$ & \\
\hline \multicolumn{6}{|l|}{$\begin{array}{l}\text { Did student grow up in Rural Area? } \\
\text { [n (\%)] }\end{array}$} \\
\hline ...Rural & 246 & $(43)$ & 327 & (57) & 0.221 \\
\hline ...Non-Rural & 303 & $(40)$ & 462 & (60) & \\
\hline \multicolumn{6}{|l|}{$\begin{array}{l}\text { Rural Training in Medical School } \\
\text { M3/M4 Years }\end{array}$} \\
\hline$\ldots$ Yes & 32 & $(56)$ & 25 & $(44)$ & 0.018 \\
\hline ...No & 525 & $(40)$ & 773 & $(60)$ & \\
\hline
\end{tabular}




\begin{tabular}{|c|c|c|c|c|c|}
\hline & \multicolumn{2}{|c|}{ Primary Care } & \multicolumn{2}{|c|}{$\begin{array}{l}\text { Non-Primary } \\
\text { Care }\end{array}$} & P value \\
\hline ...African American & 43 & $(44)$ & 54 & (56) & 0.194 \\
\hline ...Caucasian & 451 & $(40)$ & 672 & (60) & \\
\hline ...Other & 60 & $(48)$ & 65 & $(52)$ & \\
\hline $\begin{array}{l}\text { Hollingshead SES Scale [Median } \\
\text { (Minimum - Maximum)] }\end{array}$ & 56 & $(19-66)$ & 56 & $(19-66)$ & 0.076 \\
\hline \multicolumn{6}{|l|}{ Hollingshead SES Scale [n (\%)] } \\
\hline $\begin{array}{l}\text {..8-19 Unskilled laborer, } \\
\text { menial service worker }\end{array}$ & 2 & $(50)$ & 2 & (50) & 0.052 \\
\hline $\begin{array}{l}\text {...20-29 Machine operator, } \\
\text { semiskilled worker }\end{array}$ & 19 & (51) & 18 & $(49)$ & \\
\hline $\begin{array}{l}\text {..30-39 Skill craftsman, } \\
\text { clerical sales worker }\end{array}$ & 69 & $(45)$ & 84 & $(55)$ & \\
\hline $\begin{array}{l}\text {..40-54 Medium Business and } \\
\text { Minor Professional }\end{array}$ & 116 & $(42)$ & 161 & (58) & \\
\hline $\begin{array}{l}\text {...55-66 Major Business and } \\
\text { Professional }\end{array}$ & 246 & (39) & 384 & (61) & \\
\hline \multicolumn{6}{|l|}{ Full scholarship [n (\%)] } \\
\hline ...Yes & 23 & (25) & 70 & $(75)$ & 0.001 \\
\hline ....No & 534 & $(42)$ & 728 & (58) & \\
\hline \multicolumn{6}{|l|}{$\begin{array}{l}\text { Medical Student Debt Quintile } \\
\text { [n (\%)] }\end{array}$} \\
\hline$\ldots<\$ 50,000$ & 116 & $(42)$ & 161 & (58) & 0.259 \\
\hline$\ldots \$ 50,000-\$ 99,999$ & 111 & (43) & 145 & (57) & \\
\hline$\ldots \$ 100,000-\$ 134,999$ & 107 & (41) & 154 & (59) & \\
\hline$\ldots \$ 135,000-\$ 164,999$ & 134 & (44) & 173 & (56) & \\
\hline$\ldots>\$ 165,000$ & 89 & (35) & 165 & (65) & \\
\hline
\end{tabular}




\section{Receiver Operator Characteristic Curve}

Receiver Operator Characteristic curve analysis was undistinguished and showed no optimal debt level for predicting primary care that had high sensitivity and specificity. The area under the curve was only 0.49 (95\% CI 0.45- 0.52), $\mathrm{p}=0.351$. Figure 4 displays the ROC curve:

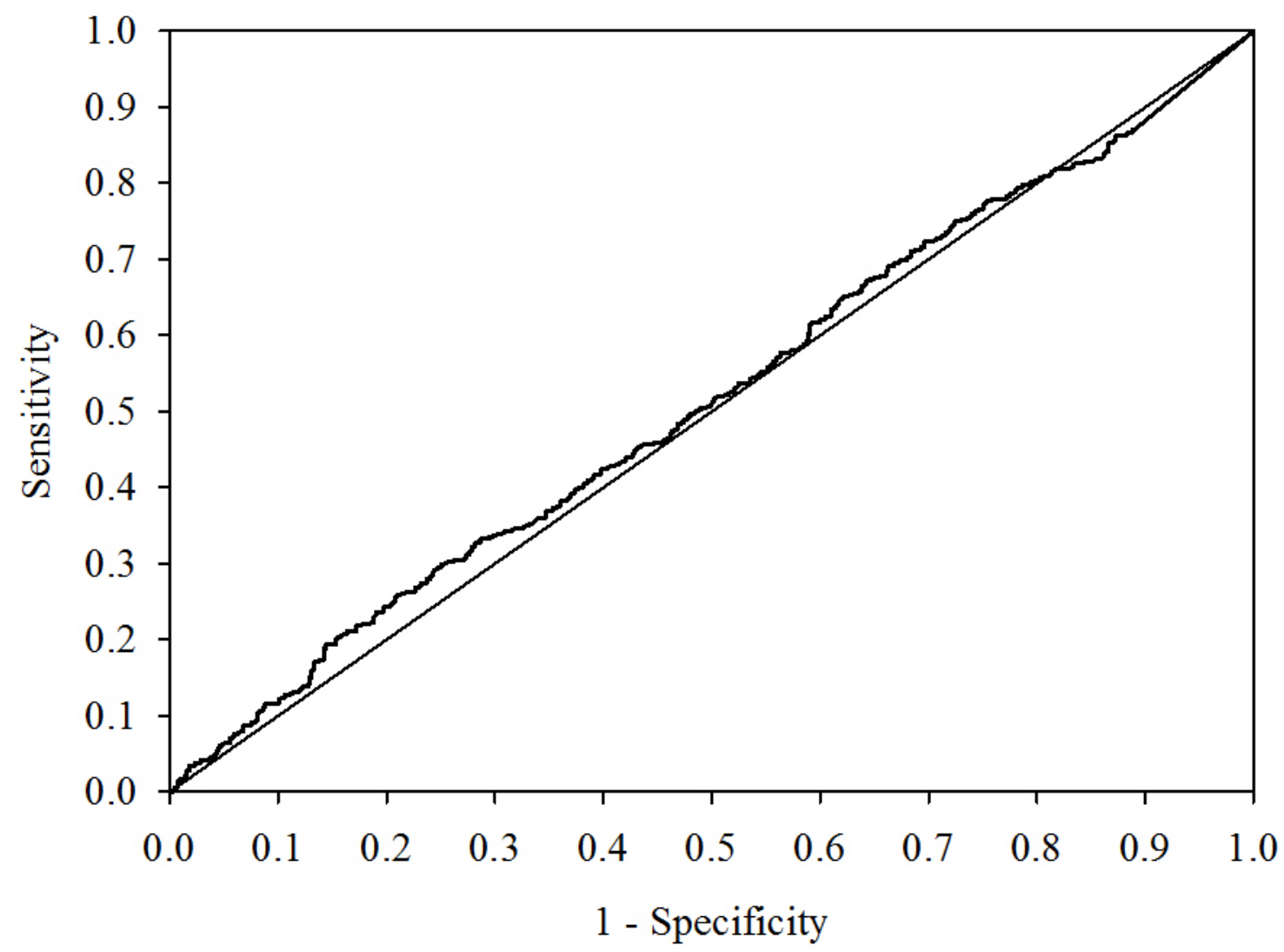

Figure 4. ROC Curve of Debt Level Predicting Primary Care Specialty Choice

\section{Training and Testing Sample Analysis of Unadjusted Odds Ratio}

As would be expected, the training sample analysis of the unadjusted odds ratio (OR) showed somewhat analogous findings to the univariate and bivariate analysis above. Mean differences were found on USMLE Step 1 scores between those who went 
into primary care and non-primary care residencies [primary care, Mean = 208.6; nonprimary care, Mean $=219.2$, unadjusted OR $=0.82(95 \%$ CI 0.74-0.90 $) \mathrm{p}<0.001]$. Females' odds of entering a primary care residency were twice that of males', unadjusted $\mathrm{OR}=2.31$ (95\% CI 1.75-3.05), $\mathrm{p}<0.001$. The Hollingshead SES score OR approached statistical significance, unadjusted OR $=0.90$ (95\% CI 0.82-1.00), $\mathrm{p}=0.057$. Further, for medical students who had full scholarships, the odds of not entering a primary care residency were over twice that of those not receiving full scholarships, OR $=0.44$ (95\% CI 0.23-0.82), $\mathrm{p}=0.009$.

Regarding the primary predictor, the unadjusted OR that compared the first four quintiles of medical student debt to the last showed only the fourth quintile $(\$ 135,000$ $\$ 164,999)$ versus the last quintile $(>\$ 165,000)$ achieved significance, unadjusted OR $=$ 1.67 (95\% CI 1.07-2.60), $\mathrm{p}=0.022$. All other comparisons for medical student debt achieved neither practical nor statistical significance. Table 8 displays these results, along with the results of the test sample. 


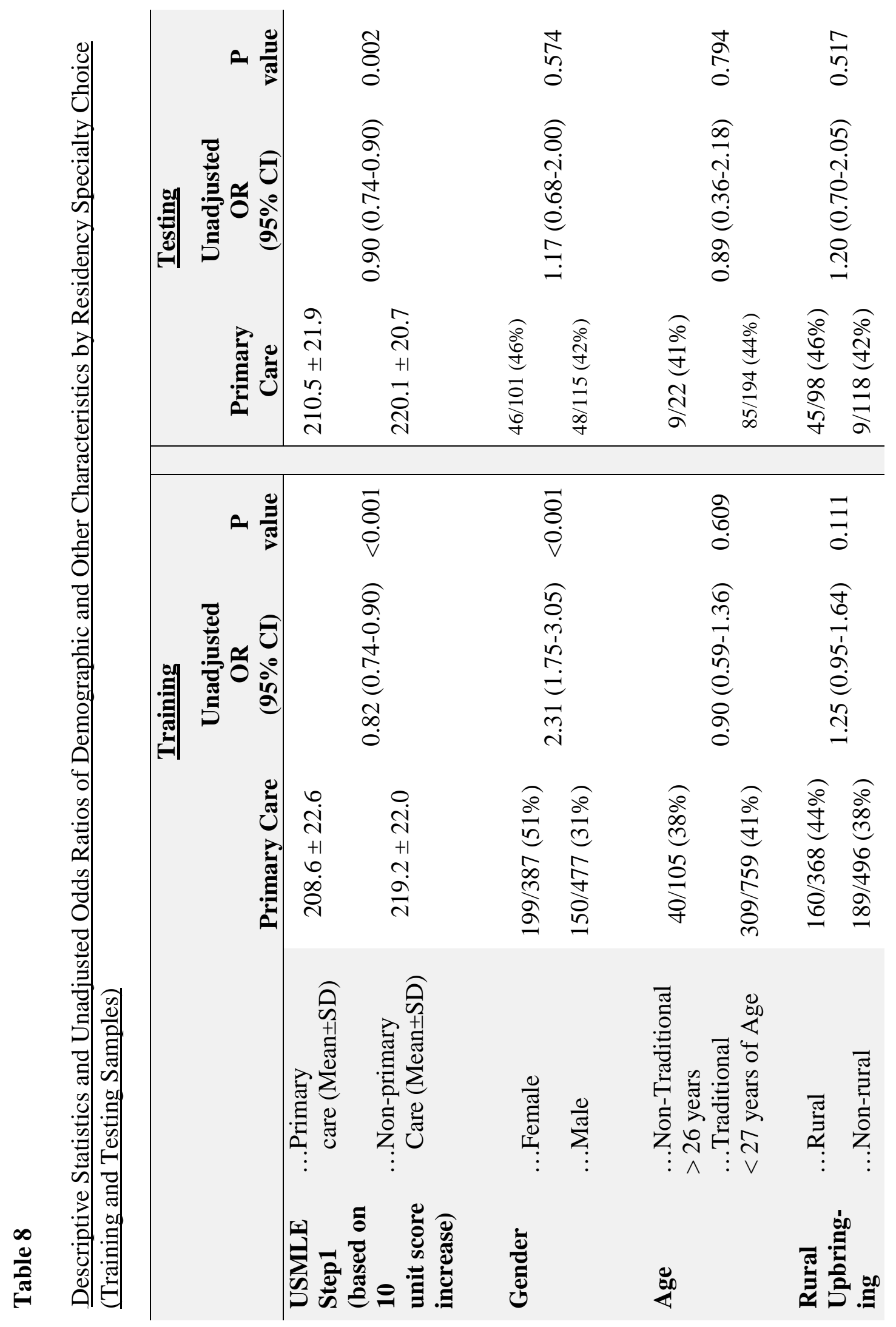




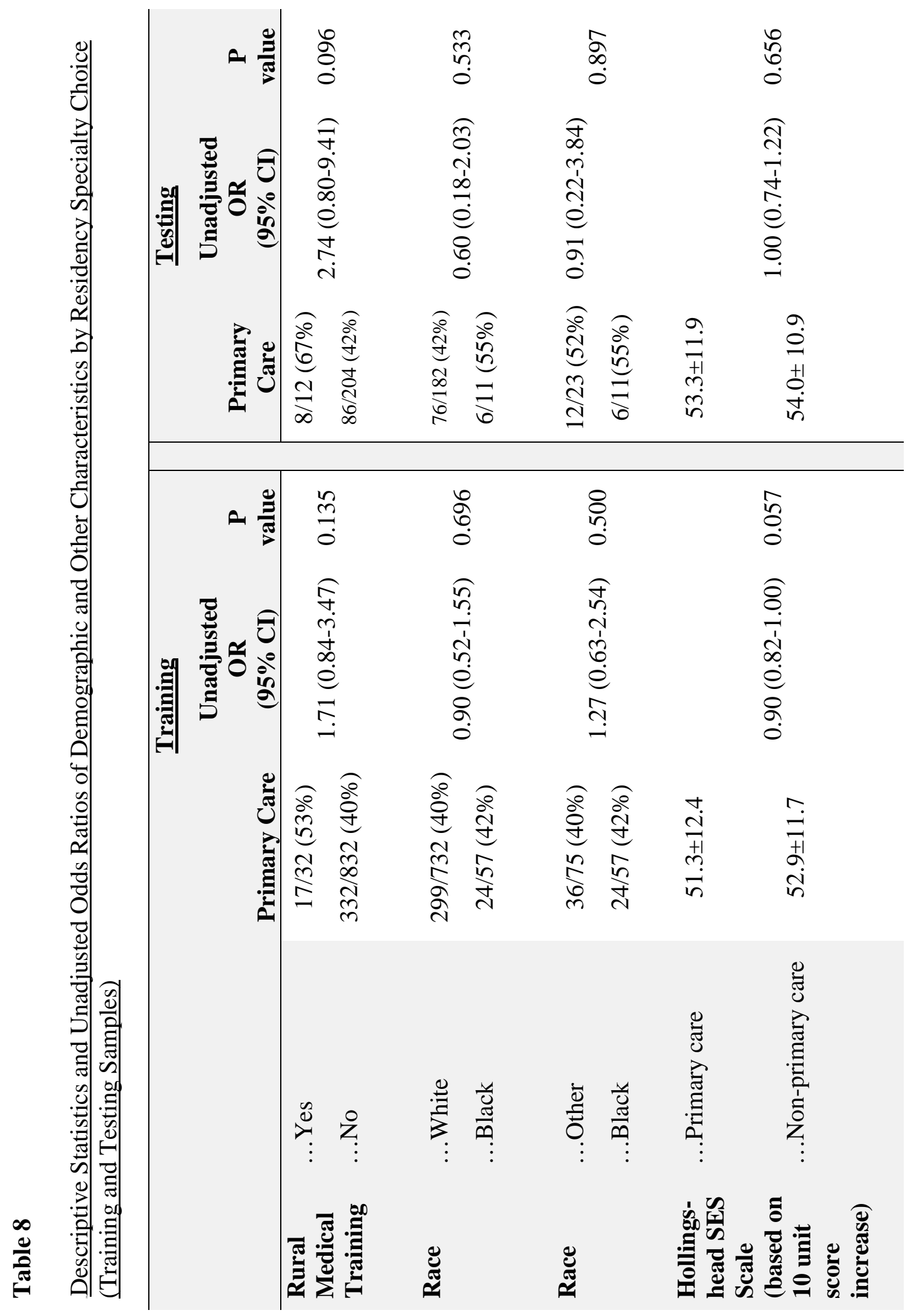




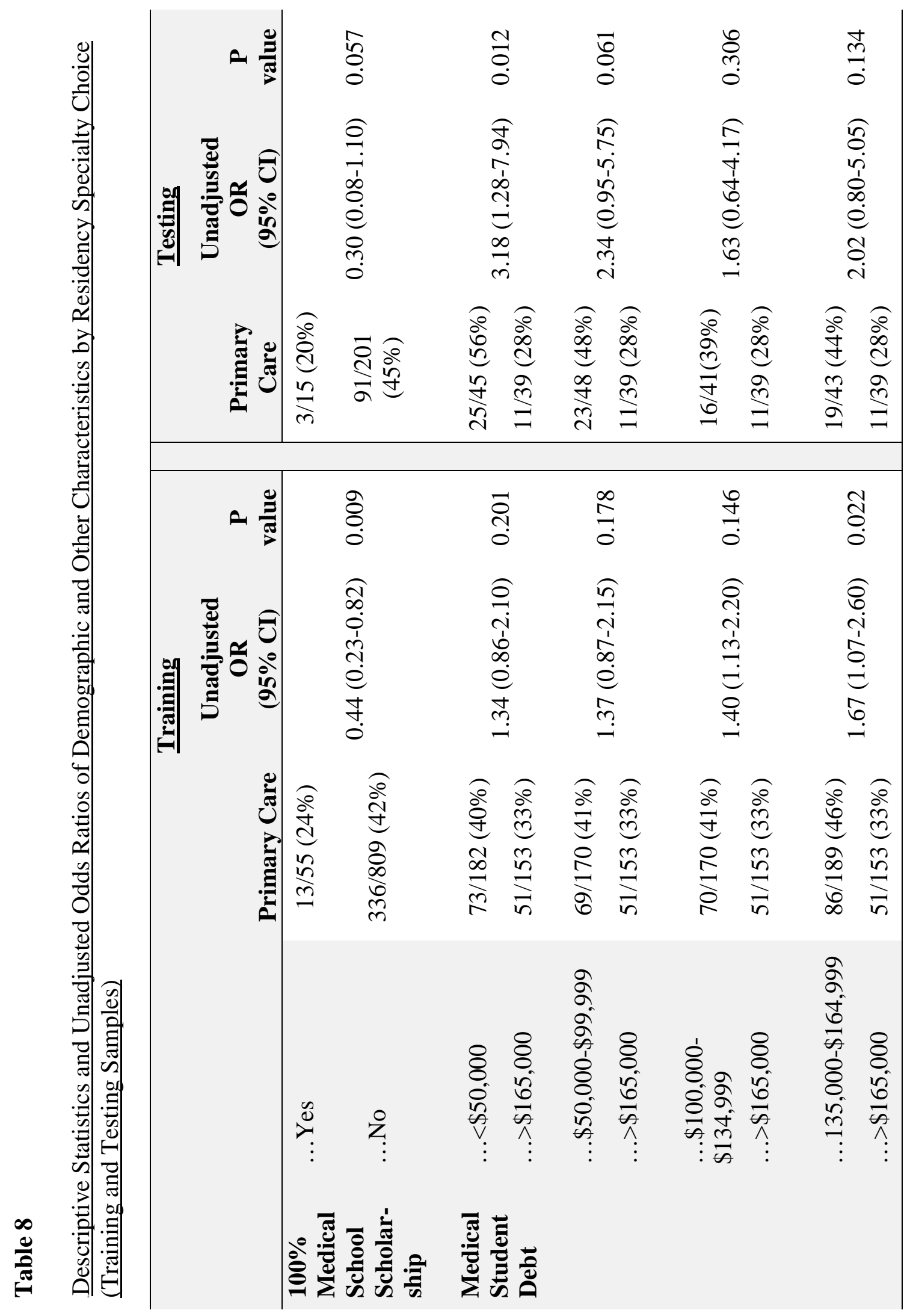




\section{Multiple Logistic Regression and Assessment of Training and Testing Samples}

Utilizing the training data set, the impact of debt on primary care residency

choice, after controlling for the other covariates in the model, was assessed through multiple logistic regression. In order to address the direct relationship between debt and primary care residency choice, two models were compared. The first model constituted all covariates in the model, excluding levels of debt. The second model built on the first model by including levels of debt. The change in the -2 log likelihood statistic indicated no association between debt (evaluated across all debt levels) and primary care residency choice, $X^{2}(\mathrm{df}=4)=5.70, \mathrm{p}=0.223$.

Next, the individual debt level coefficients were appraised. The adjusted OR comparing the lowest quintile versus the highest quintile $(<\$ 50,000$ vs $>\$ 165,000)$ and the second quintile versus the highest quintile $(\$ 50,000-\$ 99,999$ vs $>\$ 165,000)$ approached significance, $\mathrm{p}<0.10$. Further, unlike the unadjusted ORs, the adjusted ORs were practically significant, ORs $>1.5$, indicating the less debt that students had, the higher the odds of entering a primary care residency. The adjusted OR that compared the fourth quintile versus the highest quintile $(\$ 135,000-\$ 164,999$ vs $>\$ 165,000)$ remained significant, adjusted OR $=1.70$ (95\% CI 1.06-2.73), $\mathrm{p}=0.027$. The adjusted OR that compared the third quintile versus the highest quintile (\$100,000-\$134,999 vs $>\$ 165,000)$ was neither statistically or practically significant.

Other covariates that achieved significance were the USMLE Step 1 scores, adjusted OR $=0.83$ (95\% CI 0.78-0.89), $\mathrm{p}<0.001$, and gender, adjusted OR $=1.95(95 \%$ CI 1.46-2.60), $\mathrm{p}<0.001$, which remained somewhat congruent with the unadjusted ORs. 
These results are depicted in Table 9 (see page 106) under the columns where "Training” is the heading.

The testing data set was then used to attempt to validate the training data set's results. As in the training sample, the change in the -2 log likelihood statistic was used to evaluate the global hypothesis of debt's association with residency choice. The first model specifying the USMLE Step 1 scores and gender was compared with the model that added debt. The change in the -2 log likelihood statistic indicated no association between debt (evaluated across all debt levels) and primary care residency choice, $X^{2}$ $(\mathrm{df}=4)=6.98, \mathrm{p}=0.137$

The individual odds ratio coefficients were then evaluated to ascertain the final model, which mathematically is presented as:

Odds $[\mathrm{Y}=1$ (primary care) $]=$

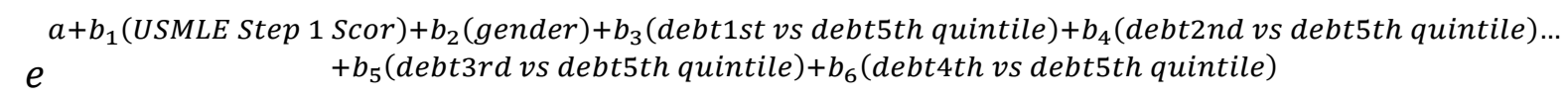

By specifying in the model the USMLE Step 1 scores, gender, and medical student debt, the medical student debt adjusted OR comparing the lowest quintile versus the highest quintile achieved significance, adjusted OR = 3.17 (95\% CI 1.25-8.09), p = 0.016. Further, the comparison of the second quintile with the highest quintile showed an increased, but non-significant, unadjusted OR $=2.44$ (95\% CI 0.97-6.17), $\mathrm{p}=0.059$. The adjusted OR comparing the fourth quintile versus the highest quintile was no longer significant. The USMLE Step 1 coefficient remained stable and significant while the gender OR became neither stable nor significant, i.e., the coefficient reversed itself in comparison to the training data set. These results are depicted in Table 9 (see page 106), under the columns where "Testing" is the heading. 
Two-way interaction effects of debt with all other variables in the model were assessed on the training data set and then compared with the testing data set. The process of testing interactions was incorporated including a single interaction term at a time. For example, levels of debt by gender were assessed after controlling for all covariates in the model, then levels of debt by race were assessed in a similar fashion until all two-way interactions of levels of debt with the covariates were examined. The interaction coefficients were non-significant or significant but unstable. The results of the analysis for the interactions are found in Appendices 3-18. 


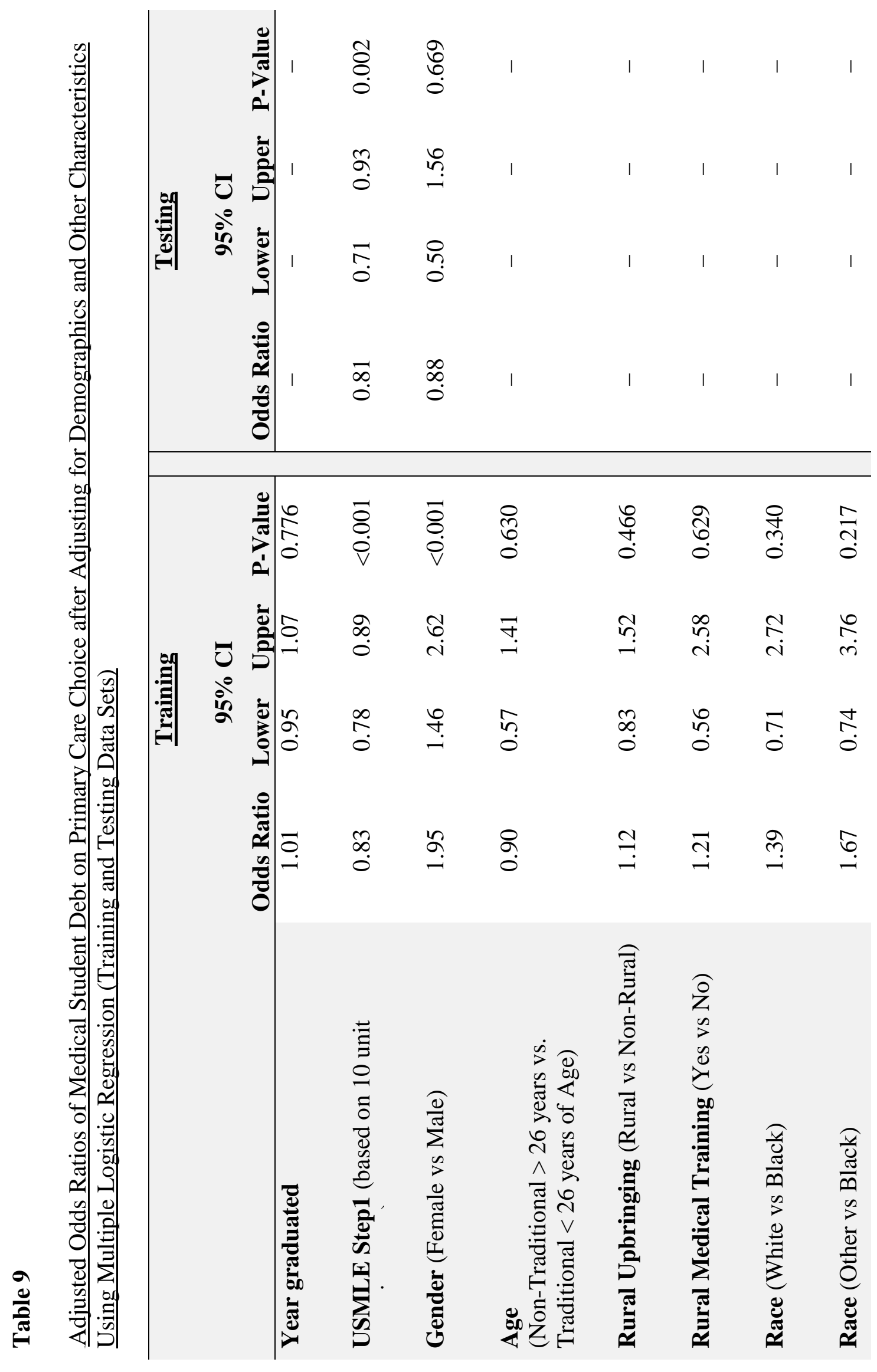




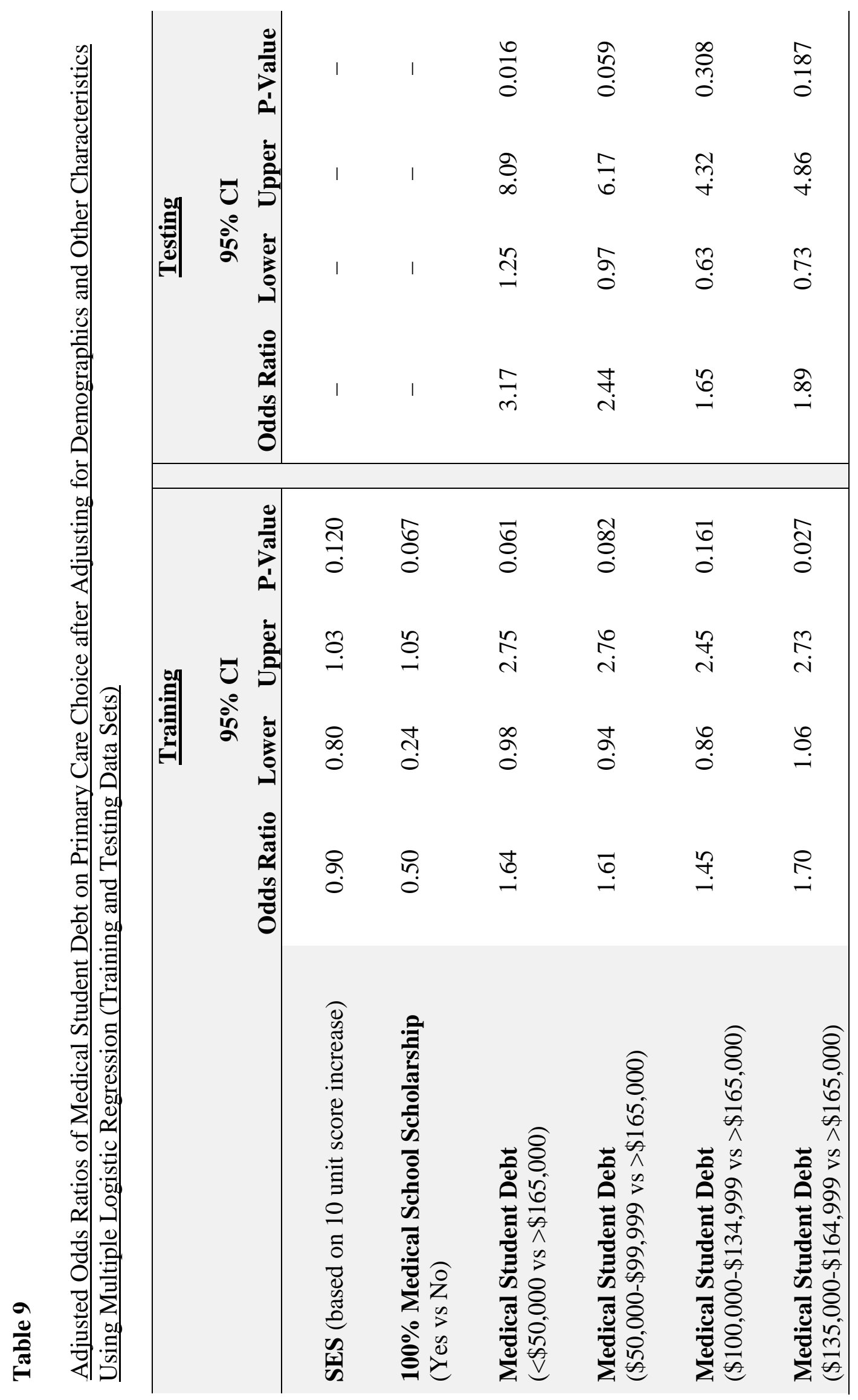




\section{Practice Location Choice}

Results of the univariate and bivariate analysis assessing the associations of study characteristics on practice location found significant associations on whether students had a rural upbringing, rural training as well as their USMLE Step 1 scores and their Hollingshead SES scores. Students who grew up in rural areas chose to practice in rural areas $(15 \%, 69 / 458)$ at higher rates than students growing up in non-rural areas (5\%, 30/601), $X^{2}(1, \mathrm{n}=1059)=31.16, \mathrm{p}<0.001$. Similarly, students who received rural training in medical school were much more likely to practice in rural locations (45\%, 19/42) than students receiving traditional training (8\%, 82/1028), $X^{2}(1, \mathrm{n}=1070)=65.5$, $p=0.001$. The Hollingshead SES scale classification achieved significance for the test of linear trend, $X^{2}(1, \mathrm{n}=10)=14.1, \mathrm{p}<0.001$; students who had lower SES classifications located in rural areas at higher rates than higher SES classifications. Regarding the primary predictor of medical student debt, no significant association was found between student debt level and residency choice. Table 10 summarizes these findings 


\section{Table 10}

$\underline{\text { Demographic and other Characteristics by Practice Location }}$

\begin{tabular}{|c|c|c|c|c|c|}
\hline & \multicolumn{2}{|c|}{ Rural } & \multicolumn{2}{|c|}{ Non-Rural } & P value \\
\hline \multicolumn{6}{|c|}{ Class Year Student Graduated [n (\%)] } \\
\hline$\ldots 2001$ & 14 & $(10)$ & 124 & $(90)$ & 0.080 \\
\hline$\ldots 2002$ & 12 & (9) & 123 & $(91)$ & \\
\hline$\ldots 2003$ & 14 & $(11)$ & 108 & (89) & \\
\hline$\ldots 2004$ & 20 & $(14)$ & 121 & $(86)$ & \\
\hline$\ldots 2005$ & 12 & $(10)$ & 113 & $(90)$ & \\
\hline$\ldots 2006$ & 11 & (8) & 119 & $(92)$ & \\
\hline$\ldots 2007$ & 12 & (9) & 123 & $(91)$ & \\
\hline$\ldots 2008$ & 6 & (4) & 138 & (96) & \\
\hline USMLE Step 1 Score [Mean (SD)] & 207.4 & $(22.1)$ & 214.1 & $(22.8)$ & 0.005 \\
\hline \multicolumn{6}{|l|}{ Gender [n (\%)] } \\
\hline ...Female & 46 & (9) & 445 & $(91)$ & 0.942 \\
\hline ...Male & 55 & (9) & 524 & (91) & \\
\hline
\end{tabular}

Age [n (\%)]

...Non-Traditional (>26 years of age) $16 \quad$ (11) $132 \quad$ (89) 0.553

...Traditional (<27 years of age) $85 \quad$ (9) $832 \quad$ (91)

Did student grow up in Rural Area?

[n (\%)]

$\begin{array}{llllll}\text {...Rural } & 69 & (15) & 389 & (85) & <0.001 \\ \text {...Non-Rural } & 30 & (5) & 571 & (95)\end{array}$

Rural Training in Medical School

$\begin{array}{lccccc}\ldots \text { Yes } & 19 & (45) & 23 & (55) & <0.001 \\ \ldots \text { No } & 82 & (8) & 946 & (92) & \end{array}$




\begin{tabular}{|c|c|c|c|c|c|}
\hline & \multicolumn{2}{|c|}{ Rural } & \multicolumn{2}{|c|}{ Non-Rural } & \multirow[t]{2}{*}{ P value } \\
\hline Race [n (\%)] & & & & & \\
\hline ...African American & 8 & (11) & 68 & (89) & 0.204 \\
\hline ...Caucasian & 88 & (10) & 803 & (90) & \\
\hline ...Other & 4 & (4) & 89 & (96) & \\
\hline $\begin{array}{l}\text { Hollingshead SES Scale [Median } \\
\text { (Minimum - Maximum)] }\end{array}$ & 48 & $(22-66)$ & 56 & $(19-66)$ & $<0.001$ \\
\hline \multicolumn{6}{|l|}{ Hollingshead SES Scale [n (\%)] } \\
\hline $\begin{array}{l}\text {..8-19 Unskilled laborer, } \\
\text { menial service worker }\end{array}$ & 0 & $(0)$ & 4 & $(100)$ & $<0.001$ \\
\hline $\begin{array}{l}\text {..20-29 Machine operator, } \\
\text { semiskilled worker }\end{array}$ & 7 & $(22)$ & 25 & (78) & \\
\hline $\begin{array}{l}\text {..30-39 Skilled craftsman, } \\
\text { clerical sales worker }\end{array}$ & 22 & (17) & 110 & (83) & \\
\hline $\begin{array}{l}\text {...40-54 Medium Business and } \\
\text { Minor Professional }\end{array}$ & 26 & (12) & 200 & (88) & \\
\hline $\begin{array}{l}\text {..55-66 Major Business and } \\
\text { Professional }\end{array}$ & 33 & (7) & 438 & (93) & \\
\hline \multicolumn{6}{|l|}{ Full scholarship [n (\%)] } \\
\hline ...Y Yes & 5 & (7) & 71 & (93) & 0.376 \\
\hline ...No & 96 & (10) & 898 & (90) & \\
\hline \multicolumn{6}{|l|}{ Medical Student Debt Quintile [n (\%)] } \\
\hline$\ldots<\$ 50,000$ & 17 & (8) & 203 & $(92)$ & 0.312 \\
\hline$\ldots \$ 50,000-\$ 99,999$ & 26 & $(11)$ & 205 & $(89)$ & \\
\hline$\ldots \$ 100,000-\$ 134,999$ & 22 & (10) & 202 & $(90)$ & \\
\hline$\ldots \$ 135,000-\$ 164,999$ & 28 & (11) & 226 & (89) & \\
\hline$\ldots>\$ 165,000$ & 8 & (6) & 133 & $(94)$ & \\
\hline
\end{tabular}




\section{Receiver Operator Characteristic Curve}

Like primary care, the Receiver Operator Characteristic curve analysis for debt on rural location was ineffective in showing an optimal debt level with high sensitivity and specificity. The area under the curve was only $0.49(95 \%$ CI 0.44-0.55), $\mathrm{p}=0.828$. Figure 5 displays the ROC curve:

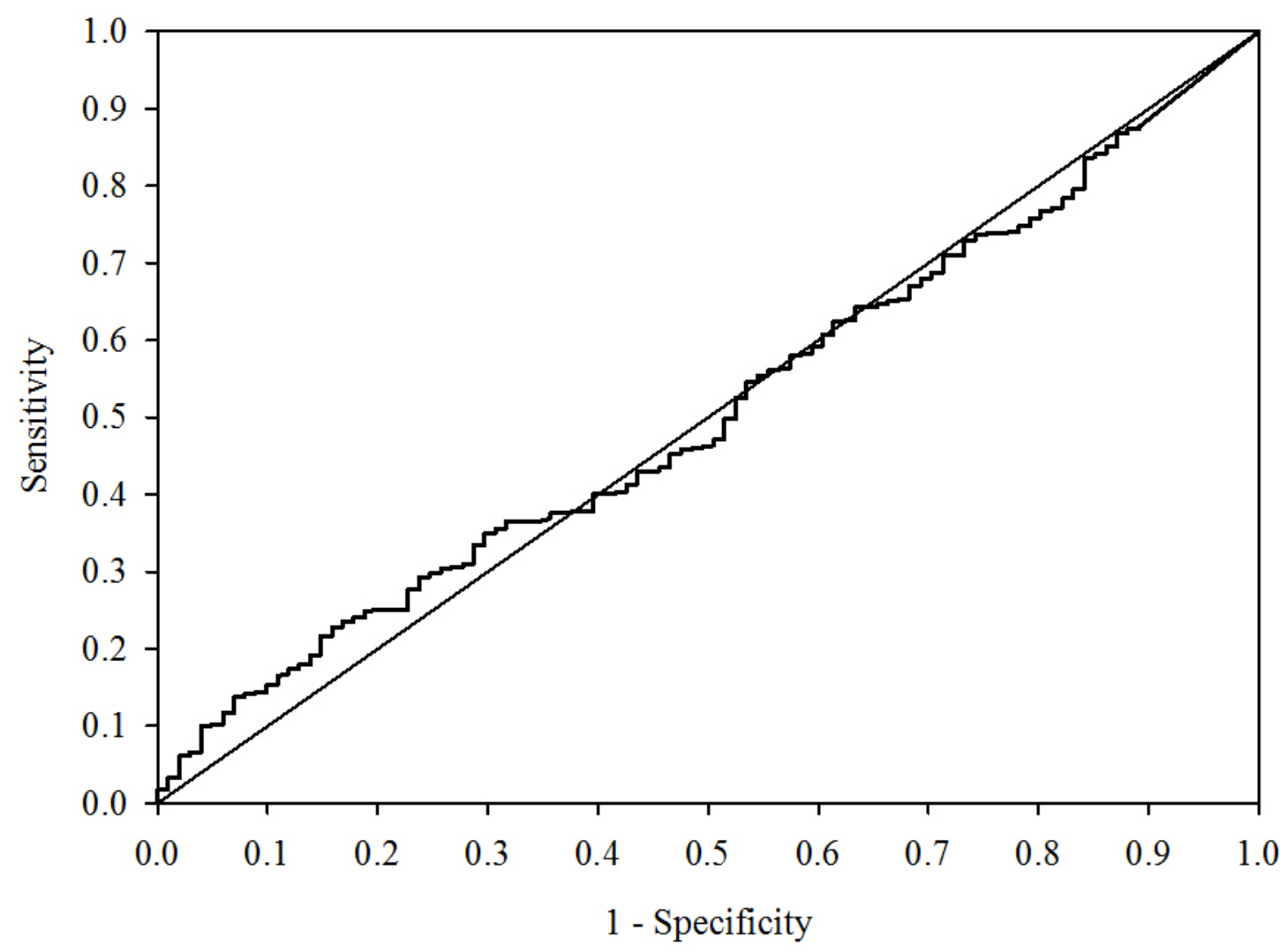

Figure 5. ROC Curve of Debt Level Predicting Rural Practice Location

\section{Training and Testing Sample Analysis of Unadjusted Odds Ratio}

The training sample results of the unadjusted ORs were consistent with the univariate and bivariate analysis. Significant associations were found between practice location with the USMLE Step 1 score, rural upbringing, rural medical school training, 
and the Hollingshead SES score. An association between "race-other” versus "black” also achieved significance as the "race-other" students were much less likely to practice in a rural area, unadjusted OR $=0.10(0.01-0.89), \mathrm{p}<0.038$. The medical student debt's unadjusted ORs were non-significant. Table 11 displays these results, along with the results of the test sample. 


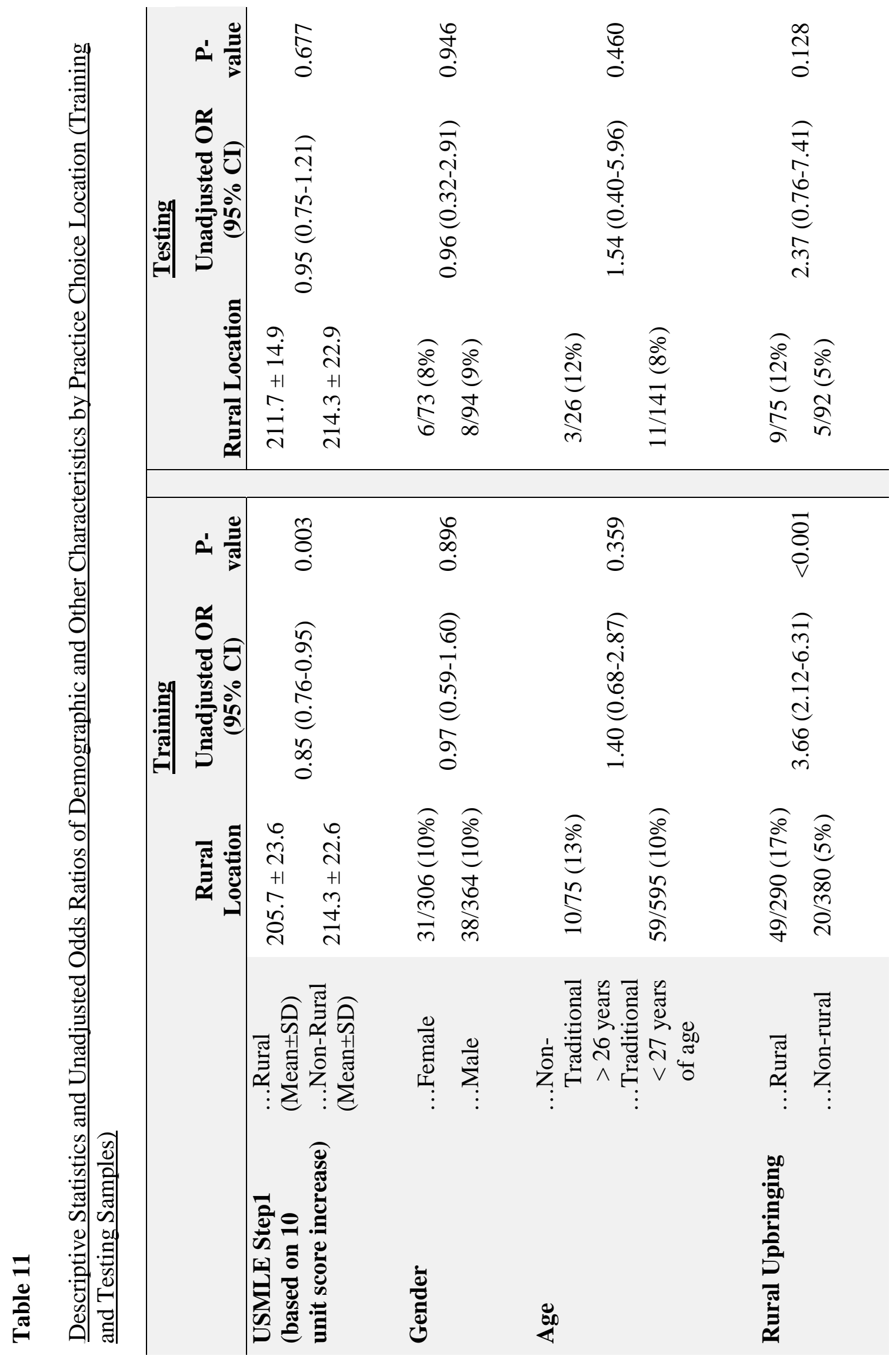




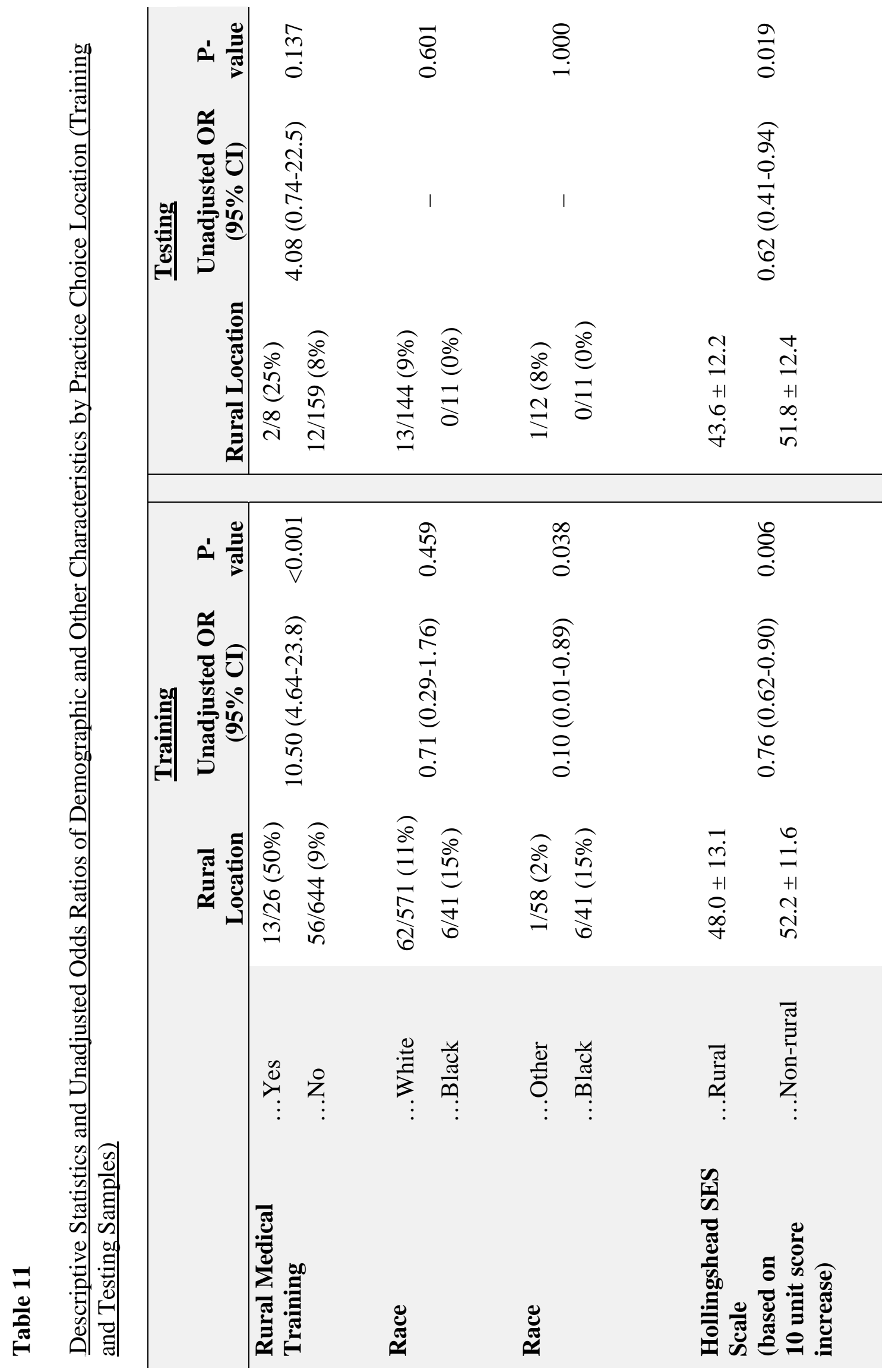




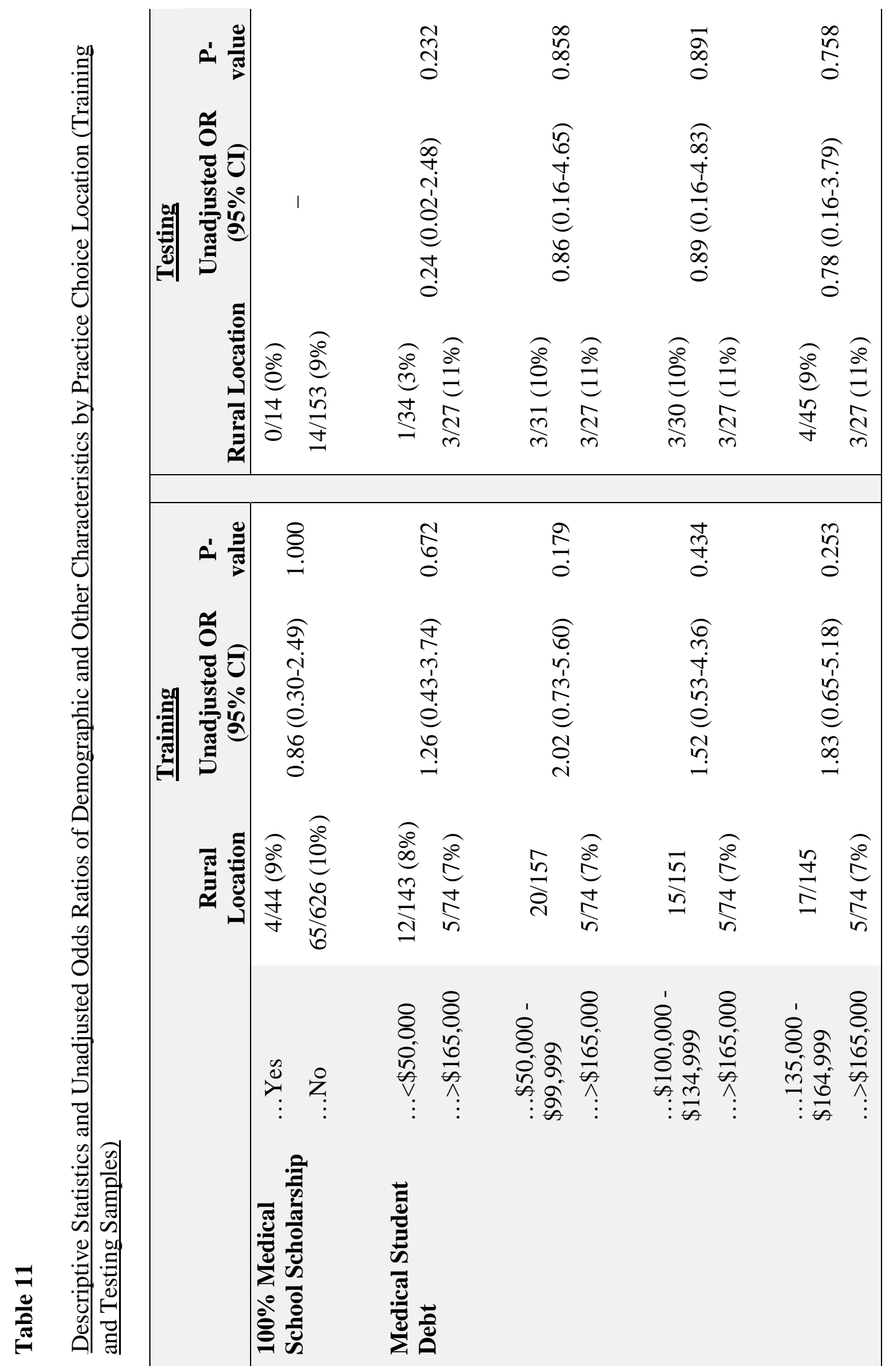




\section{Multiple Logistic Regression and Assessment of Training and Testing Samples}

The multiple logistic regression results for the training data set showed no significant association between debt and practice choice location, as evaluated by the change in the $-2 \log$ likelihood statistic, $X^{2}(\mathrm{df}=4)=1.73, \mathrm{p}=0.786$. This was further confirmed with evaluation of the individual coefficients, i.e., no comparative associations between the first four quintiles and the highest quintile were significant. Similar to the unadjusted ORs, significant results were found for the USMLE Step 1 score, adjusted OR $=0.88(95 \%$ CI 0.78-1.00), $\mathrm{p}=0.046$; rural upbringing, adjusted $\mathrm{OR}=3.68(95 \% \mathrm{CI}$ 1.97-6.87), $\mathrm{p}<0.001$; and rural medical school training, adjusted OR $=6.16$ (95\% CI 2.48-15.29), p <0.001. However, the Hollingshead SES score, and the race ("race-other" versus "black") associations no longer remained significant.

The significant coefficients were modeled on the test data set along with debt.

Hence, the final model equation was:

Odds $[\mathrm{Y}=1$ (rural practice location) $]=$

$a+b_{1}$ (USMLE Step 1 Score $)+b_{2}$ (Rural Upbringing $)+b_{3}$ (Rural Training $)+b_{4}($ debt 1 st vs debt 5 th quintile) $e^{+} b_{5}($ debt2nd vs debt5th quintile $)+b_{6}($ debt $3 r d$ vs debt 5 th quintile $)+b_{7}($ debt 4 th vs debt 5 th quintile $)$

The change in the -2 log likelihood statistic again showed no significant association between debt and practice location, $X^{2}(\mathrm{df}=4)=1.68, \mathrm{p}=0.794$. No significant associations were found on any of the individual coefficients with practice location. The debt coefficients became unstable and reversed themselves. Although rural upbringing and rural medical training in the test data set were non-significant, the coefficients were large and had practical significance. The USMLE Step 1 Score coefficients remained stable, but it was no longer meaningfully significant. Table 12 displays the coefficients for the training and testing data sets. 
Two-way interaction effects of debt with all other variables in the model were assessed on the training data set and compared with the testing data set. The interaction coefficients were non-significant or significant but unstable. The results of the analysis for the interactions are found in Appendices 11-18. 


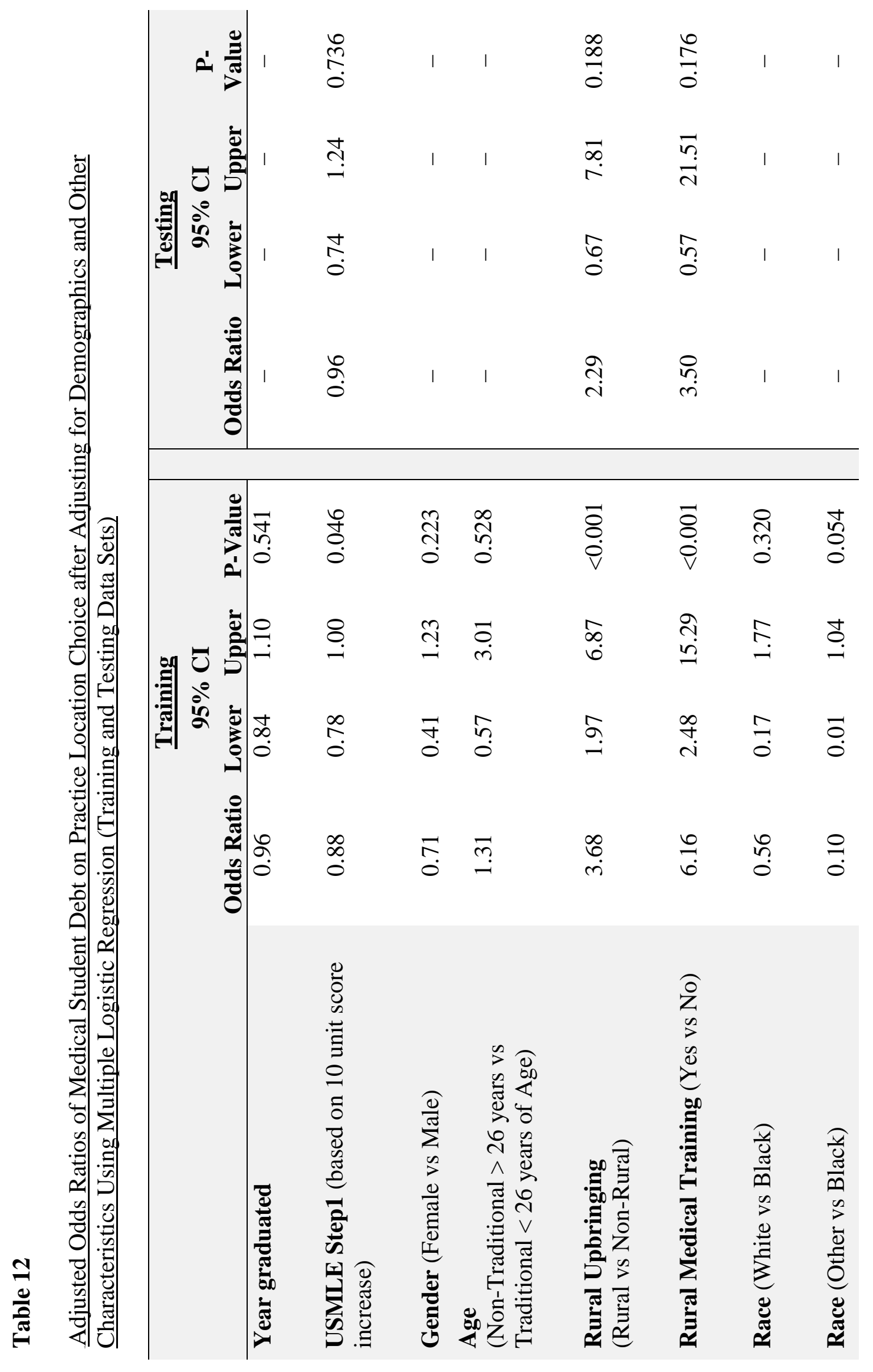




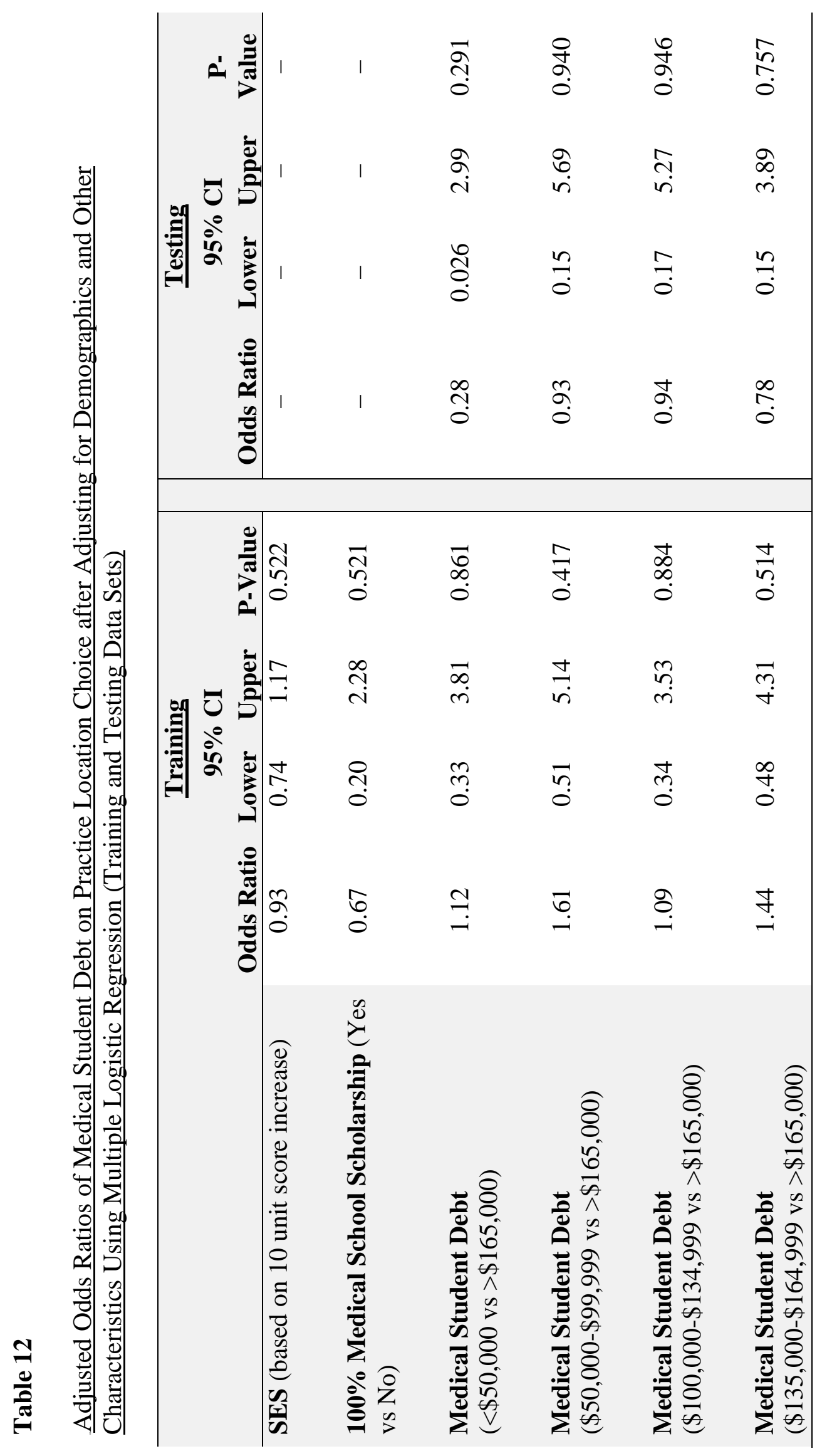




\section{CHAPTER V DISCUSSION}

An effective primary care system contributes to an effective public health system. Both systems have mutual goals that include health promotion, disease and injury prevention, and health surveillance. ${ }^{164}$ Their mutuality intensifies because of the implementation of the ACA and the push for alternative healthcare delivery approaches, i.e., Patient Centered Medical Home (PCMH) and Accountable Care Organizations (ACOs), as these approaches propel primary care to passage from providing individual patient services to focusing on the overall health of paneled populations. ${ }^{165}$ Further, PCPs are "the first level of contact of the individual, the family and the community with the national health systems ... and constitute the first element of a continuing healthcare process. ${ }^{164}$ Consequently, the US PCP and rural manpower shortage threatens the public health of the nation and Kentucky. For this reason, the emphasis of this discussion is on PCP and rural locations workforce shortage solutions. First, the focus on the findings presented is concentrated on medical student debt and solutions to minimize debt's impact on residency selection, along with debt's lack of association with practice location are discussed. Second, overall PCP and rural workforce shortage solutions are explored to provide insight in repairing this healthcare delivery problem. 


\section{Discussion of Analysis: Specialty Choice}

These study findings show that medical student debt was not associated with students' specialty choice across the range of debt. However, students with debt less than $\$ 50,000$ were more likely to choose primary care residencies than students with debt greater than $\$ 165,000$, suggesting that medical student debt may be influencing specialty choice between the extreme quintiles, but not among the middle quintiles. The study findings confirmed other studies that have found a positive association of medical student debt with specialty choice. ${ }^{15,22,113,130,145,146}$ These other studies report that students having lower levels of debt are more likely to pursue a primary care career and inversely students with higher levels of debt are more likely to choose a non-primary care specialty. This is not surprising given the 6\% -7\% annual increases in medical school tuition since 2001.

These findings also contradict findings of more recent studies showing no relationship between student debt and specialty choice. ${ }^{142,143,166}$ Perhaps the negative findings occurred due to how debt was assessed. Hauer, et al. ${ }^{143}$ dichotomized debt as greater than $\$ 120,000$ (and also only look at medical student choice of internal medicine and did not include the primary care specialties of family medicine and pediatrics). Kahn, et al. ${ }^{142}$ assessed debt as a continuous variable. This study’s modeling of debt as a continuous variable also showed no association. Phillips et al. and the Robert Graham Center $^{13}$ compared students with no debt to students with higher debt levels, i.e., \$1 to $\$ 49,999, \$ 50,000-\$ 999,000$, and so forth, in their multivariate analysis. Their findings showed no meaningfully significant odds ratio (or upper bound of a 95\% CI) greater than 
1.2. This study's analysis appraised debt, in contrast to Phillips et al., where debt greater than $\$ 165,000$ was compared to lower-level quintiles and an association was found.

The influence of social economic status did not significantly influence debt's association with specialty choice (either as a confounder or interaction effect) as questioned by the Robert Graham Center. ${ }^{13}$ Further, unlike Colquitt et al., who found interaction effects with debt and other predictor variables, ${ }^{22}$ no significant interaction effects on any predictors was confirmed with this study's data set.

One personal finance model used several common expenses and assumptions that include educational debt, residency income, starting salary after residency, spouse’s income, spouse's educational debt, retirement savings, housing and household expenses, and college savings for two children. ${ }^{18}$ The study showed that PCPs entering the workforce with a median debt of $\$ 160,000$ could repay debt and meet standard household expenses without sacrifices; that is, a primary care career is economically viable.

However, debt greater than $\$ 200,000{ }^{18}$ means physicians most likely would have to give up living in a higher-priced urban area, and/or choose loan repayment options greater than the standard 10 year plan (up to a 25 year plan), or choose a multi-year obligation to a federal loan forgiveness/repayment program. ${ }^{18,36}$ Non-PCPs could acquire educational debt up to $\$ 300,000$ without procuring more debt while having a 10 - year repayment plan and residing in any area. ${ }^{18}$ Another study had more dire findings for new PCPs and how debt would alter their lifestyles. ${ }^{36}$ However, their assumptions failed to allow for family support. Therefore, the validity of their conclusions is questionable. ${ }^{18}$ This study's findings suggest that higher debt-straddled students, by residency selection time, might have an internal calculus of factors necessary to meet debt obligations, while still 
maintaining high living standards and financially planning for their future; hence, those with lower debt have more career choices. However, further research should concentrate on subjecting non-committed medical students to the economic details, expenses, and assumptions of debt repayment to assess if this is influencing their specialty choice. ${ }^{18}$

Of note, to reconcile the contradictory findings regarding: (a) the ROC curve analysis and its inability to find an optimal cut point for medical student debt to predict primary care specialty choice, and (b) the multiple logistic regression findings that showed medical student debt may be influencing specialty choice between the extreme quintiles, the following must be considered: the ROC method is a sensitivity analysis based upon a series of dichotomous results for debt in relationship to selection of residency. The results of the logistic regression were based upon quintile assessments of debt. Hence, the methods differed as did the results. The results from the ROC method do not exclude meaningful and significant results that were obtained from the logistic regression methods.

\section{Specific Solutions Related to Medical Student Debt: Increased Pay}

The discrepancy between PCPs and non-PCPs' income is broad and this difference influences medical students from choosing primary care. ${ }^{167,168}$ One obvious solution is increasing PCPs' earnings. However, secular, technological, and interdisciplinary political trends challenge altering primary care income. ${ }^{168}$ One reason for the income discrepancy is the volume of services physicians provide. ${ }^{168}$ Under feefor-service, income is the product of the fee for each service multiplied by the quantity of services performed. ${ }^{168}$ Since the late 1990s, office visits to primary care doctors has risen less rapidly than many procedures performed by non-primary care specialists. ${ }^{168}$ 
Furthermore, volume growth from imaging, minor procedures, and diagnostic tests services not performed by PCPs - also have increased at more rapid rates. ${ }^{168}$

To increase PCPs’ earnings, the Center for Medicare and Medicaid Service’s (CMS) Resource-Based Relative Value Scale (RBRVS), often accepted by private insurers, underpins the fee-for-service physician payment mechanism. ${ }^{168}$ However, the process of establishing the RBRVS is political and contentious. ${ }^{168}$ The RBRVS uses Current Procedural Terminology (CPT) codes to price medical services. Determining CPT’s fees entail multiplying the relative value unit (RVU) by a Medicare conversion factor and adding a geographic adjustment. ${ }^{168,169}$ RVU determinants are work, practice expense, and malpractice costs with the former two determinants dictating most of the RVU. ${ }^{168-170}$ Greater value on specialized work occurs because procedural services have been determined more "intense” (skill, effort, judgment, and stress) contrasted to primary care’s evaluation and management services (history, physical examination, and medical decision-making). ${ }^{168,169,171}$ Hence, the “intensity” rating, among other factors, influences the PCP and non-PCP income disparity. ${ }^{168,169,171}$

The AMA, at Medicare’s request, formed a means for establishing and updating RVU values. ${ }^{169}$ The AMA charged the Relative Value Scale Update Committee (RUC) with the task of adding new CPTs every year and upgrading CPTs every five years. ${ }^{168,169}$ Thirty-one members constitute the RUC; with specialty societies naming 25 members (and 28 casting ballots that dictate the addition and modification of CPT codes). ${ }^{169,172}$ Representation by primary care specialties is only $18 \%(5 / 28)$, although approximately $50 \%$ of Medicare’s patient visits are to primary care physicians. ${ }^{168,169}$ Each specialty surveys around 30 members to advocate for and defend a purported RVU change. ${ }^{168}$ 
Although RUC members are supposed to be advisory, objective, and unbiased, ${ }^{169}$ controversy occurred due to Medicare’s sustainable growth rate (SGR) formula for physician payment and what critics call a lack of transparency in the RVU process. ${ }^{168,172}$ This formula curtails spending, whereby increases in one CPT code for a particular specialty results in decreases for other specialties the subsequent year. ${ }^{168,169,172}$ The SGR formula encompasses Medicare population growth, physician practice expenditures, and gross domestic product changes. ${ }^{168,169,172}$ Because of primary care physician RUC underrepresentation and PCP services constituting 50\% of overall Medicare reimbursements, non-primary care specialties have an economic interest in overruling new or not upgrading evaluation and management services and have an equal economic interest in adding or upgrading procedural services. ${ }^{168,171,172}$ Further, physician earnings from volume growth of imaging, minor procedures, and diagnostic tests is the primary factor causing the SGR to surpass designated spending and thus inversely causes PCPs' (and other doctors') economic forfeitures. ${ }^{168}$

Private insurance further exacerbates the earnings between PCPs and non-PCPs. 168 Most private insurers model their payments after the RBRVS with upward adjustments. ${ }^{168,170}$ Studies from the early 2000s show that on average private insurers paid evaluation and management services 104\% of Medicare fees, whereas most procedural services and imaging and diagnostic tests received from $120 \%$ to $130 \%$ of Medicare fees, with some achieving as high as 330\%. ${ }^{168}$ Consequently, private insurers’ preferential treatment of non-primary care services amplifies the gap between primary care services. 
In view of the above, solutions to alleviating the primary care workforce deficiencies center around RBRVS reform ${ }^{172}$ with responsibility falling on the CMS (who in the past blindly accepted RUC recommendations often at rates greater than 95\%). ${ }^{171,172}$ Increasing office visits and outpatient service codes for evaluation and management services, without sacrificing existing codes, should occur. ${ }^{171}$ These include creating codes encompassing all elements of services for children and adults dealing with chronic illness, multiple-issue management, and behavioral/mental health, along with the necessary one-on-one follow-up duties such as care coordination for patients with chronic diseases. ${ }^{168,170,171}$ Further, codes should entail both comprehensive and limited consultation care that provides valuation to different co-management levels and continuing consultative support that is non-face-to-face like time spent on the telephone and e-mail consultations. ${ }^{168,170,171}$ The new codes should be based on trustworthy data obtained from the work intensity literature and developed by knowledgeable professionals to accurately value them. ${ }^{171}$ The AMA and CMS should explicitly advocate and enforce that procedural service medicine disciplines accept parity for evaluation and management services. ${ }^{171}$ Related solutions include placing more PCPs on the RUC and altering the SGR system to protect PCPs.${ }^{168}$ In essence, "Medicare (and private payers) need to review and modify their reimbursement approaches to shift payments from procedural and imaging services to evaluation and management services. ${ }^{\prime 168}$

RBRVS reforms have been slow despite the ACA and emphasis on PCMH and ACOs. Politics heavily influences and hinders the reforms. Before 2012, PCPs held only three RUC seats, while now they hold five seats. In 2011, the American Academy of 
Family Practice Practitioners (AAFP) petitioned the AMA to add five primary care seats to the RUC including a geriatric physician, while removing three specialty group seats. ${ }^{172}$ Greater transparency in the RUC process also was advocated so that primary care public interest groups could hold RUC members accountable. ${ }^{172}$ The AMA agreed to adding an additional PCP and a geriatric physician to the RUC, while keeping all current specialties seats. ${ }^{172}$ The transparency issue compromise involved the AAFP forcing the RUC to record votes and publishing some of them online. ${ }^{172}$

The AMA decisions disheartened the AAFP, so their recourse was to provide information regularly to the CMS (along with the RUC). AAFP's first CMS submission involved six new codes affecting PCPs and their payment mechanisms.${ }^{172}$ These codes addressed first contact, continuity, comprehensive, and coordination of care services. ${ }^{172}$ The CMS dismissed much of the recommendations, stating another code addressing bundling care coordination covered their concern. ${ }^{172}$ However, the CMS did concede that some comprehensive services provided by PCPs that dealt with discharged patients returning to a community setting were overlooked and proposed creating a new series of codes, the Health Care Common Procedure Coding System G-Codes, that are currently being developed. ${ }^{172}$

Political Action Committees (PACs) also concerned primary care advocacy groups. ${ }^{172}$ In 2011 and 2012, four medical specialty PACs gave over \$1 million to political candidates running for office. ${ }^{172}$ These medical groups comprise the American Academy of Orthopedic Surgeons, the American College of Radiology, the American Society of Anesthesiologists, and the American College of Emergency Physicians. ${ }^{172}$ In summary, complications ensue in increasing PCPs' pay due to other medical specialties' 
political and financial interests. Contradictory objectives also face the federal government. They need to both contribute to increasing the PCP workforce while maintaining fiscal responsibility - hence, the government's willingness to support some, but not all, of AAFP's recommendations.

\section{Increasing PCP Pay, the ACA, Patient Centered Medical Homes and Accountable \\ Care Organizations}

The healthcare system is in transition due to the ACA pushing for reforming primary care, and new models of delivering care such as the PCMH and ACOs. The PMCH's focus is on primary care and its purpose is implementing primary care principles of "whole-person” focus, comprehensiveness, accessibility, and coordination using multidisciplinary teams to promote population health management”. ${ }^{173}$ ACOs reflect different provider groups who work together to reduce costs and increase quality of care for a designated patient group. ${ }^{173}$ PCMHs would entail practices employing PCPs, while an ACO employs both PCPs and specialist. In both models, fee-for-service and the inherent shortcomings discussed above still remain the underpinning of how physicians are paid, often with hybrid models developing that integrated fee-for-service with capitation, or pay-for-performance payment mechanisms. ${ }^{173,174}$ Because fee-for-service is at the root of physician payment, this may further limit PCPs' income.

Transitioning away from fee-for-service is costly and not without existing or

potential barriers. ${ }^{175}$ First, established fee-for-service administrative infrastructure costs billions, and change entails a financial and resource intensive sacrifice. Second, ACOs and PCMHs require a resource transfer from specialties and hospitals to primary care. Specialists, who benefit the most from fee-for-service and who often hold community 
power, may resist change to protect their finances. Third, many healthcare administrators associate fee-for-service with productivity. Accordingly, eliminating volume-based incentives leads to physician lethargy and unproductiveness. Similarly, PCPs may think that fee-for-service provides motivation to see more patients and to improve access to care. $^{175}$

Further, capitation payment models, whether outright or part of a hybrid capitation/fee-for-service model, have possible limitations. In the past, physicians have resisted capitation; PCPs burdened with sicker populations lose financially and often "pass the buck" to specialists. ${ }^{167}$ PCPs have felt burned due to capitation and managed care. ${ }^{175}$ Appropriate, robust, and scientifically-validated risk adjustments for different patient panels, each having varied levels of health status, must be considered. ${ }^{167,174,175}$ This is the most important factor in decisions to accept capitation. ${ }^{175}$ Likewise, because ACOs retain primary care physicians and specialists, the organization has discretion in determining how “shared savings” payments, like capitation or pay-for-performance, are directed. ${ }^{173}$ Politics might ensue between PCPs and specialists, and PCPs may not get their just rewards. ${ }^{173}$ In effect, the ACO must be "PCP friendly” to reward PCPs financially. Suggestions for making ACOs "PCP friendly” include paying PCPs based on their panel size, patients’ health status, and “providing bonuses for achieving quality metrics, enhanced access, reductions in expected hospital use, and patient experience.»173 Regarding quality metrics, a longstanding issue is performance measures in many areas of interest that are simply not available. ${ }^{167}$

One promising model that may increase PCPs' salary is the Rhode Island Chronic Care Sustainability Initiative (CSI). ${ }^{176,177}$ This approach’s underpinnings is to estimate 
Rhode Island's annual total medical expenses, then have the state's insurance commissioner force commercial insurers to increase primary care-related payments at the expense of specialty care losing money. ${ }^{177}$ The approach tries to rectify Medicare’s RBRVS valuation process and to circumvent the usual contractual negotiations between commercial health plans and providers, so that the services PCPs perform are no longer devalued and high-quality primary care is emphasized. ${ }^{177}$

According to John Morse, Senior Fellow in Health Affairs at the University of Louisville, this and other similar models attempt to eliminate avoidable healthcare cost "upstream” at the primary care level, which is less expensive than providing care "downstream" via specialist. ${ }^{178}$ The objective is for patients with complex chronic diseases to get additional personnel to help guide them in managing their conditions. By moving financial resources away from specialty care to primary care, it is hoped that many patients will not need specialized care. This method of healthcare delivery is thought to be more costly to payers in the short-term, but in the long-term will reduce costs. $^{178}$

The CSI, launched in 2008, is led by the Rhode Island Office of the Health Insurance Commissioner who engages payers, providers, purchasers, and other stakeholders to work together in a consensus-oriented style. ${ }^{176,177}$ The goal is to implement PCMHs across the state to more effectively care for people with chronic conditions. ${ }^{176}$ Currently all commercial health plans and all plans with Medicaid contracts are mandated to participate. ${ }^{176}$ Further, the number of participating practices are growing from an initial five primary care practices in 2008 to 36 practices as of November, 2013. ${ }^{176}$ Approximately 25\% (250,000) of Rhode Islanders are served by 297 physicians 
in this program, with the goal of expanding the CSI to serve over 500,000 patients by adding 20 practices per year until 2017. ${ }^{176}$

Initially, a council representing the Office of the Health Insurance Commissioner and pertinent stakeholders put forth several standards. ${ }^{177}$ First, each participating insurer was to allocate a proportion of medical expenses to primary care. Starting January 1 , 2010, the insurers increased primary care expenditures by six percent, and thereafter started to increase by one percentage point the annual amount of expenses to primary care until it reached $11 \%$ of commercial insurers' medical expenses. Second, insurers were to take this increase in primary care expenses and designate it to PCMHs. Third, a proportion of the financial increase allocated for expenses was to go to physician practices for the adoption of electronic health records. The final standard merely required insurers' participation in the discussion over delivery system payment reform. This included insurers providing non-competitive information about basic payment arrangements in areas of contractual performance incentives. The council acknowledged the need for increasing primary care payments, and that increasing fee-for-service payments would not be adequate. The council researched primary care financial models in the literature and what others have done "including pay-for-performance incentives, case management fees, and carefully conceived risk-sharing mechanisms.”177 However, no specific mandates were implemented to raise PCPs' salaries. ${ }^{177}$

The CSI's impact on improving PCPs' salary is unclear. Rhode Island's two dominant commercial insurers have not made increasing primary care salaries a top priority. ${ }^{177}$ Blue Cross Blue Shield of Rhode Island designates 50\% of total funding to the PCMH where they have a "specific view of the medical home as focused on members 
with complex medical needs and substantial annual medical costs." ${ }^{177}$ It is noted that Blue Cross Blue Shield sees the increased funding going to hiring more staff for the PCMHs including case managers in physicians' offices. ${ }^{177}$ Blue Cross Blue Shield also is designating $15 \%$ of funding to enhance electronic health records. ${ }^{177}$ Only a small portion of Blue Cross Blue Shield's funding goes directly to primary care reimbursement, although it is believed that Blue Cross Blue Shield's implementation of pay-forperformance financial models will eventually increase physicians’ salary. ${ }^{177}$

UnitedHealthcare's focus is also on the PCMH and improving the quality of health for patients. However, compared with Blue Cross Blue Shield, more money will go to primary care providers. ${ }^{177}$ Approximately $25 \%$ of reallocating medical expenses to primary care will go to pay-for-performance programs which should benefit PCPs in the long term, while another $25 \%$ will be dedicated to fee schedule increases where United's primary care physician fees trail the market compared with neighboring states. ${ }^{177}$

In terms of paying PCPs more, the council emphasized payment reform over fee increases. ${ }^{177}$ PCPs' salaries are expected to increase due to improved quality and the additional money allocated as result of the CSI. However, the council clearly believes that "funds must be used for improved capacity to provide primary care to patients, not simply higher payments for continuing to deliver the status quo.”177

Ultimately, in order for medical students to choose primary care, the PCMHs and ACOs payment strategies must more align PCPs' compensation with non-PCPs' compensation. However, since these models are in flux, not thoroughly vetted, or wellestablished, current medical students' residency choice, in terms of finances, can only consider fee-for-services payments. Thus, as the ACA further increases the need for more 
PCPs, the new healthcare delivery models offer no proven financial incentive to choose primary care. Even ACA’s legislation to provide small bonus payments for bolstering primary care is insufficient in achieving necessary long-term parity between primary care and specialty fields. ${ }^{179}$

\section{Specific Solutions Related to Medical Student Debt: Make Medical School Cost Equitable}

The Strategic Alternative for Funding Education (SAFE) is one innovative solution for dealing with medical student debt. ${ }^{38}$ The following summarizes the key points of SAFE. ${ }^{38}$ SAFE proponents advocate for the waiving of medical students', residents', and fellows' tuition and fees until after medical training. After residency/fellowship, the new physician pays their medical school a percentage of their gross yearly income over ten years as reimbursement for tuition costs. As a reimbursement for tuition costs, SAFE advocates estimate, based on 2008 AAMC physician salary surveys, that private medical school graduates should pay $10 \%$ of their yearly salary, while students from public schools should pay about 5\%. Accordingly, on average, private medical school graduates will pay $\$ 250,000$ (\$175,000 initial debt and $\$ 75,000$ amortized over 10 years equaling a $7.5 \%$ interest rate); public school graduates will pay $\$ 125,000$ (\$93,000 initial debt and \$32,000 amortized equaling a 6.25\% interest rate). These rates and Stafford loan rates are competitive with each other. ${ }^{38}$

Regarding the student (soon-to-be physician), physicians practicing in specialties that are more profitable would return more money to their medical school than physicians in primary care, public health professions, or performing charity work. ${ }^{38}$ Ideally, the amount tendered need not dramatically alter the physician's living standards. Further, medical students’ professional aspirations would dictate specialty choice, not debt. 
Moreover, students would not experience debt-related stress. One potential drawback is medical schools guiding their students into lucrative specialty residencies. ${ }^{38}$

Nationally, levels of parental income of most medical students (75\%) is above the fourth quintile, while less than $6 \%$ of students come from families in the lowest quintile. ${ }^{111}$ Further, parental educational level is greater for medical students, e.g., approximately half of fathers and one-third of mothers hold graduate degrees. ${ }^{112}$ ULSOM students underscore on this trend, as only 3\% of U of L 2001-2010 graduates come from Hollingshead SES scale’s two lowest categories. Experts note that more "privileged" students chose specialties over primary care to maintain prior living arrangements, while lower SES students chose primary care. ${ }^{13}$ These inter-related trends reflect a quandary concerning the PCP shortage. Under SAFE, the physician workforce potentially would expand and diversify, as lower SES and minority students would not have the intimidating factor of medical student debt preventing them from pursuing a medical degree. ${ }^{38}$ Further, the federal government also could aid the physician and allow the physicians’ medical school remuneration to be tax deductible. ${ }^{38}$

Issues facing medical school include the SAFE program's launching. ${ }^{38}$ The federal government could supply early funding by offering medical schools low-interest loans. Partial funding from financial aid and scholarships already in use could also help fund the early years. Self-perpetuating return of investment would occur seven years after the SAFE's first class starts, i.e., seven years for the students to matriculate through medical school and residency. Students participating in longer residencies would start paying back 8-12 years after starting medical school. ${ }^{38}$ 
The medical school benefits from the SAFE program by having certitude over

how much money it receives annually. ${ }^{38}$ Further, tuition increases are eliminated because, when the physician salary increases, the amount paid back to the medical school increases, and any decision made to shorten undergraduate medical education would cause no immediate economic impact. ${ }^{38}$

Other educational strategies to reduce student debt are found in sections, "Train More: Shorten the Duration of Medical Training” (page 162); "Shortening Undergraduate Medical Education: The Positive” (page 165); “Shortening Graduate Medical Education (Family Medicine): The Positive” (page 169); and “Train More: Summary” (page 171) found later in this chapter.

\section{Discussion of Analysis: Practice Location}

This study's findings found no relationship with student debt on choosing a rural practice location. This confirms the 2000 study of Pathman, et al., which also found no relationship between debt and rural practice location. ${ }^{147}$ The findings contradict the Robert Graham Center study which found a modest association with debt and rural practice (higher debt led to relocating in a rural practice). ${ }^{13}$ The final model also did not find significant associations with the variables that represented the affinity model, although the odds ratios for rural upbringing and rural medical school training were large. The lack of significant results possibly is due to the smaller sample size and low power in the testing data set, as rural practice location has been consistently shown to be associated with both rural upbringing ${ }^{55,56,103,14,81,106}$ and rural medical school training. ${ }^{9,104,109,110}$

These findings' implications, along with the fact that only six U of L medical students from 2001 to 2010 were NHSC participants and studies showing that scholarship 
and loan repayment program participant retention rates are either ineffective ${ }^{139}$ or debatable in terms of their success, ${ }^{131}$ suggest that the NHSC and other debt-relief programs are possibly not the most optimal use of public financial resources. Further, financial incentives, as a whole, may not successfully entice physicians into rural areas. As mentioned prior, one of Kentucky's scholarship and loan repayment program ended in 2003. Its replacement was the Established Practice Grant Program that provided financial startup and maintenance aid (up to seven years) for PCPs willing to work in underserved counties. This program, like its predecessor, ended last year due to lack of interest.

Given the literature’s findings regarding the affinity model’s influence on physicians practicing in rural HPSAs, resource allocation needs to consider rural upbringing and rural medical school training. ${ }^{10}$ Medical pipeline programs that encourage networking among high schools, undergraduate colleges, and medical schools facilitate a link of rural adolescent students maturing and matriculating through medical school and practicing in rural areas. ${ }^{180}$ In effect, recruiting and nurturing rural youth leads to rural retention of PCPs. ${ }^{181}$ Correspondingly, medical school rural health track programs that offer medical students experience in living and practicing in a rural location have also shown success in generating rural physicians. ${ }^{20}$ (For a more comprehensive discussion of medical pipeline programs and medical school rural health track programs see sections, “Train More: “Pipeline” Medical Educational Programs” (p.160), and “Undergraduate Medical Education Regional Rural Health Track “Pipeline” Programs” (p. 162) found later in this chapter.) Essentially, governmental monetary resources should include programs that complement the affinity model. 


\section{Overall Solutions to the Primary Care Physician and HPSA Workforce Shortage}

Primary care workforce shortage solutions have been categorized with three approaches: find someone else, train more, or waste less. ${ }^{182}$ Solutions to the primary care workforce shortage are theoretically practical, yet some advocated solutions conflict as stakeholders dissent on how to assess and meet workforce needs. ${ }^{183}$ The medical fields promote increasing the number of PCPs, while others posit the problem not as a “physician shortage”, but as a “demand-capacity” mismatch. ${ }^{184}$ Inherent within the demand capacity argument is that primary care could boost capacity to meet patient demand if clinical responsibilities are reallocated, with the help of modern technology, to non-physicians workers and to patients themselves. ${ }^{184}$ However, access to care issues are not restricted to medicine; nursing and physician assistant services also experience workforce shortages. ${ }^{181}$ For example, to meet the population’s healthcare needs, Kentucky in 2012 needed a 30\% increase in the number of practicing physician assistants, a 5\% increase in nurse practitioners (NPs), and a $12 \%$ increase in registered nurses across the state. ${ }^{10,181}$

\section{Find Someone Else: Nurse Practitioners}

The nursing profession argues it offers the greatest potential in correcting primary care workforce shortages (and, poignantly, is the most adversarial to the medical profession in challenging physicians’ status as primary care providers). Nursing and healthcare researchers note the likelihood of PCPs meeting the US primary care healthcare demands as dubious, ${ }^{184-186}$ and many PCP promotion policies, i.e., increasing class sizes, medical schools, and primary care residencies, will take years before being influential. ${ }^{187,188}$ Nurse practitioners (NPs), however, are an alternative to addressing 
much of the shortfall. ${ }^{185}$ Since the mid-1960s, NPs have supplied primary care, often in HPSAs or to diverse populations. ${ }^{185}$ The NP workforce has grown steadily and currently constitutes roughly $20 \%$ of all primary care providers, ${ }^{185}$ with $89 \%$ of NPs trained with a primary care focus. ${ }^{189}$ About $65 \%$ of NPs work in ambulatory or primary care, and from 2008 to 2025 , the profession is predicted to increase $130 \%$ by adding 6,000 to 7,000 workers annually until it achieves 198,000 persons in the field. ${ }^{185,190}$ In addition, NPs are increasing more rapidly than other primary care professions. ${ }^{189}$ Eighteen percent of NPs practice in rural communities, which is almost double the rate for PCPs. ${ }^{189}$ States with large rural populations and favorable regulatory environments have higher rates of rural NPs. Vermont, South Dakota, Wyoming, Montana, and Maine have rates of NPs greater than or equal to $40 \% .{ }^{189}$ Texas, in comparison, has both considerable areas of rural populations and an unfavorable regulatory environment; hence, only 13\% of NPs in Texas work in areas of less than 25,000 residents. ${ }^{189}$

The American Association of Nurse Practitioners (AANP) ${ }^{189}$ posits that NPs are qualified to perform primary care duties including being the first point of service for patients with undifferentiated conditions, ongoing management of acute and chronic conditions, health promotion, disease prevention, and care coordination. Their skills include requisitioning, performing, and interpreting diagnostic and laboratory tests; writing prescriptions and prescribing non-pharmacologic therapies; and teaching and counseling. NPs practice independently and collaboratively with other healthcare providers to manage patient care. ${ }^{189}$

Two separate literature reviews published in 2002 and 2011 found no differences between nurse practitioners in collaboration with physicians, than with physicians alone 
on health conditions ${ }^{185,191,192}$ and outcomes including mortality, patient satisfaction, and physical, emotional, and social functioning. ${ }^{193}$ NPs had lengthier consultations, made more inquiries than physicians, and generally did better on screening, assessment, and counseling services. ${ }^{189,191}$ The number of prescriptions, return consultations, and referrals were similar as well. ${ }^{191}$ NPs also had higher patient satisfaction than PCPs in communicating about self-management of chronic conditions. ${ }^{185,191}$

NPs' care of patients is at a minimum equal to PCPs in certain areas of medical service. ${ }^{194}$ Furthermore, NPs are more cost-effective than PCPs. A simplistic explanation is that on average NPs average salary is $57 \%$ to that of PCPs [ $\$ 92,000$ (in 2008) versus \$162,500]. ${ }^{194}$ A more in-depth explanation indicates that Medicaid, Medicare, and private insurers have compensation discrepancies between NPs and physicians. ${ }^{185,194}$ Medicaid pays NPs 75\%-100\% of physicians’ compensation for their services while Medicare pays 85\%. ${ }^{185}$ Many studies demonstrate that physicians’ cost of services is greater than NPs’ costs for the same services. ${ }^{194-196}$ The bottom line is NPs decrease medical care spending. ${ }^{194}$ Interestingly, the facts presented here come from a medical economist who lauds the cost effectiveness of NPs, ${ }^{194}$ and also from a nursing faculty researcher and the Institute of Medicine (IOM) that argue for pay reform and equal compensation ${ }^{185,187}$ which, if granted, would hinder the cost-effectiveness of NP patient care services.

\section{Obstacles Facing Nurse Practitioners as a Solution to Primary Care Shortage}

Obstacles facing NPs as being a primary care provider solution are numerous. One pertinent policy obstacle is scope of practice regulations (SOPs). ${ }^{184,185,189,194,197}$ SOPs designate NPs' (and other professions') roles and duties dictating “what work can be performed by whom.”184 They dictate the NPs’ autonomy and authority to deliver 
primary care to patients, to write prescriptions, and order tests, their compensation for services, and to be primary care providers of record. ${ }^{185,197}$ The AMA and other medical societies are antagonistic to NPs working autonomously without a PCP's supervision. They cite a physician's in-depth and more extensive education, i.e., four years of medical school and three years of residency, judged against an NP's training of four years of nursing school and two years of graduate school to justify their opposition. ${ }^{189}$ However, the medical profession possibly is just protecting its turf, ${ }^{184}$ status, and compensation.

NPs receive uniform training and must take a national certification examination. However, state regulations of SOPs vary and a variety of state agencies including boards of medicine and/or boards of nursing and pharmacy dictate the constitution of SOPs. States whose SOPs are regulated only by boards of nursing, in general, provide less constricting SOPs and allow NPs to practice to the full extent of their training without physician supervision. ${ }^{185,197}$ Conversely, states sharing SOPs with other professions often limit NPs' autonomy and compromise NPs roles and duties by mandating collaboration with or supervision by a doctor. ${ }^{185,197}$ Eighteen states have NP SOPs requiring no physician involvement needed to diagnose and treat patients or prescribe medications; eight states allow NPs to diagnose and treat patients autonomously, however, physician involvement is needed for prescribing; and 24 states require physician involvement in diagnosis, treatment, and prescribing (Figure 6). ${ }^{187,198}$ Kentucky’s SOPs distinguish NPs as primary care providers and allow them to diagnose and treat patients without physician involvement, however, physician supervision or a collaborative agreement is necessary for NPs to prescribe drugs. ${ }^{199}$ 


\section{Nurse Practitioner Scope-of-Practice Authority, 2012}

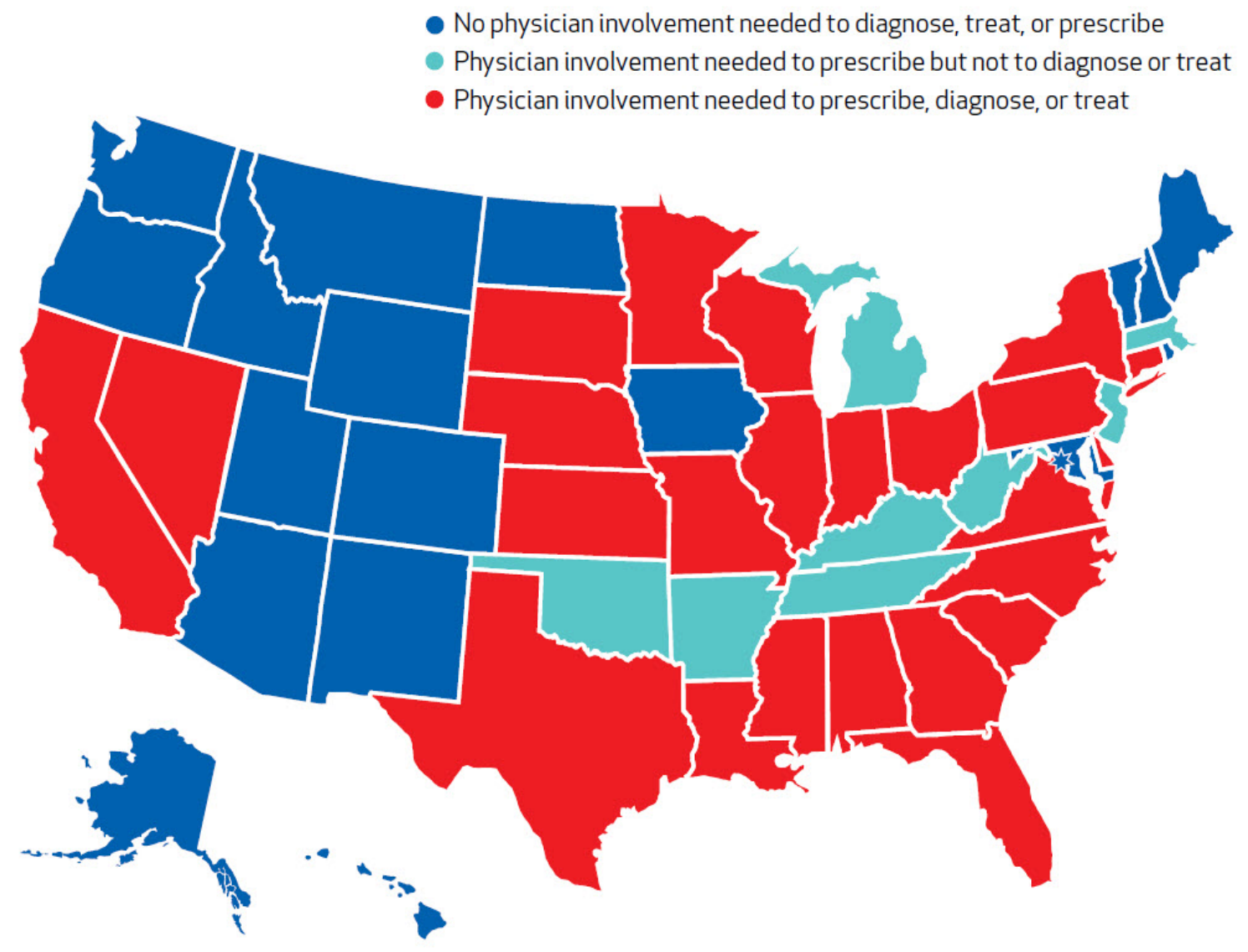

Figure 6. Nurse Practitioner Scope-of-Practice Authority, 2012. Source: Linda J. Pearson, The 2012 Pearson Report, American Journal for Nurse Practitioners as republished in A. Cassidy, 2013 Health policy brief: Nurse Practitioners and Primary Care, Health Affairs.

Restrictive SOPs have negative implications. The state-to-state variety in SOPs alter the production and utilization of the NP workforce, ${ }^{185}$ and can accentuate the misdistribution of primary care providers. ${ }^{197}$ Nurse practitioner students enroll in colleges from states that encourage NPs' autonomy and use of their range of services at higher rates, ${ }^{185}$ and studies have shown practicing NPs are more apt to move to NP SOP-friendly states diminishing the workforce in certain areas. ${ }^{197}$ One study showed that from 1998 to 2010 the quantity of NPs grew most in states with the least restrictive SOPs and the odds 
of having a NP as a primary care provider were 2.5 times greater in least restrictive states. ${ }^{200}$ Further, most states with SOPs supportive of NPs have vast, sparsely inhabited rural areas where PCP access is limited. ${ }^{183}$

SOPs intertwined with payment regulations for NP care have conflicting influences on overall healthcare cost with a medical practice's profits. Medicare's “incident to billing” permits practices to charge for services carried out by others, including NPs. ${ }^{185}$ Restrictive SOPs, where NPs must be supervised or collaborate with PCPs, foster medical practices use of "incident to bill" to charge physician rates over lower NP rates for service, benefiting the practice, but increasing overall medical cost. The "incident to bill" practice creates financial incentives to hire and retain NPs, but not as independent care providers. This may discourage NPs from working in states with restrictive SOPs. ${ }^{185,197}$ Further, physicians responsible for supervising or collaborating with NPs often have higher malpractice insurance. This leads to not hiring NPs. ${ }^{197}$ To rectify the issues caused by the variety of state NP SOPs, the National Council of State Boards of Nursing called for uniform NP SOPs nationally that permit NPs to practice to the full extent of their training in order to meet the primary care workforce shortage. ${ }^{201}$

Another obstacle impairing NPs as a primary care solution relates to professional identity and status. ${ }^{185}$ According to the AANP, the medical profession's use of pejorative terms to describe NPs marginalizes the expertise of the NP profession and the profession's ability to perform independently. ${ }^{185}$ Labels including “mid-level providers," "physician extenders," and "non-physician providers" delude the perception of NPs' competencies, implying they are sub-standard to certain PCP services that NPs are 
actually capable of providing. ${ }^{185}$ These derogatory labels influence both patient and policy-makers’ perceptions of NPs’ capabilities. ${ }^{185}$

Finally, HPSA ramifications exist on the degree that NPs “measure up” to physicians. ${ }^{202}$ Accordingly, the ACA mandated the creation of an index to identify HPSAs. NP and physician advocates argued their role should be 0.75 FTE of PCPs to account for their influence to community-based primary care. Controversy arose, however, as deeming them 0.75 FTE would sometimes elevate community supply above the HPSA threshold, causing a loss of designation status and federal monies.

\section{Nurse Practitioners and the ACA}

Opportunities for NPs to be a primary care workforce solution are emerging through the ACA and other recent healthcare systems innovations. The ACA, with its emphasis on prevention, chronic care management, and cost effective quality care, makes NPs’ functions more pertinent, along with providing NPs prospects for leadership roles. ${ }^{185}$ The ACA appropriated an annual budget of $\$ 50$ million until 2014 for piloting Nurse Managed Health Clinics (NMHC). NMHCs allow NPs opportunities to lead health centers that serve underserved and vulnerable populations by providing primary care using nursing principles such as patient-centered care. ${ }^{185,187,197}$ PCMHs allowing NPs to fulfill their potential are another primary care workforce solution. PCMHs mesh the vision of creating infrastructures to improve coordination and communication when delivering primary care with the idea of patient-centeredness. ${ }^{185}$ Modern implementation of PCMHs occurred to address the poor quality and high cost of chronic disease care. ${ }^{185}$ Initial PCMH legislation initiated by the CMS in 2006 mandated that only physicians could lead PCMHs. However, the National Committee for Quality Assurance, which now 
defines and designates practices as PCMHs, changed their stance in 2008 to allow NPs or other “clinicians" to lead PCMHs. ${ }^{185}$ Nonetheless, many physician professional organizations refuse to acknowledge NPs as PCMH leaders. ${ }^{185}$

\section{Nurse Practitioners, SOPs, and Retail Clinics}

SOPs may also limit NPs' work in retail clinics. ${ }^{203}$ Retail clinics, found in retail settings such as pharmacies, grocery stores, and big chain retailers, provide diagnosis and treatment for easily identified and remedied medical conditions. ${ }^{204}$ Retail clinics' services are limited usually to 10 simple preventive care and acute conditions that include upper respiratory and urinary tract infections, bronchitis, pharyngitis, sinusitis, otitis media and otitis externa, conjunctivitis, immunizations, screening laboratory tests, and blood pressure checks. ${ }^{204}$ Retail clinics provide affordability, convenience and ease-of-use as they require no appointment and usually are open after hours, weekends, and holidays. ${ }^{205}$ Retail clinics' convenience may discourage emergency department usage. ${ }^{206}$ Currently 47 states operate 1,400 retail clinics, with 5,000 more projected by $2015 .{ }^{203}$ A study looking at 2009 data noted retail clinics constitute a fraction of outpatient visits - approximately 6 million visits (1\%) compared to 117 million visits to emergency departments and 577 million to physician offices. ${ }^{205}$ However, by the end of 2014, retail clinic visits could account for $10 \%$ of all outpatient primary care visits. ${ }^{203}$ NPs are the most commonly used providers in retail clinics, although physician assistants and pharmacists (see below for a discussion of pharmacists in retail clinics) might also provide care. ${ }^{204}$

Some physician groups oppose retail clinics, believing they disrupt continuity of care, ${ }^{207}$ amplify over-prescription of antibiotics, ${ }^{204}$ and so jeopardize patients’ welfare and quality of care. ${ }^{204}$ Three arguments claim retail clinics escalate costs. ${ }^{203}$ First, patients 
may receive a clinic service and then receive the same service by their PCP. Second, if the clinic's quality of care is lower, patients may be hospitalized or access care in an emergency room. Finally, conflicts of interest might occur, as retail clinics both prescribe and fill prescriptions.

Nonetheless, studies have shown positive outcomes for retail clinics. One study compared the outcomes of three acute illnesses, i.e., otitis media, pharyngitis, and urinary tract infection, among retail clinics (most of which were pharmacies or owned by pharmacies), physician offices, and emergency departments. ${ }^{208}$ The study found no quality-of-care differences between the retail clinics and the physician offices, and found that retail clinics had superior quality of care than emergency departments. Further, retail clinics’ cost-of-care were 30\% lower than physician offices and $80 \%$ lower than emergency departments. ${ }^{208,209}$ Another multivariate study compared the risk of two week early return visits for adult patients using retail clinics, regular office care, and an acute care clinic. The return rate among the three primary care outlets did not differ and the authors concluded retail clinics increased access without boosting early return visits. ${ }^{210}$ Another pediatric patient study comparing return visits of otitis media patients between a retail nurse practitioner clinic and a standard medical office found return visits doubled for those in the standard medical office (21\% versus $11 \%, \mathrm{p}<0.001){ }^{211}$

Retail clinics are influenced by NPs’ scope of practice regulations. Because NPs provide the most services at retail clinics, state regulations affect clinic operations. One study showed retail clinics had lower costs than non-retail healthcare settings per average primary care related episode. ${ }^{203}$ The study also found that retail clinic cost-per-patient episode was lower when NPs could practice independent of a physician, although NPs 
having prescribing privileges resulted in slightly higher cost compared to not having this privilege ${ }^{203}$ If SOPs hinder NPs in retail clinics, then they may not be able to meet patient needs causing patients to seek treatment in less cost-effective settings. Further, regulations mandating that retail clinics need physician supervision over NPs increase cost. With the usage of retail clinics increasing, the 2014 national cost savings from retail clinics could be $\$ 1.8$ billion, ${ }^{203,212}$ and with all NPs practicing independently, an additional $\$ 810$ million savings is projected to occur. ${ }^{203}$ According to this study, permitting NPs to practice unimpeded in retail clinics would increase the efficiency of the healthcare system and would not lower the quality of care. ${ }^{203}$

Kentucky's retail clinics are primarily located in the central and western parts of the state and in urban areas. ${ }^{10}$ Most of eastern Kentucky lack these clinics, which is where most of the current PCP needs exist. ${ }^{10}$ To expand retail clinics, it is suggested that incentives be used, such as tax breaks, Medicare reimbursements for retail clinic services, and the encouragement of private sector partnerships to encourage the private sector expansion of retail clinics into rural areas with the highest PCP needs. ${ }^{10}$

\section{Find Someone Else: Physician Assistants}

Physician assistants (PAs) afford another solution to increase the primary care workforce. PAs are certified and licensed healthcare professionals prepared to work under medical supervision. ${ }^{213}$ They perform a variety of medical services usually in collaboration with or under a physician’s direction, including physical examinations, diagnosing and treating sicknesses, ordering and interpreting tests, aiding in surgery, writing prescriptions, and delivering patient education, health promotion and preventive healthcare. ${ }^{213,214}$ Like NPs, PAs' emergence sprung in the late 1960s to fill physician 
shortages, specialty maldistributions as physicians shifted to specialty practices ${ }^{186}$, and geographical maldistributions. ${ }^{215}$ After the Korean War, the PA profession took returning Vietnam veteran medics and trained them to be PAs with the hopes they would play important roles in primary care. ${ }^{186,215,216}$ PAs' influence on unmet healthcare needs was meaningful, although diminished by there being fewer than 20,000 actively practicing PAs until the 1990s. ${ }^{216}$ A "primary care"-focused healthcare system that became vogue in the 1990s called for the PA profession to increase its numbers. ${ }^{216}$ Currently there are 86,700 PAs practicing in the US. ${ }^{217}$ Coinciding with their physician directors/ collaborators, 33\% of PAs worked in primary care (with much of their other specialty practice patterns similar to those of physicians) and account for roughly $10 \%$ of the US primary care workforce. ${ }^{186}$ Geographically, PAs are less likely to work in rural settings than urban settings; usually the larger the Metropolitan area, the greater the PA concentration exists. ${ }^{218}$ However, at least 9\% of PAs work in rural practices with the vast majority of PA rural practices being primary care. ${ }^{218}$

Several pertinent characteristics enhance PAs as being a healthcare workforce solution. First, PAs are flexible and adaptable. ${ }^{186,213}$ All PAs get training in primary care and other specialties, so even though they may practice in one specialty, they can easily transition to another. ${ }^{186,213}$ Almost half have reported practicing in primary care during their careers and report working in two or three specialties over their work lives. ${ }^{186}$ Further, PAs train in a broad range of clinical settings; ${ }^{213}$ their adaptability allows them to locate to rural HPSAs ${ }^{213}$ and practice somewhat autonomously using telemedicine or other technology. ${ }^{213,216}$ PAs’ nimbleness allows them to easily address specialty and 
geographic maldistributions facing the US, ${ }^{186,213,216}$ particularly if state SOPs and other regulations are favorable. ${ }^{186}$

PAs' educational programs are brief and on average take two years, with one year of training being in a clinical setting. ${ }^{186,213}$ Programs vet students based on having patient care skills and usually four years of experience, ${ }^{219}$ along with knowledge in the basic and behavioral sciences. ${ }^{213}$ PAs’ postgraduate residency programs are non-compulsory and most last only 12 months. ${ }^{186}$ The brevity of PAs’ education allows trainees to enter the workforce enabling a more immediate solution to the primary care workforce dilemma.

Once trained, according to one literature review, ${ }^{218}$ PAs can perform $85 \%$ to $90 \%$ of services conventionally provided by PCPs, and on average, complete 61 outpatient visits per week, while physicians complete 74 visits. The PA/physician FTE ratio was 0.83. Further, single practice physicians who employ PAs were compared with those who did not; physicians employing PAs augmented their average quantity of weekly patient visits (127 versus 116), reduced work week hours (47 versus 49), and boosted net income (\$220,000 versus \$186,900), despite lower office visit fees. Other studies have shown PAs as cost beneficial. A multivariate study of 12,700 medical office visits with patients having acute medical disorders that compared PAs and physicians showed no statistical difference between PAs and physicians in use of laboratory and imaging costs, and PAs' episodic costs for every condition was less, indicating PAs delivered care for less, possibly due to their lower salaries. ${ }^{218,220,219}$

Another literature review evidenced that PAs' quality of care is comparable to physicians' quality of care for patients with similar conditions, and PAs also provide high levels of patient satisfaction. ${ }^{219}$ Further, PAs have similar or less risk than physicians in 
being liable for malpractice according to actuarial studies. ${ }^{218,219}$ Patients’ acceptance of PAs is high, ${ }^{219}$ especially when it alleviates time delays in seeing a PCP, ${ }^{215,221}$ when patients had prior exposure to PAs, ${ }^{221}$ or when patients had uncomplicated health ailments. $^{215}$

\section{Obstacles Facing Physician Assistants as a Solution to Primary Care Shortage}

Three obstacles will impact PAs’ capacities to influence the healthcare workforce shortage. ${ }^{186}$ First, interest in the PA profession and PA training applicant pool since 2007 has risen annually between 11\% and 20\%. However, the increase from 2012 to 2013 was only $6 \%(n=19,786)$, suggesting that the growth is declining. Coinciding, an additional 65 PA educational programs are expected to seek accreditation by 2016, bringing the number of PA programs to 238. Hence, quality PA aspirants must continue to increase proportionally as the overall volume of PA programs increases. ${ }^{186}$

HRSA introduced one solution to the falling interest in PA careers and the primary care workforce shortage as a whole. ${ }^{222}$ The Primary Care Training and Enhancement (PCTE) Title VII program awarded funding for the educational enrichment of PAs among other primary care providers. In 2012, the Physician Assistant Training in Primary Care Program, a funding program branch within the PCTE, offered PA educational institutions increased grant scoring for colleges rewarding veterans with military healthcare training and experience. ${ }^{222}$ Schools accommodating the unique needs of veterans, i.e., career counseling, separation planning, careers that transition between military and civilian employment, and provide educational credit for military knowledge and experience, are most suitable to receive grant funding. ${ }^{222}$ Of course, PA education programs not receiving funding also should market to the 50,000 military medical 
personnel discharged between 2006 and 2010 to help alleviate the primary care workforce shortage. ${ }^{222}$

Second, PA educational programs face shortages of faculty, clinical preceptors, and clinical training sites. With the demand for PAs' increasing salaries, many PA faculty chose to go back to clinical practice. In 2010 and 2011, 7\% of PA faculty returned to become clinicians. Further, the average age of PA faculty is 50 years with half over the age of 50; shortages will be amplified due to faculty reaching retirement age. ${ }^{186}$ The Physician Assistant Educational Association has initiated several mechanisms to increase faculty recruitment and retention, including providing financial incentives and recognitions programs. ${ }^{186}$

Third, state legislators, regulators, and health workforce planners' allowance of physicians flexibility in delegating PAs’ responsibilities must be addressed. ${ }^{186}$ Inherently, PAs are less antagonistic toward achieving autonomy from physicians than their NP counterparts which makes them appealing to medicine. ${ }^{213,216}$ According to the American Academy of Physician Assistants, ${ }^{223}$ each PA's scope of practice is based on education and experience, facility policy, state law, and physician delegation. Of the four determinants of PAs' SOPs, the latter two are most pertinent. Starting in the early 1970s, PA laws allowed supervising physicians to delegate responsibilities based on the PA's capabilities. The “delegatory” laws changed, however, to become more regulatory as state legislators and licensing boards created checklists of services that PAs could perform. In the mid-1990s, for most states these checklists regulations began to reverse back to delegatory SOPs; currently, in most states, the PAs' SOP is determined by the delegatory decision made by the supervising physician. ${ }^{223}$ Nonetheless, physicians having 
more PA delegatory power could still help increase efficiency in the healthcare workforce. ${ }^{186}$ In Kentucky, for example, the 2013 passage of House Bill 104 eliminated the constraint that PAs must have a physician on site to perform their functions; in effect, physicians will only have to be available by phone. ${ }^{10}$ Similar discussions are going on across the United States. ${ }^{10}$

\section{Find Someone Else: Pharmacists}

Pharmacists' contributions to alleviating the primary care workforce shortage could be important. Pharmacists’ training includes more than dispensing prescriptions and offering medication counseling. Their knowledge of pharmacology, pharmacokinetics, pharmaceutics, and pharmaco-economics give them greater knowledge than physicians in the area of medication management services. ${ }^{224}$ This knowledge is vital for the US healthcare system and the battle to treat the rising aged population (and others), many with chronic diseases and multiple comorbidities who take five or more pharmaceuticals monthly. ${ }^{225}$ Pharmacists' ability to manage patients’ complex diseases and their treatment regimens can help fill the gap that is occurring as primary care services rise due to increased outpatient surgeries, briefer hospital durations, and decreased recuperation time. ${ }^{225}$

Pharmacists, since 2004, can earn a PhD degree and have certain training commonalities with NPs and PAs. ${ }^{209,225}$ Besides pharmacology, pharmacists’ training includes obtaining medical histories, completing health screening and prevention assessments, executing and interpreting diagnostic and laboratory tests, instructing on health and nutrition, screening and referring patients to specialists and other healthcare providers, and empowering patients to be in control of their healthcare. ${ }^{225}$ Training 
emphasis is also placed on fostering health improvement and wellness and disease

prevention with other members of an inter-professional team of healthcare providers. ${ }^{225}$ Although pharmacists, NPs, and PAs have overlapping qualifications, pharmacists' training emphasizes therapeutics more than NPs' and PAs' training which emphasizes diagnostic skills. These diverging emphases allow the professions to complement each other for a team-oriented approach to patient care as presented in a PCMH. ${ }^{225}$

\section{Is There Is a Sufficient Supply of Pharmacists?}

Two academic pharmacist experts presented conflicting views regarding the supply and demand of pharmacists. ${ }^{209,226}$ One expert noted since 2008 studies have shown a sufficient supply or even an oversupply of pharmacists in the next 10 years. Further, longitudinal studies have shown many pharmacists continue working after retirement age. Accordingly, having sufficient membership capacity can allow pharmacists to perform new functions, along with fulfilling their traditional medication management responsibilities. ${ }^{209}$ However, the Pharmacy Workforce Commission stated that pharmacists' demand will go unchanged, and the demand scenario and workforce projection is based on pharmacists fulfilling traditional dispensary roles, along with increased time spent on counseling and educating patients which would be offset by greater use of technology and pharmacy technicians. ${ }^{226}$ Consequently, the Workforce Commission's projection of a sufficient workforce does not account for pharmacists' involvement in non-dispensing roles. ${ }^{226}$

\section{Pharmacists and Retail Clinics}

Pharmacists' roles in easing primary care workforce shortages may take two avenues. The primary care-related training that pharmacists receive qualifies them to 
provide these clinical services at retail clinics such as community-based pharmacies. ${ }^{209}$ Community pharmacies and pharmacists can provide diagnostic, screening, and interpretation of these tests. ${ }^{209,227}$ Examples include testing for HIV, pregnancy, cholesterol, as well as assessments of pre-diabetes and hypertension. Once conducted, the pharmacists can provide education or referrals. ${ }^{206,209,227}$ Pharmacists offer the provision of preventive health and wellness services such as diabetes prevention and management, childhood asthma education, and obesity education. ${ }^{209}$

Pertinent to pharmacists’ primary care skills is that $90 \%$ of the US population lives within 5 miles of a retail pharmacy. ${ }^{209,228}$ Pharmacists have successfully provided immunizations and vaccines at times more convenient than in traditional settings. ${ }^{209,229}$ One study showed that 30\% of immunizations (out of 6,250,000 annual inoculations) from Walgreens ensued during evenings, weekends, or federal holidays, ${ }^{209,229}$ and over 1 million immunizations occurred during typical lunch hours. ${ }^{229}$ The study just mentioned, and the Mehotra, et al., study mentioned above under "NPs and Retail Clinics,” which included some pharmacists as primary care providers, demonstrate that pharmacists are qualified to meet many primary care needs facing the US.

\section{Obstacles Facing Pharmacists in Retail Clinics}

SOPs, like NPs and PAs, regulate pharmacists. In 45 states, pharmacists and physicians are regulated to cooperate in a collaborative drug therapy management (CDTM). CDTM entails physicians and pharmacists combining their expertise for optimal outcomes through proper medication use and enhanced patient care services. ${ }^{34}$ In five states, pharmacists have some degree of latitude to prescribe medicine. Pharmacists’ CDTM functions generally include: (a) initiating, modifying, and monitoring drug 
therapy; (b) ordering and performing laboratory tests; (c) evaluating patients' therapeutic reaction; (d) providing medication education and counseling; (e) administering medications. ${ }^{225}$ However, the scope of CDTM varies among states and many do not utilize pharmacists' capabilities fully. ${ }^{230}$ For example, 49 states give pharmacists vaccination privileges; however, states deny the use of other proficiencies. ${ }^{225,230}$

\section{Pharmacists and Team-Based Care}

Pharmacists’ roles may incorporate being a part of community-based interdisciplinary health teams, medical homes, and ACOs. ${ }^{209,224,226}$ Pharmacists' teambased roles center on quality improvement and providing complementary skills to team members in order to improve physician productivity. ${ }^{226}$ Physicians often have limited time to effectively address medication with patients. ${ }^{226}$ One study notes physicians average 49 seconds discussing new medications with patients. ${ }^{226}$ Further, many patient medication histories are erroneous. Hence, patients become susceptible to unsuitable or harmful medication intake. ${ }^{226}$ Pharmacists, as care team partners, can collaborate with physicians on patient medication management and develop long-term relationships with patients and their relatives. These personal bonds permit pharmacists to "focus on patient-specific prescribing options, actual medication use at home, pharmacotherapy management and monitoring, and follow-up on the achievement of desired medication outcomes. ${ }^{\text {226 }}$ Pharmacists' interactions with the unhealthiest patients can reduce the patient's and society's overall healthcare costs. ${ }^{226}$ One literature review noted several quality and cost-based measures improving when pharmacists provide medication management services (MMS) in ACOs and integrated care teams. ${ }^{226}$ One study that examined four clinics showed that sites without MMS had 11\% more spending growth 
and failed to achieve treatment goals at rates comparable to sites with MMS (17\% nonMMS versus 39\% MMS); further, over 4,000 medication problems were corrected in the MMS clinics. ${ }^{226,231}$ Another study looking at 4,800 patients over 10 years showed that patients receiving pharmacist-provided MMS achieved a 55\% improvement in chronic conditions, with an estimated cost savings of $\$ 86$ per encounter. ${ }^{226,232}$ If pharmacists' MMS and the corresponding quality improvement gains can eliminate patients from returning to their medical homes and ACOs at lower rates, then better care can lead to lower demands on primary care services.

\section{Obstacles Facing Pharmacists in Team-Based Care}

Pharmacists confront policy obstacles in collaborating with others for team-based care. $^{226,233}$ Policymakers need to alter Medicare Part B, much of Medicare Part D, Title 18, Part E, Section 1861 of the Social Security Act, and commercial health plans, so pharmacists can have provider status in their implementation of MMS ${ }^{209,226,228}$ Currently, physician practices have no means to pay for pharmacists' MMS as medications are "pharmacy benefits” encompassing drug coverage and utilization, but payment schemes

do not incorporate compensating MMS task. ${ }^{234}$ Payment for MMS task now consists only of "innovative payments" like capitated care management fees or quality improvement performance incentives. However, reluctance of ACOs and physician practices to hire pharmacists will occur as having recognized provider status is linked with payment. ${ }^{226,233}$ In summary, whether pharmacists' roles incorporate working in pharmacies, retail clinics, medical homes, or ACOs "state policies fall short of ensuring that pharmacy workers are properly positioned to engage in such activities as MMS, preventive and public health 
services, and the management of increasingly costly and complex pharmaceutical agents."209

\section{Finding Someone Else and Team-Based Care}

Team-based care, as defined by the Institute of Medicine (IOM), is "the provision of health services to individuals, families, and/or their communities by at least two health providers who work collaboratively with patients and their caregivers - to the extent preferred by each patient - to accomplish their goals within and across settings to achieve coordinated high-quality care.”235 The goal of team-based care is “to keep patients healthier at lower costs by enabling providers to work efficiently at maximum license.”236 Two promising team-based primary care models developing from the ACA are the PCMH and the ACO. Both models' success depends upon systematic change in primary care delivery where innovative new roles emerge, team members’ capabilities are leveraged, and new technology is utilized. ${ }^{182,237}$ In effect, the concept begins with the patient as a team member and then connecting the patient and family to the healthcare team, i.e., physicians, NPs, PAs, and pharmacists. ${ }^{238}$ PCMHs and ACOs seek to reduce physician services not directed toward the better care of the patient, diminish the fee-forservice payment structure, and minimize malpractice suits. ${ }^{238}$ Further, a reduction in patient-induced demand also may occur as grand-aides (discussed below) and other nonprofessionals provide in-home patient preventive care and health education before they re-enter clinics, practices, or emergency rooms. ${ }^{238}$

According to the Robert Wood Johnson Foundation LEAP Project (Learning from Effective Ambulatory Practices) that identified the US 25 most high-performing primary care practices, core members of the most successful PCMHs include NPs and PAs who 
functioned as full primary care clinicians. ${ }^{239}$ However, LEAP and other sources, ${ }^{182}$ identified other professions that increase the effectiveness of patient care. Medical assistants (MAs) roles have expanded to include administrative and nursing roles, ${ }^{240}$ along with panel management responsibilities and health coaching. ${ }^{182}$ For example, MAs perform chart reviews to identify gaps regarding patients’ chronic and preventive care needs; after team communication with the practice's primary care providers, MAs provide information and coach patients to be active partners in their care. ${ }^{182,239}$ Studies show that MAs assuming panel management responsibilities improve rates of colorectal cancer screening and improve diabetes and depression patient outcomes with those not receiving MA care. ${ }^{239}$ According to the LEAP authors, MAs in many states can undertake any medical duty under a physician’s supervision. ${ }^{239}$ However, the actual citation they referenced cited only California as allowing MAs to undertake any medical duties under a physician's supervision and did not address other states as giving MAs these responsibilities. $^{241}$

LEAP researchers and others note and advocate for the changing of registered nurses’ (RNs) primary care roles. ${ }^{182,238}$ RNs involvement in patient care and management is deepening as they adopt duties in managing chronic conditions like diabetes, hypertension, and asthma. ${ }^{239}$ Responsibilities include patient medication support, making home visits, coordinating complex specialty care, assisting clinicians with multiple diagnoses, polypharmacy, and hospital and emergency department services. ${ }^{239}$ One expert argues for the alteration of experienced registered nurses' SOPs to allow more independent responsibility if they pass proficiency tests. ${ }^{238}$ 
A third team-based care labor innovation is community health workers (CHWs) and grand-aides. These non-clinical workers provide health education, make home visits and follow-up phone calls. ${ }^{188}$ Grand-aides have both experience and training in medical care prior to becoming grand-aides, and then they receive 200 hours of additional training. ${ }^{238}$ These workers, in collaboration with their nurse supervisors, provide patients with chronic disease management as well as primary and preventive care instruction. ${ }^{238}$ Studies have shown that clinics that leverage grand-aides have reduced patients' congestive heart failure readmission rates by $50 \% .{ }^{238}$ Another study, conducted by the physician responsible for the grand-aide idea, evidenced that 62\% (290/468) of a Houston clinic's pediatric patients could have been seen via a grand-aide home visit and 74\% (297/402) of rural Virginia’s ER patients could have been seen in a similar grand-aide manner. ${ }^{242}$ Total per visit cost savings using a grand-aide instead of the clinic or ER is $\$ 183$ and $\$ 158$, respectively. ${ }^{242}$ Moreover, one study using three different assumptions estimated that from $50 \%$ to $77 \%$ of preventive care and $25 \%$ to almost $47 \%$ of chronic care can be accomplished by non-clinician team members which could increase a PCP's panel size between 1,387 to 1,947 patients. The latter estimate approaches a twofold increase in the average US physician panel size of about 2,300. ${ }^{134}$

The ACA requests a tie between clinicians and patients; community health workers and grand-aides could be this link. ${ }^{238} \mathrm{CHWs}$ can assist in patient insurance enrollment and can navigate relationships among providers across different settings such as EDs, primary care, and specialists' offices. ${ }^{206}$ Further, community health centers, which often function as PCMHs and provide indigent patient care, are projected to grow 
as the ACA is continually implemented. Their cost-effectiveness success is due to their employing lower-cost non-clinical workers like CHWs and grand-aides. ${ }^{206}$

Training health team workers to function interdependently and not in silos reflects an obstacle facing team-based care. The most demanding challenges in implementing a PCMH are regulatory and cultural preferences, enforced by the fee-for-service reimbursement system. ${ }^{243}$ Regarding cultural preferences, physicians often refuse to relinquish autonomy, work as team members, share patient responsibility, office space, or examination rooms. ${ }^{235}$ Pressures surface from the overlap of different professional roles, different professional workloads, and the different professions' perceived competence. ${ }^{243}$ ACOs and PCMHs have complementary features including fostering electronic records usage, patient registries, and patient education. ${ }^{244}$ However, they differ as ACOs have incentives for providers to work collaboratively to reduce costs and improve quality such as payment strategies like bundling and capitation, while PCMHs do not. ${ }^{244}$ Accordingly, PCMHs primarily use fee-for-service reimbursement systems that maximally compensate PCPs for one-on-one patient interaction, while NPs or PAs' patient visits received reduce compensation and non-physician personnel services are often not reimbursed. ${ }^{244}$ Hence, estimating (and then eliminating) the primary care workforce shortage entails more than projecting the needed number of health professionals. It also includes making forecasts based on each profession's capabilities, assessing the available existing and anticipated workforce, and developing payment mechanisms that encourage diminishing healthcare costs and bettering patient outcomes. ${ }^{240}$ 


\section{Train More: “Pipeline” Medical Educational Programs}

Medical “pipeline” educational programs may address the physician workforce shortage, particularly in rural HPSAs and URMs. ${ }^{180}$ These initiatives encourage

alliances among K-12 schools, undergraduate colleges, medical schools, and other health professional schools to enrich curricula, afford first-hand learning opportunities, and improve student academics beginning in middle or high school. ${ }^{180}$ Information concerning these programs and their outcomes are limited.

Kentucky’s Professional Education Preparation Program (PEPP), established in 1980 by the Kentucky General Assembly, is one such “pipeline” program designed to increase the physician (and other health professional) workforce. Two studies coauthored by this study’s author describes the program and its academic outcomes. ${ }^{181,245}$

Accordingly, PEPP participants engage in two summer residential workshops conducted at the University of Louisville and the University of Kentucky. The pre-college summer workshops recruit HPSAs and URM student groups to attend these programs after their senior years of high school. The program delivers academic enhancement in college-level mathematics and science, occupational exploration, a clinical introduction to medicine and dentistry, preparing for the pre-health curriculum, and counseling for admissions requirements and moving to post-bachelor programs. Instruction also includes ways to aid an effective transition to college. Students also serve at healthcare organizations and participate in community service. PEPP's second module, occurring after two years of college, stresses entrance exams and application development preparation for the medical and dental school admissions process. During this program, students live, attend classes, and take practice exams together. Students also engage in sessions emphasizing 
completing applications. The development of participants' oral and written communication skills is also emphasized.

Between 1997 and 2009, of the 1,080 participants who earned a bachelor's degree, 739 (69\%) went on to pursue a graduate or professional degree in any field, 631 (58\%) went on to pursue a graduate or professional degree in the clinical sciences, and 533 (49\%) have earned or are in training for a medical or dental degree. ${ }^{181}$ Further, over half of those who became physicians are currently practicing in rural areas of Kentucky (59 out of 111). ${ }^{245}$ This study’s findings and PEPP’s positive academic outcomes help validate the value of PEPP programs in imparting career exposure, academic enhancement, and sponsorship for rural and minority pre-health students. PEPP participants' college graduation rates are notable as participants succeed in their professional educational goals.

Common themes of PEPP and similar programs may boost the retention of rural physicians. ${ }^{10}$ These themes include (a) encouraging investment in pre-college afterschool and summer programs in rural regions that foster student enthusiasm around medical profession careers, with an emphasis on rural practice in order to establish retention; (b) providing medical field mentors throughout the four-year college education experience whom the students shadow to acquire a better understanding of the physician experience; (c) using preferential-based mechanisms to allow students of these programs to gain guaranteed or early acceptance into medical school in order to build a strong rural pipeline. ${ }^{10}$ 


\section{Undergraduate Medical Education Regional Rural Health Track "Pathway” Programs}

Another related solution to improve the rural pipeline and corresponding physician rural retention are UME rural health track programs that allow medical students to undergo their clinical rotations and residencies in rural areas. Kentucky has two such programs: the University of Louisville’s Trover Rural Track program and the University of Kentucky’s Rural Physician Leadership Program. ${ }^{10}$ Pikeville University’s osteopathic medicine program also can be considered a regional health program. ${ }^{10}$ The author of this study evaluated the impact of the University of Louisville medical students' participation in the Trover Rural Track Program and their residency choices and practice location selections. ${ }^{20}$ Medical students who participated in the program were 4.5 times more likely to choose family medicine and over six times more likely to choose to work in a nonmetropolitan area. These findings emphasized the value of rural medical training to place rural students into rural practice. These data support the worth of a small regional rural clinical campus in enhancing the affinity model of retaining rural students back into rural practice. ${ }^{20}$ The program's positive outcomes (and other similar programs) encouraged the financial investment and political capital of expanding these programs. ${ }^{10}$

\section{Train More: Shorten the Duration of Medical Training}

The AAMC has urged medical schools to increase enrollment by $30 \%$ to address current and predicted physician shortages. ${ }^{49}$ The typical minimum educational time to practice medicine is 11 years - four years of pursuing a bachelor's degree; four years of medical education; and at least three years completing an accredited residency. ${ }^{246}$ Some academic physicians note that with clinical sciences and medical practices’ growing complexity, no physician can be competent in research skills and in all aspects of clinical 
care, and, consequently, recognize that multidisciplinary teams coincide with effective care. $^{236,247}$ The team-based models’ emergence permits physicians’ roles and expectations to change, along with possible opportunities to change and shortened traditional medical training. ${ }^{236,247}$ Condensing medical education’s duration may boost physician supply, particularly in primary care, and reduces personal and societal expenses in generating doctors. $^{247,248}$

\section{Shorten Training: Combined Premedical School Curriculum/Medical School Programs}

One source notes that approximately 30 US medical schools have implemented six- or seven-year medical programs that reduce premedical training (the traditional bachelor's degree) from four years to 2 to 3 years. ${ }^{247}$ Analogously, some European medical schools have six years of training following high school graduation. A 1997 literature review evidenced that, between 1966 and 1996, combined bachelor/medical school programs achieved competency levels equivalent to traditional medical students concerning United States Medical Licensing Examination board scores (USMLE), had lower dropout rates, and, as practicing physicians, their patients had similar outcomes. $^{247,249}$

\section{Shorten Training: “Pathway” Programs, Combined Undergraduate Medical Education/Graduate Medical Education Based on a Competency-Based Curriculum}

Some medical professionals argue for a medical education competency-based model, in contrast to the traditional mentality of undergraduate medical education lasting four years and residencies lasting three (or more) years. ${ }^{236,250}$ A competency-based curriculum (CBC) has been recommended by the American Osteopathic Association and the American Association of Colleges of Osteopathic Medicine to generate physicians 
capable of producing better healthcare outcomes and to more efficiently produce PCPs. ${ }^{250}$ The UME/GME pathway would include five principles: (a) a focus on team-based patient centered care; (b) a focus on a competency-based curriculum; (c) the educational experience would imbibe a belief in life-long medical education, as continuous throughout one's career; (d) the educational administration would entail UME/GME collaboration; and (e) concentrate on healthcare delivery science positioning PCPs to be inter-professional healthcare team leaders. ${ }^{250}$

Admissions to a CBC osteopathic pathway program would be based on students' aptitude for success and their commitment to primary care. ${ }^{250}$ Students' UME and GME advancement would occur as students demonstrate competencies in the areas being trained; students' responsibilities would increase as they demonstrate the ability to handle more charges. ${ }^{250}$ Emphasis on producing physicians would be based on mastering physician-related competencies and not on time. Consequently, the time for generating PCPs could be reduced from the traditional 11 years of study (post-high school) to 9 years. $^{250}$

Addressing policy issues is necessary for a CBC’s acceptance. Two key policy issues are accreditation and financial considerations. ${ }^{250,251}$ For a CBC pathway to be permissible, the accreditation-based criteria for osteopathic institutions of four years of UME training and 130 weeks of GME training would have to be eliminated. ${ }^{250,251}$ Board certifications of physicians based on competencies and not on a predetermined duration of study would have to be legitimated. ${ }^{250,251}$ In effect, the competency-based curriculum's success depends on medical school accreditors, graduate medical education accreditors, and board authorities to sanction this concept. ${ }^{250,251}$ 
Financially, medical schools' and GME’s funding hails from numerous avenues, including tuition, state government, scholarships, and Medicare in funding the separate parts of a physician’s training. ${ }^{250,251}$ However, competency-based education would integrate funding, possibly causing change in the funding streams' allocation; CBC pathways call for more UME participation in the GME programs' administration. ${ }^{250,251}$ Suggestions, like redistributing GME funding to the trainee (such as a voucher system) and not the institution, could be one of many innovative funding mechanisms to address the financial aspect of competency-based education. ${ }^{250}$ Moreover, one would assume that the underlying concepts and issues applicable to osteopathic training are similar to allopathic training. (Interestingly, CBC pathway programs for allopathic training are only scantily mentioned in the literature. ${ }^{236}$ )

\section{Shorten Training: Undergraduate Medical Education}

Reducing the traditional four-year undergraduate medical education (UME) program from four to three years offers another, albeit controversial, solution to shorten medical education. ${ }^{236,247,248,252}$ Some experts contend that Flexner’s 1910 model of medical education that edicts two years of both preclinical science and two years of clinical training is unwarranted. ${ }^{247,252}$ Medical schools such as Duke University and the University of Pennsylvania take basic science courses in the first year or year and a half, respectively. Further, Harvard University’s medical school provides all clinical training during a 15-month time period. Other US medical schools recently initiating three-year programs for select candidates include New York University, Mercer University, and Texas Tech University, while Louisiana State University, Indiana University, East 
Tennessee State University, and the University of Kentucky are considering three year programs. $^{252}$

Outcomes data on these training programs are either limited or not comprehensive. ${ }^{247,253}$ One advocate of this model noted that no evidence exists that demonstrates that these medical students will perform worse than traditional UME students on USMLE board examinations, placement in residency programs, or other significant metrics of competence. $^{247}$

\section{Shortening Undergraduate Medical Education: The Positive}

Shortening UME offers numerous benefits. First, student debt is reduced by $25 \%$ in a 3-year UME model; the debt reduction coincides with further earnings from starting practice one year earlier. $^{252}$ Second, the duration of graduate medical education has markedly increased, causing “age creep” for physician entry into medical school. That is, compared to 30 years ago, physicians’ professional entry age is much older. Reducing any medical education training stage duration permits physicians to start practice earlier $^{236,252}$ which might diminish physician burnout and women’s fertility concerns associated with delay childbearing. ${ }^{236}$ The idea of starting practice sooner with less debt might potentially be an enticement for students to choose medicine as a career that otherwise would not. Finally, medical schools using the three-year model employ a linkage between the medical school and residency programs at their own institutions. ${ }^{252}$ This UME-GME continuum promotes an opening to track longitudinal competencybased learning and clinical outcomes. ${ }^{252}$ 


\section{Shortening Undergraduate Medical Education: The Negative}

Arguments against shortening medical school training also exist. ${ }^{248}$ In the 1990 s, 67 US medical schools implemented combined BA-MD six or seven year programs. By 2011, only 20\% of these programs still offered abbreviated training. Additionally, time reduction occurs early via the BA degree, not in reducing the four-year medical school curriculum. Issues revolve around students and faculty feeling pressured by the concentration of material. In one discontinued condensed program, one-quarter of students volunteered for a one- to two-year training extension and often experienced stigmatization as being deficient for not completing the compressed program. Students successfully completing the abbreviated program often were exhausted, having studied non-stop for $95 \%$ of the three years in the program. Faculty frustration also surfaced toward the curriculum inadequacies due to material removed. Moreover, both faculty frustration and curriculum inadequacies will worsen as medical knowledge increase. Further, although advocates for briefer medical school programs believe students can meet training requirements, this is debatable. One recent study of residency program directors noted that medical students completing four years of traditional training were wanting in the organization and application of medical knowledge to patient care, professionalism related to assuming responsibility and working unsupervised, and overall professional maturity; shorter medical school durations would intensify these issues. ${ }^{254}$ Students enrolling in accelerated programs and choosing primary care also have been a disappointment. Students in combined BA-MD programs have entered primary care at higher rates, but not near the anticipated rates of $60 \%$ to $75 \%$. Overall, the proportion of students consistently choosing primary care did not increase. Consequently, shortening 
the medical school curriculum opponents argue that only a select, elite few students would benefit from the shorter training. ${ }^{236,248}$

\section{Shorten Training: Graduate Medical Education}

As previously mentioned, US medical school enrollment is commissioned to increase by 30\%. However, medical school enrollment must coincide to available core GME training programs. Based on a four-year residency, roughly 30,000 new GME positions would be needed in core specialty programs by decade's end just to sustain the present physician workforce supply/demand ratio. ${ }^{255}$ Currently, Medicare subsidizes approximately 90,000 residencies, costing taxpayers $\$ 9$ billion annually in direct and indirect medical education payments. To create the 30,000 new GME slots, an increase of \$3 billion (or \$12 billion total) would be necessary, which contradicts some policymakers’ goals to decrease Medicare spending for debt reduction. ${ }^{247}$ Further, many of the roughly 150 sponsoring medical schools or teaching hospitals would still experience residency constraints regarding the programs’ maximum amount of residents permitted due to accreditation requisites. ${ }^{255}$

One approach to address the GME position shortage is shortening the physician training length for core specialties. ${ }^{247,255,256}$ In the mid-1970s, the year-long internship removal across all specialties decreased total educational time without evident harmful effects on GME training quality. ${ }^{255}$ Regarding family medicine, residency reduction from three to two years has been proposed. ${ }^{255,256}$ Completing family practice residencies usually take three years, which mimics pediatrics, internal medicine, and other primary care specialties’ training duration. ${ }^{256,257}$ Family medicine residents’ current training involves comprehensive skills in infant care, pediatrics, OB/GYN, internal medicine, 
aged care, psychiatry and behavioral sciences, and population and community-based

public health. ${ }^{256,257}$ Family medicine training also prepares residents to function in settings like family health centers, and hospital areas such as childbirth wards and intensive care units. ${ }^{256,257}$

\section{Shortening Graduate Medical Education (Family Medicine): The Positive}

One public supporter for reducing the family medicine residency training duration proposed limiting family practitioners' roles and settings to practicing in only ambulatory settings. ${ }^{256}$ This supporter noted several positive profession-related, personal, economic and societal reasons for a family medicine residency training duration reduction of one year, ${ }^{256}$ with some reasons possibly enticing more medical students to enter family medicine. First, by being ambulatory-based PCPs only, family practitioners’ work in a dominant setting streamlining a distinct professional identity, which is in a confused state ${ }^{256,257}$ while other PCPs work in settings in which they excel, such as the intensive care unit, the hospital, or labor and delivery. ${ }^{256}$ Accordingly, a family practitioner would serve primarily as the healthcare systems' gatekeeper and maintain the capacity to integrate patients into healthcare services. ${ }^{256,257}$ Second, the family medicine profession’s acceptance of this idea may be boosted by the fact that ambulatory care is the principal healthcare market in the US with over 217 outpatient monthly visits compared to eight patient monthly visits per 1,000 persons. ${ }^{256,258}$ Third, enhancement of family medicine’s competition to satisfy the primary care shortage gap will occur if the more competent family medicine providers, compared with NPs and PAs, enter the workforce at greater rates due to shorter training duration. Fourth, medical students considering family medicine residencies, as well as other specialties, could be given the option in family 
medicine residencies to train a third or fourth year to develop ICU, hospital, or labor and delivery practice skills, along with other skills. A shorter training duration, along with additional training options “down the road," could entice more medical students to enter family medicine and primary care. Fifth, family practitioners’ smaller salaries, compared to other specialties, could make a training duration reduction favorable to debt-ridden medical students. Clearly entering practice early and earning \$100,000 annually compared to the $\$ 40-50,000$ residency salary is significant. Additionally, more income acquired earlier in one's working life would accrue and compound at greater rates over the smaller residency income throughout the physician's career. (See the section, “Shortening Undergraduate Medical Education: The Positive” (page 166) in this chapter, that addresses UME debt relief.) Finally, and as mentioned above, society benefits with a two-year family practice residency. ${ }^{256}$ Taxpayers subsidize GME education through Medicare payments; theoretically, training costs for two years would be one-third the cost of three years. ${ }^{247,256}$ Moreover, reallocations of savings to incentivize new family practice physicians to serve in HPSAs could decrease geographic maldistributions. ${ }^{256}$

Regarding pediatrics and internal medicine, it is noted that two-year residencies can also train competent physicians. ${ }^{247}$ Accordingly, third-year activities, such as supervising, teaching interns, and performing research, though important, are nonessential to clinical practice. ${ }^{247}$ Moreover, eliminating a residency’s third-year will compel residency training programs and hospitals to modify programs securing residents' clinical competence. ${ }^{247}$ 


\section{Shortening Graduate Medical Education: The Negative}

One significant objection to two-year residencies is the Accreditation Council for Graduate Medical Education’s (ACGME) 2002 established core competency criteria regarding practice-based learning and improvement. Specifically, a resident "must be able to investigate and evaluate their patient care practices, assimilate scientific evidence, and improve the patient care practice.”259 The justification for opponents of residency training duration reduction for keeping the third year centers on conducting research to help residents acquire skills in assimilating scientific evidence. To implement two-year residencies, ACGME must reconcile with those who undervalue the potential time and experience necessary to acquire this core competency.

Reducing core residencies’ educational periods will not by itself ensure an adequate physician supply, but reducing training length will allow for more residents being trained in core specialties without increasing current Medicare funding. ${ }^{255}$ Further, decreasing training time would initially lead to fewer residents in training within individual programs; however, over time, the quantity of residents in each year of training will be increased. ${ }^{255}$

\section{Train More: Summary}

Opinions on the quality of physicians produced from the above accelerated medical degree programs are positive and negative; further, the literature evaluating the programs are mixed and scant. It has been suggested that an evaluation of current programs underway should be conducted to look at both program design and quality of

outcomes. ${ }^{10}$ States, such as Kentucky, should consider pilot programs and evaluate these programs. $^{10}$ 
Regarding financial considerations and medical student debt, there are four alternatives: (a) decreasing medical school duration; (b) decreasing residency duration; (c) reducing medical school tuition; (d) increasing residency compensation. The former two had the largest impact on net present value according to one study of general internists and internal medicine subspecialists. ${ }^{38,260}$ Net present value is a financial amount based on the present worth of money collected (i.e., physician income) or paid out (i.e., medical school tuition) prospectively. ${ }^{260}$ Decreasing medical school by one year brought an additional net present value of $\$ 160,000$ and $\$ 230,000$ for internal medicine and subspecialists, respectively; eliminating one year of residency for subspecialists resulted in a net present value of $\$ 170,000 .{ }^{260}$ Financial benefits accrue primarily through becoming a practicing physician one year earlier and the income collected during the supplementary year, rather than a reduction from eliminating one year of tuition and fees. ${ }^{260}$ Further, diminishing medical school tuition for one year resulted only in a $\$ 30,000$ savings and boosting residency payment increased the net present value for general internists by $\$ 60,000$, and $\$ 100,000$ for internal medicine subspecialists. ${ }^{260}$ The latter considerations are improbable, because medical schools will not likely ease tuition as it is unrestricted funding (of which medical schools have limited sources), ${ }^{38}$ and hospitals and/or Medicare are unlikely to increase resident stipend. ${ }^{38,247}$ The study concludes the findings on internal medicine and subspecialties are applicable to other medicine fields. The higher the specialty income, the more net present value impact a one-year reduction in undergraduate or graduate medical training would have based on opportunity cost. ${ }^{260}$ 


\section{Waste Less: Non-Technology}

"Waste less” translates into increasing physician efficiencies. Increasing physician efficiency has been defined as "the ability to serve a larger population at a constant level of quality, to expand comprehensiveness or improve the quality of care delivered to a population with a given input of physician time or effort, or both.."182 One article documenting physicians' work time stated that greater than $50 \%$ of their time is used for clerical or administrative functions that contribute no patient care value. ${ }^{182}$ These tasks include electronic health records patient data entry, signing off on test results, prescription renewals, interacting with insurance companies and health plans, logging on and off computers, and dealing with electronic billing. ${ }^{182}$ Consequently, physicians' time and efforts are wasted on unrelated direct patient care activities and primary care inefficiencies are pervasive. ${ }^{182}$

The section, “Finding Someone Else and Team-Based Care” (page 156) in this chapter, addresses some ways physician time inefficiencies can be improved. Several other options also increase physician efficiency. One includes redesigning the clinical workflow. ${ }^{182}$ This coincides with team-based care as physicians reside in "flow stations" working side-by-side with the primary care team as opposed to occupying a private office. ${ }^{182}$ Flow stations enhance real-time communication and diminish time lost when one team member cannot find another member to request support or communicate information. Related to flow stations are "flow managers." ${ }^{182}$ MAs or other staff can increase physician efficiency by being a physician "flow manager.” The flow manager provides guidance to the physician by telling them the day-to-day assignments the physician needs to perform. Specifically, the flow manager provides real-time input to the 
physician by making remarks such as: "You can see the patient now," "Return this call," and "Sign this form"; basically the flow manager aids the physician in staying on task. Flow managers' duties also could include dictating, in real time on an electronic tablet or pad, the physician's patient recommendation and work up to alleviate the physician having to do this. Physicians using flow managers note a more efficient and less stressful workday. Moreover, other clinic layout modifications can improve efficiency. ${ }^{182}$ Printers in every exam room, workstations using large monitors to assess patients' arrival and visit status, and standardizing the exam rooms' equipment locations can diminish wasteful time and effort. ${ }^{182}$ If physicians saved 30 minutes per day because of all these changes, and the changes are broadly implemented, large dividends in healthcare efficiency would be achieved. ${ }^{182}$ In effect, 30 additional minutes per day, translated into one extra patient office visit for the 150,000-200,000 PCPs working 200 annual workdays would add up to 30 to 40 million additional annual patient visits. ${ }^{182}$

\section{Waste Less: Technology}

Health information technology (HIT) usage is increasing. Office-based electronic health records (EHRs) basic system implementation has risen from $10 \%$ in $2004^{261}$ to $54 \%$ in $2011^{262}$ to $72 \%$ in $2013 .{ }^{261,263}$. Further, in $2012,40 \%$ of physicians were using more comprehensive EHRs. ${ }^{263}$ Moreover, approximately $17 \%$ of all US adults use ehealth technology, while $85 \%$ would like to use protected communication systems to correspond with their healthcare provider. ${ }^{261,262,264}$ Additionally, possibly 56\% of all office-based physicians have made lab test results and other information electronically accessible to patient. ${ }^{261,262}$ 


\section{Technology: Digital Clinical Workflow Systems}

HIT can be classified with three categorizations. ${ }^{261}$ Accordingly, these include (a) digital clinical workflow systems such as EHRs, clinical decision support systems (CDSS), or computer provider order entry systems (CPOEs); (b) consumer e-health or mobile health (m-health) tools; (c) telemedicine or remote care. ${ }^{261}$ EHRs allow physicians to digitally capture their patients' treatment history and then electronically share the information with all participants in the patients' healthcare process including laboratories, hospitals, nursing homes, specialists, out-of-state providers, and even the patients. ${ }^{265}$ Fully operative EHRs permit all stakeholders prompt access to the patient's health information, producing better coordinated, patient-centered care. ${ }^{265}$ A CDSS is an IT application that analyzes patient information to help healthcare professionals diagnose patient's ailments, predict future health events, specify treatment options, and make clinical decisions. ${ }^{266}$ For success, CDSSs and the healthcare practice’s clinical workflow must be integrated and interoperable with EHRs which often is a difficult task. ${ }^{266}$ CPOEs are systems that permit medical providers direct entry of patient treatment orders by sharing instructions through a computer network to medical personnel responsible for servicing an order, including office staff, pharmacists, radiologists, and laboratory technicians. ${ }^{267}$ Potentially, CPOEs can reduce errors associated with completion time delays, handwriting or transcriptions mistakes, and incorrect doses. ${ }^{267}$ CPOEs also permit point-of-care or offsite order entry and streamline inventory positing of charges. ${ }^{267}$ Most pertinently, these digital clinical workflow systems are central components that help foster team collaboration and delegation. ${ }^{261}$ 


\section{Digital Clinical Workflow Systems' Impact on Efficiency (Assessment of the Literature)}

Technology's potential for increasing physician and other healthcare providers'

efficiency is thought by many to be positive, ${ }^{261}$ although the research is contradictory or inconclusive due to formal long-term evaluations being unavailable. ${ }^{261,268-275}$ This synopsis's report on HIT's impact on physician service demand primarily uses Wiener, Yeh, and Blumenthal's recent literature review which analyzed pertinent individual studies and previously published systematic literature reviews, ${ }^{261}$ along with their online appendix which further summarizes their assessments. ${ }^{276}$ The authors note they conducted the most thorough review to date. This study's synopsis articulates their projections and reviews the original articles found in the appendix or the original articles themselves.

Regarding digital clinical workflow technology like EHRs, CDSSs, and CPOEs, the potential effect, according to Wiener, et al., is deemed to increase the efficiency and productivity, along with allowing more physician delegation of responsibilities to other medical personnel. ${ }^{261}$ The authors note that if $30 \%$ of US healthcare organizations and physician practices adopt these technologies, then physician demand could decrease 2$4 \%$; if $70 \%$ adopt these technologies, then demand could decrease 4-8\%; and full implementation of these technologies could decrease demand 5-10\%. ${ }^{261}$ Accordingly, initial implementation of the systems leads to temporary reductions in productivity, followed by long-term increases in productivity and efficiency. ${ }^{261,276}$ Unfortunately, Wiener, et al.'s review and appendix may not fully support this finding. One individual study, discussed in detail by the authors, showed that, after an EHR implementation in four Hawaiian hospitals, productivity actually decreased until the EHRs were removed. ${ }^{277}$ 
Another study examining physician practices and their implementation of EHRs noted some practices did have short-term decreases in productivity, followed by increased productivity; however, other practices studied had decreased productivity for years after the EHRs implementation. ${ }^{278}$ The third discussed study arguing that clinical workflow technology increases productivity actually focused on consumer e-health technology. ${ }^{279}$ Moreover, other Wiener, et al., HIT studies they examined showed 45\% (5/11) of the studies and systematic reviews noted clinical workforce technology notably increased physician productivity and efficiency, ${ }^{270,272,280-282}$ while the remainder either showed negligible increases, no change, or actual decreases in productivity and efficiency. ${ }^{268-}$ $270,275,283,284$

\section{Technology: Consumer E-Health}

Consumer e-health has been defined as "a broad category of electronic tools and services that are consumer-oriented, but that overlap with health information technology, a term more conventionally used in the context of technology for healthcare providers. ${ }^{264}$ Consumer e-health technology enables patients, families, and caregivers to actively participate in patient care of themselves or their loved ones. ${ }^{264}$ The technology includes: (a) protected internet portals for personal stakeholders to retrieve personal health information from EHRs; (b) patient-provider secure e-mail messaging; (c) personal monitoring devices; (d) mobile health apps; (e) web-based sites for health and wellness information, guidance, education, and social support. ${ }^{264}$ E-health technology also allows the patient to access data on healthcare treatments and cost. E-health facilitates patient engagement in their health and patient engagement has been associated with better chronic disease healthcare outcomes such as reduced readmission rates and medical 
errors compared to non-engaged patients. ${ }^{264}$ Receiving patient-provider e-mails and having access to health records have been associated with improved quality outcomes ${ }^{264,285}$ such as improving blood pressure in controlling blood glucose, ${ }^{264,286}$ and better preventive care. ${ }^{264}$ In effect, improved quality outcomes from e-health may, in the long run, reduce the need for physician services.

\section{Consumer E-Health's Impact on Efficiency (Assessment of the Literature)}

Wiener, et al. posits that e-health technology can lower physician services’ demand such as inpatient care, emergency department care, and office visits because ehealth facilitates self-care. ${ }^{261}$ Accordingly, if $30 \%$ of US consumers and physicians adopt this technology, a physician demand reduction of 4-9\% would be achieved; if 70\% adopt e-health, then a reduction of $8-19 \%$ would occur, and a $100 \%$ adoption rate would lead to a 10-25\% physician demand decrease. However, Wiener, et al., e-health technology's estimates, based on their literature review, may not be justified. Only 3/10 studies had definite positive findings regarding healthcare utilization reduction. ${ }^{280,287,288}$ Three out of ten publications had mixed reviews, with two of these studies being systematic reviews ${ }^{285,289}$ and one being a randomized trial. ${ }^{290} \mathrm{~A}$ mixed study refers to a study that would have a reduction in emergency rooms visits over time, while an increase in office visits, or vice versa (for example). Moreover, 3/10 publications had negative findings with one being a systematic review, ${ }^{291}$ one being a retrospective cohort study, ${ }^{292}$ and one being a randomized controlled trial. ${ }^{292}$ A publication with negative findings refers to healthcare utilization actually increasing as a result of e-health. Finally, one systematic review argued that there is insufficient randomized controlled trials to gauge the impact 
of electronic patient portals. ${ }^{293}$ Ultimately, the research from all the studies cited appeared methodologically sound and their conclusions varied.

\section{Technology: Telemedicine}

A telemedicine definition is "the use of advanced telecommunications technologies to exchange health information and provide healthcare services across geographic, time, social and cultural barriers.”294 Two telemedicine technologies are noted to support rural, home, school, and prisons. ${ }^{294}$ First, video teleconferencing permits patient consultation whereby one provider and patient at a remote site link with a specialist at a medical workplace through video. With both locations having telemedicine equipment, the specialist examines the patient. Equipment includes high resolution cameras, microphones, electronic stethoscopes that remotely gauge breath and heart sounds, electronic otoscopes for examinations, and google glasses. Second, "store and forward” telemedicine technology permits digital image transfers from one site to another for review. Telemedicine subsidizes both diagnostic and evaluative medicine for patients and their physicians. ${ }^{294}$ Telemedicine can help meet patient needs and demands in HPSAs, as PCPs used telemedicine in collaboration with remotely located NPs and PAs in rural locations. ${ }^{294}$

\section{Telemedicine’s Impact on Efficiency (Assessment of the Literature)}

The evidence documented by Wiener, et al., supporting the positive impact of telemedicine appears accurate. Their cited systematic reviews and individual articles indicated that videoconferencing and "store and forward" telemedicine exhibits potential for decreasing healthcare utilization and referral rates, while maintaining diagnostic correctness and quality. ${ }^{274,276}$ Moreover, both telemedicine types show promise in altering 
the distribution of tasks in that PCPs may reduce specialty referral, ${ }^{261,276,295}$ particularly in psychiatry and dermatology, ${ }^{261,276,296}$ stroke care ${ }^{297}$ and diabetes care, ${ }^{261,276,298}$ among others. Another telemedicine intervention study demonstrated that the aged had fewer hospital days and emergency room visits versus a control group. ${ }^{261,276,299}$ The evidence on telemedicine's rural health impact is also positive. One study posited that telemedicine allowed the Medical College of Georgia Sickle Cell Center to increase clinical encounters statewide by $34 \%$ with only one new PA. ${ }^{261,276,300}$ Telemedicine also allowed the Milwaukee VA Center and their specialists to successfully serve rural pulmonary care patients without traveling long distances and missing work days. ${ }^{261,276,301}$ In effect, telemedicine may help alleviate the rural health physician shortage disadvantage.

Wiener, et al., estimated that if US videoconferencing telemedicine is increased, then $30 \%$ physician would in real time reach remotely 2-5\% more patients; if videoconferencing increased 70\%, then physicians would reach $4-11 \%$ more patients, and this technology’s full implementation would allow physicians to reach 5-15\% more patients. ${ }^{261}$ Regarding “store and forward” technologies, a 30\% increase in the US could allow physicians to provide 4-7\% more patient care; a 70\% technological increase with provide 8-15\% more care; and full implementation would allow for a 10-20\% increase in patient care. $^{261}$ The productivity increases arise due to PCPs delegating care to NPs and PAs, or specialist delegating tasks to PCPs. ${ }^{261}$ These projections seem valid.

\section{Telemedicine's Impact on Rural Recruitment and Retention}

Telemedicine‘s impact on rural recruitment and retention also may be positive. A qualitative study using the Delphi method noted several areas that telemedicine can shape the rural healthcare landscape. ${ }^{302}$ Regarding continuing medical education events, experts 
agreed that telemedicine can act as an incentive to recruit and retain physicians by replacing travel and allowing for updating knowledge easier. Professionally, telemedicine inducements for recruitment or retention include the ability to professionally network and experience team integration, acquiring medical support from colleagues in decision making regarding complex cases, increasing the feeling of security and decreasing the feeling of isolation, and improving continuity of care. Telemedicine utilization can also extend a rural location's service variety and accessibility, produce a stimulating workplace, increase access to specialized equipment, and permit linkage with University centers. The authors recommended that the findings should be used as a conceptual model for further studies on physician recruitment and retention in rural areas. ${ }^{302}$

\section{Telemedicine and Rural Kentucky}

The Deloitte report noted Kentucky has robustly implemented telemedicine. ${ }^{10}$ Accordingly, as of 2012, the state had over 200 telemedicine facilities. Kentucky has strongly advocated for the reimbursement of telemedicine services and is one of a few states that require both Medicaid and private insurers to cover telemedicine. Unfortunately, Kentucky’s Medicaid system only reimburses for psychiatric and specialist services, not PCP services. The importance of this limitation is that if a PCP practitioner in Kentucky is considering a telemedicine investment, then they would possibly consider the fact that they would receive private insurance reimbursement, but not Medicaid, because many rural patients are Medicaid recipients. Hence, legislation needs to be altered to allow Medicaid reimbursement of PCP services. ${ }^{10}$ 


\section{Technology: Government Incentives to Overcome HIT Barriers}

HIT and e-health applications’ influence on future physician demand is contingent on the US healthcare system's adoption rate of a digital infrastructure. ${ }^{261}$ Barriers inherent within the US healthcare system justify government intervention in brokering HIT adoption. A strategic policy to facilitate HIT’s embracement by the US healthcare system and eliminate the barriers was legislated in the Health Information Technology for Economic and Clinical Health (HITECH) Act of 2009 which authorized \$29 billion over 10 years for qualified entities to adopt electronic health records (EHRs) or other health information technology. ${ }^{303}$ The act’s “meaningful use” provision emphasized five pillars of health outcome policy priorities, one of which was improving efficiency in the healthcare system, ${ }^{304}$ but all pillars related to using EHRs to improve health and healthcare. $^{303}$

\section{HITECH and HIT Economic Barriers}

Economic barriers have hindered the propagation of EHRs and other electronic information systems. ${ }^{278,294,303}$ Fee-for-service payment arrangements do not induce the US healthcare system to implement EHRs to increase efficiencies. ${ }^{303}$ The proceeds occurring from EHRs ensue more to patients and payers, not physicians or hospitals. ${ }^{303}$ Inversely, capitated payment structured organizations have been among the earliest adopters of EHRs, ${ }^{261}$ indicating financial incentives to improve health outcomes promote the implementation of the EHRs. Moreover, one 2004 qualitative study interviewing ninety physician or EHR managers from 30 physician organizations noted practices employing EHRs have encountered prohibitive startup costs and uncertain economic

value over time. ${ }^{278}$ Accordingly, a practices’ upfront costs range from $\$ 16,000-\$ 36,000$ 
per physician, and some practices lost more from seeing fewer patients during the EHR transition period. Financial advantages differed greatly, from $\$ 0$ in practices that made few paper process changes, to $\$ 20,000$ per-physician, per-year, for practices that eliminated most paper processes. ${ }^{278}$

The HITECH legislation offers grant and incentive monies to Medicare-receiving hospitals or professionals who validate they have embraced electronic health records (EHR) technology over three stages: (a) data capture and sharing, i.e., defining the data that should be electronically collected; (b) emphasize the uses of EHRs to improve healthcare processes; (c) improve outcomes. ${ }^{303}$ Consequently, recipients receive $\$ 44,000$ over five years and $\$ 63,750$ over six years. Participation is voluntary, but those failing to partake will experience penalties to their Medicare/Medicaid fees from 1\% up to $3 \%$ or beyond. Basically, HITECH funding is the federal government's attempt to correct market failures that hinder HIT's dissemination by directly paying providers the cost of adopting health information technology. ${ }^{303}$

\section{HITECH and HIT Logistical and Technical Barriers}

Another barrier in adopting HIT is the logistical and technical aspects. ${ }^{278,294,303}$ Physician practices in healthcare organizations find difficulty in evaluating and understanding EHRs complexities given the marketplace's assorted HIT offerings. Without resources and knowledge, hesitancy occurs in investing extensive capital in systems that may not meet healthcare professionals’ needs. ${ }^{278,303}$ Lacking HIT expertise, obstacles occur in installing, supporting, using and upgrading EHRs over time. ${ }^{278,303}$ For example, physicians, particularly in small group practices, have to use considerable and continuous time tailoring their electronic forms for documentation and then conduct staff 
training. ${ }^{278}$ Larger physician organizations are more apt to successfully implement complementary changes due to deeper resources such as leadership, previous process change experiences, financial resources, and information systems support staff. ${ }^{278}$ However, despite the larger physician practice’s advantages, many physicians from these groups still spend considerable additional time with complementary changes ${ }^{278}$. Moreover, physicians using EHRs require more time initially for months or even years after the EHR's implementation causing lengthier work days, fewer patients treated, or both. ${ }^{278}$ The learning curve can be time-consuming and steep due to the complexity of numerous screens, options, and navigational aids, and EHRs' usability - particularly for progress notes - create excessive work time. These matters strengthen the tentativeness of providers in implementing HITS due to the disruption of their professional daily activities. $^{303}$

To counteract the logistical and technical obstacles associated with implementing HIT, HITECH established the Office of the National Coordinator for Health Information Technology (ONC) and equipped it with $\$ 2$ billion in funding. ${ }^{303}$ Accordingly, the ONC was charged with establishing HIT regional centers with the purpose of assisting healthcare providers with adopting and using EHRs. The centers are mandated to set up local offices close to their providers in order to provide hands-on assistance with the adoption of technology. The ONC was also charged with training 50,000 health information technology professionals to work with providers and vendors. Moreover, “certified” EHR systems were designated to have "meaningful use” capabilities. That is, healthcare organizations and practices are required to adopt the certified systems as it acts 
as a form of consumer protection; in effect, the systems are verified, but not guaranteed, to be user friendly.

\section{HITECH and HIT Health Information Exchange Complications}

A third barrier for HIT implementations is related to health information exchange complications. ${ }^{303}$ In view of that, healthcare organizations have apprehensions with their abilities to effectively and seamlessly transfer electronic health information among different information systems with other caretakers given the thousands of HIT systems in play and the countless number of users. This problem's intensity increases due to the need for collaboration among vendors and healthcare organizations when they are natural competitors with one another. Mandates for HITECH included specifying the standardization of HITs with shared languages in order to exchange information. Moreover, \$300 million was designated for states to foster health information exchange. The legislation also specified that a national governing approach to a universal health information network be established. ${ }^{303}$

\section{HITECH and HIT Privacy and Security Barriers}

A fourth barrier to adopting HIT is privacy and security concerns. ${ }^{294,303}$ Specifically, public anxiety about public health information losses or mishandling could negatively impact the diffusion of health information technology. ${ }^{303} \mathrm{HITECH}$ stipulated regulations to help alleviate consumer fears. ${ }^{303}$ These included (a) increasing HIPAA financial fines for negligent violations of safeguarded health information from a maximum of $\$ 25,000$ to $\$ 1.5$ million per infringement; (b) inhibiting health information usage for marketing and fund-raising intentions unless patients sanction their use; (c) the 
ONC is charged with creating other health information protection mechanisms that will give consumers greater control over the involvement of their health information data.

Another feature to address privacy and security concerns, along with reducing the financial barriers of HITECH, would be implementing the "VISA" model. Banks, at one point, were at the brink of pecuniary disintegration until they united in a joint effort and shared a common infrastructure linking unrelated consumers, merchants, and financial institutions in the secure and private exchange of credit card financial information. ${ }^{305}$ The success of VISA's collaborative efforts has caused the cost of a credit card transaction to be less than a penny. ${ }^{305}$ Experts advocating HIEs emphasize the success of VISA:

"The healthcare system needs a viable organizational model wrapped around a flexible, interoperable network that can accommodate the individual needs of every user or community - regardless of vendor, application, or platform. The governance of this organization must be controlled by those who use and benefit from it. It must provide important safeguards in the area of privacy and security, by way of a set of commonly adopted principles for cooperation, etc. This will shift the competitive landscape away from competing on which organization has patient data to how well each provider uses that information to improve patient care and convenience.,305

\section{Waste Less: Summary}

In summary, much evidence is surfacing that these manpower and technological innovations are reducing costs and improving quality; however, insufficient data exist addressing technology's impact on the healthcare workforce. ${ }^{235,237}$ Thus, these healthcare system changes offer possible solutions to the PCP and rural HPSAs shortage. However, the new emphasis on increased primary care services and achieving high-quality patient outcomes may involve the US needing more PCPs, as many of these systems also face worker shortages. ${ }^{206}$ Further, new technology could increase PCP demand if physicians become more assessable to patients through shared records and additional video or e-mail visits. $^{237}$ 
However, the contrary literature findings of HIT’s impact on the physician workforce does not necessitate that technology will be a bust for the medical field. Common sense and technology's impact in other fields suggest otherwise. Wiener et al., projections may come to fruition, but, to do so, HIT studies should focus more on formative evaluations, i.e., evaluations conducted to assess why a HIT in a healthcare organization or medical practice was successful or not, as well as summative evaluations, i.e., was healthcare utilization decreased or increased. Specifically, studies should address the impact of organizational culture on a HIT's implementation. For example, one study found that an EHR system failed due to dysfunctional implementation traits arising in the organization, i.e., the organizations compliant culture prevented constructive feedback, and the personnel did not adjust well to changing roles and responsibilities. ${ }^{277}$ With HITECH's “carrot and stick” mandates causing the "fast-track” of HIT adoption with contradictory knowledge of the impact on efficiency, focuses should be on what organizations do right and wrong during implementation, and this information should be disseminated broadly.

\section{Conclusion}

Solving the problem to PCP and rural physician maldistributions has been the focus for public health and medical professionals for decades. The ACA makes correcting these maldistributions more pressing. Nonetheless, the AMA and other medical organizations' leadership in solving these problem seems wanting, and they are not fulfilling their public responsibility to society, in spite of the elite status bestowed

upon medicine by the public. ${ }^{306}$ These findings suggest that medical students' level of debt may influence residency choice between the lower and higher extremes of debt, 
albeit modestly. Medicine's failure to address the influence of economics on the PCP shortage weakened their monopoly status over healthcare as NPs and other professions fill the maldistribution void. ${ }^{16}$

Alternative healthcare professions' seeming ability to meet patient needs, governmental reimbursement policies based on Medicare's RBRVS code and the contentiousness between PCPs and non-PCPs, and medical school's escalating tuition offer negative consequences. ${ }^{16,306}$ First, healthcare expertise deteriorates if other healthcare professions, including osteopathic physicians, provide medical care solo. Medical students in general are high achievers ${ }^{307}$ and are more apt to look at their occupation as more life-encompassing than other healthcare professionals who identify with their occupation less intensely. Further, medicine triumphs other healthcare professions due to rigorous training that gives physicians, not only technical and clinical skills, but the overall comprehension of the human body that lie beneath these skills. ${ }^{307}$ This is why the shortening of physicians' training is possibly harmful to healthcare. Consequently, PCPs' supervision of NPs and other non-medicine professions is necessary for maintaining optimal patient care.

Second, PCPs lose bargaining powers. As NPs and others flood the healthcare market and provide PCP services, and as governmental reimbursement policies continue to be contentious, PCPs' income erodes. ${ }^{307}$ Future or current medical students, facing enormous debt, may observe these trends and choose not to go to medical school ${ }^{307}$ or to train in high paying specialties. Rising medical school tuition may further lead to even more lower SES students, who are more apt to become PCPs, foregoing medical school, 
while students with higher SES standings further increase their footing in medicine and choose non-PCP disciplines to maintain their accustomed lifestyle. ${ }^{307}$

Further, even NPs and other healthcare professionals' impact on the primary care shortage are questionable. Despite NPs' services, the vast majority of physician shortage estimates include their current and expected input in the predicted deficiencies. ${ }^{308}$ Also, those NPs and PAs in the workforce are choosing to work in non-primary care specialties because of the pay. ${ }^{308}$ Only one-third of NPs currently work in primary care and 50\% are expected to leave. ${ }^{308}$ Future NPs and others may continue the trend of choosing to not work in primary care.

Compounding this are the new healthcare models such as ACOs and PCMHs that promote systematic efficiencies and quality in the system. ${ }^{308}$ In order to achieve better health outcomes, primary care practices may have to significantly reduce patient panels. ${ }^{308}$ Many PCMHs incorporating team-based care have successfully improved panel outcomes, but at the cost of greatly reducing panel sizes. ${ }^{308}$ Hence, although efficiencies are increased, the goal of quality and better outcomes may worsen the primary care shortage as a whole. ${ }^{308}$

Ultimately, in order for medicine trainees to choose primary care, "shared savings” payment mechanisms and PCMHs and ACOs must more align PCPs' compensation with non-PCP compensation. However, since these models are in flux, not thoroughly vetted, or well established, current medical students’ residency choice, in terms of their finances, only can consider fee-for-services payments. Thus, as the ACA further increases the need for more PCPs, the new healthcare delivery models offer no proven financial incentive to choose primary care. (Even ACA's legislation to provide 
small bonus payments for bolstering primary care is insufficient in achieving necessary long-term parity between primary care and specialty fields.) $)^{24,33}$

Given the above issues and the medicine profession's "Rome burned, while Nero fiddled" mentality in addressing the PCP supply issue and association with student debt, perhaps the SAFE proposal ${ }^{38}$ would provide a non-contentious, feasible, and somewhat immediate solution to increase PCPs in the workforce. By having medical students pay a percentage of their income after residency, debt's influence on specialty choice would be minimized and less persuasive. The greatest challenge would be the federal government providing medical schools low interest loans until the first round of medical trainees matriculate out of their residencies into the workforce. However, ultimately, medical schools would have a self-sustaining financial model.

The biggest benefit is the opportunity provided to lower and working class students who reject attending medical school due to debt-related fears. These students would perceive medicine as a financially realistic career. Since these students choose primary care specialties in greater numbers than their upper SES counterparts, the SAFE proposal offers a viable midrange solution to the PCP shortage.

Regarding rural practice location, limited financial resources, both federal and state, should consider shifting some monies from the NHSC and other debt relief programs into pipeline programs that start in middle school and high school and support students through medical school. ${ }^{309}$ The literature shows that many participants (30\%) of debt relief programs do not fulfill their obligations and those meeting their obligations leave the HPSA after completion, indicating these programs do not provide stability or long term solutions for the areas served. ${ }^{131,139}$ This study's findings also showed very few 
U of L medical students entered the federal NHSC and that the state of Kentucky eliminated its debt relief and grant establishment programs due to lack of participants. Consequently, financial incentives and debt relief policies may not be the most optimal use of resources to solve the physician geographic maldistribution problem.

Although the findings did not confirm the affinity model that students who grow up in rural areas or who participate in rural training in medical school are more likely to relocate in rural areas, the affinity model and rural pipeline programs have been established in the literature. Kentucky's PEPP program demonstrates that, by engaging and mentoring adolescents to undertake medical careers, many go on to healthcare graduate programs and become physicians, dentists, and nurses. Fifty-three percent of PEPP participants who became physicians and practice in Kentucky work in rural areas (albeit, osteopathic and non-PCPs constitute some of this workforce). Further, research has shown rural practice location success with medical schools incorporating rural pathway programs that draft and admit students likely to practice in rural areas, and then provide rural training usually in the third and fourth year of medical school. ${ }^{8,20,109,110}$ Also, as mentioned previously, evaluation of the University of Louisville's Trover Rural Track program has shown the program to be highly successful in terms of graduates practicing in rural areas. ${ }^{10}$ These programs' positive outcomes, along with the questionable long-term realization of debt relief programs to retain physicians, should cause policy makers to consider shifting some financial resources into rural pipeline and pathway programs.

Thus, medical associations, along with state and federal policymakers, should consider integrating the SAFE proposal, along with rural pipeline, and pathway programs 
as a solution to the PCP and rural shortages. Pipeline programs' ability to draft rural teenagers to attend medical school becomes easier without potential massive debt fears. Matriculants are more likely to go into primary care and rural areas knowing the amount owed to the medical school is prorated based on income, and that this prorating would not hinder their living standard that, for many pipeline participants, is predicated on a rural lifestyle. The rural track programs would affirm the benefits of a rural practice and counteract the influence of rural students getting their only medical training in metropolitan areas and then being lured away from practicing in rural areas after completing medical training. ${ }^{102}$ Ultimately, these strategies would provide success for both Kentucky and the nation. 


\section{REFERENCES}

1. Carrier E, Yee T, Stark L. Matching supply to demand: addressing the US primary care workforce shortage. NIHCR Policy Analysis No. 7 2011;

http://www.nihcr.org/PCP_Workforce.html. Accessed 11/18/2014.

2. Salsberg E, Grover A. Physician workforce shortages: implications and issues for academic health centers and policymakers. Acad Med. 2006;81(9):782-787.

3. Young AG, Chaudhry H, Rhyne J, Dugan M. A census of actively licensed physicians in the United States, 2010. JMR. 2011;96(4):10-20.

4. Petterson SM, Liaw WR, Phillips RL, Jr., Rabin DL, Meyers DS, Bazemore AW. Projecting US primary care physician workforce needs: 2010-2025. Ann Fam Med. 2012;10(6):503-509.

5. Shi L, Singh, D. The Delivery of Healthcare in America: A Systems Approach. 3rd ed: Jones and Bartlett Publishers, Inc.; 2004.

6. Dill MJ, Salsberg ES. The complexity of physician supply and demand: projections through 2025. 2008; 1-94. Available at: http://www.innovationlabs.com/pa_future/1/background_docs/AAMC\%20Compl exities\%20of\%20physician\%20demand,\%202008.pdf. Accessed 11/24/2014.

7. Rosenblatt RA, Chen FM, Lishner DM, Doescher MP. The future of family medicine and implications for rural primary care physician supply: final report 125. University of Washington;2010.

8. Rabinowitz HK, Diamond JJ, Markham FW, Wortman JR. Medical school programs to increase the rural physician supply: a systematic review and projected impact of widespread replication. Acad Med. 2008;83(3):235-243.

9. McGaha AL, Garrett E, Jobe AC, et al. Responses to medical students' frequently asked questions about family medicine. Am Fam Physician. 2007;76(1):99-106.

10. Deloitte Consulting. The Commonwealth of Kentucky healthcare workforce capacity report. Frankfort, KY: Kentucky Benefit Health Exchange;2013.

11. Reach of Louisville. Louisville primary care Association (LPCA): Primary Care and Oral Health Workforce Study. Louisville, Kentucky2011.

12. Rosenblatt RA, Chen FM, Lishner DM, Doescher MP. Do medical schools have a responsibility to train physicians to meet the needs of the public? the case of persistent rural physician shortages. Acad Med. 2010;85(4):572 - 574.

13. Phillips RL, Dodoo, M. S., Petterson, S., Xierall, I., Bazemore, A., Teevan, B., Bennett, K., Legagneur, C., Rudd, J., Phillips, J. Specialty and Geographic Distribution of the Physician Workforce: What Influences Medical Student and Resident Choice. Robert Graham Center; March 2, 2009.

14. Looney SW, Blondell, R.D., Gagle, J.R., Pentacost, M.W. Which medical school applicants will become generalist or rural-based physicians? J Ky Med Assoc. 1998;96:189-193. 
15. Rosenblatt RA, Andrilla CH. The impact of U.S. medical students' debt on their choice of primary care careers: an analysis of data from the 2002 medical school graduation questionnaire. Acad Med. 2005;80(9):815-819.

16. Ellerin BE. Debt, demographics, and dual degrees: American medicine at the crossroads part 2: external and internal threats to the monopoly model. J Am Coll Radiol. 2007;4(7):479-486.

17. Phillips JP, Weismantel DP, Gold KJ, Schwenk TL. Medical student debt and primary care specialty intentions. Fam Med. 2010;42(9):616-622.

18. Youngclaus JA, Koehler PA, Kotlikoff LJ, Wiecha JM. Can medical students afford to choose primary care? An economic analysis of physician education debt repayment. Acad Med. 2013;88(1):16-25.

19. American Medical Student Association (AMSA). Medical students oppose doubling interest rates on Stafford Student Loans. 2013; http://www.amsa.org/AMSA/Homepage/About/News/061713.aspx. Accessed July 16, 2013.

20. Crump WJ, Fricker RS, Ziegler C, Wiegman DL, Rowland ML. Rural track training based at a small regional campus: equivalency of training, residency choice, and practice location of graduates. Acad Med. 2013.

21. Campos-Outcalt D, Senf J, Pugno PA, McGaha AL. Family medicine specialty selection: a proposed research agenda. Fam Med. 2007;39(8):585-589.

22. Colquitt WL, Zeh MC, Killian CD, Cultice JM. Effect of debt on U.S. medical school graduates' preferences for family medicine, general internal medicine, and general pediatrics. Acad Med. 1996;71(4):399-411.

23. U.S. Department of Health and Human Services. Physician supply and demand: projections to 2020. Washington, DC: Health Resources and Service Administration; 2006.

24. Phillips RL, Jr., Turner BJ. The next phase of Title VII funding for training primary care physicians for America's health care needs. Ann Fam Med. 2012;10(2):163-168.

25. Baicker K, Chandra A. Medicare spending, the physician workforce, and beneficiaries' quality of care. Health Aff (Millwood). 2004;Suppl Web Exclusives:W4-184-197.

26. Baicker K, Chandra A. Cooper's analysis is incorrect. Health Aff (Millwood). 2009;28(1):w116-118.

27. Starfield B, Shi L, Macinko J. Contribution of primary care to health systems and health. Milbank Q. 2005;83(3):457-502.

28. Baicker K, Fisher ES, Chandra A. Malpractice liability costs and the practice of medicine in the Medicare program. Health Aff (Millwood). 2007;26(3):841-852.

29. Starfield B, Shi L, Macinko J. Physicians and quality: answering the wrong question. Health Aff (Millwood). 2009;28(2):596-597; author reply 597.

30. Health Workforce Information Center. Supply and demand. 2012; http://www.hwic.org/topics/introduction.php?id=49. Accessed 12/12/2012.

31. US Department of Health and Human Services. The physician workforce: projections and research into current issues affecting supply and demand. 2008; http://bhpr.hrsa.gov/healthworkforce/reports/physwfissues.pdf. Accessed $11 / 18 / 2014$. 
32. Okrent D. Healthcare workforce: future supply versus demand. Robert Wood Johnson Foundation Grant; April 2011.

33. Spetz J. Health Reform and the Healthcare Workforce. Houston, TX: James A. Baker III Institute for Public Policy 2012.

34. Dorsey ER, Jarjoura D, Rutecki GW. Influence of controllable lifestyle on recent trends in specialty choice by US medical students. Jama. 2003;290(9):1173-1178.

35. Dorsey ER, Jarjoura D, Rutecki GW. The influence of controllable lifestyle and sex on the specialty choices of graduating U.S. medical students, 1996-2003. Acad Med. 2005;80(9):791-796.

36. Palmeri M, Pipas C, Wadsworth E, Zubkoff M. Economic impact of a primary care career: a harsh reality for medical students and the nation. Acad Med. 2010;85(11):1692-1697.

37. Hadley J, Mitchell JM. The growth of managed care and changes in physicians' incomes, autonomy, and satisfaction, 1991-1997. Int J Health Care Finance Econ. 2002;2(1):37-50.

38. Weinstein L, Wolfe H. A unique solution to solve the pending medical school tuition crisis. Am J Obstet Gynecol. 2010;203(1):19 e11-13.

39. Dunn L. Physician supply and demand in the next 10 years. Hospital-Physician Relationships and Accountable Care Organizations 2011; http://www.beckershospitalreview.com/hospital-physicianrelationships/physician-supply-and-demand-in-the-next-10-years.html. Accessed January 9, 2013.

40. Colwill J, Cultice, J., Kruse, R. Will generalist physician supply meet demands of an increasing an aging population? Health Aff (Millwood). 2008;27(3):10.

41. Cooper RA, Getzen TE, McKee HJ, Laud P. Economic and demographic trends signal an impending physician shortage. Health Aff (Millwood). 2002;21(1):140154.

42. Buchmueller TC, Grumbach K, Kronick R, Kahn JG. The effect of health insurance on medical care utilization and implications for insurance expansion: a review of the literature. Med Care Res Rev. 2005;62(1):3-30.

43. Kirch DG, Henderson MK, Dill MJ. Physician workforce projections in an era of health care reform. Annu Rev Med. 2012;63:435-445.

44. Dall T. The effect of increased insurance coverage under healthcare reform on the demand for primary care and specialist physicians. Paper presented at: AAMC Physician Workforce Conference; May 7, 2010.

45. Department of Health and Human Services. Fact sheet: creating jobs and increasing the number of primary care providers. Washington, DC2010.

46. Department of Health and Human Services. Justification of Estimates for Appropriations Committees. Washington DC2014.

47. The White House: Office of the Press Secretary. FACT SHEET: Creating Healthcare Jobs by Addressing Primary Care Workforce Needs. 2012; http://www.whitehouse.gov/the-press-office/2012/04/11/fact-sheet-creatinghealth-care-jobs-addressing-primary-care-workforce-n. Accessed February 23, 2015. 
48. Kentucky Institute of Medicine Task Force Report. Comprehensive Statewide Physician Workforce Study. 2007;

http://www.kyiom.org/pdf/KMAWorkforceReport9-24-07.pdf. Accessed 11/24/2014.

49. Anderson DM, Whitler ET, Johnson AO, Elam CL, Wilson EA, Asher LM. Increasing the medical school applicant pool: a key to training more rural physicians. J Ky Med Assoc. 2009;107(9):355-360.

50. Center for Workforce Studies Association of American Medical Colleges. Recent studies and reports on physician shortages in the US. In: Association of American Medical Colleges, ed2012.

51. United Health Foundation. America's health rankings: 2012 Kentucky health statistics. 2014; http://www.americashealthrankings.org/KY/2012. Accessed 03/16/2015.

52. Bennett KL, Phillips JP. Finding, recruiting, and sustaining the future primary care physician workforce: a new theoretical model of specialty choice process. Acad Med. 2010;85(10 Suppl):S81-88.

53. Barer M, Wood I, Schneider D. Towards improved access to medical services for relatively underserved populations: Canadian approaches, foreign lessens. University of British Columbia1999.

54. Mathews M, Seguin M, Chowdhury N, Card RT. Generational differences in factors influencing physicians to choose a work location. Rural Remote Health. 2012;12:1864.

55. Brooks RG, Walsh M, Mardon RE, Lewis M, Clawson A. The roles of nature and nurture in the recruitment and retention of primary care physicians in rural areas: a review of the literature. Acad Med. 2002;77(8):790-798.

56. Rabinowitz HK, Diamond JJ, Markham FW, Paynter NP. Critical factors for designing programs to increase the supply and retention of rural primary care physicians. JAMA. 2001;286(9):1041-1048.

57. Rabinowitz HK, Diamond JJ, Markham FW, Santana AJ. The relationship between entering medical students' backgrounds and career plans and their rural practice outcomes three decades later. Acad Med. 2012;87(4):493-497.

58. Novielli K, Hojat M, Park PK, Gonnella JS, Veloski JJ. Change of interest in surgery during medical school: a comparison of men and women. Acad Med. 2001;76(10 Suppl):S58-61.

59. Lambert EM, Holmboe ES. The relationship between specialty choice and gender of U.S. medical students, 1990-2003. Acad Med. 2005;80(9):797-802.

60. Buddeberg-Fischer B, Klaghofer R, Abel T, Buddeberg C. Swiss residents' speciality choices--impact of gender, personality traits, career motivation and life goals. BMC Health Serv Res. 2006;6:137.

61. Barnhart J, Shekelle P, Lewis C. The effect of a medical school's admission and curriculum policies on increasing the number of physicians in primary care specialties. Acad Med. 1996;71(3):293-295.

62. Schieberl JL, Covell RM, Berry C, Anderson J. Factors associated with choosing a primary care career. West J Med. 1996;164(6):492-496. 
63. Schwartz RW, Jarecky RK, Strodel WE, Haley JV, Young B, Griffen WO, Jr. Controllable lifestyle: a new factor in career choice by medical students. Acad Med. 1989;64(10):606-609.

64. Hedden L, Barer ML, Cardiff K, McGrail KM, Law MR, Bourgeault IL. The implications of the feminization of the primary care physician workforce on service supply: a systematic review. Hum Resour Health. 2014;12:32.

65. Rabinowitz HK, Diamond JJ, Markham FW, Santana AJ. Increasing the supply of rural family physicians: recent outcomes from Jefferson Medical College's Physician Shortage Area Program (PSAP). Acad Med. 2011;86(2):264-269.

66. Colwill JM, Cultice JM. The future supply of family physicians: implications for rural America. Health Aff (Millwood). 2003;22(1):190-198.

67. Randolph GD, Pathman DE. Trends in the rural-urban distribution of general pediatricians. Pediatrics. 2001;107(2):E18.

68. Barley GE, Reeves CB, O'Brien-Gonzales A, Westfall JM. Characteristics of and issues faced by rural female family physicians. J Rural Health. 2001;17(3):251258.

69. Wainer J. Work of female rural doctors. Aust J Rural Health. 2004;12(2):49-53.

70. Rourke LL, Rourke J, Brown JB. Women family physicians and rural medicine. Can the grass be greener in the country. Can Fam Physician. 1996;42:1063-1067, 1077-1082.

71. Association of American Medical Colleges (AAMC). America needs a more diverse physician workforce. https:/www.aamc.org/download/87306/data/. Accessed July 26. 2013.

72. Reede JY. A recurring theme: the need for minority physicians. Health Aff (Millwood). 2003;22(4):91-93.

73. Cohen JJ, Gabriel BA, Terrell C. The case for diversity in the health care workforce. Health Aff (Millwood). 2002;21(5):90-102.

74. Cohen JJ. The consequences of premature abandonment of affirmative action in medical school admissions. JAMA. 2003;289(9):1143-1149.

75. Benkert R, Peters RM, Clark R, Keves-Foster K. Effects of perceived racism, cultural mistrust and trust in providers on satisfaction with care. $J$ Natl Med Assoc. 2006;98(9):1532-1540.

76. Armstrong K, Ravenell KL, McMurphy S, Putt M. Racial/ethnic differences in physician distrust in the United States. Am J Public Health. 2007;97(7):12831289.

77. Freeman J, Ferrer RL, Greiner KA. Viewpoint: Developing a physician workforce for America's disadvantaged. Acad Med. 2007;82(2):133-138.

78. Nivet MA. Minorities in academic medicine: review of the literature. $J$ Vasc Surg. 2010;51(4 Suppl):53S-58S.

79. Saha SS, Shipman SA. The rationale for diversity in the health professions: a review of the evidence. U.S. Department of Health and Human Services 2006.

80. Horner RD, Samsa GP, Ricketts TC, 3rd. Preliminary evidence on retention rates of primary care physicians in rural and urban areas. Med Care. 1993;31(7):640648. 
81. Royston PJ, Mathieson K, Leafman J, Ojan-Sheehan O. Medical student characteristics predictive of intent for rural practice. Rural Remote Health. 2012;12:2107.

82. Pathman DE, Konrad TR. Minority physicians serving in rural National Health Service Corps sites. Med Care. 1996;34(5):439-454.

83. Mick SS, Lee SY, Wodchis WP. Variations in geographical distribution of foreign and domestically trained physicians in the United States: 'safety nets' or 'surplus exacerbation'? Soc Sci Med. 2000;50(2):185-202.

84. Fink KS, Phillips RL, Jr., Fryer GE, Koehn N. International medical graduates and the primary care workforce for rural underserved areas. Health Aff (Millwood). 2003;22(2):255-262.

85. Weissman JS, Campbell EG, Gokhale M, Blumenthal D. Residents' preferences and preparation for caring for underserved populations. J Urban Health. 2001;78(3):535-549.

86. Baer LD, Ricketts TC, Konrad TR, Mick SS. Do international medical graduates reduce rural physician shortages? Med Care. 1998;36(11):1534-1544.

87. Mick SS, Lee SY. Are there need-based geographical differences between international medical graduates and U.S. medical graduates in rural U.S. counties? J Rural Health. 1999;15(1):26-43.

88. Mullan F, Politzer RM, Davis CH. Medical migration and the physician workforce. International medical graduates and American medicine. JAMA. 1995;273(19):1521-1527.

89. Vongnild L. A review of the international medical graduate in American medicine. http://www.aspr.org/displaycommon.cfm?an=1\&subarticlenbr=512. Accessed August 8, 2013.

90. Mullan F. The metrics of the physician brain drain. $N$ Engl J Med. 2005;353(17):1810-1818.

91. Assessing Medical School Admissions Policies: Implications of the US Supreme Court's Affirmative Action Decisions. 2003.

92. Fullinwider R. The Standford Encyclopedia of Philosophy: Affirmative Action. 2011; http://plato.stanford.edu/archives/win2011/entries/affirmative-action. Accessed 11/24/2014.

93. Castillo-Page L. Diversity in medical education: facts and figures 2012. In: Diversity Policy and Programs, ed. Washington DC: Association of American Medical Colleges; 2012.

94. Rich EC, Mullan F. Commentary: evaluating Title VII investments in primary care training: drop in the ocean, or levee against the flood? Acad Med. 2008;83(11):1002-1003.

95. Fryer GE, Jr., Meyers DS, Krol DM, et al. The association of Title VII funding to departments of family medicine with choice of physician specialty and practice location. Fam Med. 2002;34(6):436-440.

96. Reynolds PP. A legislative history of federal assistance for health professions training in primary care medicine and dentistry in the United States, 1963-2008. Acad Med. 2008;83(11):1004-1014.

97. Newton W, Arndt JE. Learning from history: the legacy of Title VII in academic family medicine. Acad Med. 2008;83(11):1030-1038. 
98. Reynolds PP. Title VII innovations in American medical and dental education: responding to 21st century priorities for the health of the American public. Acad Med. 2008;83(11):1015-1020.

99. Davis AK, Reynolds PP, Kahn NB, Jr., et al. Title VII and the development and promotion of national initiatives in training primary care clinicians in the United States. Acad Med. 2008;83(11):1021-1029.

100. Faulkner A, Wilson E., Whitler, E., Asher L. Role of international medical graduates in Kentucky medicine:: implications for workforce planning and medical education. 2012; 417-421. Available at:

http://ruralhealth.med.uky.edu/sites/default/files/KmaImg.pdf. Accessed $11 / 24 / 2014$.

101. Gill H, McLeod S, Duerksen K, Szafran O. Factors influencing medical students' choice of family medicine: effects of rural versus urban background. Can Fam Physician. 2012;58(11):e649-657.

102. Crandall LA, Dwyer, J. W., Duncan, R. P. Recruitment and Retention of Rural Physicians: Issues for the 1990s. J Rural Health. 1990;6(1):19.

103. Rabinowitz HK, Diamond JJ, Hojat M, Hazelwood CE. Demographic, educational and economic factors related to recruitment and retention of physicians in rural Pennsylvania. J Rural Health. 1999;15(2):212-218.

104. Stratton TD, Geller JM, Ludtke RL, Fickenscher KM. Effects of an expanded medical curriculum on the number of graduates practicing in a rural state. Acad Med. 1991;66(2):101-105.

105. Fryer GE, Jr., Stine C, Vojir C, Miller M. Predictors and profiles of rural versus urban family practice. Fam Med. 1997;29(2):115-118.

106. Orzanco MG, Lovato C, Bates J, Slade S, Grand'Maison P, Vanasse A. Nature and nurture in the family physician's choice of practice location. Rural Remote Health. 2011;11(3):1849.

107. Crump WJ, Fricker RS, Ziegler CH. Outcomes of a preclinical rural medicine elective at an urban medical school. Fam Med. 2010;42(10):717-722.

108. Crump WJ, Barnett D, Fricker S. A sense of place: rural training at a regional medical school campus. J Rural Health. 2004;20(1):80-84.

109. Quinn KJ, Kane KY, Stevermer JJ, et al. Influencing residency choice and practice location through a longitudinal rural pipeline program. Acad Med. 2011;86(11):1397-1406.

110. Kane KY, Quinn KJ, Stevermer JJ, et al. Summer in the country: changes in medical students' perceptions following an innovative rural community experience. Acad Med. 2013;88(8):1157-1163.

111. Jolly PR. Medical school tuition and young physicians' indebtedness. Health Aff (Millwood). 2005;24(2):527-535.

112. Grbic D, Garrison, G., Jolly, P. Diversity of US medical school students by parental education: analysis in brief. Acad Med. 2010;9(10).

113. Kiker B, Zeh M. Relative income expectations, expected malpractice premium costs, and other determinants of physician specialty choice. J Health Soc Behav. 1998;39(2):152-167. 
114. Greysen SR, Chen C, Mullan F. A history of medical student debt: observations and implications for the future of medical education. Acad Med. 2011;86(7):840845.

115. Naradzay JF. Into the deep well: the evolution of medical school loan debt. JAMA. 1998;280(21):1881.

116. Altenderfer M, West M. How medical students finance their education: results of a survey of medical and osteopathic students, 1963 - 1964. Washington, DC: US Department of Health, Education and Welfare; 1965.

117. Kassebaum DG, Szenas PL, Schuchert MK. On rising medical student debt: in for a penny, in for a pound. Acad Med. 1996;71(10):1124-1134.

118. American Association of Medical Colleges (AAMC). AAMC data book: medical school and teaching hospitals by the numbers,. 2009; https://www.aamc.org/data/databook/. Accessed 11/24/2014.

119. American Association of Medical Colleges (AAMC). Medical student education: cost, debt, and resident stipend facts. AAMC debt fact card. Association of American Medical Colleges 2010; https://www.aamc.org/download/152968/data/10debtfactcard.pdf. Accessed 11/20/2012.

120. Ludmerer K. Time to heal: American medical education from the turn-of-thecentury to the era of managed care. New York, NY: Oxford University Press; 1999.

121. Millis J. A rational public policy for medical education and its financing. New York, NY: National Fund for Medical Education; 1971.

122. Institute of Medicine. Cost of education and health professions. Washington, DC: National Academy of Sciences Press; 1974.

123. Carnegie Council on Policy Studies in Higher Education. Progress and problems in medical and dental education: federal support versus federal control. In: Carnegie Council on Policy Studies in Higher Education, ed. Washington, DC: Jossey-Bass Publishers; 1976.

124. Steinbrook R. Medical student debt--is there a limit? N Engl J Med. 2008;359(25):2629-2632.

125. Jolly PR. Diversity of US medical students by parental income. AAMC Analysis in Brief 2008; https://www.aamc.org/download/142770/data/aibvol9_no10.pdf. Accessed 11/24/2014.

126. Kwong JC, Dhalla IA, Streiner DL, Baddour RE, Waddell AE, Johnson IL. Effects of rising tuition fees on medical school class composition and financial outlook. Cmaj. 2002;166(8):1023-1028.

127. Weeks WB, Wallace AE. The more things change: revisiting a comparison of educational costs and incomes of physicians and other professionals. Acad Med. 2002;77(4):312-319.

128. Ebell MH. Future salary and US residency fill rate revisited. JAMA. 2008;300(10):1131-1132.

129. Frank E, Feinglass S. Student loan debt does not predict female physicians' choice of primary care specialty. J Gen Intern Med. 1999;14(6):347-350. 
130. Vanasse A, Orzanco MG, Courteau J, Scott S. Attractiveness of family medicine for medical students: influence of research and debt. Can Fam Physician. 2011;57(6):e216-227.

131. Barnighausen T, Bloom DE. Financial incentives for return of service in underserved areas: a systematic review. BMC Health Serv Res. 2009;9:86.

132. Pathman DE, Morgan JC, Konrad TR, Goldberg L. States' experiences with loan repayment programs for health care professionals in a time of state budget cuts and NHSC expansion. J Rural Health. 2012;28(4):408-415.

133. Pathman DE, Konrad TR, King TS, Taylor DH, Jr., Koch GG. Outcomes of states' scholarship, loan repayment, and related programs for physicians. Med Care. 2004;42(6):560-568.

134. Altschuler J, Margolius D, Bodenheimer T, Grumbach K. Estimating a reasonable patient panel size for primary care physicians with team-based task delegation. Ann Fam Med. 2012;10(5):396-400.

135. US Department of Health and Human Services Health Resources and Services Administration. NHSC clinician retention: a story of dedication and commitment. 2012; http://nhsc.hrsa.gov/currentmembers/membersites/retainproviders/ retentionbrief.pdf. Accessed 11/24/2014.

136. Kentucky Medical Association (KMA). Rural Kentucky Medical Scholarship Fund Established Practice Grant Program. https://www.kyma.org/content.asp?q_areaprimaryid=5\&q_areasecondaryid=4\&q _areatertiaryid=6. Accessed October 16, 2013.

137. Kentucky Office of Rural Health. Kentucky State Loan Repayment Program. 2015; http://ruralhealth.med.uky.edu/kentucky-state-loan-repayment-program. Accessed 02/23/2015.

138. Marshall Z. Interview with Zack Marshall, Legislative Director for Representative John Yarmouth. In: Ziegler C, ed2015.

139. Sempowski IP. Effectiveness of financial incentives in exchange for rural and underserviced area return-of-service commitments: systematic review of the literature. Can J Rural Med. 2004;9(2):82-88.

140. Rosenthal MP, Marquette PA, Diamond JJ. Trends along the debt-income axis: implications for medical students' selections of family practice careers. Acad Med. 1996;71(6):675-677.

141. Bowman MA, Haynes RA, Rivo ML, Killian CD, Davis PH. Characteristics of medical students by level of interest in family practice. Fam Med. 1996;28(10):713-719.

142. Kahn MJ, Markert RJ, Lopez FA, Specter S, Randall H, Krane NK. Is medical student choice of a primary care residency influenced by debt? MedGenMed. 2006;8(4):18.

143. Hauer KE, Durning SJ, Kernan WN, et al. Factors associated with medical students' career choices regarding internal medicine. JAMA. 2008;300(10):11541164.

144. Senf JH, Campos-Outcalt D, Kutob R. Factors related to the choice of family medicine: a reassessment and literature review. J Am Board Fam Pract. 2003;16(6):502-512. 
145. Grayson MS, Newton DA, Thompson LF. Payback time: the associations of debt and income with medical student career choice. Med Educ. 2012;46(10):983-991.

146. McDonald FS, West CP, Popkave C, Kolars JC. Educational debt and reported career plans among internal medicine residents. Ann Intern Med. 2008;149(6):416-420.

147. Pathman DE, Konrad TR, King TS, Spaulding C, Taylor DH. Medical training debt and service commitments: the rural consequences. J Rural Health. 2000;16(3):264-272.

148. Hollingshead A, B. Four factor index of social status. Yale University; 1975.

149. Child Mind Institute. Hollingshead Four-Factor Index of Socioeconomic Status (SES-Child). 2012;

http://fcon_1000.projects.nitrc.org/indi/enhanced/assessments/ses-child.html. Accessed 09/30/2013.

150. Cirino PT, Chin CE, Sevcik RA, Wolf M, Lovett M, Morris RD. Measuring socioeconomic status: reliability and preliminary validity for different approaches. Assessment. 2002;9(2):145-155.

151. American Academy of Familyy Physicians. Primary Care. http://www.aafp.org/about/policies/all/primary-care.html\#primary. Accessed 10/01/2013.

152. Ricketts TC, Johnson-Webb KD, P. T. Definitions of rural: a handbook for health policy makers and researchers. In: US Department of Health and Human Services, ed. Washinton, D.C.,1998.

153. SPSS Statistics for Windows [computer program]. Version Version 22.0. Armonk, NY: IBM; 2013.

154. SAS 9.1.3 Help and Documentation [computer program]. Cary NC: SAS Institute Inc.; 2013.

155. Zweig M, Campbell, G. Receiver-operating characteristic (ROC) plots: a fundamental evaluation tool in clinical medicine. Clin. Chem. 1993;39:561-577.

156. Brannick M. Logistic Regression. 2012; http://luna.cas.usf.edu/ mbrannic/files/regression/Logistic.html. Accessed 10/07/2013.

157. Allison P. Logistic regression: using the SAS system-theory and application. Cary, North Carolina: SAS Institute; 1999.

158. Norusis MJ. SPSS 12.0 statistical procedures companion. Upper Saddle River, NJ 07458: Prentice-Hall, Inc.; 2003.

159. Hair JF, Anderson, R.E., Tatham, R.L., Black, W.C. Multivariate data analysis. 5th ed. Upper Saddle River, New Jersey: Simon and Schuster Company; 1998.

160. Allison P. Logistic regression for rare events. 2012; http://www.statisticalhorizons.com/logistic-regression-for-rare-events. Accessed $10 / 20 / 2014$

161. Little RJ. A test of missing completely at random for multivariate data with missing values. J. Am. Statist. Assoc. 1988;83:1198-1292.

162. Bartlett J. When is complete case analysis unbiased? 2013; http://thestatsgeek.com/2013/07/06/when-is-complete-case-analysis-unbiased/. Accessed 11/23/2014, 2014. 
163. American College of Physicians. 2012 Internal Medicine Residency Match Virtually Unchanged from 2011.

http://www.acponline.org/newsroom/match_day_2012.htm. Accessed 02/15/2015.

164. Stevenson Rowan M, Hogg W, Huston P. Integrating public health and primary care. Healthc Policy. 2007;3(1):e160-181.

165. Landon BE, Grumbach K, Wallace PJ. Integrating public health and primary care systems: potential strategies from an IOM report. JAMA. 2012;308(5):461-462.

166. Phillips J, Petterson, S., Bazemore, A., Phillips, R. . A Large Retrospective Multivariate Analysis of the Relationship Between Medical Student Debt and Primary Care Practice in the United States. Paper presented at: North American Primary Care Research Group2012.

167. Berenson RA, Rich EC. US approaches to physician payment: the deconstruction of primary care. J Gen Intern Med. 2010;25(6):613-618.

168. Bodenheimer T, Berenson RA, Rudolf P. The primary care-specialty income gap: why it matters. Ann Intern Med. 2007;146(4):301-306.

169. Hirsch JA, Silva E, 3rd, Nicola GN, et al. The RUC: a primer for neurointerventionalists. J Neurointerv Surg. 2014;6(1):61-64.

170. Committee on C, Nomenclature, Gerstle RS, et al. Application of the resourcebased relative value scale system to pediatrics. Pediatrics. 2014;133(6):11581162.

171. Kumetz EA, Goodson JD. The undervaluation of evaluation and management professional services: the lasting impact of current procedural terminology code deficiencies on physician payment. Chest. 2013;144(3):740-745.

172. Mitchell CH, Spinelli RJ. Medicare reform and primary care concerns for future physicians. J Am Osteopath Assoc. 2013;113(10):776-787.

173. Edwards ST, Abrams MK, Baron RJ, et al. Structuring payment to medical homes after the affordable care act. J Gen Intern Med. 2014;29(10):1410-1413.

174. Berenson RA, Rich EC. How to buy a medical home? policy options and practical questions. J Gen Intern Med. 2010;25(6):619-624.

175. Goroll AH, Schoenbaum SC. Payment reform for primary care within the accountable care organization: a critical issue for health system reform. JAMA. 2012;308(6):577-578.

176. Paradise J, Gold JA, Wang W. Leveraging Medicaid in a Multi-Payer Medical Home Program: Spotlight on Rhode Island's Chronic Care Sustainability Initiative 2013; http://kff.org/medicaid/issue-brief/leveraging-medicaid-in-a-multi-payermedical-home-program-spotlight-on-rhode-islands-chronic-care-sustainabilityinitiative/. Accessed 02/18/2015.

177. Koller CF, Brennan TA, Bailit MH. Rhode Island's novel experiment to rebuild primary care from the insurance side. Health Aff (Millwood). 2010;29(5):941-947.

178. Morse J. Interview with John Morse, Senior Fellow in Health Affairs, University of Louisville. In: Ziegler C, ed March 12, 2015.

179. Sigsbee B. The income gap: specialties vs primary care or procedural vs nonprocedural specialties? Neurology. 2011;76(10):923-926.

180. Pechura CM. Programs of the Robert Wood Johnson Foundation to develop minority medical careers. Am J Med Sci. 2001;322(5):290-292. 
181. Leslie KF, Chism, A, Jones, F., Rowland, M., Ziegler, C. From Pipeline to Practitioner: Building Kentucky's Healthcare Workforce. J Ky Med Assoc.2014.

182. Shipman SA, Sinsky CA. Expanding primary care capacity by reducing waste and improving the efficiency of care. Health Aff (Millwood). 2013;32(11):1990-1997.

183. Cunningham R. On workforce policy, consensus is hard to find. Health Aff (Millwood). 2013;32(11):1871-1873.

184. Bodenheimer TS, Smith MD. Primary care: proposed solutions to the physician shortage without training more physicians. Health Aff (Millwood). 2013;32(11):1881-1886.

185. Poghosyan L, Lucero R, Rauch L, Berkowitz B. Nurse practitioner workforce: a substantial supply of primary care providers. Nurs Econ. 2012;30(5):268-274, 294.

186. Glicken AD, Miller AA. Physician assistants: from pipeline to practice. Acad Med. 2013;88(12):1883-1889.

187. Cassidy A. Health policy brief: Nurse Practitioners and Primary Care. . Health Aff (Millwood). 2013.

188. Kellermann AL, Saultz JW, Mehrotra A, Jones SS, Dalal S. Primary care technicians: a solution to the primary care workforce gap. Health Aff (Millwood). 2013;32(11):1893-1898.

189. American Association of Nurse Practitioners. Nurse practitioners in primary care. 2013; http://www.aanp.org/publications/position-statements-papers. Accessed February 16, 2014.

190. Auerbach DI. Will the NP workforce grow in the future? new forecasts and implications for healthcare delivery. Med Care. 2012;50(7):606-610.

191. Horrocks S, Anderson E, Salisbury C. Systematic review of whether nurse practitioners working in primary care can provide equivalent care to doctors. BMJ. 2002;324(7341):819-823.

192. Newhouse RP, Stanik-Hutt J, White KM, et al. Advanced practice nurse outcomes 1990-2008: a systematic review. Nurs Econ. 2011;29(5):230-251.

193. Naylor MD, Kurtzman ET. The role of nurse practitioners in reinventing primary care. Health Aff (Millwood). 2010;29(5):893-899.

194. Bauer JC. Nurse practitioners as an underutilized resource for health reform: evidence-based demonstrations of cost-effectiveness. J Am Acad Nurse Pract. 2010;22(4):228-231.

195. Chenoweth D, Martin N, Pankowski J, Raymond LW. Nurse practitioner services: three-year impact on health care costs. J Occup Environ Med. 2008;50(11):12931298.

196. Dierick-van Daele AT, Steuten LM, Metsemakers JF, Derckx EW, Spreeuwenberg C, Vrijhoef HJ. Economic evaluation of nurse practitioners versus GPs in treating common conditions. Br J Gen Pract. 2010;60(570):e28-35.

197. Pohl JM, Hanson C, Newland JA, Cronenwett L. Analysis \& commentary. Unleashing nurse practitioners' potential to deliver primary care and lead teams. Health Aff (Millwood). 2010;29(5):900-905.

198. Pearson L. The 2013 Pearson Report: a National Overview of Nurse Practitioner Legislation and Healthcare Issues. 2013. 
199. Barton Associates. NP scope of practice laws. 2013;

http://www.bartonassociates.com/nurse-practitioners/nurse-practitioner-scope-ofpractice-laws/. Accessed December 18, 2013.

200. Kuo YF, Loresto FL, Jr., Rounds LR, Goodwin JS. States with the least restrictive regulations experienced the largest increase in patients seen by nurse practitioners. Health Aff (Millwood). 2013;32(7):1236-1243.

201. National Council of State Boards of Nursing. Consensus model for APR in regulation: licensors, accreditation, certification and education. 2008.

202. Ricketts TC, Fraher EP. Reconfiguring health workforce policy so that education, training, and actual delivery of care are closely connected. Health Aff (Millwood). 2013;32(11):1874-1880.

203. Spetz J, Parente ST, Town RJ, Bazarko D. Scope-of-practice laws for nurse practitioners limit cost savings that can be achieved in retail clinics. Health Aff (Millwood). 2013;32(11):1977-1984.

204. Kaissi A, Charland T. The evolution of retail clinics in the United States, 20062012. Health Care Manag (Frederick). 2013;32(4):336-342.

205. Mehrotra A, Lave JR. Visits to retail clinics grew fourfold from 2007 to 2009, although their share of overall outpatient visits remains low. Health Aff (Millwood). 2012;31(9):2123-2129.

206. Dow A, Bohannon, A., Garland, S., Mazmanian, P., Retchin, S. The effects of expanding primary care access for the uninsured: implications for the health care workforce under health reform. Acad Med. 2013;88(12):1855-1861.

207. Reid RO, Ashwood JS, Friedberg MW, Weber ES, Setodji CM, Mehrotra A. Retail clinic visits and receipt of primary care. J Gen Intern Med. 2013;28(4):504512.

208. Mehrotra A, Liu H, Adams JL, et al. Comparing costs and quality of care at retail clinics with that of other medical settings for 3 common illnesses. Ann Intern Med. 2009;151(5):321-328.

209. Maine LL, Knapp KK, Scheckelhoff DJ. Pharmacists and technicians can enhance patient care even more once national policies, practices, and priorities are aligned. Health Aff (Millwood). 2013;32(11):1956-1962.

210. Rohrer JE, Angstman KB, Furst JW. Impact of retail walk-in care on early return visits by adult primary care patients: evaluation via triangulation. Qual Manag Health Care. 2009;18(1):19-24.

211. Rohrer JE, Garrison GM, Angstman KB. Early return visits by pediatric primary care patients with otitis media: a retail nurse practitioner clinic versus standard medical office care. Qual Manag Health Care. 2012;21(1):44-47.

212. Parente S, Town, RJ. The Impact of Retail Clinics on Costs, Utilization, and Welfare. Cambridge, (MA): National Bureau of Economic Research2010.

213. O'Connor TM, Hooker RS. Extending rural and remote medicine with a new type of health worker: physician assistants. Aust J Rural Health. 2007;15(6):346-351.

214. American Academy of Physician Assistants. Information about PAs and the PA profession. 2005; https://www.orthocarolina.com/assets/user/media/Information _About_PAs_and_the_PA_Profession.pdf. Accessed 11/24/2014. 
215. Halter M, Drennan V, Chattopadhyay K, et al. The contribution of physician assistants in primary care: a systematic review. BMC Health Serv Res. 2013;13:223.

216. Cooper RA. New directions for nurse practitioners and physician assistants in the era of physician shortages. Acad Med. 2007;82(9):827-828.

217. Bureau Of Labor Statistics. Occupational Outlook Handbook: physician assistants. 2012; http://www.bls.gov/ooh/Healthcare/Physician-assistants.htm. Accessed January 17, 2014.

218. Hooker RS, Everett CM. The contributions of physician assistants in primary care systems. Health Soc Care Community. 2012;20(1):20-31.

219. Mittman D, Cawley, JF, Fenn, WF. Physicians Assistant in the United States. $\mathrm{Br}$ Med J. 2002;325(7362):485 -487.

220. Hooker RS. A cost analysis of physician assistants in primary care. JAAPA. 2002;15(11):39 - 48.

221. Dill MJ, Pankow S, Erikson C, Shipman S. Survey shows consumers open to a greater role for physician assistants and nurse practitioners. Health Aff (Millwood). 2013;32(6):1135-1142.

222. Brock D, Bolon S, Wick K, et al. The military veteran to physician assistant pathway: building the primary care workforce. Acad Med. 2013;88(12):18901894.

223. American Academy of Physician Assistants. Professional issues, issues brief: physician assistant scope of practice. 2011;

http://www.aapa.org/uploadedFiles/content/The_PA_Profession/Federal_and_Stat e_Affairs/Resource_Items/PI_PAScopePractice_110811_Final.pdf. Accessed January 19, 2014.

224. Smith MA. Pharmacists and the primary care workforce. Ann Pharmacother. 2012;46(11):1568-1571.

225. Manolakis P, Skelton JB. Pharmacist contribution to patient care the UScollaborating to address unmet patient care needs the emerging role for pharmacists to address the shortage of primary care providers. Am J Pharm Educ. 2010;74(10).

226. Smith M, Bates DW, Bodenheimer TS. Pharmacists belong in accountable care organizations and integrated care teams. Health Aff (Millwood). 2013;32(11):1963-1970.

227. Kuehn BM. CDC pilot program will offer free rapid HIV tests through pharmacies. JAMA. 2012;308(4):327.

228. National Association of Chain Drug Stores. NACDS Industry Profile. Alexander Virginia 2011.

229. Goad JA, Taitel MS, Fensterheim LE, Cannon AE. Vaccinations administered during off-clinic hours at a national community pharmacy: implications for increasing patient access and convenience. Ann Fam Med. 2013;11(5):429-436.

230. Alliance for Pharmacists Provide Patient Care. How pharmacists are already benefiting from pharmacists' services. 2013; http://www.allianceforpharmcare.com/docs/How_Patients_Are_Already_Benefiti ng_from_Pharmacists_Services.pdf. Accessed January 22, 2014. 
231. Isetts BJ, Brummel AR, de Oliveira DR, Moen DW. Managing drug-related morbidity and mortality in the patient-centered medical home. Med Care. 2012;50(11):997-1001.

232. Ramalho de Oliveira D, Brummel AR, Miller DB. Medication therapy management: 10 years of experience in a large integrated health care system. $J$ Manag Care Pharm. 2010;16(3):185-195.

233. American Pharmacists Association. Pharmacists belong on frontline of primary care. 2013; http://www.pharmacist.com/pharmacists-belong-frontline-primarycare. Accessed January 20, 2014.

234. Abramowitz PW. Achieving provider status for pharmacists. Am J Health Syst Pharm. 2013;70(3):184.

235. Grover AM, Niecko-Najjum LM. Primary care teams: are we there yet? implications for workforce planning. Acad Med. 2013;88(12):1827-1829.

236. Pershing SMD, Fuchs VRP. Restructuring Medical Education to Meet Current and Future Health Care Needs. Acad Med. 2013;88(12):1798-1801.

237. Erikson C. Will new care delivery solve the primary care physician shortage?: A call for more rigorous evaluation. Healthcare. 2013;1(1-2):8-11.

238. Garson AJ. New systems of care can leverage the health care workforce: how many doctors do we really need? Acad Med. 2013;88(12):1817-1821.

239. Ladden MD, Bodenheimer T, Fishman NW, et al. The emerging primary care workforce: preliminary observations from the primary care team: learning from Effective Ambulatory Practices Project. Acad Med. 2013;88(12):1830-1834.

240. Fraher E, Ricketts T, Lefebvre A, Newton W. The Role of Academic Health Centers and Their Partners in Reconfiguring and Retooling the Existing Workforce to Practice in a Transformed Health System. Acad Med. 2013;88(12):1812-1816.

241. Dower C. Medical assistants in California: legal scope of practice. 2012; http://futurehealth.ucsf.edu/LinkClick.aspx?fileticket=SfdfTM3DUfU\%3d\&tabid =161. Accessed January 24, 2014.

242. Garson A, Jr., Green DM, Rodriguez L, Beech R, Nye C. A new corps of trained Grand-Aides has the potential to extend reach of primary care workforce and save money. Health Aff (Millwood). 2012;31(5):1016-1021.

243. Chesluk BJ, Holmboe ES. How teams work--or don't--in primary care: a field study on internal medicine practices. Health Aff (Millwood). 2010;29(5):874-879.

244. American Hospital Association. 2010 Committee on Research. AHA research synthesis report: accountable care organizations. 2010; http://www.hret.org/accountable/index.shtml. Accessed 11/24/2014.

245. Chism A, Leslie K, Ziegler C, Jones F. From pipeline to physician: practice outcomes of the Professional Education Preparation Program. J Ky Med Assoc. 2014;112:253-258.

246. Nolan N. Is shortening medical education the answer to the dr. shortage? 2013; http://thedifferentialdiagnosis.com/post/63965473193/is-shortening-medicaleducation-the-answer-to-the. Accessed 02/25/2015.

247. Emanuel EJ, Fuchs VR. Shortening medical training by 30\%. Jama. 2012;307(11):1143-1144. 
248. Goldfarb S, Morrison G. The 3-year medical school--change or shortchange? $N$ Engl J Med. 2013;369(12):1087-1089.

249. Loftus LS, Willoughby TL, Connolly A. Evaluation of student performance in combined baccalaureate-MD degree programs. Teach Learn Med. 1997;9(4):248253.

250. Shannon SC, Buser BR, Hahn MB, et al. A new pathway for medical education. Health Aff (Millwood). 2013;32(11):1899-1905.

251. Bell HS, Ferretti SM, Ortoski RA. A three-year accelerated medical school curriculum designed to encourage and facilitate primary care careers. Acad Med. 2007;82(9):895-899.

252. Abramson SB, Jacob D, Rosenfeld M, et al. A 3-year M.D.--accelerating careers, diminishing debt. $N$ Engl J Med. 2013;369(12):1085-1087.

253. O'Connor Grochowski C, Halperin EC, Buckley EG. A curricular model for the training of physician scientists: the evolution of the Duke University School of Medicine curriculum. Acad Med. 2007;82(4):375-382.

254. Lyss-Lerman P, Teherani A, Aagaard E, Loeser H, Cooke M, Harper GM. What training is needed in the fourth year of medical school? Views of residency program directors. Acad Med. 2009;84(7):823-829.

255. Whitcomb ME. Decreasing the length of residency training: a public policy perspective. Acad Med. 2013;88(12):1802-1803.

256. Zweifler J. Why we should reduce family practice training to two years. Acad Med. 2003;78(9):885-887.

257. Green LA, Fryer GE, Jr. Family practice in the United States: position and prospects. Acad Med. 2002;77(8):781-789.

258. Green LA, Fryer GE, Jr., Yawn BP, Lanier D, Dovey SM. The ecology of medical care revisited. N Engl J Med. 2001;344(26):2021-2025.

259. Joyce B. An introduction to competency-based residency education. ACGME 2006; http://umm.edu/professionals/gme/competencies. Accessed 11/24/2014.

260. Dorsey ER, Nincic D, Schwartz JS. An evaluation of four proposals to reduce the financial burden of medical education. Acad Med. 2006;81(3):245-251.

261. Weiner JP, Yeh S, Blumenthal D. The impact of health information technology and e-health on the future demand for physician services Health Aff (Millwood). 2013;32(11):1998-2004.

262. Jamoom E, Beatty P, Bercovitz A, Woodwell D, Palso K, Rechtsteiner T. Physician adoption of electronic health record systems: United States, 2011. 2011; http://www.cdc.gov/nchs/data/databriefs/db98.htm. Accessed March 4, 2014.

263. King J, Patel V, Furukawa M. Physician adoption of electronic health record technology to meet meaningful use objectives: 2009-2012. In: The Office of the National Coordinator for Health Information Technology, ed. Vol No. 7. Washington, DC: ONC Data Brief; 2012.

264. Ricciardi L, Mostashari F, Murphy J, Daniel JG, Siminerio EP. A national action plan to support consumer engagement via e-health. Health Aff (Millwood). 2013;32(2):376-384.

265. Garrett P, Seiman, J. EMR vs EHRs-what is the difference? 2011; http://www.healthit.gov/buzz-blog/electronic-health-and-medical-records/emr-vsehr-difference/. Accessed March 5, 2014. 
266. Rouse M. Clinical Decision Support Systems (CDSS). 2010; http://searchhealthit.techtarget.com/definition/clinical-decision-support-systemCDSS. Accessed March 5, 2014.

267. Miliard M. Healthcare IT index: computerized physician order entry (CPOE). 2012; http://www.healthcareitnews.com/directory/computerized-physician-orderentry-cpoe. Accessed March 5, 2014.

268. Zheng K, Haftel HM, Hirschl RB, O'Reilly M, Hanauer DA. Quantifying the impact of health IT implementations on clinical workflow: a new methodological perspective. J Am Med Inform Assoc. 2010;17(4):454-461.

269. Lau F, Kuziemsky C, Price M, Gardner J. A review on systematic reviews of health information system studies. J Am Med Inform Assoc. 2010;17(6):637-645.

270. Niazkhani Z, Pirnejad H, Berg M, Aarts J. The impact of computerized provider order entry systems on inpatient clinical workflow: a literature review. J Am Med Inform Assoc. 2009;16(4):539-549.

271. Eslami S, Abu-Hanna A, de Keizer NF. Evaluation of outpatient computerized physician medication order entry systems: a systematic review. J Am Med Inform Assoc. 2007;14(4):400-406.

272. Chaudhry B, Wang J, Wu S, et al. Systematic review: impact of health information technology on quality, efficiency, and costs of medical care. Ann Intern Med. 2006;144(10):742-752.

273. Palen TE, Ross C, Powers JD, Xu S. Association of online patient access to clinicians and medical records with use of clinical services. JAMA. 2012;308(19):2012-2019.

274. Ekeland AG, Bowes A, Flottorp S. Effectiveness of telemedicine: a systematic review of reviews. Int J Med Inform. 2010;79(11):736-771.

275. Poissant L, Pereira J, Tamblyn R, Kawasumi Y. The impact of electronic health records on time efficiency of physicians and nurses: a systematic review. $J$ Am Med Inform Assoc. 2005;12(5):505-516.

276. Wiener JP, Yeh S, Blumenthal D. The impact of health information technology and e-health on the future demand for physician services appendix. Health Aff (Millwood). 2013;32(Number 11):1998 - 2004.

277. Scott JT, Rundall TG, Vogt TM, Hsu J. Kaiser Permanente's experience of implementing an electronic medical record: a qualitative study. BMJ. 2005;331(7528):1313-1316.

278. Miller RH, Sim I. Physicians' use of electronic medical records: barriers and solutions. Health Aff (Millwood). 2004;23(2):116-126.

279. Liederman EM, Lee JC, Baquero VH, Seites PG. The impact of patient-physician Web messaging on provider productivity. J Healthc Inf Manag. 2005;19(2):81-86.

280. Chen C, Garrido T, Chock D, Okawa G, Liang L. The Kaiser Permanente electronic health record: transforming and streamlining modalities of care. Health Aff (Millwood). 2009;28(2):323-333.

281. Garrido T, Jamieson L, Zhou Y, Wiesenthal A, Liang L. Effect of electronic health records in ambulatory care: retrospective, serial, cross sectional study. BMJ. 2005;330(7491):581. 
282. Holroyd-Leduc JM, Lorenzetti D, Straus SE, Sykes L, Quan H. The impact of the electronic medical record on structure, process, and outcomes within primary care: a systematic review of the evidence. J Am Med Inform Assoc. 2011;18(6):732-737.

283. Eslami S, de Keizer NF, Abu-Hanna A. The impact of computerized physician medication order entry in hospitalized patients--a systematic review. Int J Med Inform. 2008;77(6):365-376.

284. Bright TJ, Wong A, Dhurjati R, et al. Effect of clinical decision-support systems: a systematic review. Ann Intern Med. 2012;157(1):29-43.

285. Goldzweig CL, Towfigh AA, Paige NM, et al. Systematic review: secure messaging between providers and patients, and patients' access to their own medical record: evidence on health outcomes, satisfaction, efficiency and attitudes. Washington (DC)2012.

286. Zhou YY, Kanter MH, Wang JJ, Garrido T. Improved quality at Kaiser Permanente through e-mail between physicians and patients. Health Aff (Millwood). 2010;29(7):1370-1375.

287. Bergmo TS, Kummervold PE, Gammon D, Dahl LB. Electronic patient-provider communication: will it offset office visits and telephone consultations in primary care? Int J Med Inform. 2005;74(9):705-710.

288. Lorig KR, Ritter PL, Dost A, Plant K, Laurent DD, McNeil I. The expert patients programme online, a 1-year study of an internet-based self-management programme for people with long-term conditions. Chronic Illn. 2008;4(4):247256.

289. Jackson CL, Bolen S, Brancati FL, Batts-Turner ML, Gary TL. A systematic review of interactive computer-assisted technology in diabetes care. interactive information technology in diabetes care. J Gen Intern Med. 2006;21(2):105-110.

290. Ross SE, Moore LA, Earnest MA, Wittevrongel L, Lin CT. Providing a webbased online medical record with electronic communication capabilities to patients with congestive heart failure: randomized trial. $J$ Med Internet Res. 2004;6(2):e12.

291. Stellefson M, Chaney B, Barry AE, et al. Web 2.0 chronic disease selfmanagement for older adults: a systematic review. J Med Internet Res. 2013;15(2):e35.

292. Lorig KR, Ritter PL, Laurent DD, Plant K. The internet-based arthritis selfmanagement program: a one-year randomized trial for patients with arthritis or fibromyalgia. Arthritis Rheum. 2008;59(7):1009-1017.

293. Ammenwerth E, Schnell-Inderst P, Hoerbst A. The impact of electronic patient portals on patient care: a systematic review of controlled trials. $J$ Med Internet Res. 2012;14(6):e162.

294. Myers MR. Telemedicine: an emerging health care technology. Health Care Manag (Frederick). 2003;22(3):219-223.

295. Harno K, Paavola T, Carlson C, Viikinkoski P. Patient referral by telemedicine: effectiveness and cost analysis of an Intranet system. $J$ Telemed Telecare. 2000;6(6):320-329.

296. Aas IH. Telemedicine and changes in the distribution of tasks between levels of care. J Telemed Telecare. 2002;8 Suppl 2: 1-2 
297. Switzer JA, Levine SR, Hess DC. Telestroke 10 years later--'telestroke 2.0'. Cerebrovasc Dis. 2009;28(4):323-330.

298. Malasanos TH, Burlingame JB, Youngblade L, Patel BD, Muir AB. Improved access to subspecialist diabetes care by telemedicine: cost savings and care measures in the first two years of the FITE diabetes project. $J$ Telemed Telecare. 2005;11 Suppl 1:74-76.

299. Kobb R, Hoffman N, Lodge R, Kline S. Enhancing elder chronic care through technology and care coordination: report from a pilot. Telemed J E Health. 2003;9(2):189-195.

300. Woods KF, Johnson JA, Kutlar A, Daitch L, Stachura ME. Sickle cell disease telemedicine network for rural outreach. J Telemed Telecare. 2000;6(5):285-290.

301. Raza T, Joshi M, Schapira RM, Agha Z. Pulmonary telemedicine--a model to access the subspecialist services in underserved rural areas. Int J Med Inform. 2009;78(1):53-59.

302. Duplantie J, Gagnon MP, Fortin JP, Landry R. Telehealth and the recruitment and retention of physicians in rural and remote regions: a Delphi study. Can J Rural Med. 2007;12(1):30-36.

303. Blumenthal D. Implementation of the federal health information technology initiative. N Engl J Med. 2011;365(25):2426-2431.

304. Centers for Disease Control and Prevention. Meaningful Use. 2012; http://www.cdc.gov/ehrmeaningfuluse/introduction.html. Accessed February 28, 2014.

305. Johnson S. Banking on healthcare - What VISA learned 30 years ago points the way for a 21st century healthcare system. 2005; http://www.touchbriefings.com/pdf/1251/johnson.pdf. Accessed October 12, 2005.

306. Ellerin BE. Debt, demographics, and dual degrees: American medicine at the crossroads: part 1: marketplace issues. J Am Coll Radiol. 2007;4(6):362-370.

307. Ellerin BE. Debt, demographics, and dual degrees: American medicine at the crossroads: part 3: A paradigm shift or a return to the basics? J Am Coll Radiol. 2007;4(8):537-546.

308. Phillips RL, Jr., Bazemore AM, Peterson LE. Effectiveness over efficiency: underestimating the primary care physician shortage. Med Care. 2014;52(2):9798.

309. Henry JA, Edwards BJ, Crotty, B. Why do medical graduates choose rural careers? Rural Remote Health. 2009, 9:1083. 


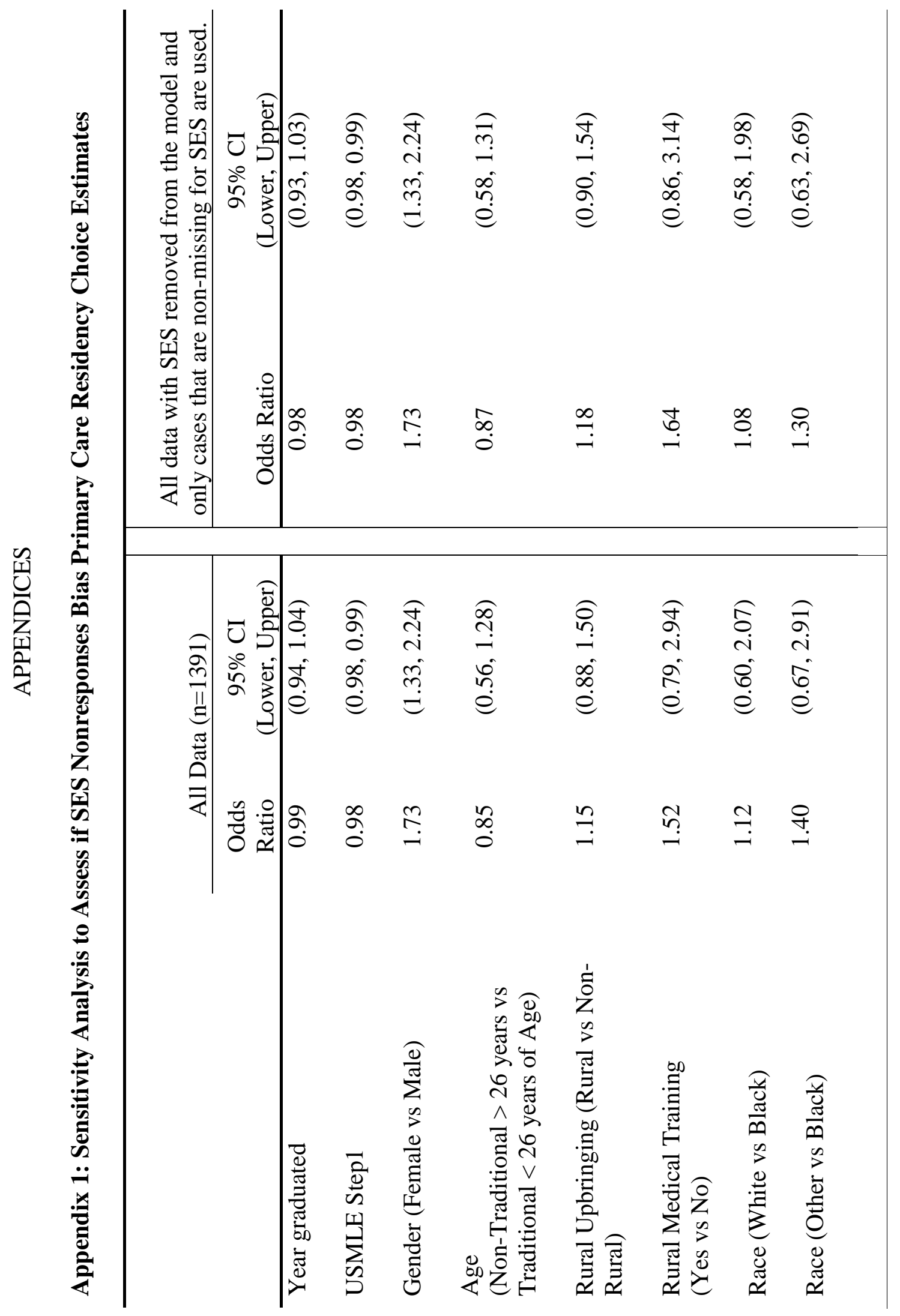




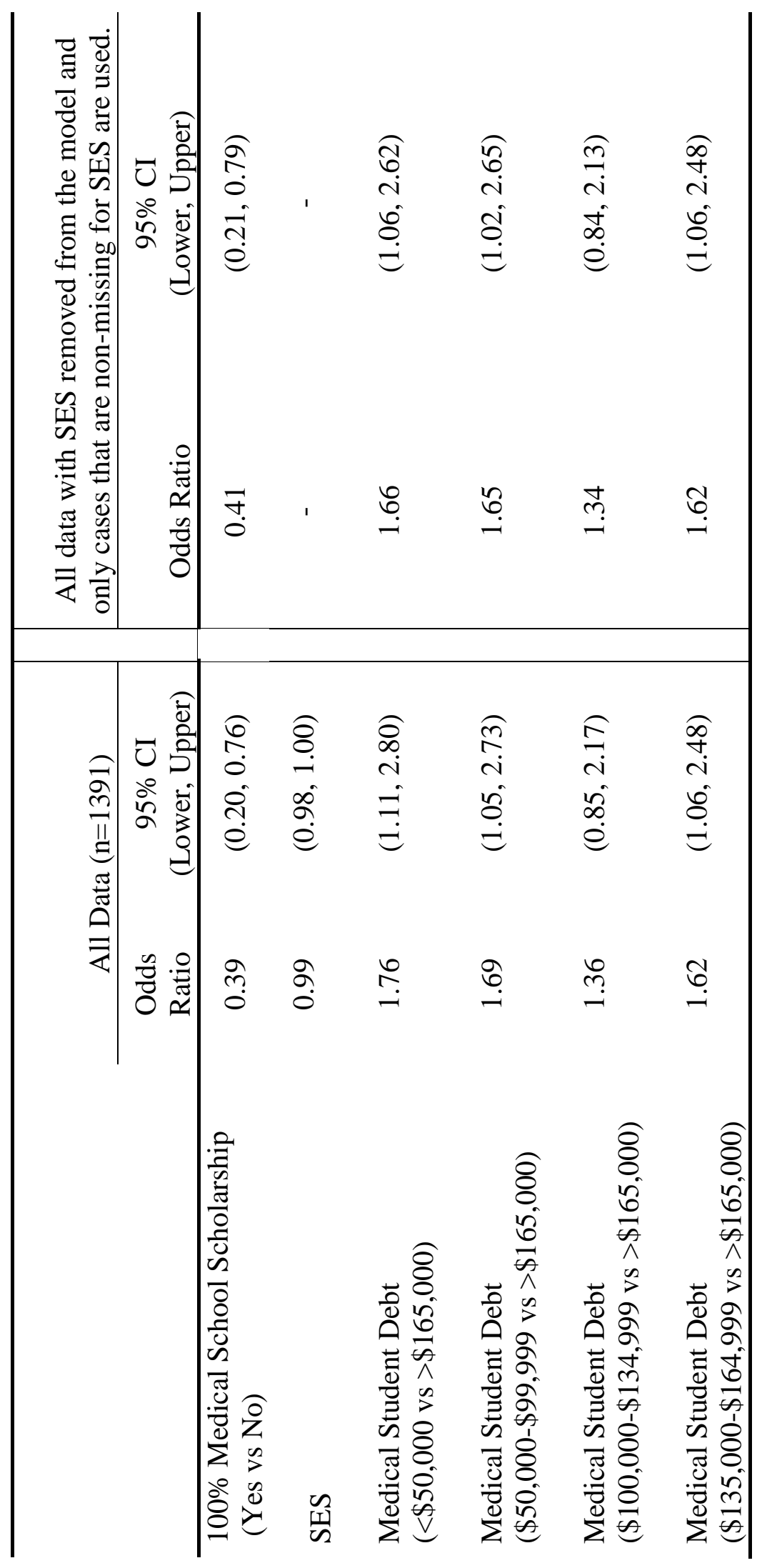




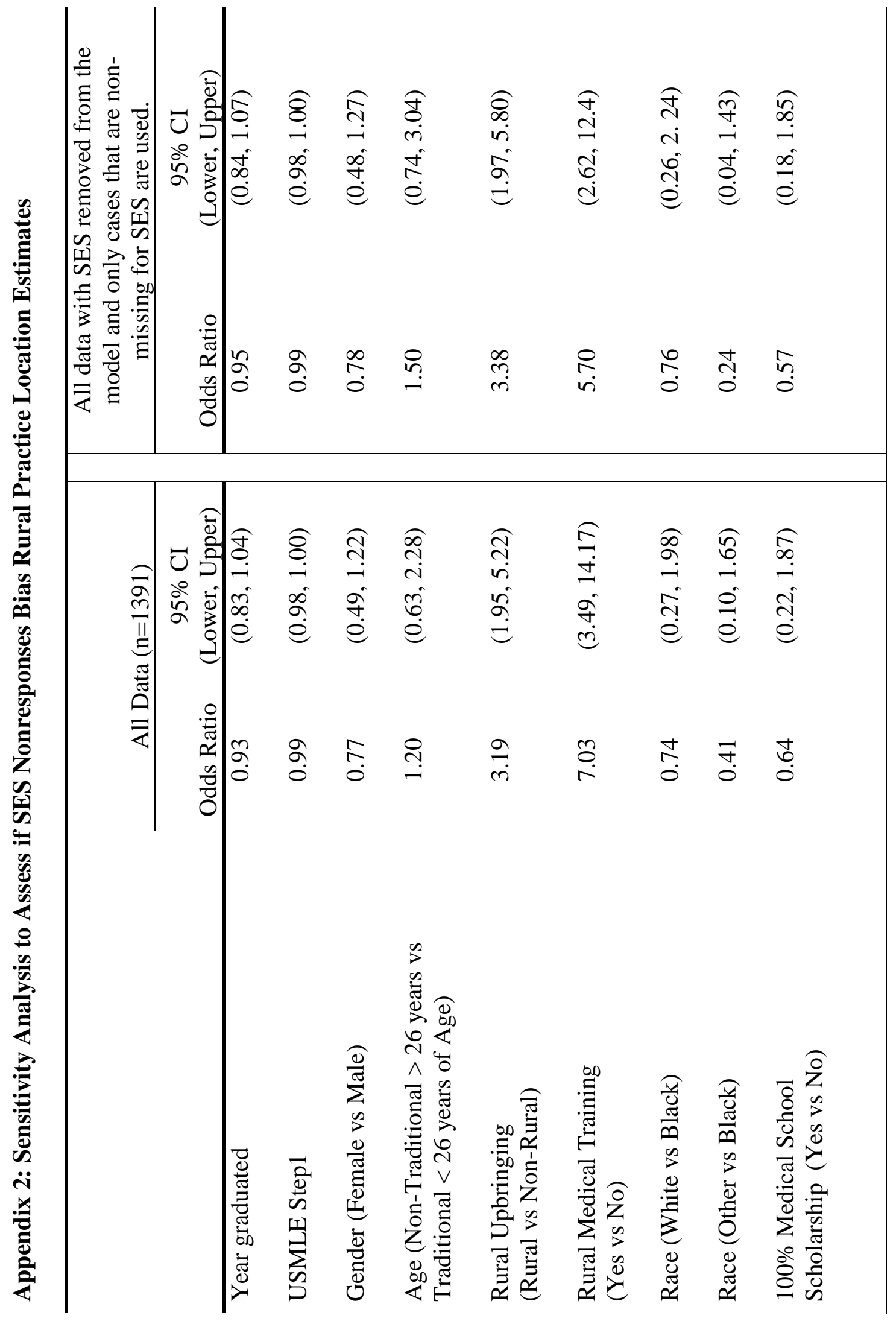




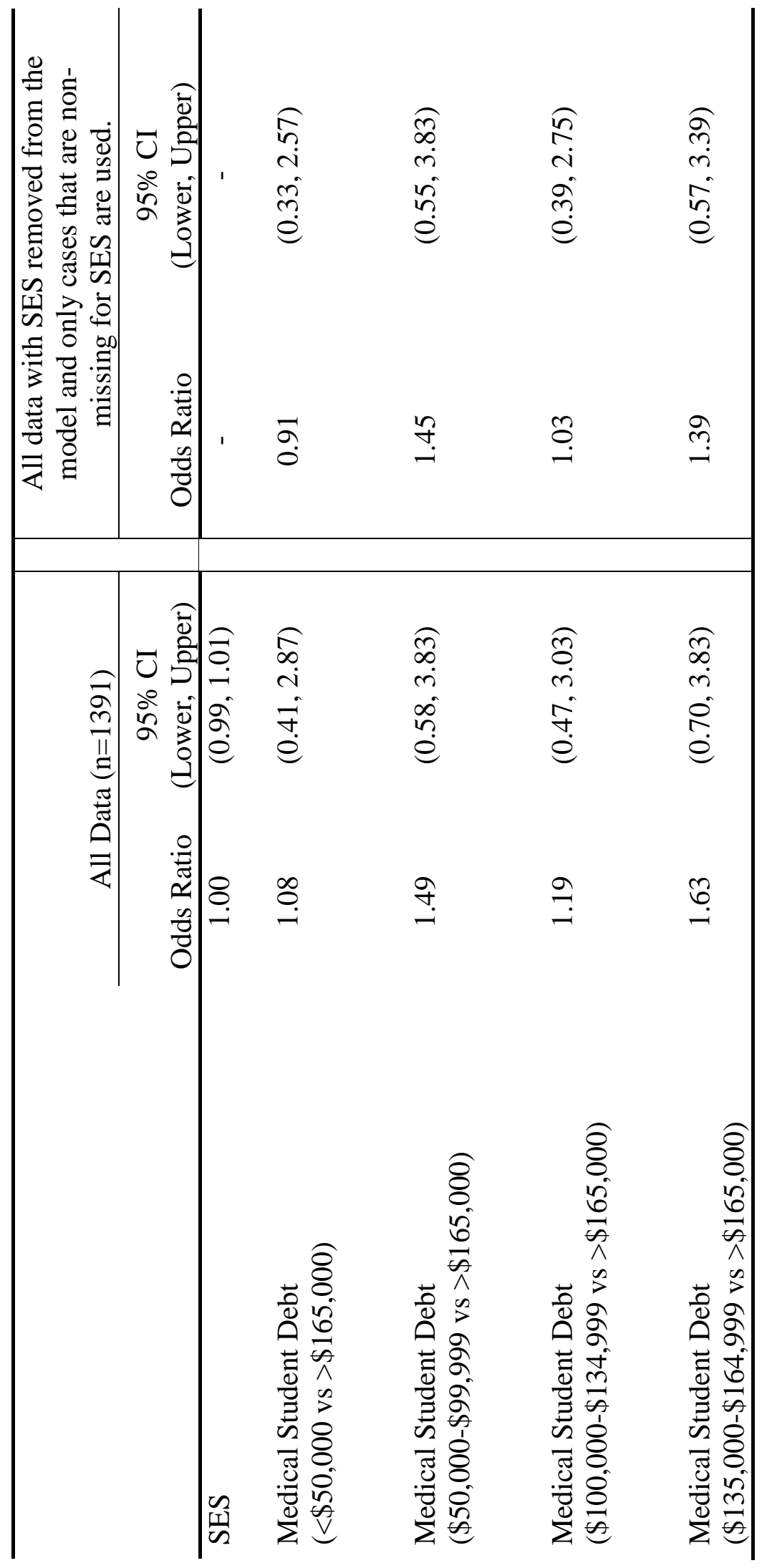




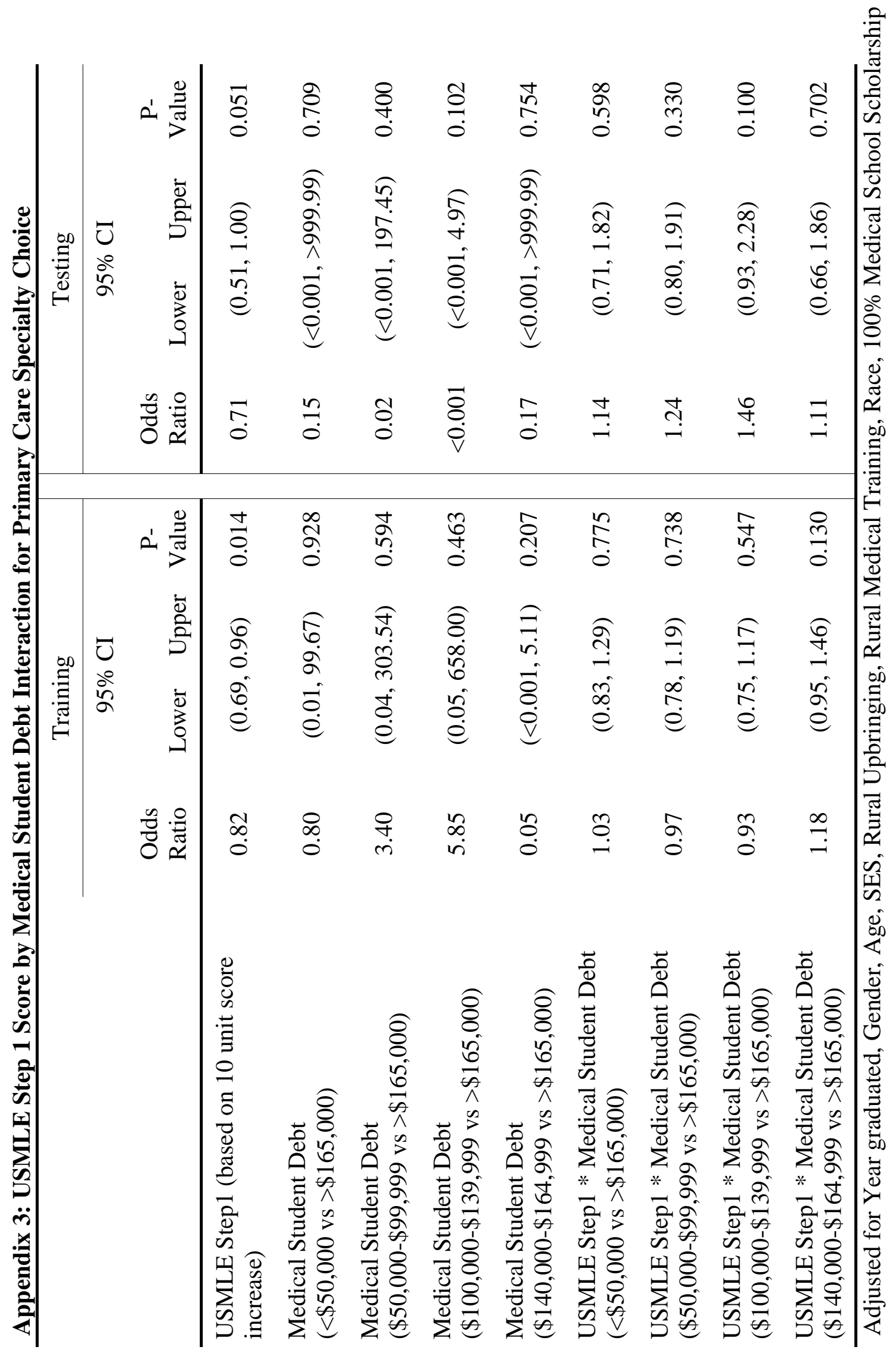




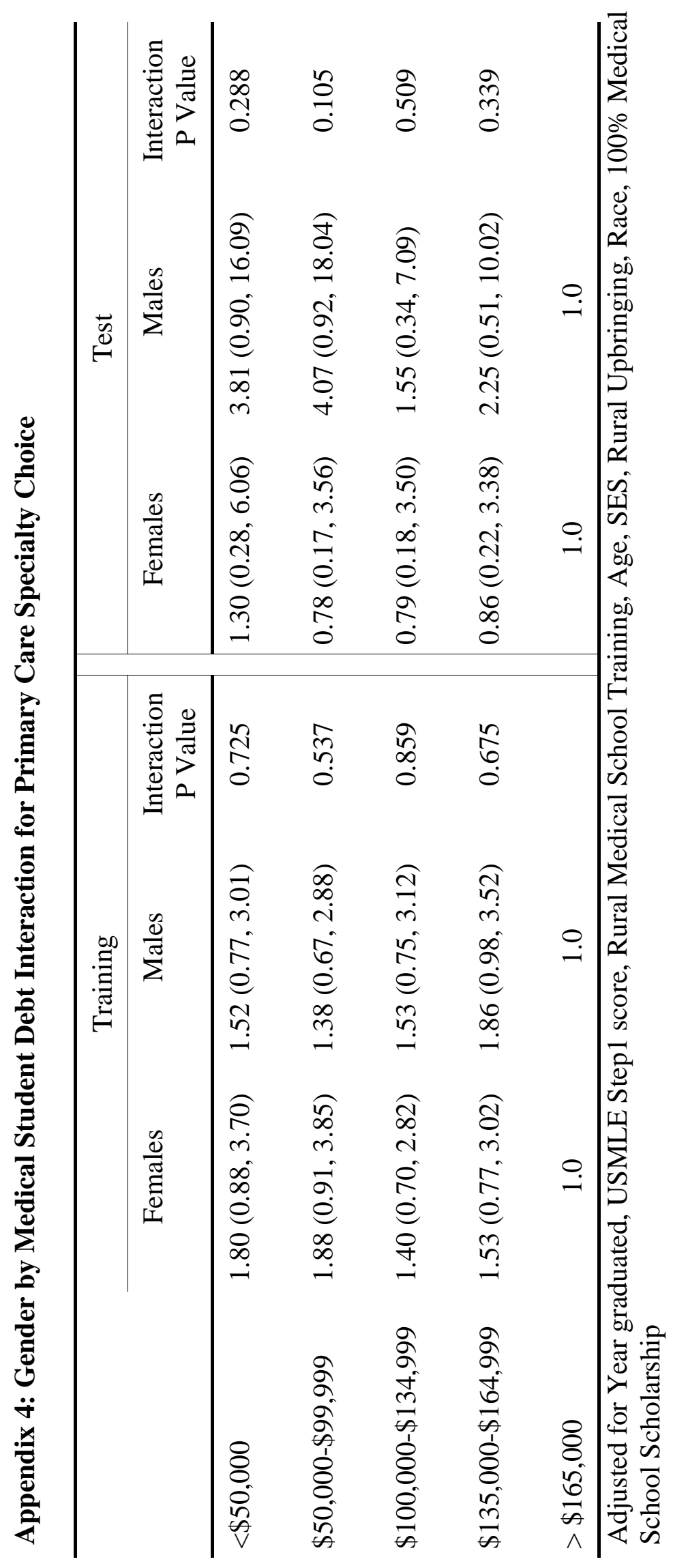




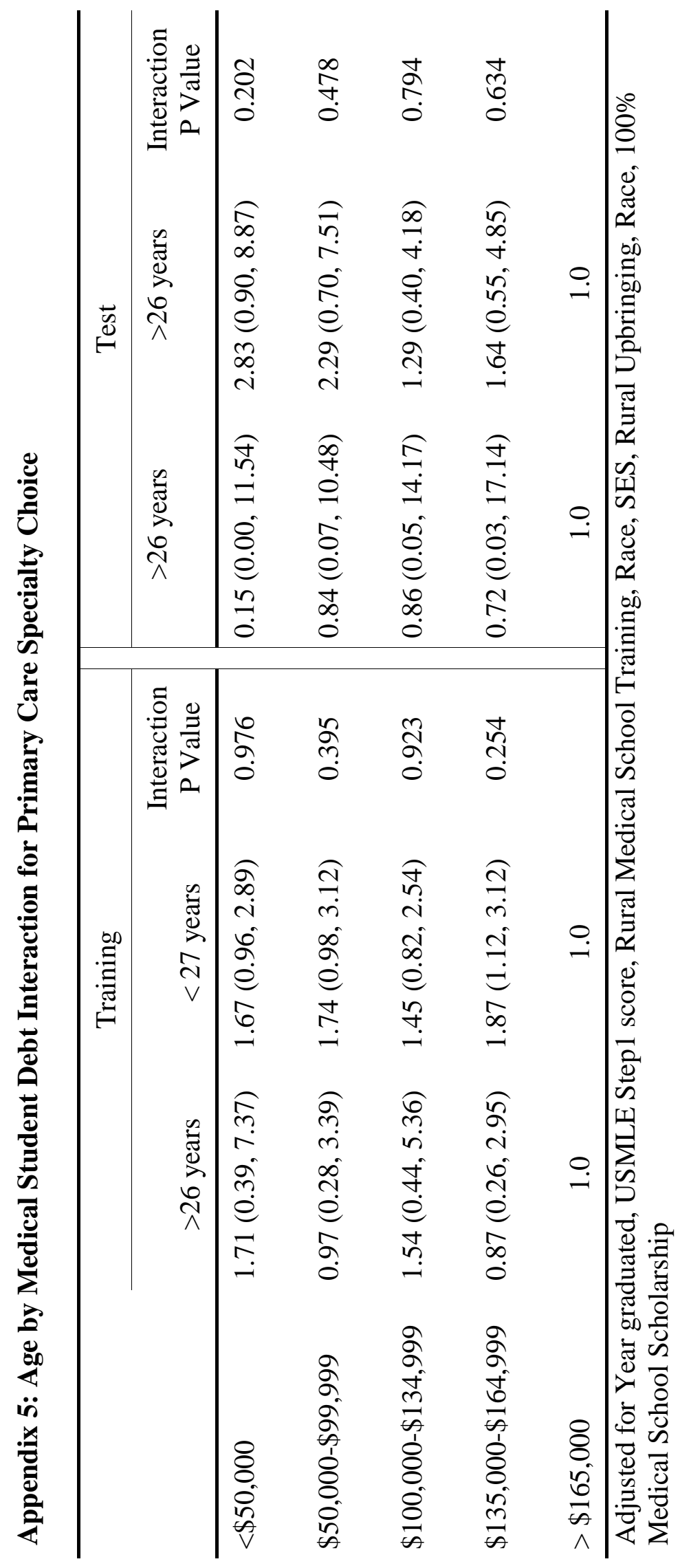




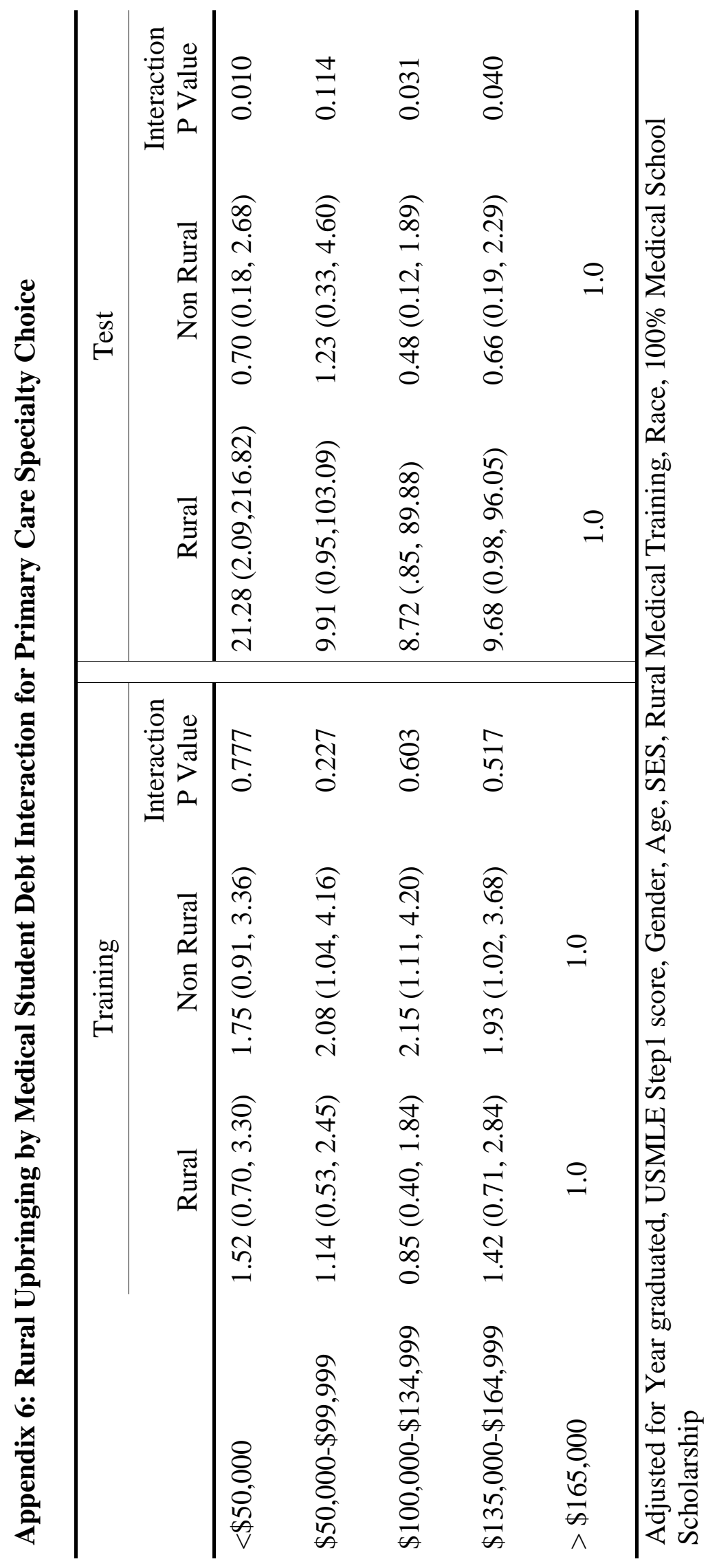




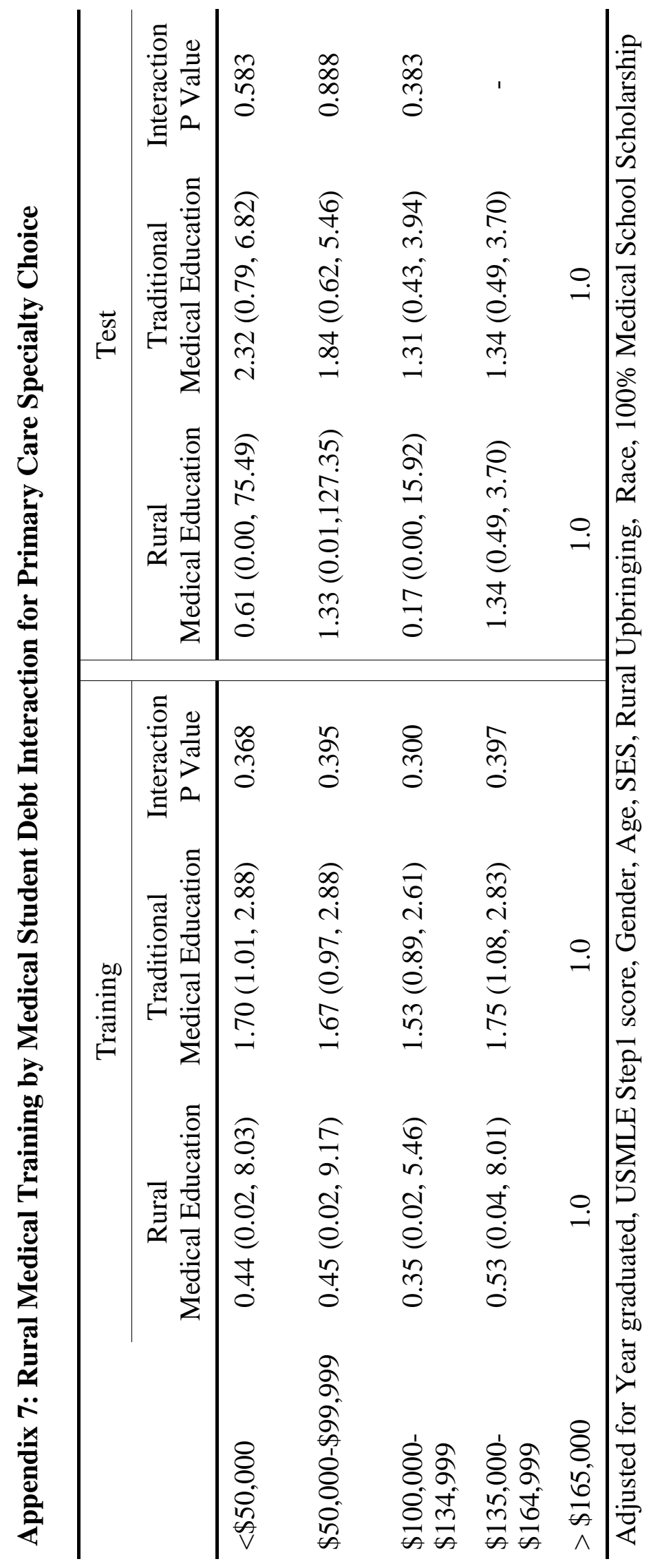




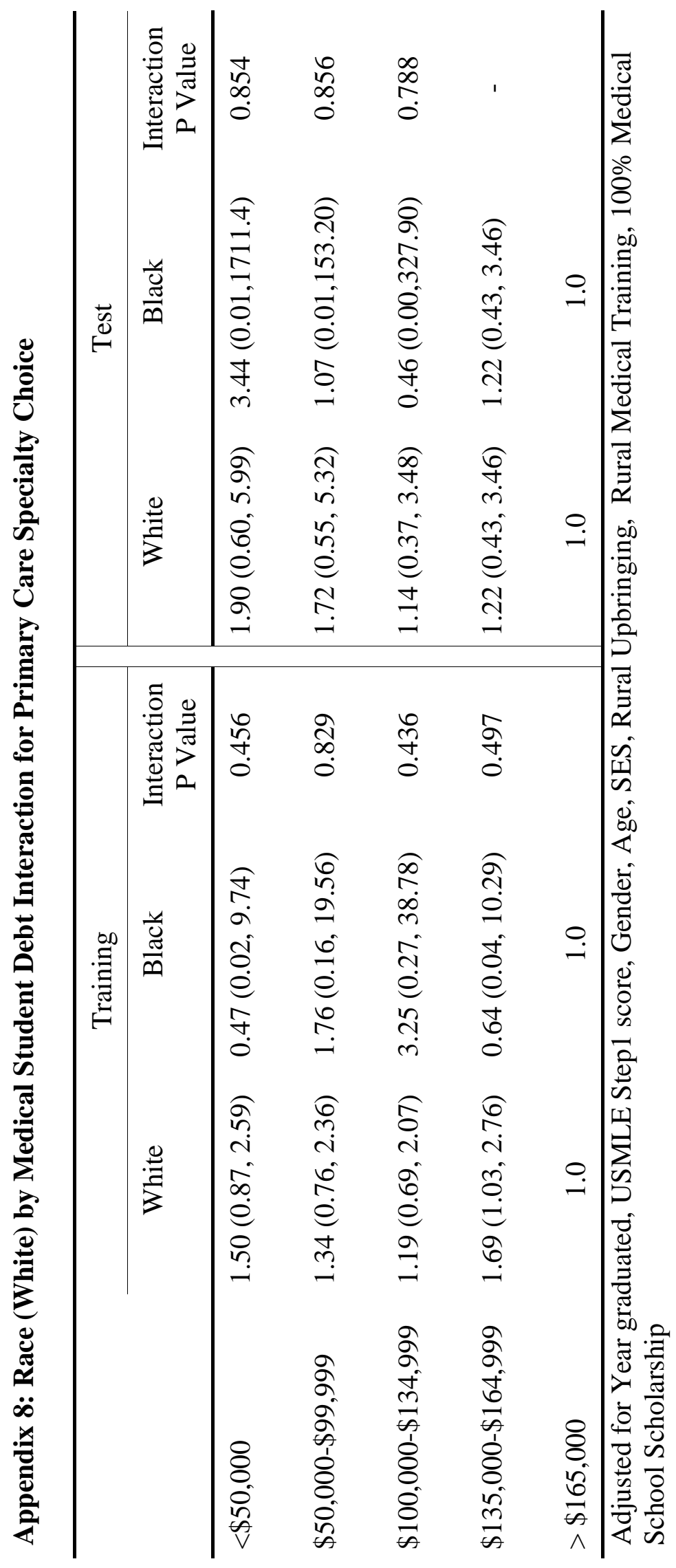




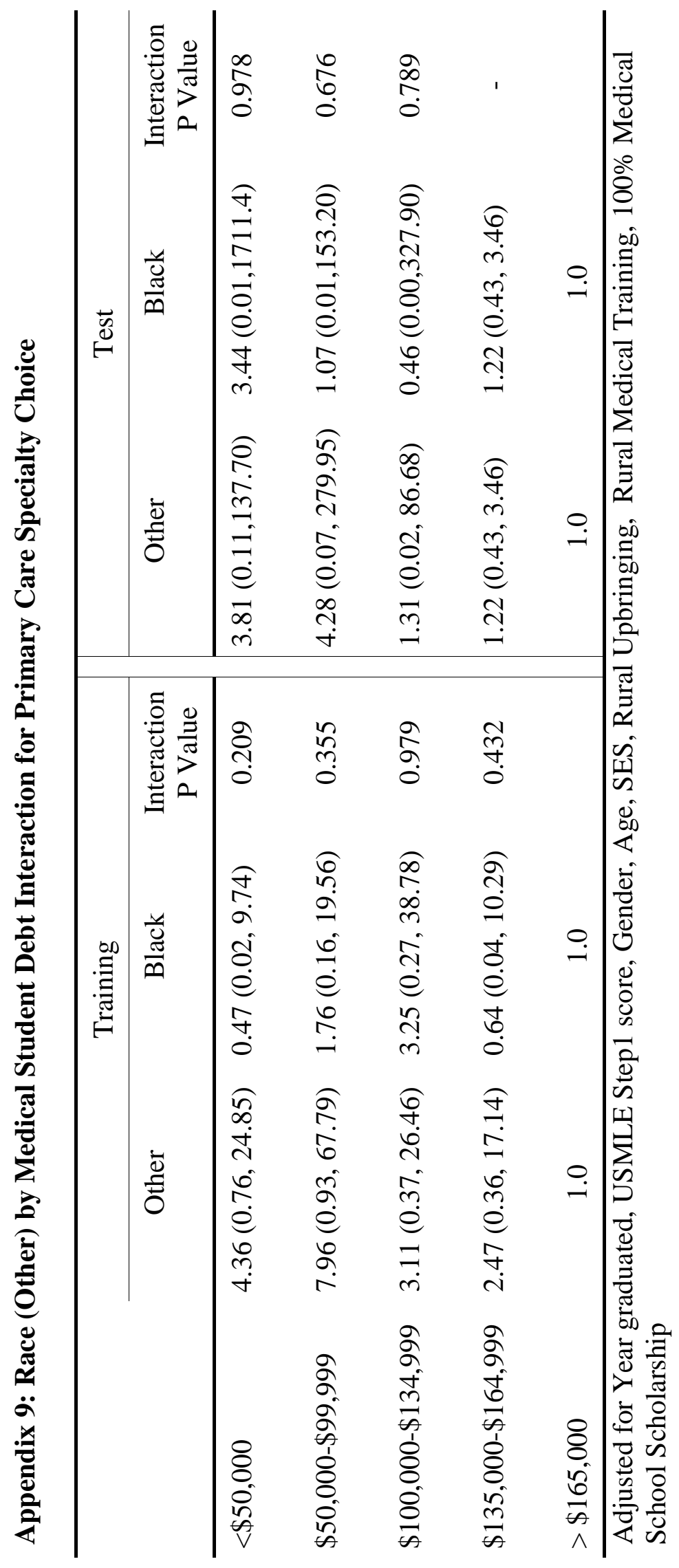




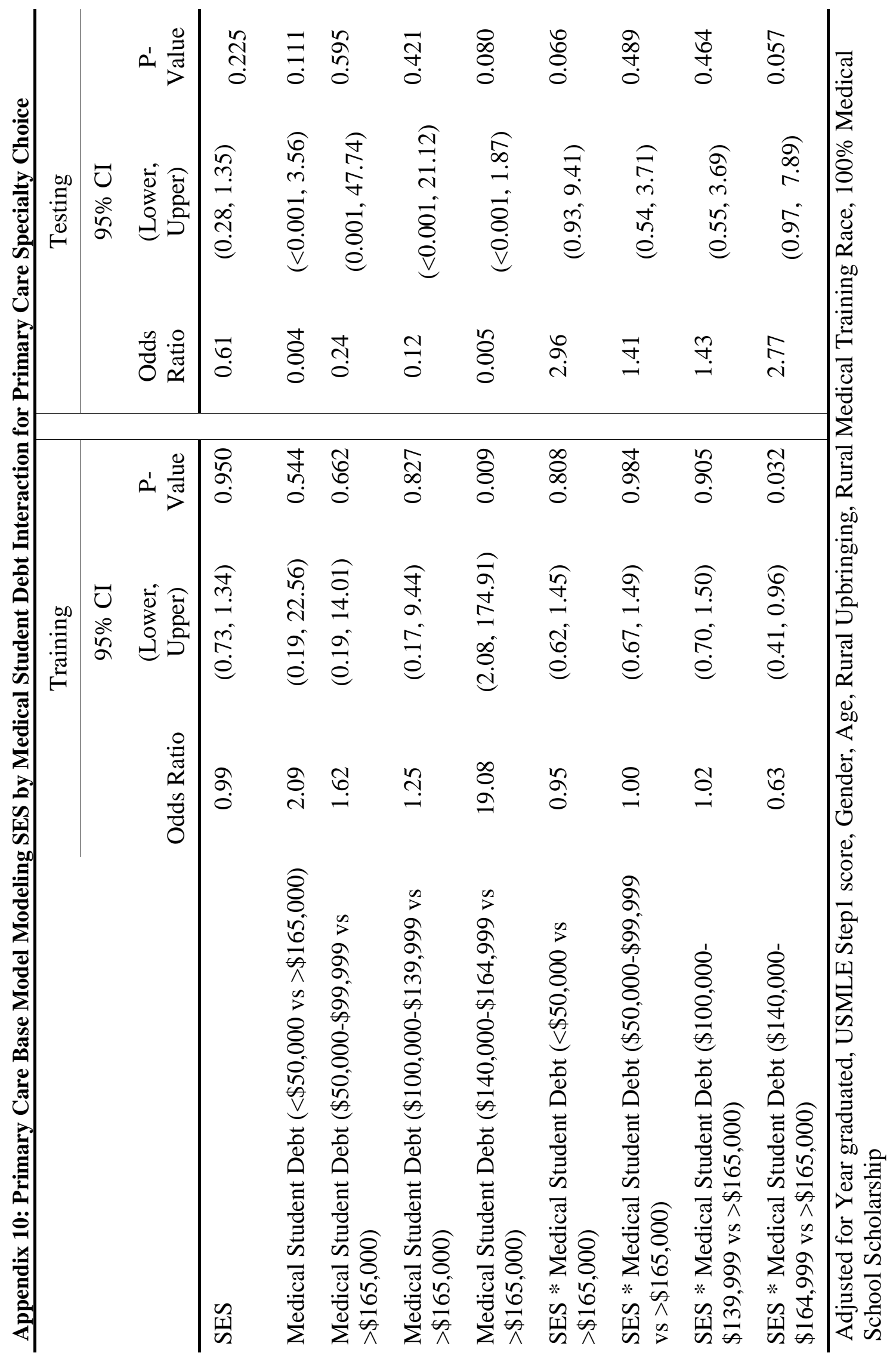




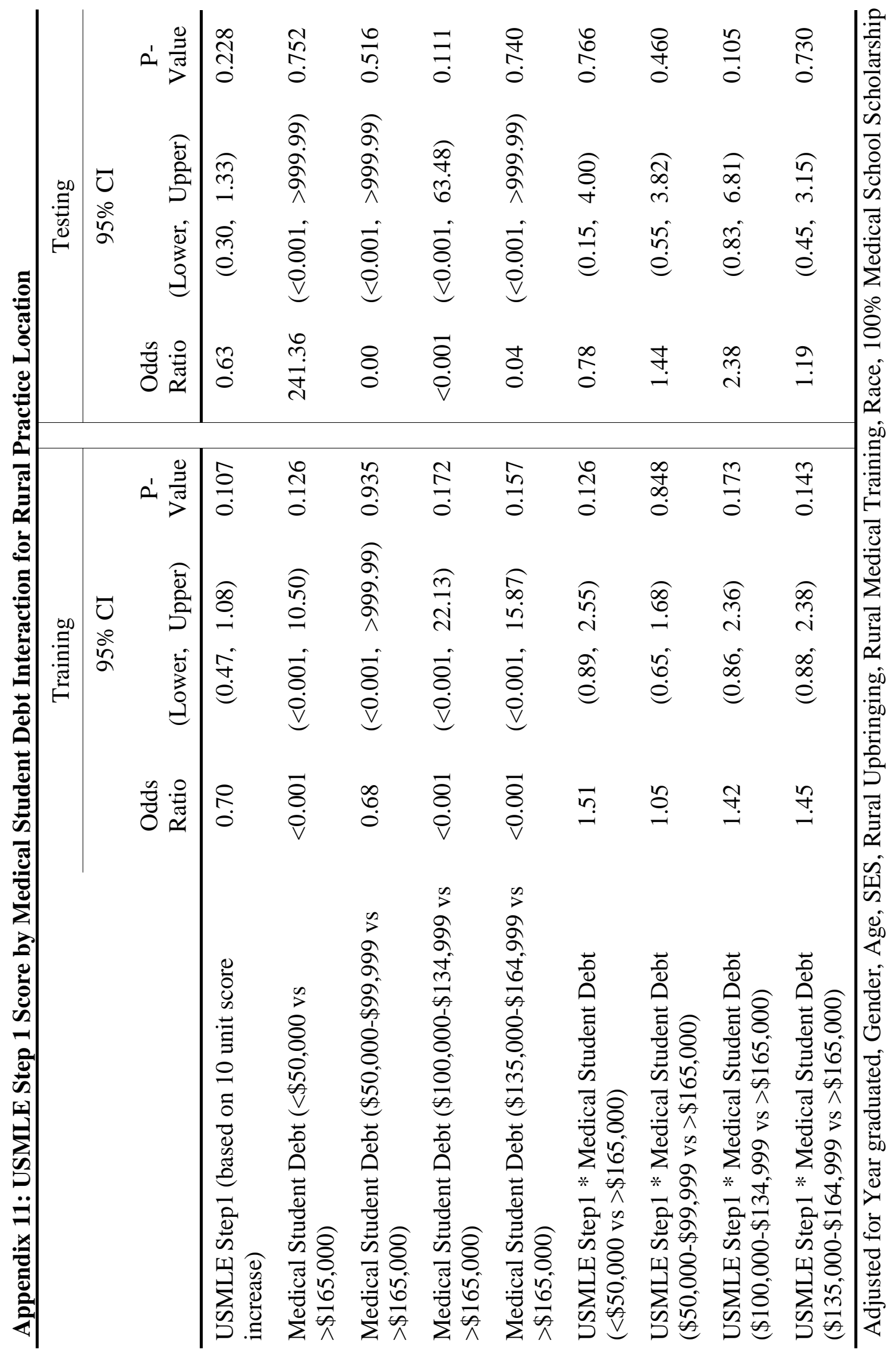




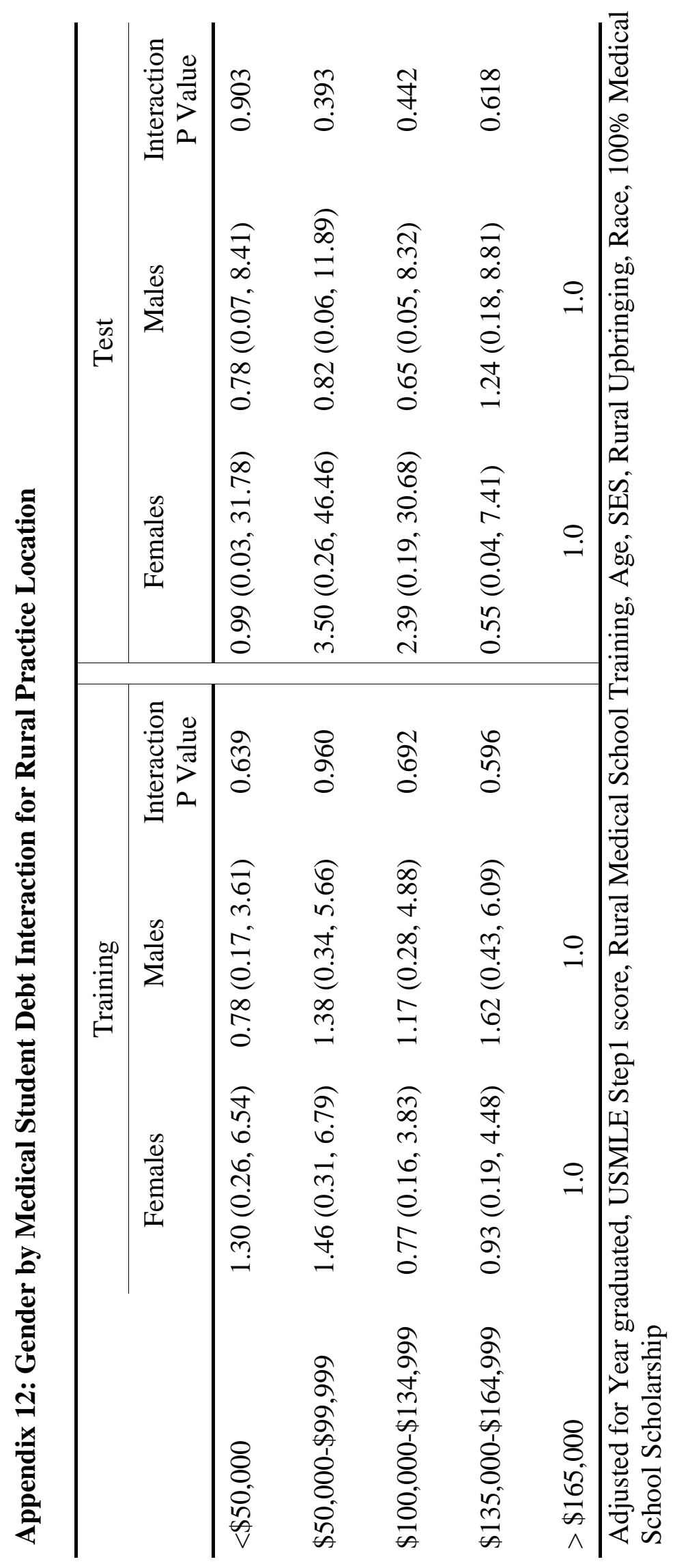




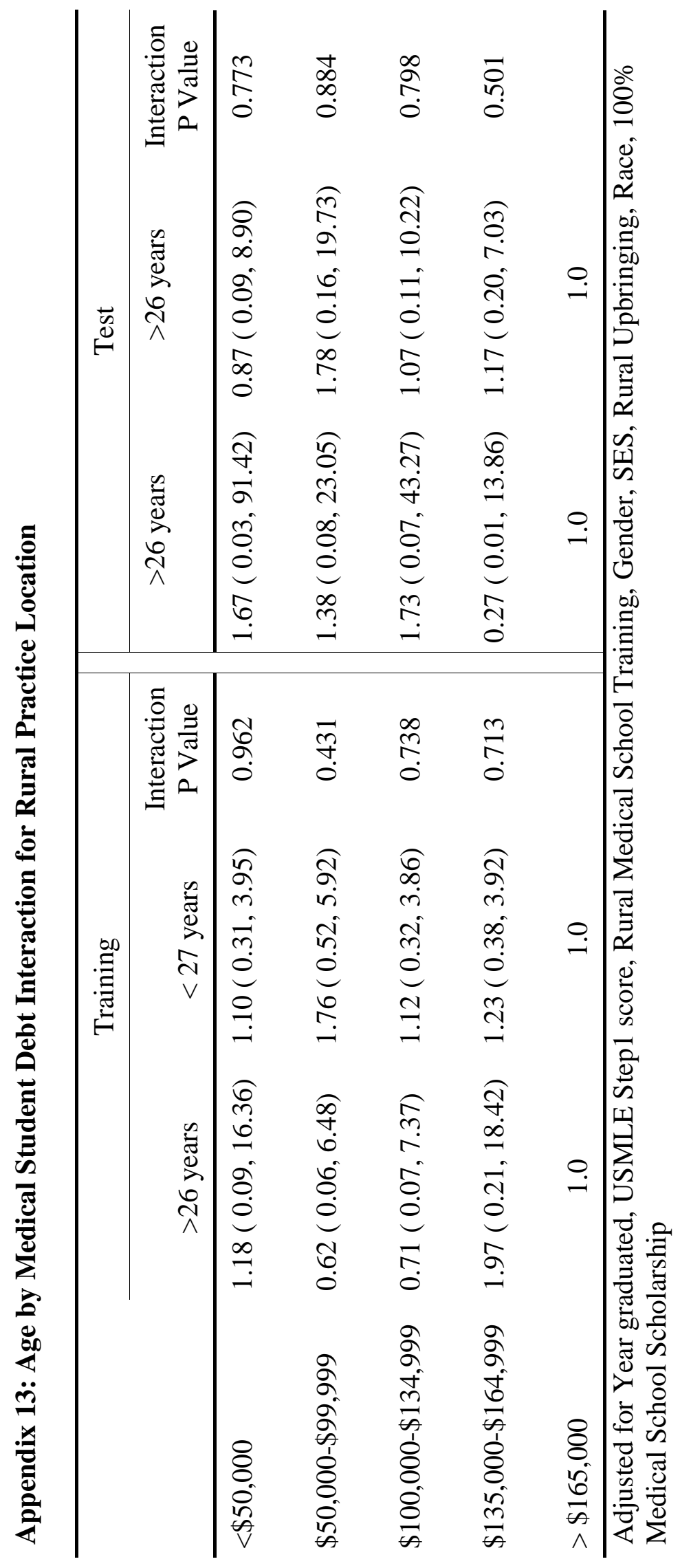




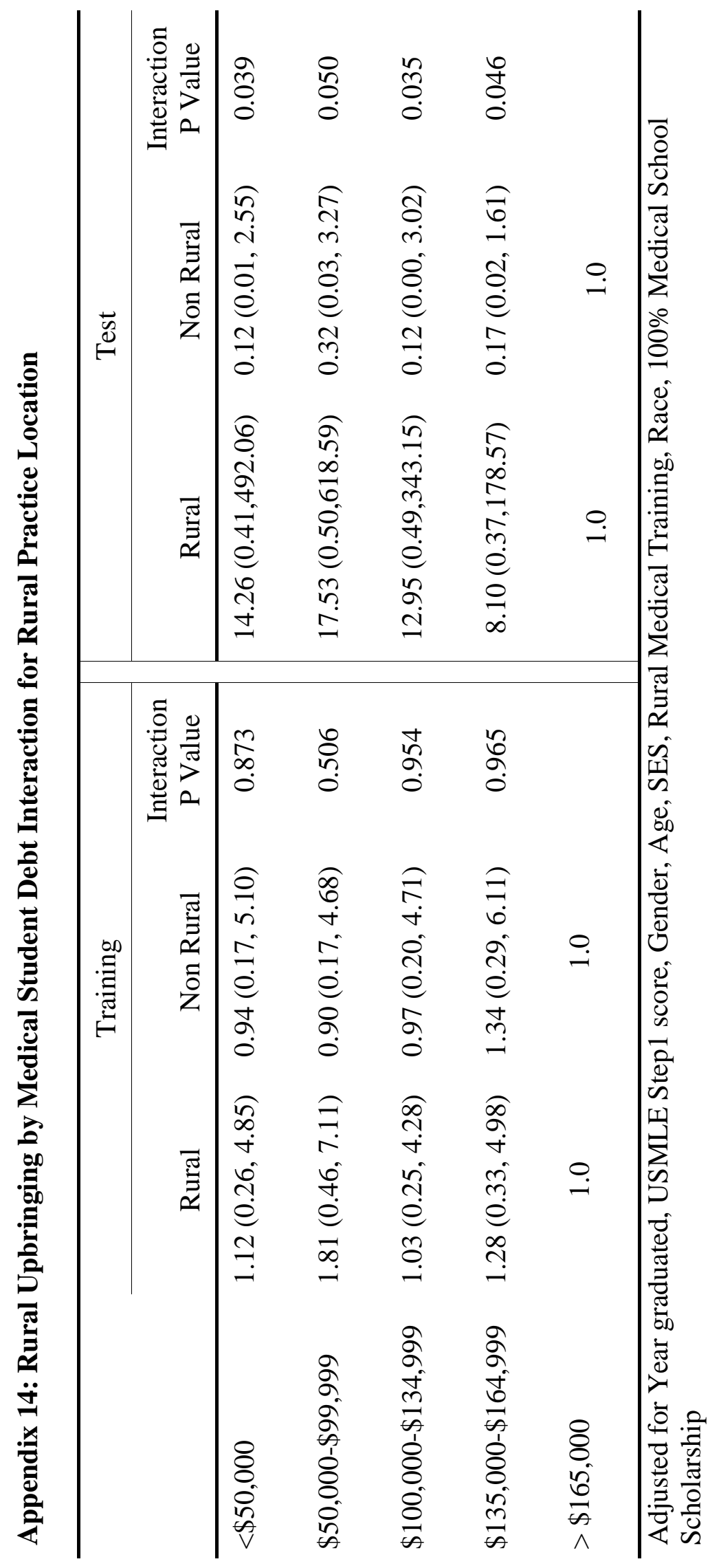




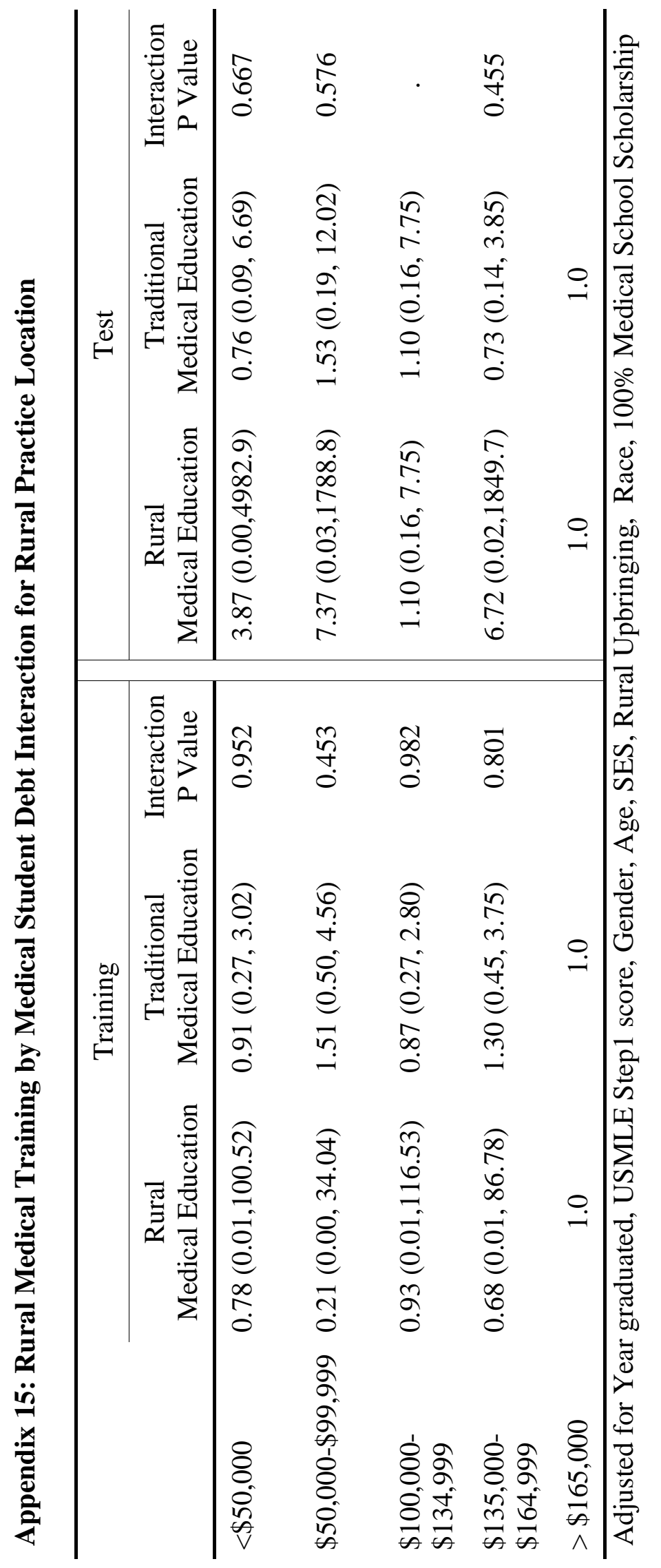




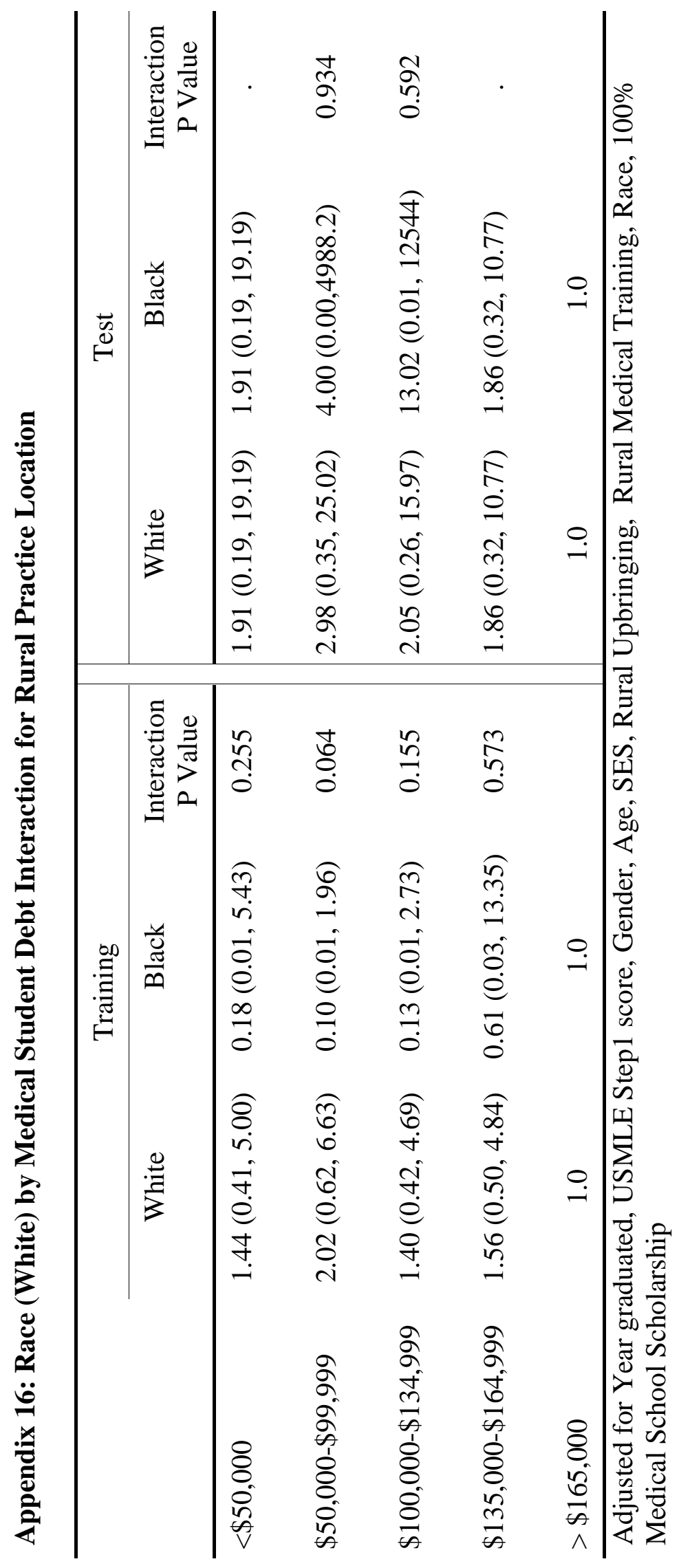




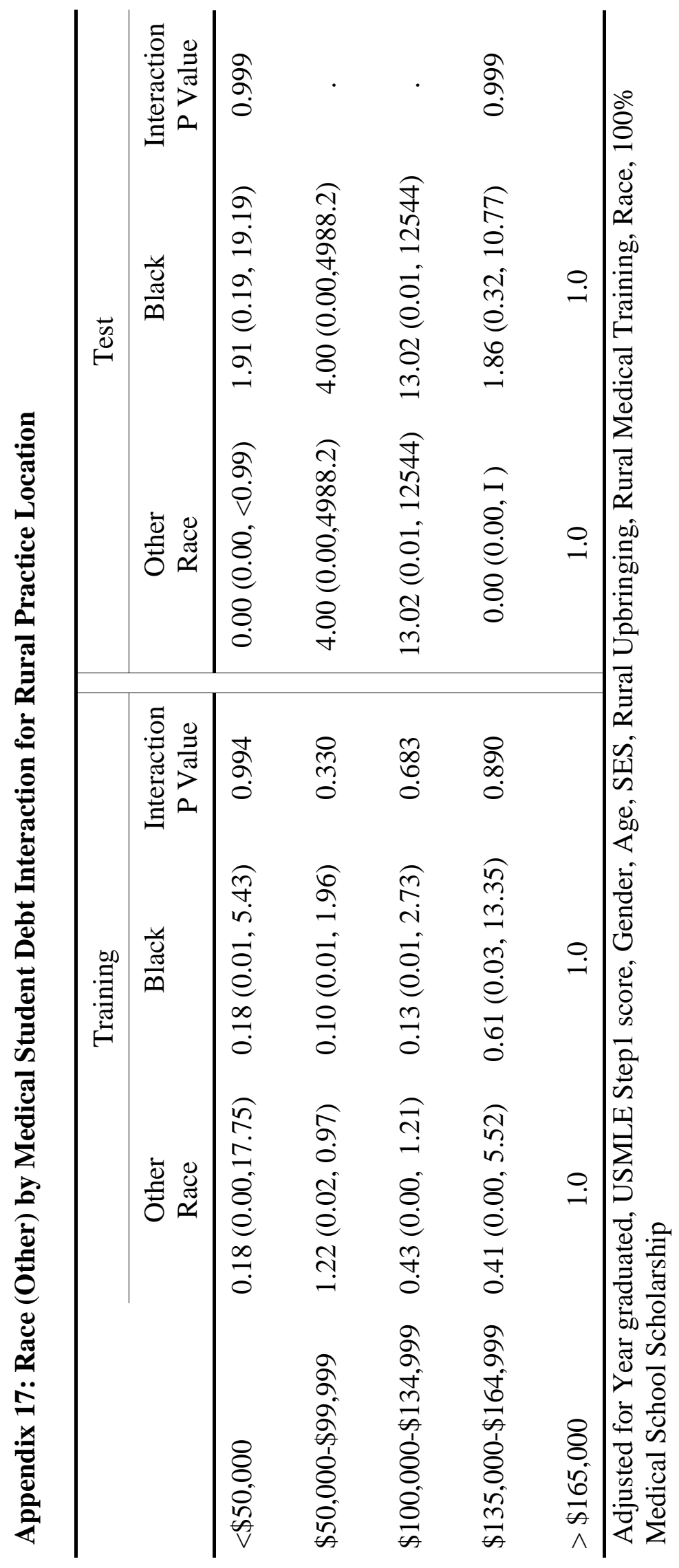




\section{Appendix 18: SES by Medical Student Debt Interaction for Rural Practice Location}

\begin{tabular}{|c|c|c|c|c|c|c|}
\hline & \multicolumn{3}{|c|}{ Training } & \multicolumn{3}{|c|}{ Testing } \\
\hline & \multicolumn{3}{|c|}{$95 \%$ CI } & \multicolumn{3}{|c|}{$95 \%$ CI } \\
\hline & $\begin{array}{l}\text { Odds } \\
\text { Ratio }\end{array}$ & (Lower, Upper) & $\begin{array}{c}\text { P- } \\
\text { Value }\end{array}$ & $\begin{array}{l}\text { Odds } \\
\text { Ratio }\end{array}$ & (Lower, Upper) & $\begin{array}{c}\text { P- } \\
\text { Value }\end{array}$ \\
\hline SES & 1.22 & $(0.58,2.56)$ & 0.609 & 1.12 & $(0.45,2.78)$ & 0.803 \\
\hline $\begin{array}{l}\text { Medical Student } \\
\text { Debt }(<\$ 50,000 \\
\text { vs }>\$ 165,000)\end{array}$ & 7.13 & $(0.06,904.01)$ & 0.427 & 10.81 & $(0.00,>999.99)$ & 0.562 \\
\hline $\begin{array}{l}\text { Medical Student } \\
\text { Debt (\$50,000- } \\
\$ 99,999 \text { vs } \\
>\$ 165,000)\end{array}$ & 21.75 & $(0.26,>999.99)$ & 0.174 & 28.97 & $(0.04,>999.99)$ & 0.325 \\
\hline $\begin{array}{l}\text { Medical Student } \\
\text { Debt (\$100,000- } \\
\$ 134,999 \text { vs } \\
>\$ 165,000)\end{array}$ & 4.08 & $(0.04,391.42)$ & 0.546 & 2.45 & $(0.00,>999.99)$ & 0.786 \\
\hline $\begin{array}{l}\text { Medical Student } \\
\text { Debt }(\$ 135,000- \\
\$ 164,999 \text { vs } \\
>\$ 165,000)\end{array}$ & 0.82 & $(0.01,92.61)$ & 0.934 & 180.44 & $(0.41,>999.99)$ & 0.095 \\
\hline $\begin{array}{l}\text { SES * Medical } \\
\text { Student Debt } \\
(<\$ 50,000 \mathrm{vs} \\
>\$ 165,000)\end{array}$ & 0.68 & $(0.28, \quad 1.69)$ & 0.407 & 0.64 & $(0.15,2.75)$ & 0.545 \\
\hline $\begin{array}{l}\text { SES * Medical } \\
\text { Student Debt } \\
(\$ 50,000- \\
\$ 99,999 \text { vs } \\
>\$ 165,000)\end{array}$ & 0.58 & $(0.25,1.34)$ & 0.201 & 0.58 & $(0.16,2.09)$ & 0.405 \\
\hline
\end{tabular}




\begin{tabular}{|c|c|c|c|c|c|c|}
\hline $\begin{array}{l}\text { SES * Medical } \\
\text { Student Debt } \\
(\$ 100,000- \\
\$ 134,999 \text { vs } \\
>\$ 165,000)\end{array}$ & 0.76 & $(0.32,1.80)$ & 0.528 & 0.91 & $(0.25,3.24)$ & 0.880 \\
\hline $\begin{array}{l}\text { SES * Medical } \\
\text { Student Debt } \\
(\$ 135,000- \\
\$ 164,999 \text { vs } \\
>\$ 165,000)\end{array}$ & 1.10 & $(0.45,2.67)$ & 0.840 & 0.31 & $(0.09,1.13)$ & 0.076 \\
\hline
\end{tabular}

Adjusted for Year graduated, USMLE Step1 score, Gender, Age, Rural Upbringing, Rural Medical Training, Race, 100\% Medical School Scholarship 


\section{Appendix 19: List of Abbreviations}

AAMC: Association of American Medical Colleges

AANP: American Association of Nurse Practitioners

ACA: Accountability Care Act

ACGME: Accreditation Council for Graduate Medical Education

ACO: Accountable Care Organizations

AHRQ: Agency for Healthcare Research and Quality

AMA: American Medical Association

AMCAS: American Medical College Association Survey

ARRA: American Recovery and Reinvestment Act

CBC: competency-based curriculum

CHWs: Community Health Workers

CLS: controllable lifestyle specialties

CMS: Center for Medicare and Medicaid Services

CDSS: clinical decision support systems

CDTM: collaborative drug therapy management

CPI: consumer price index

CPOEs: computer provider order entry systems

CPT: Current Procedural Terminology

EHRs: electronic health records

FIPs: financial incentive programs

FTE: full-time equivalent

GME: Graduate Medical Education 
HIT: health information technology

HITECH: Health Information Technology for Economic and Clinical Health

HPSAs: health professional shortage areas

HRSA: Health Resources and Service Administration

IMG: international medical school graduates

IOM: Institute of Medicine

KHBE: Kentucky Health Benefits Exchange

KIOM: Kentucky Institute of Medicine

KMA: Kentucky Medical Association

LEAP: Learning from Effective Ambulatory Practices

MAR: missing at random

MAs: medical assistants

MCAR: missing completely at random

MMS: medication management services

MUC: medically underserved communities

NHSC: National Health Service Corps

NMHC: Nurse Managed Health Clinics

NPs: Nurse Practitioners

ONC: Office of the National Coordinator for Health Information Technology

PAs: Physician Assistants

PACs: Political Action Committees

PCMH: Patient Centered Medical Home 
PCPs: primary care physicians classified as Family Medicine, Internal Medicine, and Pediatric specialties (as defined by the Agency for Healthcare Research and Quality)

PCTE: Primary Care Training and Enhancement Title VII program

PPHF: Prevention and Public Health Fund

PEPP: Kentucky’s Professional Education Preparation Program

PRM: Physician Requirements Model

PSDM: Physician Supply and Demand Model

PSM: Physician Supply Model

RBRVS: Resource-Based Relative Value Scale

RNs: Registered Nurses

ROC: Receiver Operator Characteristics

RUC: Relative Value Scale Update Committee

RUCC: Rural-Urban Continuum Codes

RVU: relative value unit

SAFE: Strategic Alternative for Funding Education

SOP: scope of practice regulations

SES: social economic status

SGR: sustainable growth rate

UME: Undergraduate Medical Education - M1 through M4 years

USMLE: United States Medical Licensing Examination

ULS: uncontrollable lifestyle specialties

ULSOM: University of Louisville School of Medicine

URM: underrepresented minority 
USMG: United States medical school graduates 


\section{CURRICULUM VITA}

\section{Craig H. Ziegler}

5419 Logwood Avenue

Louisville. Kentucky 40272

Cell: (502) 777-2205 Office: (502) 852-1870

E-mail: craig.ziegler@louisville.edu

Professional Objectives: Research, Evaluation, Statistical Programmer, Statistical and Database Analyst/Consultant.

Education: $\quad$ B.S. in Sociology. University of Louisville, Louisville, Ky. Specialty: Sociology with Social Work Certification.

GPA is 3.7 on a 4.0 system. Graduated with Honors.

M.A. in Sociology. University of Louisville, Louisville, Ky. Specialty: Emphasis in Research Methodology, Survey Design, Questionnaire Construction \& Multivariate Statistical Analyses.

GPA is 3.6 on a 4.0 system.

Ph.D. Candidate in Public Health/Heath Management and Systems Science. University of Louisville, Louisville, Ky. GPA is 3.8 on a 4.0 system.

\section{Skills:}

- $\quad$ Sound analytical \& organizational abilities.

- $\quad$ Solid computer knowledge including UNIX, IBM mainframe \& PC experience.

- $\quad$ Strong research and statistical expertise.

- $\quad$ Reliable team player with excellent interpersonal communication skills.

\section{Awards:}

- 1994 Nominated for 1994 IT Outstanding Employee of the Year - "Star" Award.

- 2002 HSC Award for Curriculum Innovation Through Technology

- 2002 University of Louisville Outstanding Performance Award for Classified and Professional/Administrative Staff

- $\quad 2015$ Graduate Dean's Citation for Significant Accomplishments during Graduate Career at the University of Louisville 


\section{Experience:}

\section{7-Present Office of Undergraduate Medical Education/Graduate Medical Education and Diversity, Louisville, Ky. Biostatistician}

Have joint roles with these departments working as statistician. Responsibilities include providing statistical, graphics and database support for various research projects that focus on medical education. Hardware: Windows NT/2000, IBM Mainframe, VM CMS, and UNIX. Computer Language and Software: SPSS for Windows, Excel, SigmaPlot, SAS and the SAS language, R, AMOS, STATXACT, SUDAAN, PASS, SamplePower, SPSS/Data Entry Builder, HTML, PRELIS, LISREL, MAPLE, QuatroPro, WordPerfect, Microsoft Word, Excel, Access, Filemaker Pro, and Visual Basic.

1991- 2006 University of Louisville, Information Technology/Department of Family and Community Medicine/School of Public Health Louisville. KY. Biostatistician Worked as statistical, graphics, \& database consultant for various faculty, students, and staff designing research studies and writing the statistical/research components of grant proposals and journal articles, also analyzed data/interpreted results using Windows based software. Provided statistical consulting on various research projects including experimental designs, topics pertaining to survey methodology, questionnaire development and data collection instruments, power analysis and multivariate statistics. Reviewed and critiqued research protocols for the University of Louisville Cancer Center. Evaluated and made recommendations to purchase statistical software for the University community; provided support for the recommended software. Organized and conducted formal and informal training for researchers regarding statistical and graphical software; taught graduate level courses in SPSS and SAS software. Developed item analysis application for School of Medicine which integrated Visual Basic with SPSS. "Troubleshooter" for SPSS and other statistical software and spreadsheets for the University.

\section{8 - 2006 Spalding University School of Nursing, Louisville, Kentucky, Adjunct}

\section{Faculty}

Organized and conducted statistical training sessions for graduate students. Worked with students after formal training session to conduct research for graduation requirements.

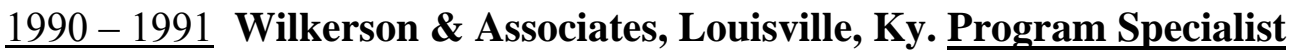

Wrote programs for processing of marketing research data. Work with database files; coding data and performing statistical runs.

\section{6 - 1990 U. of L. Sociology Department, Louisville, Ky. Research Assistant}

Assisted professors on various research projects. Responsibilities included input, analysis, interpretation of data, survey/questionnaire construction. This also included instructing respondents and area organizations of purposes of studies and collecting/systematizing/monitoring requested information. 


\section{Teaching:}

2002-2004 Statistical Computing: SAS Base Programming and SAS STAT, University of Louisville.

2000-2002 Statistical Computing: SPSS and Excel Lab coinciding with Intro to Biostatistics, University of Louisville.

Have taught SPSS short courses and training sessions for the University of Louisville and Spalding University on an annual basis since 1993.

\section{Current Publications in Refereed Journals:}

Crump, W., Fricker, S. , Ziegler, C., Wiegman, D. Seeking the Best Dose of Rural Experience: Comparison of Three Rural Pathways Programs at One Medical School." Journal of Kentucky, Medical Association, Vol 113, No 1, January 2015.

Chism, A., Leslie, K., Ziegler, C., Jones, V. "From Pipeline to Physician: Practice Outcomes of the Professional Education Preparation Program." Journal of Kentucky Medical Association, Vol 112, No 11, November 2014.

Sutton,E., Richardson, J., Ziegler, C., Bond, J., Burke-Poole, M. McMasters, K.. "Is USMLE Step 1 Score a Valid predictor of Success in Surgical Residency?" The American Journal of Surgery, Vol 208, Issue 6, December 2014.

Elam, C., Ziegler, C., Dunatov, L., Miller, K., McDowell, S., Rowland, M.. "Research Perceptions of Kentucky Medical Students: Does Gender Make a Difference?" Journal of Kentucky, Medical Association, Vol 113, No 1, January 2015.

Leslie, K., Jones, V., Ziegler, C., Chism, A., Rowland, M., Elam, C., Snyder, C.

"Academic Outcomes of the Professional Education Preparation Program." Journal of Kentucky Medical Association, Vol 112, No 11, November 2014.

Kerrick, S., Miller, K., Ziegler, C. "Using Continuous Quality Improvement (CQI) to Sustain Success in Faculty Development for Online Teaching." Journal of Faculty Development., Vol29, No 1, January 2015.

Miller, K., Ziegler, C., Elam, C., Dunatov, L., McDowell, S., Rowland, M. "Perceptions of Skills, Experience, and Attitudes on the Conduct of Research: a View Across the Continuum of Medical Learners in Kentucky's Three Medical Schools." Medical Science Educator. June 2014.

Sutton, E., Irving, M., Ziegler, C., Gyusung, Lee, G., Parker, A. "The Ergonomics of Women in Surgery.” Surgical Endoscopy. Vol. 28 (4):1051-5., April 2014.

Crump, W., Fricker, S., Ziegler, C., Wiegman, D., Rowland, M. "Rural Track Training Based at a Small Regional Campus: Equivalency of Training, Residency Choice, and Practice Location of Graduates.” Academic Medicine, Vol. 88, No. 8 / August 2013. 
Greenberg R., Ziegler C., Borges N., Elam C., Stratton T., Woods S. "Medical student interest in academic medical careers: a multi-institutional study." Perspect Med Educ. Apr 16, 2013.

Self, M., Bumpous, J., Ziegler, C., Potts, K. “Risk Factors for Hemorrhage After Chemoradiation for Squamous Carcinoma." JAMA Otolaryngology-Head \& Neck Surgery, April 1 $1^{\text {st }}, 2013$.

Patel, P., Bickel, S., Ziegler C., Miller, K. “An Evaluation of the University of Louisville School of Medicine Pediatric Summer Externship Program.” Medical Science Educator. Issue 22(4) (October 2012).

Patel, P., Roberts, J., Ziegler C., Ostapchuk, M., Miller, K. “The Responsible Use of Online Social Networking: Who Should Mentor Medical Students." Teaching and Learning in Medicine. Issue 24 (4), 348-354, 2012.

Miller, K., Ziegler, C., Greenberg. R., Patel. P., Carter, M. "Why Physicians Should Share PDA/Smartphone Findings with Their Patients." Journal of Health Communication International Perspectives. Issue 17: 54-61, 2012.

Roberts, D., Reid, J., Conner, A., Barrer, S., Miller, K., Ziegler, C. “A Replicable Model of a Health Literacy Curriculum for a Third Year Clerkship." Teaching and Learning in Medicine. Issue 24 (3), 200-210, 2012.

Patel, P., Kischnick, D.,Bickel, S., Ziegler, C., Miller, K. "Evaluating the Utility of PeerAssisted Learning in Pediatrics." Medical Science Educator. Issue 21(4) (October 2011).

Rowland, M., Greenberg, R., Elam, C., Ziegler, C. "Medical Students and Healthcare Reform: Perceptions and Knowledge." Kentucky Medical Association Journal, Vol. 109 April 2011, pp. 16-21.

Roberts, J., Ostapchuk,M., Miller, K., Ziegler, C. "What Do Residents Already Know About Healthcare Reform and What Should We Be Teaching Them?" Journal of Graduate Medical Education, June 2011, pp 155-161.

Crump, W., Fricker, S., Ziegler, C. "Outcomes of a Preclinical Rural Medicine Elective at an Urban Medical School” Family Medicine, Vol. 42 Nov-Dec 2010, pp. 717-722.

Hertweck, P., Ziegler, C., Logsdon, M. "Outcome of Exposure to Community Violence in Adolescent Females." Journal of Pediatric \& Adolescent Gynecology. Vol. 23, Issue 4, Pages 202-208

Latif, R., Chhabra, N., Ziegler, C., Turan, A., Carter,M. "Teaching Surgical Airway Using Fresh Cadavers and Confirming Placement Non-surgically." Journal of Clinical Anesthesia (2010) 22, 598-602 
Ostapchuk, O., Patel, P., Miller, K., Ziegler, C., Greenberg, R., Haynes, G.. 'Improving Residents' Teaching Skills: a Program Evaluation of Residents As Teachers Course." Medical Teacher, Feb 2010, Vol. 32 Issue 2, pe49-e56. URL Link: http://informahealthcare.com/doi/full/10.3109/01421590903199726

Elam, C., Ziegler, C., Greenberg, R., Baily, B. “Assessing Professionalism in Medical School Applicants.” College and Universities, Vol. 85 Nbr. 2, October 2009.

Campbell,M., Preminger, J., Ziegler, C.. "The Effect of Age on Visual Enhancement in Adults with Hearing Loss." Journal of the Academy of Rehabilitative Audiology, 40, 1132.

Patel, P., Greenberg, R, Miller, K., Carter, M., Ziegler, C. “Assessing Medical Students', Residents', and the Public's Perceptions of the Uses of Personal Digital Assistants." Med Educ Online [serial online] 2008;13:8 . Available from http://www.med-edonline.org

Logsdon, M., Hertwick, P., Ziegler, C., Pintino-Foltz, M. “Testing Bioecological Model to Examine Social Support in Postpartum Adolescents." Journal of Nursing Scholarship, Volume 40, Number 2, June 2008 , pp. 116-123(8).

Preminger, J., Ziegler, C. "Can Auditory and Visual Speech Perception Be Trained within a Group Setting?” American Journal of Audiology, Volume 17, No 1., June 2008, pp. 80-97.

Tregaskiss, A., Goodwin, A., Bright, L., Ziegler, C., Acland, R. " "Three-Dimensional CT Angiography: a Powerful Tool for Flap Research." Journal of Clinical Anatomy. Volume 20, Issue 2, Pages 116 - 123, June 2006.

Stetson, B., Carrico, A., Beacham, A., Ziegler, C., Mokshagundam, S. "Feasibility of a Pilot Intervention Targeting Self-care Behaviors in Adults with Diabetes Mellitus." Journal of of Clinical Psychology in Medical Settings. Volume 13, Number 3, Pages 239-249, September, 2006.

Grady, J., Bumpous, J., Fleming, M., Flynn, M., Ziegler, C. “Advantages of a Targeted Approach in Minimally Invasive Radioguided Parathyroidectomy Surgery for Primary Hyperparathyroidism." Laryngoscope 116(3):431-5, March 2006.

Cloud, R., Besel, K., Bledsoe, L., Golder, L., McKiernan, P., Patterson, D., Ziegler, C. "Adapting Motivational Interviewing Strategies to Increase Posttreatment 12-step Meeting Attendance: Rationale, Feedback, and Other Suggestions to Facilitate Implementation." Alcohol Treatment Quarterly. Vol. 24, No. 32006.

Logsdon, M., Hutti, M., Ziegler, C. "Patient Satisfaction: a Critical Outcome to Document the Contributions of WHNP's to the Practice Setting." Women's Health Care, 2005; 4(2), 25-29. 
Preminger, J., Carpenter, R., Ziegler, C. "A Clinical Perspective on Cochlear Dead Regions: Speech Intelligibility and Subjective Hearing Aid Benefit." Journal of the American Academy of Audiology 2005; 16(8):600-613.

Zambroski, C., Moser, D., Ziegler, C. "Impact of Symptom Prevalence and Symptom Burden on Quality of Life in Patients with Heart Failure.” European Journal of Cardiovascular Nursing. Sept. 2005 4(3):198-206.

Stetson, B., Beachum, A., Frommelt, S., Boutelle, K., Cole, J., Looney, S., Ziegler, C. "Exercise Lapse in High-risk Situations in Long-term Exercisers: An Application of the Relapse Prevention Model.” Annals of Behavioral Medicine. Aug. 2005 30(1):25-35, 2005.

Culligan, P., Blackwell, L., Murphy, M., Ziegler, C., Heit, M.. “A Randomized, DoubleBlinded, Sham-Controlled Trial of Postpartum Extracorporeal Magnetic Innervation to Restore Pelvic Muscle Strength in Primiparous Patients." American Journal of Obstetrics and Gynecology 2005 May; 192(5):1578-82.

Morpurgo, E., Vitale, G., Galandiuk. S., Kimberling, J., Ziegler, C., Polk, H. "Clinical characteristics of familial adenomatous polyposis and management of duodenal adenomas.” Journal of Gastrointestinal Surgery 2004; 8(5):559-564.

Cloud, R., Ziegler, C., Blondell, R. "What is Alcoholics Anonymous Affliation?" Substance Use and Misuse, 2004, Volume 39 (7): 1119-1138.

Morpurgo, E., Petras, R., Kimberling, J., Ziegler, C., Galandiuk, S. “Characterization and Clinical Behavior of Crohn's Disease Initially Presenting as Crohn's Colitis.” Diseases of Colon and Rectuma, 2003 Jul; 46(7): 918-24.

Fleming, D., Ziegler, C., Baize, T., Mudd, L., Goldsmith, G., Herzig, R. “Cefepime versus ticarcillin and clavulanate potassium and aztreonam for febrile neutropenia therapy in high-dose chemotherapy patients." American Journal Clinical Oncology, 2003, Jun; 26(3): 285-8

Coleman, M., Looney, S., O’Brien, J. Ziegler, C., Pastorino, C., Turner,C. "The Eden Alternative: Findings after One Year of Implementation." Journal of Gerontology: Medical Sciences 2002, Vol. 57A, No 7, M422-M427.

Winter, P., Harris, M., Ziegler, C. "Community College Reverse Transfer Students: A Multivariate Analysis." Community College Journal of Research and Practice, 25:271$282,2001$.

Mills, B., Weiss, M., Liu, M., Ziegler, C., Lang, C. "Blood Glutathione and Cysteine Changes in Cardiovascular Disease." Journal of Laboratory and Clinical Medicine.

135:396-401, May 2000. 
Raju, P., Lonial, S., Gupta, Y., Ziegler, C.. "The Relationship between Market Orientation and Performance in the Hospital Industry: A Structural Equations Modeling Approach." Health Care

Management Science (3): 237-247, 2000.

Stewart, D., Delacruz, T., Ziegler, C., Goldsmith, L. "The Use of Extracorporeal Membrane Oxygenation in Patients with Gram- Negative or Viral Sepsis." Perfusion. 12 (1): 156-62, 1997.

\section{Acknowledgments in Books for Statistical Expertise:}

"Counseling for Prejudice Prevention and Reduction." Daya Sandhu and Cheryl Aspy. (1997). Alexandria, VA: American Counseling Association.

"Empowering Women for Gender Equity." Daya Sandhu and Cheryl Aspy. (1999). Alexandria, VA: American Counseling Association.

\section{Grants}

- Southern Group on Educational Affairs (SGEA) Research in Medical Education P. Patel, with Co-Investigators, Ruth Greenberg, K.H. Miller, M. Carter, \& C. Ziegler. July 2007-July 2008, \$3,000.

"PDA Use in Medical Education: A Multi-site Study of Medical Student, Resident, and Patient Perceptions."

- NIH -Department of Health and Human Services

1 R03 DC004939-01A1

Jill E. Preminger, Ph.D. (PI) 7/30/03 - 6/30/06

$\$ 50,000$ each year for 3 years $\quad(10 \%)$

"The Efficacy of Aural Rehabilitation programs"

The major goal is to examine the efficacy of adult group aural rehabilitation training, for adults with hearing loss, offered in a classroom environment.

(Statistician on the grant) 
- School of Medicine University of Louisville Grant-In-Aid, Jill Preminger, Ph.D., (PI) 10/02/02 - 10/02/04

$$
\$ 15,000 \text { Total }
$$

"The Clinical Utility of Measuring Dead Regions"

The major goal is to examine the clinical impact of cochlear dead regions which are locations along the basilar membrane within the cochlea where inner hair cell populations appear to respond to tonal stimuli during pure tone testing, but in fact do not transmit information along the auditory nerve. The specific aim of this project is to determine the impact of cochlear dead regions on speech recognition ability in quiet and in noise.

(Statistician on the grant)

- NIH - Department of Health and Human Services

1 R15 NR08492-01

Deborah Armstrong, Ph.D. (PI) 7/1/04-6/30/05 (10\%)

"Perinatal Loss and the Birth of a Subsequent Child “

The purpose of this study is to evaluate the influence of previous perinatal loss on parents' emotional distress during and after the birth of a subsequent healthy infant.

(Co-Investigator)

- Norton Foundation

Marianne H. Hutti, Ph.D. (PI) 7/1/02 - 6/30/03

Norton Foundation Grant $\quad \$ 7,922$

“Emotional Distress in Pregnancy After Perinatal Loss”

The purpose of this study is to determine differences in levels of depressive symptoms, pregnancy-specific anxiety, continuing grief intensity, and the quality of intimate partnered relationships for expectant parents in a pregnancy subsequent to previous perinatal loss.

(Statistician on the grant) 


\section{Conference Presentations, Publications in Non-Refereed Journals and Abstracts:}

Simpson, R., Leslie, K., Jones, V., Ziegler, C. "Where Are They Now? Practice Locations of Health Career Pipeline Program Participants." Poster Session at the $11^{\text {th }}$ Annual AAMC Health Workforce Research Conference, Alexandria, VA (upcoming, April 2015).

Leslie,K., Jones, V., Ziegler, C., Casey, M., Zolj, A., Calderon, C., Dillon, W. "Implementing a Community-Based CPR Training Initiative Utilizing Pre-Medical Students as Facilitators." Panel presentation at the Ninth Annual Kentucky Engagement Conference, Morehead, KY, November 2014.

Zolj, A., Calderon, C., Dillon, W., Leslie, K., Jones, V., Ziegler, C., \& Casey, M. “Start the Heart: a Community-Based Approach to Increase Bystander Initiated CPR in Cardiac Arrest." Poster Session at the Tenth Annual Meeting of the Kentucky Chapter of the American College of Cardiology, Louisville, KY, October 2014.

Chism, A., Leslie, K., Ziegler, C., \& Jones, V. "From pipeline to practice, recruiting physicians to underserved regions of Kentucky." Poster Session at the University of Louisville Department of Pediatrics Annual Poster Session, Louisville, KY, June 2014.

Leslie, K., Chism, A., Jones, V., Ziegler, C., Rowland, M., Elam, C. "from Pipeline to Practitioner: Building a Diverse Healthcare Workforce." Poster Session at the Tenth Annual AAMC Health Workforce Research Conference, Washington, DC., May 2014.

Leslie, K., Jones, V., Rowland, M., Elam, C., Ziegler, C., Chism, A. "Changing the Face of Health Care through Pipeline Enrichment Programs." AAMC: group on Diversity and Inclusion. April 26-29, 2014. San Diego, Ca.

Elam, C., Ziegler, C., Dunatov, L. Miller, K., Rowland, M., McDowell, S. "Institutional Climate and Medical Students' Perceptions of their Attitudes, Needs, and Skills in the Conduct of Research: Does Gender Matter?" Southern Group on Educational Affairs (SGEA) March 20-22, 2014. Given 2014 Outstanding Poster by a Professional Educator Award.

Elam, C., Ziegler, C., Dunatov, L. Miller, K., Rowland, M., McDowell, S. "Perceptions of Research among Kentucky Medical Students and Residents Oral Presentation" at the Southern Group on Educational Affairs (SGEA) April 18-20, 2013, Savannah, GA.

Irving, M., Suttton, E., Ziegler, C., Lee, G., Parker, A. "The Ergonomics of Women in Surgery.” Research Louisville. September 18-20, 2012. Louisville, Kentucky.

Rowland, M., Jones, V., Ziegler, C. “Assessing Gender Differences in Knowledge, Ability, and Attitudes of Cross-Cultural Training and its Importance in the Medical Education Curriculum." Southern Group on Educational Affairs Annual Conference Poster Session. Lexington, KY. April 19, 2012. 
Self, E., Potts, K., Ziegler, C., Bumpous, J. “An Analysis of Risk Factors for LifeThreatening Hemorrhage Following Concomitant Chemotherapy and Irradiation Therapy for Oropharyngeal Squamous Cell Carcinoma." Research Louisville. October 10-14.

Patel, P., Kischnick, D., Bickel, S., Ziegler, C., Miller, K. "Evaluating the Utility of Peer-Assisted Learning in Pediatrics." Research Louisville. October 10-14.

Carothers, B., Multerer, S., Rowland, M., Ziegler, C, Patel, P. “A Mock Interview Program for Senior Medical Students.” Research Louisville. October 10-14.

Carter M., Bohnert C., Rowland M., Ziegler C. "Clinical Skills Exams: Do Students Type More on their Post-Encounter Notes if the Stakes are Increased?" Southern Group on Educational Affairs, Regional Conference to be held April 14-16, 2010, Houston, TX.

Patel, P., Kischnick, D., Bickel, S., Ziegler, C., Miller, K. "Evaluating the Utility of Peer-Assisted Learning in Pediatrics." Poster Presentation Council on Medical Student Education in Pediatrics (COMSEP). March $3^{\text {rd }}-7^{\text {th }}, 2011$, San Diego, Ca.

Remmel, K., Ziegler, C., Moore, K., Vaishnav, A., Abou-Chebl, A., Troung, V. "What Should Be Included In An Outpatient Diagnostic Evaluation of Transient Ischemic Attack? " Poster Presentation International Stroke Conference. February 8-11, 2011, Los Angeles, Ca.

Troung, V., Shah, J., Spray, R., Vaishnav, A., Ziegler, C., Remmel, K., Abou-Chebl, A. "Baseline Creatinine Levels Are Not Needed Prior to CTA/CTP Imagining in Acute Ischemic Stroke Evaluation.” Poster Presentation International Stroke Conference. February 8-11, 2011, Los Angeles, Ca.

Troung, V., Spray, R., Remmel, K., Ziegler, C., Abou-Chebl, A. “ Successful Endovascular Acute Stroke Intervention Prevents Infarct Core Growth.” Poster Presentation International Stroke Conference. February 8-11, 2011, Los Angeles, Ca.

Carter, M., Rowland, M., \& Ziegler, C. "Measuring Student Motivation in Writing PostEncounter Notes after Clinical Skills Exams.” Presented at 2010 Southern Group on Educational Affairs Regional Conference. April 15-17, Oklahoma City, OK.

Greenberg, R., Ziegler, C., Halpern, E. “The Impact of a Required Course on Medicine and Religion on Second-Year Medical Students." Presented at 2010 Southern Group on Educational Affairs Regional Conference. April 15-17, Oklahoma City, OK.

Greenberg, R., Ziegler, C., Elam, C., Stratton, T., Woods, S., Borges, N. "Career Aspirations of Medical Students: Findings from a Multi-site Investigation." Presented at 2010 Southern Group on Educational Affairs Regional Conference. April 15-17, Oklahoma City, OK. 
Latif, R., Ziegler, C., Turan, A., Carter, M. "Anatomy Does Not Always Follow the Rules. Teaching US Guided Central Venous Catheter Placement.: Presented at the American Society of Anesthesiologists Annual Meeting. October 17-21, New Orleans, LA, 2009.

Smith, E., Latif, R., Memon, S., Bautista, A., Ziegler, C., Wahdwa, A. "A Randomized Blinded Study to Assess the Effectivenes of Simulation-based Training for U/S-guided Central Venous Access Placement Using Aseptic Technique.” Poster Presentation Research!Louisville.

October 12-16, 2009, Louisville, Ky.

Bautista, A., Latif, R., Memon, S., Smith, E., Ziegler, C., Wadhwa, A. "The Effectiveness of Didactic Training and Patient Simulator in Improving Knowledge and Comfort Level on Ultrasound Guided Central Venous Catheter Placement.” Poster Presentation Research!Louisville.

October 12-16, 2009, Louisville, Ky.

Elam, C., Ziegler, C., Greenberg, R., Bailey, B., Martindale, J. “Assessing Professionalism in Medical School Applicants". Presented at AAMC Annual Meeting, October $31^{\text {st }}-$ November $5^{\text {th }}, 2008$, San Antonio, Texas.

Logsdon, M., Hutti, M., Ziegler, C. "Patient Satisfaction with Health Care Provided by WHNP's: A Pilot Test of the WHNP Patient Opinion Survey". Abstract published in Women's Health Care, 4(6), 30, 2005.

Preminger, J., Ziegler, C. "Auditory-Alone and Auditory-Visual Speech Performance in Adults with Hearing Loss". Aging and Speech Communication Conference, October 912, 2005 , Indiana University, Bloomington, Indiana.

Zambroski, C., Moser, D., Ziegler, C.. "Clinicians Must Examine Multiple Dimensions of the Symptom Experience to Improve Health-Related Quality of Life." The $9^{\text {th }}$ Annual Scientific Meeting of the Heart Failure Society of America, September 18-21, 2005.

Manning, L., Lewis, A., Armstrong, D., Hutti, M., Ziegler, C., "Father's Emotional Response to Subsequent Pregnancy After Perinatal Loss.” 29th Annual MNRS Research Conference, April 1-4, 2005, Cincinnati, OH.

Rayner, A., Ziegler, C., Cassady, J. "Epidemiology of Depression in Long Term Care." Presented at American Public Health Association Scientific Sessions, November 15-19, 2004. San Francisco, California.

Zambroski, C., Lennie, T., Chung, M., Heo, S., Smoot, T., Ziegler, C. "Use of the Memorial Symptom Assessment Scale-Heart Failure in Heart Failure Patients." Presented at the American Heart Association Scientific Sessions, November 7-10, 2004, New Orleans, Louisiana. 
Humphrey, T., Keeton, M., Kim, S., Ziegler, C., Krigger, K. "Pre and Post Test HIV Counseling in Primary Care and Reproductive Medical Offices." Poster Presentation Research!Louisville, November 8-12, 2004, Louisville, Ky.

Gopathi, S., Newton, K., Coleman, M., Ziegler, C. "Factors Associated with Improved Chronic Disease Self-Management: Analysis of Living Well Workshops, A Pilot Study." Poster Presentation Research!Louisville, November 8-12, 2004, Louisville, Ky.

Logsdon, M., Hutti, M., Ziegler, C. "Patient Satisfaction with Health Care Provided by Women's Health Nurse Practitioners: A Pilot Test of the Women's Health Nurse Practitioner Patient Opinion Survey." Presented at the 7th annual conference of the National Association of Women's Health Nurse Practitioners, October 13-16, 2004, Chicago, Illinois.

Grady, J., Bumpous, J., Fleming,M., Flynn, M., Ziegler, C. “Advantages of a Targeted Approach in Minimally Invasive Radioguided Parathyroidectomy Surgery for Primary Hyperparathyroidism." 6th International Conference on Head and Neck Cancer, August 7-11, 2004, Washington D.C.

Culligan, P., Blackwell, L., Murphy, M., Ziegler, C., Heit, M. “A Blinded, ShamControlled Trial of Postpartum Extracorporeal Magnetic Innervation to Restore Pelvic Muscle Strength in Primiparous Patients." Presented at The American Urogynecologic Society 25th Annual Scientific Meeting, San Diego, CA, July 27-29, 2004.

Rayner, A., Holloman, S., Ziegler, C. " 'Constant Request for Attention and Help." American Medical Directors Association 27th Annual Symposium, March 3-7, 2004, Phoenix, AZ.

Holloman, S., Ziegler, C., Rayner, A., Miles, T. "Monitoring Symptoms of Depression Using the Minimum Data Set (MDS)." American Medical Directors Association 27th Annual Symposium, March 3-7, 2004, Phoenix, AZ.

Leanhart, J., Zambroski, C., Ziegler, C. "Comparing Quality of Life Between Healthy Community Dwelling Adults and Those With End-Stage Heart Failure." Poster Presentation Southern Nursing Research Society February 19, 2004.

Hutti, M., Armstrong, D., Ziegler, C., McGlothlin, C., Thompson, R. "Emotional Distress in Pregnancy After Perinatal Loss." Southern Nursing Research Society Annual Conference, Orlando, FL, February, 2003

Spencer, N., Coleman, M., Newton, K., Ziegler, C., Patterson, R.. "Factors Important to Patient Self Management of Diabetes Mellitus." Research!Louisville, November 3-5, 2003, Louisville, Ky. 
Flaspoehler, S., Ziegler, C., Seger, R., Weinrich, S. "The Impact of Treatment (Intervention or Comparison) on Men's Knowledge of Sexual Side Effects From Prostate Cancer Treatment". Staff Colloquium of Metropolitan Urology Group, Jeffersonville, Indiana.

T. Wright, T., Ziegler, C., James, K., Wheeler, C., Seger, R., Russell, G., Dorsey, M., Quaye, S., Weinrich, S.. "Influence of Family History on Attitudes Toward Prostate Cancer Screening.” April 2003 Staff Meeting of Norton Hospital Oncology Nursing Staff, Norton Hospital, Louisville, KY.

Coleman, M., Looney, S., O’Brien,J., Ziegler, C., Pastorino, C., Turner, C. "The Eden Alternative: Findings after One Year of Implementation." The Gerontological Society of America 55 Annual Scientific Meeting, November 22-26, 2002, Boston, Ma.

Bailey, E., Weinrich, S., Powe, B., Miller, B., Seger, R., James, K., Conley, K., Ziegler, C. "The Impact of Income on Fatalism in Prostate Cancer Education and Screening Programs.” Research Louisville. Louisville, KY (September, 2002).

Tashtoush, R., Mokshagundam, S., Ziegler, C., Stetson, B.. "Dietary Behavior Patterns and Cardiovascular Risk Factors in Type 2 Diabetes Mellitus." Diabetes Abstract Book $62^{\text {nd }}$ Scientific Session June 14-June $18^{\text {th }}, 2002,51-52$, A620.

Mallory, M., Ziegler, C. "Through the Forensic Eyes of Ultrasound: Is a Novel View of Retained Bullets Accurate Enough?” American Institute of Ultrasound in Medicine (AIUM) 46th Annual Convention Preliminary Program, March 10-13, 2002, Nashville, Tennessee.

Mallory,S., Smock, W., Ziegler, C. "Through the Forensic Eyes of Ultrasound: Is a Novel View of Retained Bullets Accurate Enough?" [Abstract] J Ultrasound Med 21:S:1-5:131, S-97, March 2002.

Martin, C., Jacobs, D., Ziegler, C., Weinrich, S. "Attitudes about Prostate Cancer Screening in Informed Men: An Original Research Study." R.N. -Nursing Research News.

Tashtoush, R., Stetson, B., Mokshagundam, S., Ziegler, C. "Dietary Behavior Patterns and Cardiovascular Risk Factors in Type 2 Diabetes Mellitus Implications for Treatement." Research!Louisville , October 29-November 2, 2001, Louisville, Ky.

Hurt, A., Coleman, M., Newton, K., Roberts, K., Ziegler, C. "Factors Contributing to High Health Care Resource Utilization in Passport Managed Care Population." Research!Louisville, October 29-November 2, 2001, Louisville, Ky.

Wesolowski, H., Brooks, L., Ziegler, C. "The Relationship Between Obstructive Sleep Apnea and Allergies in Children." Research!Louisville , October 29-November 2, 2001, Louisville, Ky. 
Estes, M., Jacobs, D., Martin, C., Seger, R., Washington, R., Ziegler, C., Weinrich, M., Weinrich, S.. "Knowledge of Potential Side Effects from Prostate Cancer Treatment and Values Toward Prostate Cancer Screening." Research!Louisville , October 29November 2, 2001, Louisville, Ky.

Hutti, M., Rosenblatt, N., Looney, S., East, K., Ziegler, C. "Barriers to Prenatal Care in Women of Low Versus Middle Income and Higher." National Association of Nurse Practitioners in Women's Health $4^{\text {th }}$ Annual Conference on Women's Health Care in the New Millennium, October 10-13, 2001 Walt Disney World, Fl.

Lonial, S., Raju, P., Gupta, Y., Ziegler, C. “Quality Context, Market Orientation, and Performance in Hospital Industry: An Examination of the Relationship Using Structural Equation Modeling." $6^{\text {th }}$ International Conference on Recent Advances in Retailing and Service Science, July 18-21, 1999 Las Croabas, Puerto Rico.

Lonial, S., Raju, P., Gupta, Y., Ziegler, C. "Market Orientation and Performance in Hospital Industry: A SEM Approach." Second International Conference on Operations and Quantitative Management, Ahemdabad, January 3-6, 1999.

Lonial, S., Raju, P., Gupta, Y., Ziegler, C. "Critical Factors of Quality in Healthcare Settings" Institute of Operation Research and Management Science National Conference, October 26, 1998.

Talley, J., Krucoff, M., Tcheng, J., Rawert, M., Ziegler, C. "Survival of Patients with Severe Ischemic Left Ventricular Dysfunction: Results from the High Risk Myocardial Ischemia Trial-II Registry." American Heart Association National Conference, Novenmber 14-17, 1994.

Leesar, M., Maldonado, C., Joseph, A., Miodrag, S., Prince, C., Vemulapalli, P., Choudhary, S., Vogel, R., Ziegler, C. "Intracoronary Ultrasound Based Modifications of PTCA Procedure." American Heart Association National Conference, November 8-11, 1993.

Leesar, M., Maldonado, C., Joseph, A., Miodrag, S., Prince, C., Vemulapalli, P., Choudhary, S., Vogel, R., Ziegler, C., Talley, D.. "Procedure Cost of PTCA With and Without Intracoronary Ultrasound.” American Heart Association National Conference, November 8-11, 1993.

\section{Memberships:}

American Statistical Association (Kentucky Chapter)

Alpha Kappa Delta Honor Society

Golden Key National Honor Society.

References: Furnished upon request. 